\title{
On the Credibility of Macroeconomic Reform and Stabilization Policies
}

\section{A Game-theoretical Perspective}

\author{
Dissertation \\ zur Erlangung des wirtschaftwissenschaftlichen \\ Doktorgrades des Fachbereichs Wirtschaftswissenschaften \\ der Universität Göttingen
}

\author{
vorgelegt von \\ Georg Königsberg \\ aus Lemgo
}

Frankfurt 1999 
Erstgutachter: Prof. Dr. Hermann Sautter

Zweitgutachter: Prof. Dr. Günter Gabisch

Tag der mündlichen Prüfung: 6. 7. 1999

Gleichzeitig erschienen in der Digitalen Bibliothek der Staats- und Universitätsbibliothek Göttingen (SUB) unter

http://www.sub.uni-goettingen.de/ebene_1/1_ediss.htm 


\section{ABSTRACT}

The formation of macroeconomic policy is conceptualized as on-going process of interaction between private individuals and a centralized policymaker. This interaction is inherently strategic in nature and lends itself to a gametheoretical treatment. Starting from the basic principle of rational expectations, the analysis advances a theoretical perspective on the related concepts of macroeconomic credibility (time-consistency) and reputation in a developing economy context. Therefore the focus will be on macroeconomic policies aimed at economic stability and structural reform, with the main emphasis on monetary and exchange rate policies dedicated to disinflation. The macroeconomic games described here are an attempt to formalize the process of policy formation which are governed by a dynamic process in which one of the players in the economy, the private sector, form their expectations from the actions of the other player, the government. More specifically, this involves modeling of people's reactions to announced regime shifts in economic policy over time. The feedback of private behavior on the government's incentives is an essential element of credibility that has an important impact on the real development of the economy.

\section{ZUSAMMENFASSUNG}

Die Ausgestaltung von Wirtschaftspolitik wird als Prozess wiederholter Interaktion zwischen einer zentralisierten Politikinstanz und privaten Individuen vorgestellt. Diese Interaktion ist inhärent strategisch und eignet sich daher für eine spieltheoretische Behandlung. Die in dieser Arbeit auf der Grundlage der Spieltheorie erarbeiteten makroökonomischen Modelle dienen der Formalisierung eines dynamischen Prozesses von Politikgestaltung. In diesen Spielen bildet ein autonom handelnder Privatsektor Erwartungen über die zukünftigen Handlungen einer Regierung. Die dabei entstehende Rückkopplung von der Ewartungsbildung des Privatsektors auf die Anreize der Regierung hat weitreichende Konsequenzen für die Entwicklung sowohl nominaler als auch realer Größen in der Wirtschaft. Aufbauend auf dem grundlegenden Prinzip der rationalen Erwartungen erarbeitet die Analyse eine Konzeptionalisierung der makroökonomischen Glaubwürdigkeit (Zeitkonsistenz) und Reputation vor dem Hintergrund von Strukturreform und Stabilisierungspolitik in Entwicklungsländern. Unterschiedliche Ansätze

sind besonders der Geld- und Wechselkurspolitik zur Inflationsbekämpfung gewidmet. 


\section{CONTENTS}

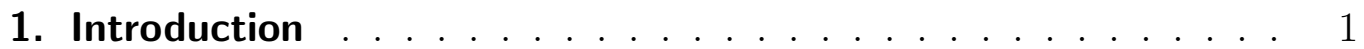

1.1 An eightfold path to credibility . . . . . . . . . . 3

1.2 Game theory . . . . . . . . . . . . . . . . 6

1.3 Overview . . . . . . . . . . . . . . . 8

Part I Expectations and Game Theory 13

2. Expectations and macroeconomic policy . . . . . . . . . . 14

2.1 A simple model of the inflationary process . . . . . . . . 15

2.2 Static expectations . . . . . . . . . . . . . . . . 17

2.3 Adaptive expectations . . . . . . . . . . . . . . . . . 17

2.4 Rational expectations . . . . . . . . . . . . . . . . . . . 19

2.5 The time inconsistency of optimal plans . . . . . . . . 23

3. Elements of a game-theoretical analysis . . . . . . . . . 28

3.1 Game and payoff structure . . . . . . . . . . . . . . 29

3.2 Information structure . . . . . . . . . . . . . . . . . 31

3.3 Solution concepts . . . . . . . . . . . . . . . . . 32

3.3 .1 One stage games . . . . . . . . . . . . . . . . 32

3.3 .2 Dynamic games . . . . . . . . . . . . . . . . . . 34

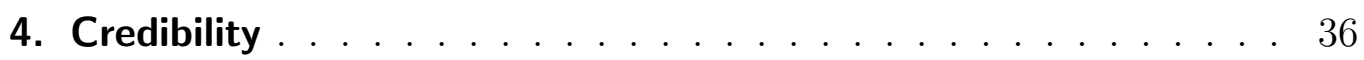

4.1 Subgame perfect equilibrium and credibility . . . . . . . 37

4.1 .1 Discretionary regime . . . . . . . . . . . . . . . . . . 39

4.1 .2 Commitment regime . . . . . . . . . . . . . . . . . 41

4.1 .3 Comments . . . . . . . . . . . . . . . . . . . 43

4.2 The Barro and Gordon model of monetary policy . . . . . . . 44

4.2 .1 Game structure . . . . . . . . . . . . . . . . . 45

4.2 .2 Payoff structure . . . . . . . . . . . . . . . 45 
4.2 .3 One-shot game . . . . . . . . . . . . . . . 47

4.2.4 Trigger mechanisms and reputation . . . . . . . . . 52

4.3 Alternative concepts of credibility . . . . . . . . . . 56

4.3.1 Political constraints . . . . . . . . . . . . 56

4.3.2 Inconsistent policies . . . . . . . . . . . . . . . 58

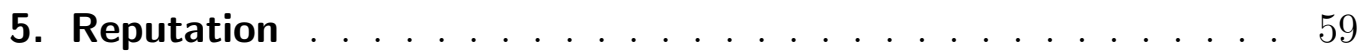

5.1 Signaling and Government Behavior . . . . . . . . . . . 61

5.2 Perfect Bayesian equilibrium . . . . . . . . . . . . . 65

5.2.1 Pooling equilibrium . . . . . . . . . . . 67

5.2.1.1 The Intuitive Criterion . . . . . . . . . . 70

5.2 .2 Separating equilibrium . . . . . . . . . . 72

5.2.2.1 Cheap Talk . . . . . . . . . . . . 72

5.2.2.2 Correlated strategies . . . . . . . . . . 74

5.2.3 Some remarks on the equilibrium concept. . . . . . 75

5.3 Monetary stabilization policy under intrinsic uncertainty . . . 77

5.3.1 Bayesian learning process of the private sector . . . . 78

5.3 .2 Incentives of the government . . . . . . . . . . 81

5.3.2.1 Expected inflation . . . . . . . . . 81

5.3.2.2 Current disutility of reputation . . . . . . . 82

5.3.2.3 Future benefit of reputation . . . . . . . . 83

5.3.2.4 Indifference curve . . . . . . . . . . . . . 84

5.3.3 Equilibrium policy . . . . . . . . . . . 85

5.3.3.1 Unique separating equilibrium . . . . . . . 87

5.3.3.2 Pooling equilibrium . . . . . . . . . 87

5.3.4 Reputation over a finite time horizon . . . . . . . 88

Part II Exchange-rate-based stabilization policy 91

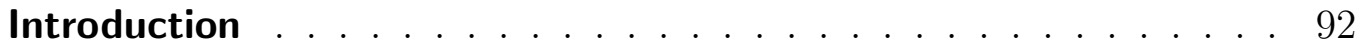

6. Commitment vs. discretion in a stochastic model . . . . . . . . 97

6.1 Model structure . . . . . . . . . . . . . . . . . . . . . . . . 98

6.2 Equilibrium policy under alternative regimes . . . . . . . . 102

6.2.1 Semi-discretionary regime $(\mathrm{C})$. . . . . . . . . . . 102

6.2.2 Fixed exchange rate regime $(\mathrm{F})$. . . . . . . . . . 104

6.2.3 Discretionary regime (D) . . . . . . . . . . 104 
6.2.4 Surprise regime $(\mathrm{M})$. . . . . . . . . . . 106

6.3 Welfare comparison . . . . . . . . . . . . . . 107

6.4 Discussion . . . . . . . . . . . . . . . . . 109

7. Reputation . . . . . . . . . . . . . . . . . . . 112

7.1 Model structure . . . . . . . . . . . . . . . . . 112

7.2 Incentives to mimic and signal . . . . . . . . . . . . . 114

7.2.1 Perfect information . . . . . . . . . . . . 116

7.2 .2 Imperfect information . . . . . . . . . . . . . 116

7.3 Separating equilibrium . . . . . . . . . . . . . . . . . . 119

7.3.1 Indifference curves . . . . . . . . . . . . . . . . . 123

7.3.2 Refinements of the equilibrium . . . . . . . . . . . 125

7.4 Pooling equilibrium . . . . . . . . . . . . . . . . . . . . . . . . . . . . . . . . . . . .

7.5 Welfare comparison . . . . . . . . . . . . . 132

7.6 Discussion . . . . . . . . . . . . . . . . . 135

8. Concluding remarks . . . . . . . . . . . . . . . . . . . . . 139

$\begin{array}{lr}\text { Appendix } & 142\end{array}$

A. Monetary policy . . . . . . . . . . . . . . . . . . . . . . 143

A.1 Precommitment solution . . . . . . . . . . . . . . . 143

A.2 Discretionary solution . . . . . . . . . . . . . . . 143

A.3 Trigger strategy . . . . . . . . . . . . . . . . . . . . 145

A.4 Reputational indifference curves . . . . . . . . . . . . . 146

A.5 Time paths for $\theta_{t}$ and $\rho_{t} \ldots \ldots \ldots \ldots$. . . . . . . . 146

B. Exchange rate policy . . . . . . . . . . . . . . . . . . . . . . . . 148

B.1 Semi-discretionary solution . . . . . . . . . . . . . 148

B.2 Fixed exchange rate. . . . . . . . . . . . . . . . . . . . 149

B.3 Discretionary solution . . . . . . . . . . . . . . . . . . . . 149

B.4 Expected loss . . . . . . . . . . . . . . . . . 150

B.5 Separating equilibrium . . . . . . . . . . . . . . 151

B.5.1 Separating conditions, strong government . . . . . . 151

B.5.2 Separating conditions, weak government . . . . . . 152

B.5.3 Equilibrium strategies . . . . . . . . . . . . 154

B.6 Pooling equilibrium . . . . . . . . . . . . . . . 154 
B.6.1 Pooling conditions, weak government . . . . . . . . . . 154

B.6.2 Pooling conditions, strong government . . . . . . . 156

B.6.3 Equilibrium strategies . . . . . . . . . . . . 157

B.7 Reputational indifference curves . . . . . . . . . . . . . . . 157

B.7.1 Indifference curves $\bar{V}^{0} \ldots \ldots$. . . . . . . . . . . . . 159

B.7.2 Testing the Intuitive Criterion . . . . . . . . . . 160

List of symbols . . . . . . . . . . . . . . . . . . . . . . . . . . . . 162

Bibliography ....................... 165 


\section{LIST OF FIGURES}

3.1 Rational expectations Equilibrium . . . . . . . . . 34

4.1 Discretionary Regime . . . . . . . . . . . . . . . 39

4.2 Commitment Regime . . . . . . . . . . . . . . . . . 42

5.1 Government Signalling . . . . . . . . . . . . . 62

5.2 IndiffERENCE CURVE . . . . . . . . . . . . . 85

6.1 Timing of the Stochastic game . . . . . . . . . . 101

7.1 SEPARATING EQUILIBRIUM . . . . . . . . . . . . . . . . . . 124

7.2 Polling Equilibrium I . . . . . . . . . . . . . . . . . 129

7.3 Pooling Equilibrium II . . . . . . . . . . . . . . . 132 


\section{LIST OF TABLES}

1.1 Eightfold Path to Credibility $\ldots \ldots \ldots \ldots$

4.1 Outcomes of the ONE-STAge GAME . . . . . . . . . . 50

4.2 Payoff Structure $(\Delta=2) \ldots \ldots \ldots \ldots \ldots$

4.3 IntERTEMPORAL POLICY OPTIONS . . . . . . . . . . 54

5.1 Payoff structure of the government . . . . . . . . 63

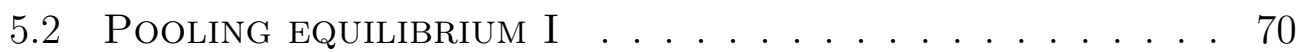

5.3 Pooling Equilibrium II $(\mathrm{A}) \ldots \ldots \ldots \ldots$

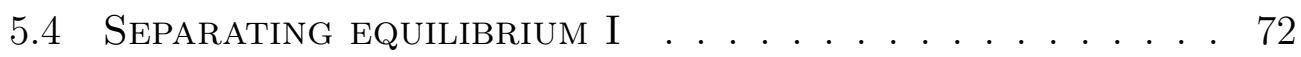

5.5 Separating equilibrium II - "Cheap-Talk" . . . . . . 74

5.6 ERBS PROGRAMS IN PRACTICE . . . . . . . . . . 95

6.1 Alternative exchange Rate Regimes . . . . . . . . . 107

6.2 Policy outcomes under alternative Regimes . . . . 109 


\section{INTRODUCTION}

One of the more favorable aspects of the debt crisis that ignited in 1982 was the fact that it unleashed a wave of reforms never before seen in a large parts of the developing world. To the surprise of most observers, the countries hardest hit by this crises were the ones that were more than willing to apply policy measures which were far-reaching, both in intensity and scope. The broad package of reform measures that were the backbone of these efforts has ephemerally come to be known as the Washington consensus, first introduced by Williams, J. (1990). The essential elements of this consensus were dominated by efficiency considerations of the neoclassical paradigm, peppered by the think-tanks of IMF and World Bank. The catalog of measures included macroeconomic policy reforms aimed at achieving economic stability (fiscal, monetary and exchange rate policies), but also comprised of microeconomic and structural reforms meant to promote structural reform and growth. The policies prescribed in the Washington Consensus were no easy pills to swallow by any standards, even in times of economic tranquillity. And although commitment to the this orthodoxy varied across countries and over time it is a tribute to the tenacity and commitment of the political authorities in charge that many countries, e.g. in Latin America, have come to within

reaching distance of completing the items on this agenda in a period of no more than a few years during the 1980s.

However, the economic turmoils that have beset the global economy in the latter half of the nineties, most recently culminating in the devaluation of the Brazilian currency, have cast a pale shadow of doubt over the efficacy underlying supposedly "efficient-enhancing" reforms. Even prior to the realization of the sobering events in East Asia, Russia or Brazil, one must face the dire reality that many of these reform initiatives were suddenly abandoned or entirely diluted by the very same politicians who had been their most ardent supporters. Although the signs of reform in Latin America have been hopeful of late, "Success and failure on this continent follow one another in rapid succession, enthusiasm and wild hopes yield to disappointment 
and discouragement." ${ }^{1}$ These experiences have made it clear that devising successful policies requires more than devising blueprints; it also requires an understanding of the forces that govern policy-making.

When pressed to explain why the practice of reform so often diverges from prescription, journalists and economists alike will instinctively invoke the specter of a credibility deficit to describe the unobservable liability that the policymaker faces when implementing a new policy. Most economic advisors would agree that a necessary condition for the success of any economic policy is that it is accompanied by credibility and the failure of the reforms to "deliver the goods" is quite simply a failure by the government to abide by this principle. Since it has become a universal answer to all puzzles related to policy-making, it should be no surprise that the Washington consensus takes it as granted by not shedding a word about credibility considerations.

One cannot, however, shake off the feeling that something very crucial is lacking in policy debates where vague allusions to "lack of public support", "commitment", "uncertainty of government motives" or "political costs of policy reversal" are offered as blanket category that appeal to our basic heuristic interpretation of credibility but offer no starting point in way of economic analysis. Commenting on the possibility that the Asian crisis may prove contagious for Latin American reforms, for example, JosEPH STIGLITZ very recently noted that "The countries of Latin America should realize that there is a systematic relationship between credible policy and economic success." ${ }^{2}$ Such allusions to credibility are quite common but they unfortunately provide no basis for a positive analysis.

The purpose of this thesis is to advance some theoretical examination and perspective on the related concepts of macroeconomic credibility (timeconsistency) and reputation in a developing economy context. Therefore the focus will be on macroeconomic policies aimed at economic stability (monetary and exchange rate policy) and structural reform policies, such as the removal of relative-price distortions and government intervention. The issues surrounding stabilization and reform are confronted with game-theoretic reasoning because it has proven itself as the analytical tool par excellence for

\footnotetext{
${ }^{1}$ Eduardo Lizano (1995), p. 1.

${ }^{2}$ Quoted from the Frankfurter Allgemeine Zeitung, April 17, 1998, p. 16. The original text in German is: "Die Länder Lateinamerikas sollten sich ... besinnen, daß eine systematische Beziehung zwischen einer glaubwürdigen Politik und wirtschaftlichen Erfolg besteht."
} 
examining economic-political systems that are characterized by strategic interdependence. The macroeconomic games described here are an attempt to formalize the process of policy formation which is governed by a dynamic process in which one of the players in the economy, the private sector, form their expectations from the actions of the other player, the government. More specifically, this involves modeling of people's reactions to announced shifts in economic policy (so-called "regime shifts") over time. The feedback of private behavior on the government's incentives is an essential element of credibility.

\subsection{An eightfold path to credibility}

To economists and non-economists alike, the concept of credibility used extensively in policy roundtables seems to appeal directly to our sentiments of "trustworthiness", "loyalty" or "confidence". These intangible notions underlie many social transactions and are central to the functioning of governments, friendships and business relationships. In this sense, the term credibility can be closely associated with interactions between two or more parties that requires us to anticipate the responses of the others involved in this transaction. Therefore, an important reason why credibility is perhaps such an inaccessible concept is because it is fundamentally a microeconomic problem, which does not yield itself easily to the macroeconomic form of analysis, where economic aggregates will probably mask or distort much of the interaction that takes place between individuals and government in the economy. Before embarking on a macroeconomic analysis of credibility it is therefore meaningful to briefly outline some general principals of credibility that underly the theoretical analysis used later.

Economic transactions involving mutual trust embody a strong flavor of strategic interdependence. For a number of transactions, individual decisionmaking is influenced by the ability to depend on the reliability of someone or put slightly differently - the degree to which agents consider themselves bound by (verbal) promises. Bank authorities must decide the reliability of a

loan applicant, employers must decide how much responsibility to delegate to their employees, consumers must decide if they are to trust the content of the advertisements they see. In all these cases the decision of one party, which by convention is often called the principal, to take a specific action depends on the trustworthiness or credibility of the other party, the agent. The means 
of the agent to convey his credibility is verbal communication, but there are situations where he can undertake actions to underline his commitment (such as making a downpayment for the loan, or profit-sharing schemes of employers). Whatever the case, these attempts at establishing credibility are strategic since they are aimed at influencing the decision of the principal. ${ }^{3}$ Strategic actions including verbal promises are utilized to favorably change the principal's expectations about the response to his action.

The channels through which the agent is able to enhance or establish credibility are multitudinous, and in many cases depend on the economic context that is to be described. But it is perhaps possible to derive some common elements that all credible strategies must possess, regardless of the context in which credibility plays a role. In a brief essay, Dixit AND NALEBUfF (1992) elaborate on eight devices that in their opinion, offer the "credibility-debtor" the strategic means to pay off his liability. These are all general principals that even a non-economist could relate to, but the reason they carry special significance is that they transcend all economic situations and therefore find application in microeconomic as well as macroeconomic settings, but other settings, such as political also come to mind ${ }^{4}$. I have taken the liberty to summarize their principles in Table (1.1).

Using this table as a rough guide, what general principles are necessary for a government's policies to be viewed as credible? Assuming that the government can be described as the agent of the public, one of the major themes that will figure predominantly in this thesis will be that one method

3 The question that unfolds is whether the agent is (or believes that he is) in a position to take actions or verbal promises that help him to uphold his credibility. If, on the contrary, it is posited that the credibility of the agent is entirely independent of any actions he undertakes, then it is not possible in this case to establish a strategic interdependence since the actions of one party have no influence whatsoever on the decision-making process of the other. In this case any analysis of the credibility phenomenon would be a trivial undertaking.

4 The article of DixiT AND NALEBUfF happened to appear in a book commemorating the contributions of Thomas Schelling who was responsible, as they comment, for "bringing a new dimension to politics, business, and everyday life" (p. 161). One book by Schelling in particular, titled The Strategy of Conflict (1960), is considered by many as a catalyst for bringing strategic considerations and subsequently game theory, into the wider arena of academic debate, most notably in economics and politics. Written during the height of the Cold War, its center of interest lies in non-zero sum games of military conflict (with special focus on nuclear warfare). It is engagingly written and, quite surprisingly, does not resort to any formal descriptions. 
Tab. 1.1: Eightfold Path to CRedibility

\begin{tabular}{|c|l|}
\hline 1. & Establish and use reputation. \\
2. & Write contracts. \\
3. & Cut off communication. \\
4. & Burn bridges behind you. \\
5. & Leave the outcome to chance. \\
6. & Move in small steps. \\
7. & Develop credibility through teamwork. \\
8. & Employ mandated negotiating agents. \\
\hline
\end{tabular}

Source: Dixit and Nalebuff (1992), p.162-163.

that allows the government to establish credibility vis-à-vis the public is to alter its incentives so that it becomes more costly or impossible to back down from its promises. These notions of credibility are captured in (2) "writing contracts" and the rather metaphorical term (4) "burn bridges behind you". In the policy domain that we will examine both of these notions would require the government to establish some institutional safeguard that binds the government to the policy it proposed. In the first case (2), this involves making it costly in terms of the government's objectives (perhaps prestige or power) to renege on his promises. In the second case (4), credibility could be secured by limiting the government's use of discretionary powers. Although one senses prevailing degree of Politikverdrossenheit in the industrialized economies, the problem of credibility plays an insignificant role for economic policymaking because the discretionary powers vested in the executive branch of government have been effectively checked in a sophisticated political framework. Developing economies have yet to establish sufficient institutional restraints that diminish the discretionary excesses of the executive. We will see that one of the main method to establish credible policies lies in "tying one's hands", "burning its bridges" behind itself, i. e., by effectively deterring the government from acting in a discretionary manner, the government can mitigate the time-inconsistency problem closely related to credibility problem and thus enhance welfare.

From a conceptual point of view, "establishing reputation" (1), also requires a framework that alters the incentives of the government in such a way 
that makes it costly to renege on a previously made policy plan. But the concept of reputation embodies the notion that the past history of policy can be used as a helpful indicator for the evaluation of future policy. This implicitly assumes a repeated confrontation between the government and the private sector, where the latter form their actions on the basis of the government's "track-record" of government policy. By acting consistently over time the government can build up a reputation and utilize this asset to meet strategic ends. Instead of requiring an institutional corset to restrain the discretionary potential of government, reputation has the interesting property of functioning as an informal constraint on government behavior. Given the intertemporal aspect of reputation, to see how reputation works in a game-theoretic context requires a higher level of sophistication than the Nash equilibrium concept offers.

The game-theoretic tools to be employed in the following chapters sets structural limits to the analysis of credibility issues. We will be mostly concerned with policy topics surrounding time-inconsistency and reputation. However, heuristic references to other analogies from Table (1.1) can be made. For example, an important issue of reform in developing economies involves the timing and sequencing of government policy. To establish credibility, many economists argue that reforms should be carried out gradually, or in terms of (6), that a government "move in small steps". The reasons can be traced to political-economy considerations. Faster reforms, although efficient, have the downside of resulting in larger short-term costs and thus in a stiffer political opposition. Economic agents will generally recognize these short-term adjustment costs associated directly with reform, but will have difficulties in perceiving the long-run benefits. ${ }^{5}$

\subsection{Game theory}

The experiences of reform in the developing world have made it strikingly clear that good economics does not necessarily translate into good results. Any theory that purports to analyze the formation of policy must take into

\footnotetext{
${ }^{5}$ Of course, one could also postulate that a quick reform would be more beneficial by reducing the the time for pressure groups to organize themselves into a potent force in opposition to reform. Funke, N. (1993), Edwards, S. (1990), Falvey, R. K., Cha Dong (1992) and Sell, F. L. (1993) offer surveys of these competing views on issues of timing.
} 
account that a government can only commit to the economic variables it controls, not the results it hopes to generate. Regardless of how well-articulated the program or how frequently it was publicly announced, policy will be less effective if it is not capable of translating the government's action into a response by the private sector as predicted in a theoretical model. In other words, credibility and reputation are both crucial elements in any analysis of policy-making.

There are compelling reasons to simply delegate the analysis of policy formation and the problems of credibility to the domain of political science, but a lack of a rigorous and powerful theoretical framework in the field of economics should not be cited as a reason. With its emphasis on the strategic interactions between rational individuals, the methods of game theory have helped to pave the way for an in-depth analysis in real-life economic, political as well as social situations. This work will accordingly take a positive stand on the merits of game theory for an analysis of policymaking. As JOHN HARSANYI (1995) notes,

In principle, every social situation involves strategic interaction among participants. Thus, one might argue that proper understanding of any social situation would require game-theoretic analysis.

Interdependence is the salient feature of all economic decision-making in situations involving two or more decision-making parties. The Washingtonstyle reform proposals ignore this important fact. The tenets that form the backbone of these reforms can perhaps be traced to the neoclassical theorizing that delegates the policymaker to the role of a passive agent, a mere delegate of optimal control theory. Knowing the consequences of the policy measures, it is simply a matter of arithmetic to find the "right" set of policies and the analyst could move on to the normative problem of policy advice. But such a view entirely subsumes individual incentives and individual behavior that can be generated by the strategic interaction between the political authority and the public. Indeed, it is no wonder then that in its original form the Washington consensus does not even pay lip-service to credibility considerations.

In order to analyze the problems surrounding credibility in a game context it will be both convenient and necessary to view the political authority and the public as individual decision-making actors with both parties optimizing a well-defined objective function and taking into account expectational effects of their decisions. This puts the approach adopted here in opposition 
to traditional Keynesian perspective, in which expectations were assumed to be exogenous to the model. Underlying this approach is the crucial assumption that the economic actors have rational expectations. This explicitly includes the political authority such that the "policymaker is . . a rational and maximizing agent, or collection of agents, who respond to incentives and constraints just like the rest of the economy" 6 . Central to game-theoretic reasoning is the concept of equilibrium as a solution concept. A Nash equilibrium embodies the fundamental idea of economics, that people (governments as well) act in accordance with their incentives.

The concepts, terminology and models from game theory have come to dominate many areas of economics and the field of macroeconomics makes no exception the this general trend. The vast number of contributions on the alleged inflationary bias of monetary policy attest to the fact that the blending of game-theory with monetary policy has been and continues to be an especially fertile ground for economists ${ }^{7}$. Most contributions on macroeconomic policy games trace their heritage back to the pioneering article on timeinconsistency under rational expectations by KYDLAND AND PRESCOTT (1977), formalized by BARRO AND GORDON (1983). The scenarios are set mainly in industrialized economies; the analysis presented her shifts the focus to the reforming developing economies. What unites these diverse contributions is that they all derive their motivation from the intellectual challenge of conceptualizing credibility.

\subsection{Overview}

The dissertation has been divided into two main parts. Following this introduction, Part I (covering Chapters 2-5) will prepare the reader for the game-theoretical arguments that will be used throughout the chapters. The game-theoretical tools build upon each other and will be presented in an increasing level of sophistication. In terms of the policy environment, these introductory chapters will be held as general as possible, but do not deny their heritage from the field of monetary economics. This part will also make ample use of graphics to characterize the game-theoretic setting and will be

\footnotetext{
${ }^{6}$ See Persson and Tabellini (1991), p. 1.

${ }^{7}$ As of this writing, some recent contributions to this ever-expanding field are SvenNson, L. (1997), Gärtner, M. (1997) or Ellis And Steinar (1997) just to name a few.
} 
more didactic in scope. We start off in Chapter 2 by showing that macroeconomic policy is the product of an interdependence between the behavioral patterns of private individuals and centralized policymakers. Using a simple model of the inflationary process as a reference point, it is shown that when expectations are conditioned by a policymaker's behavior (i. e. the monetary stance he chooses), the outcome of policy depends on the way that the process of expectation formation is modeled. We explore the ramifications of adaptive expectations (Section (2.3)) and rational expectations (Section (2.4)) en détail. It turns out that the assumption of rational expectations is central for understanding the strategic environment in which policy outcomes are determined. Under rational expectations, it will be shown that policy can be time-inconsistent and therefore entirely self-defeating. This reassessment of macroeconomic policy due to KYDLAND AND PRESCOTT will also be examined since it provides a neat definition of credibility.

The strategic interaction between government and private sector lends itself to a game-theoretic interpretation and the basic concepts of a game theoretic interpretation of macroeconomic policy are presented in Chapter 3. Macroeconomic policy will be characterized as a game between a centralized government and private sector (within which there are no strategic interactions). Basic concepts (equilibrium, rules, strategies) are described and interpreted for the macroeconomic setting. A solution to the macroeconomic game predicts, for a prespecified circumstance (i.e. parameter values), the choices of the agents and the corresponding outcomes.

After this preliminary discussion, Chapter 4 sets the scene for the examination of credibility in a game-theoretic framework. The first section (4.1) of this chapter begins by placing a policy of macroeconomic reform in a generalized game-theoretic framework. In the extensive form presentation of this game, a benevolent (i. e. social-welfare maximizing) government announces a policy measure that is designed to alleviate a suboptimal situation in the domestic economy. In this context, the concept of credibility will be shown to be closely related to the game-theoretic concept of subgame perfection. A more formal presentation of a credibility dilemma is provided by a game theoretical analysis of monetary policy, introduced to the reader in the rendering of the BARRO AND Gordon-type model in Section (4.2). In the setting of a static one-period game, a change of monetary regime (e.g. following a more contractionary course) intends to reduce expectations of future inflation, which reduces the real costs of disinflation. It is shown that 
if the government is vested with discretionary powers, it is only rational for it to deviate from these plans, to "surprise" the public by reneging on his announcement. A basic insight of this one-period model is that if a government is able to exercise complete and costless discretion in its monetary regime, the economy is thrown into an inferior (subgame perfect) Nash-equilibrium in which inflation remains at its former level. This "inflationary bias" due to lack of institutional constraints is a theme that we will encounter again in Part II. The simple elegance of the BARRO AND GoRDON-type model therefore not only provides an insight into the 'rules-versus-discretion' discussion of monetary policy, but more importantly serves to frame the game-theoretic reasoning of macroeconomic policy in the chapters that follow.

Chapter 5 formalizes the concept of reputation by starting off with a generalization of the strategic interaction between the government and the private sector in a setting of asymmetric information. In an extended form game of Section (5.1) we analyze the complex chain of reasoning that underlies the concept of equilibrium when private information is present. Private sector beliefs, including those not played in equilibrium are elevated to the level of importance of strategies in the determination of pooling or separating equilibria. The equilibrium concept of a Perfect Bayesian equilibrium is discussed in Section (5.2). The role of policy history and uncertainty is examined in a two-period model in Section (5.3), focusing again on monetary policy within the setup of a repeated game with incomplete information of the private sector. Intrinsic uncertainty enters the analysis through private information the government possesses about its preferences regarding inflation vs. output. This asymmetric distribution of information gives a weak type of government the incentive to act strategically by taking actions to misrepresent its information, a strong type is committed to a policy of zero inflation. The basic idea is that the short-run costs from playing low inflation are endured in order to enhance the weak government's reputation for low inflation. Inflation expectations evolve through a learning process in which the public updates its beliefs as new information becomes available. The government's reputation is identified with the probability with which the private sector believes that it is the type which is committed to low inflation. This setup illustrates how reputation may discipline the uncommitted government to "play" a strategy of low inflation. Reputation is more likely to sustain a policy of low inflation the higher the government's reputation is when it enters office and the lower its discount rate of policy outcomes. This 
section also pays credit to reputation in a (monetary) stabilization policy and presents a model framework that can be used to analyze the evolution of reputation over time.

Part II (Chapters 6 and 7) delves into the policy implications of credibility and reputation in the context of an exchange rate stabilization program. Taking the lead from the monetary games of Part I, we will examine these issues from the perspective of a government torn between the objectives of inflation and external balance. A brief review of the experiences of a select group of countries illustrate the dilemma a policymaker faces when using the exchange rate as a policy instrument. Keeping the exchange rate fixed to stabilize prices can prove unsustainable in the long-run if the country faces a shortage of foreign exchange reserves or an external borrowing constraint. In a similar vein, a government attempting to keep its currency from depreciating may find its foreign reserves exhausted and its borrowing approaching a limit. In such a setting, the government might be tempted to renege on its former commitment to a nominal anchor. Inflation arises because price setters rationally fear that the authorities will try to devalue in order to depreciate the real exchange rate.

Chapter 6 begins by presenting a model of a small economy producing traded and non-traded goods which illustrates the situation of a government attempting to stabilize inflation via a nominal anchor under external (random) shocks. Due to a systematic deficit in the external account, the government must weigh its desire to achieve a reduction in its external deficit with its ulterior motive of stabilizing the domestic price level, a composite of non-traded and traded goods prices. The game theoretic analysis involves a one-shot game and perfect information in which the basic time-inconsistency proposition under alternative institutional settings of the exchange rate regime is explored. Under a discretionary regime it is shown that adherence to an exchange rate rule is time inconsistent and this inherent devaluation bias of discretionary policy undermines the credibility of a fixed (or semi-fixed) exchange rate. A welfare analysis shows that a trade-off arises between the benefits of lower inflation via the nominal anchor and exchange rate flexibility under variable shocks. Because of the stochastic nature of exchange rate fluctuations there is potential for improving welfare.

To analyze the issue of reputation within the context of an exchange rate stabilization, intrinsic uncertainty enters the analysis in Chapter 7 by assuming two types of governments that differ with respect to the cost incurred from 
reneging on a fixed-exchange rate regime. Now the the policy dilemma facing a government trying to cope with the twin objectives of inflation stabilization and external balance is placed in a two-period game setting. A separating equilibrium is shown to exist in which it is in the interest of a strong (lowinflation) government to break the inflationary bias by distinguishing itself from a weak (high-inflation) government. Thus, while the high-inflation government wants to conceal its identity by mimicking an exchange rate policy consistent with low inflation (for the sake of manipulating expectations), a low-inflation type wants its identity to be made known through a process of signaling. The low-inflation type could signal its type by setting the rate of devaluation in the first period of the game so low that the other would not want to imitate her even if she could thereby be identified as being less prone to devalue. The incentives of the different types of government to engage in mimicking or signaling activity has implications on the end result of inflation and the external balance. The "reputation effect" that influences the decisions of both the strong and weak government may thus alleviate the devaluation bias associated with the time consistency problem faced by the government. The dissertation ends with a few concluding remarks. 


\section{Part I}

\section{EXPECTATIONS AND GAME THEORY}




\section{EXPECTATIONS AND MACROECONOMIC POLICY}

In a world fraught by uncertainty, expectations about the future profile of events play a crucial role for the study of economics. The certainty of tomorrow's existence juxtaposed with the uncertainty of tomorrow's events explains why individual agents engage in numerous forward-looking activities such as investment in capital and saving in financial assets or why they are willing to accept intrinsically worthless paper (money) in exchange for tangible commodities and services. On a macroeconomic level, intertemporal uncertainty matters most when decisions are irreversible. For example, expectations about the future course of monetary policy strongly affect the contracted wage for the contract period, which in turn influences realized inflation. The ups and downs of stock prices reflect the expected future stream of dividends and earnings. Bond-holders desire suitable compensation in the form of interest which is directly influenced by fluctuations in expected inflation and exchange rates. The eminence of uncertainty in economic situations makes the representation of expectations an albeit complex but an indispensable undertaking. Today most would therefore agree that it impossible "to provide a sensible treatment of macroeconomic theory without resort to some model of expectation formation," 1

Despite their undeniable importance, expectations long received superficial treatment in macroeconomic analysis. KEYNES emphasized the significance of the uncertain nature of the future, but uncertainty entered his analysis in an exogenous fashion. He was equally confounded when it came to examining the effects of policy on inflation, because the analysis ignored the influence of nominal expectations on behavior. ${ }^{2}$ Not surprisingly, in order to make up for this deficit, the macroeconomic mode of analysis that

\footnotetext{
${ }^{1}$ See BegG (1982), p. 22.

2 See Leijonhufvud (1983), p.32
} 
immediately followed KEYNES attempted to provide a more coherent theory of expectation formation. With the advent of rational expectations the focus of inquiry shifted away from the concern with the effect of expectations on investment spending and liquidity preference to the effect of expectations on real outcomes in monetary and fiscal policy. This reappraisal meant that economists should take a closer look at the dynamic process by which economic agents update their expectations as time progresses.

The following sections illustrate in a historical perspective how economists have grappled with formalization of the expectation formation process. To concentrate on expectations, we will abstrtact from other influences and start with a simple model of inflation process that depends solely on expectations about monetary policy.

\subsection{A simple model of the inflationary process}

At a very basic level, any model used to describe expectational behavior should not be led by "wild and unpredictable imaginations", but rather should obey the rule that expectations are made "by intelligent consideration and reconsideration of observed changes." 3 Also, since individuals are incapable of making a correct assessment of true probabilities of future variables, individuals are assumed to make subjective assessments of the probabilities to forecast uncertain events. Given an assessment of uncertainty at the date expectations are to be formed, it is then possible to construct a theory of expectations formation which relies on available information at this date. ${ }^{4}$ As a final requirement, the unobservable process of expectation formation should rely only on observable variables.

In the following a simple model is presented in which the demand for real money balances is assumed to be a function of the expected inflation rate. This model serves the purpose of presenting some standard expectational hypotheses and their influence on the process governing the inflation process. It also presents a framework in which a policy parameter - in this case the

\footnotetext{
${ }^{3}$ See Machlup (1983), p.173.

${ }^{4}$ If, at any moment in time, agents do not possess complete knowledge of the probability distribution, they can form conditional best estimates by using information that becomes available over the course of time. These forecasts converge to the actual (subjective) probabilities through a process of Bayesian updating. Leaping ahead a bit, extensive application of this rule will be made in the Chapters 5 and 7 covering reputational effects.
} 
money supply — directly effects price level formulation. ${ }^{5}$ The demand for real money balances is given by

$$
\frac{M_{t-1}}{P_{t-1}}=\alpha_{1}-\frac{\beta\left(P_{t}^{e}-P_{t-1}\right)}{P_{t-1}}
$$

where $M_{t-1}$ is the money supply at time $t-1, P_{t}^{e}$ is the expectation of the domestic price level formed by economic agents for the following period $t$, and $\alpha_{1}$ and $\beta$ are positive constants. Equation [2.1] simply states that the higher expected inflation rate (right-hand term of [2.1]), the lower the demand for real money balances will be.

When using this model it is typically assumed that a centralized policymaker (such as the central bank) controls the value of $M$ (the policy instrument) at the beginning of every period which determines the amount of money demanded. If the market for real money balances clears, then the movement of a variable $P$ can be indirectly controlled through variations in the level of this policy parameter. But the monetary authority's power over $P$ is not absolute since expectations of the future path of the price level ultimately determine the efficacy of the agency's policy instrument. The monetary authority can only provide an input, "it can attempt to commit itself on variables it controls; but the promised results are only as credible as the commitment and the theory that generates the results." 6 The interdependent character of private sector and government decisions provides the link between the actions of a political entity and the expectations of the private sector and is central to understanding credibility.

Rearranging eq. [2.1] we get

$$
P_{t-1}\left(M_{t-1}, P_{t}^{e}\right)=\frac{M_{t-1}}{\alpha}+\frac{\beta}{\alpha} P_{t}^{e}
$$

where $\alpha=\alpha_{1}+\beta>\alpha$ hence $\beta / \alpha<1$. A solution to the equation above would ultimately involve deriving the time path of $P$ (i.e. solving for a first-order difference equation). In order to acquire a unique solution it is necessary to specify the behavior of the monetary authority captured in its choice of $M_{t}$. Since $P_{t}^{e}$ cannot be observed for this purpose it is also necessary to have some theory or model of expectation formation that relates $P_{t}^{e}$ to variables

\footnotetext{
${ }^{5}$ The model was first presented by CAGAN (1956) in his study of the demand for real balances during hyperinflations. The model presented here is the discrete time case of the continuous model presented in BlANCHARD AND FisCHER (1989), p. 195-198.

${ }^{6}$ See Schelling (1982), p. 78.
} 
that are observable. The inflation process generated by eq. [2.2] therefore is subject to the choice of expectation model that is chosen. In what follows, we will outline three assumptions that can be made about expectations.

\subsection{Static expectations}

One extremely simple "theory" of expectational behavior was to assume that economic agents always expect that the most recently observed value of any variable will continue to prevail in the near future. Such a generalized 'theory' of static expectations could be represented algebraically by the equality

$$
P_{t}^{e}=P_{t-1}
$$

such that the expected future price level $P_{t}^{e}$ (at the beginning of period $t$ ) was equivalent to the last observable price level, $P_{t-1}$, regardless of the development of other variables in the economy. ${ }^{7}$ The assumption of static expectations is a very simple approximation of how expectations are formed in real economic situations. But it does share a common trait with other more elaborate theories of expectation formation by making unobservable expectations a function of an observed variable.

\subsection{Adaptive expectations}

Monetarists argued that the expectation of the future price level is driven mainly by agent's experience of previous inflation rates. The application of adaptive expectations (or extrapolative expectations) became the standard approach for modeling expectations (used, e.g., to validate the permanent income hypothesis). The adaptive expectations hypothesis (AEH) is a special case of a more general framework in which expectations of $P$ are related to current and past values in a distributed lag fashion ${ }^{8}$. In algebraic terms the

\footnotetext{
7 Some economic variables become observable with a certain time lag. Therefore an alternative presentation for variables with data collection delays one could assume that $S_{t}^{e}$ is equal to $S_{t-2}$, where $S$ is an observable economic variable.

8 Adaptive expectations hypothesis is derived from the more general model

$$
P_{t}^{e}=\lambda_{0} P_{t}+\lambda_{1} P_{t-1}+\lambda_{2} P_{t-2}+\cdots+\lambda_{n} P_{t-n}
$$

where the $\lambda_{j}$ coefficients are parameters that are constant over time. For the AEH, these coefficients are assumed to sum to 1 and additionally the $\lambda_{j}$ decrease exponentially in value
} 
movement of price expectations following the AEH can be written as

$$
P_{t}^{e}-P_{t-1}^{e}=\lambda\left(P_{t-1}-P_{t-1}^{e}\right)
$$

which says that economic agents derive their expectations at the outset of period $t$ by a fraction $\lambda$ of the forecast error $\left(P_{t-1}-P_{t-1}^{e}\right)$. In other words expectations in the current period are revised if the value of the price level forecasted in the previous period is different from the actual realization of this variable, i.e., the case when market participants are surprised (e.g. by the actions of the policymaker or unforeseen events).

The time path of price expectations is highly sensitive to the specification of $\lambda$, a parameter exogenous to the economic model. Consider the extreme cases: for $\lambda=0$ agents are completely myopic and do not revise their expectations under any circumstances such that $P_{t}^{e}=P_{t-1}^{e}$. If $\lambda$ takes on the value 1 , then current expectations are myopically linked to the previous observed price level $P_{t}^{e}=P_{t-1}$, i.e. static expectations. It follows that for $\lambda=1$ agents never "learn" from their mistakes and consistently make incorrect forecasts. Eq. [2.5] above can be rewritten as

$$
P_{t}^{e}=\lambda P_{t-1}+(1-\lambda) P_{t-1}^{e}
$$

which is a first-order adaptive expectations equation. The term $P_{t-1}^{e}$ can be derived analogously as $P_{t-1}^{e}=\lambda P_{t-2}+(1-\lambda) P_{t-2}^{e}$. Substituting the expectations of past variables in this fashion ad infinitum we can derive the following term,

$$
\begin{aligned}
P_{t}^{e} & =\lambda P_{t-1}+\lambda(1-\lambda) P_{t-2}+\lambda(1-\lambda)^{2} P_{t-3}+\cdots+\lambda(1-\lambda)^{n-1} P_{t-n} \\
& =\lambda \sum_{i=1}^{\infty}(1-\lambda)^{i-1} P_{t-i}
\end{aligned}
$$

Substituting this expression for $P_{t}^{e}$ into function (2.2) and moving the time index up by one yields

$$
P_{t}=\frac{M_{t}}{\alpha}+\frac{\beta}{\alpha} \lambda \sum_{i=0}^{\infty}(1-\lambda)^{i} P_{t-i}
$$

which makes the movement of $P$ depend solely on observable variables $\left(M_{t-1}\right.$ and current and all past realizations of $P$ ). An economic agent's "best" guess as $P$ goes back in time. Adaptive expectations then are mathematically nothing more than the geometrically distributed lag of past values of the variable (with the restriction that the sum of the distributed lag coefficients equal unity). 
of an unobserved variable - expected price - can linked to the observable variables - actual price in all previous periods and the current monetary stance $M_{t-1}$. The AEH has the implication that the most recent observations on the actual price level dominate the formation of expectations about the development of prices in the future. Expectations are disproportionately linked with the most recent past. ${ }^{9}$

One of the strengths of the adaptive expectations approach is that it was the first to recognize the role of past history in the formation of expectations. By assuming a retrospective position it assumed that the economy is structurally stable in that today's outcomes are not vastly dissimilar from yesterday's. But the mathematical expression in [2.8] shows that expectations are entirely backward-looking, formed without reference to current information about the future. Such a backward-looking way of expectation formation implies that people will make non-random errors in predicting the value of variables in the future. This did not fit well with standard neoclassical economic assumption that agents do not consistently repeat the same mistakes. Another criticism involves information. The AEH assumes that economic agents regard only the past values of the variables they are trying to forecast. This means that these agents voluntarily limit themselves to a very narrow set of information when forming expectations. ${ }^{10}$ Any improvement over adaptive expectations approach would have to concern itself with the incentives to acquire information and exploit profitable opportunities for revising behavior (i.e. avoiding regular sources of error).

\subsection{Rational expectations}

A richer theory of expectations was first proposed by JoHn MuTH (1961) in a microeconomic context of market commodity demand and supply. The basic idea that MUTH projected was that economic agents make decisions in such a way that leaves little room to make errors in a systematic fashion. The expectations are governed instead by "economic thinking" in the sense that agents try to avoid the costs of of systematic forecast errors by revising their expectations accordingly. In order to avoid non-random errors the agents

\footnotetext{
${ }^{9}$ From $[2.7]$ we can see that price expectations decline geometrically in proportion with $0<\lambda<1$.

${ }^{10}$ See BegG (1982), p. 25-26.
} 
uses all available information in the "best way" possible, that is, rationally. ${ }^{11}$ Further information is appropriated only if the expected benefit exceeds the cost.

RoBERT LuCAS, JR. was the first to recognize that this principal of expectation formation has general applicability to a wide range of expectations about economic phenomena. In a number of exceptional contributions ${ }^{12}$ he was able to link this principle of decision making to macroeconomic decision making and thus open the analysis of expectations formation to the study of economic policy. The REH was central in moving the elemental role of information into mainstream economics by accepting that informational activities are similar the same as any other economic activity that economic man undertakes with the marginal benefits of information-gathering holding the balance with the costs necessary to collect this information.

Under the REH, the behaviorial pattern of agents is inherently forwardlooking in the sense that current decisions depend not only upon the current and past states of the environment, but also upon the entire expected future profile of events, including anticipated economic policy. Private agents form expectations by making optimal use of all relevant information. The rational expectations hypothesis (REH) can be summarized as "the consistent application of the hypothesis of rational behavior in genuinely dynamic situations, with uncertainty about the future, imperfect information and costly information gathering" ${ }^{13}$. Rational expectations does not simply look at the past value and past forecast errors of the variable to be forecast, as in adaptive expectations, but uses what is known of the determinants of the variable to make predictions.

The point of departure of rational expectations is that individuals do not (voluntarily) make systematic errors. To express analytically the hypothesis that agents avoid non-random errors, the REH invokes a mathematical

\footnotetext{
${ }^{11}$ For brief description of Muth's model see Palley (1993), p. 9-13. Machlup (1983), p. 174, considers the term rational a misleading misnomer. The term "rational expectations ... denotes correct expectations (or expectations in conformance with those of some economic theorists of the neoclassical school)." The misappropriation of this term by Muth was continued when rational expectation was carried over to macroeconomic thinking so that "battling against the continued use of the misnomer would be fighting a hopeless cause." I will make no airs of overthrowing this consensus, but it is worthwhile for the later game-theoretic concept of equilibrium to keep this distinction in mind.

${ }^{12}$ For a broad survey of LuCAS' contributions to economic science see SvEnsson (1996).

${ }^{13}$ Svensson (1995), p. 2
} 
condition that rules out such errors. When forming an expectation for $P_{t}$, this condition ensures that $P_{t}-P_{t}^{e}$ should not be systematically related to any information possessed by the agents in period $t-1$ when expectations are formed. From the vantage point of period $t-1, P_{t}$ is a random variable. The predicted value of the price level $P_{t}^{e}$ is made using all of the information available the period or periods before $t^{14}$. The expectational hypothesis can be adopted by postulating that

$$
P_{t}^{e}=E\left(P_{t} \mid \Omega_{t-1}\right)
$$

where $E$ is the mathematical expectations operator and $\Omega_{t-1}$ is the set of information available at period $t-1$. In other words, this condition requires that the subjective expectation (forecast) of $P_{t}$ held by agents in $t$ be equal to the objective (mathematical) expectation of $P_{t}$ conditional on the information set $\Omega_{t-1} \cdot{ }^{15}$

The rational expectations hypothesis implicates an intelligent economic agent that possesses an underlying economic model which describes the way in which the variable to be forecasted is generated. In our case the demand for money function can serve the individual as a useful model for the inflation process, since it describes the policy process generating $P_{t}$ in successive periods. Accordingly, the only logically coherent way to forecast $P_{t}$ is to use the probability distribution of this (random) variable as expressed in this model [2.8] as the basis for computing $E\left(P_{t} \mid \Omega_{t-1}\right)$. The rational expectations solution for the movement of $P$ given $\Omega_{t-1}$ using [2.8] is computed as

$$
P_{t-1}=\frac{M_{t-1}}{\alpha}+\frac{\beta}{\alpha} E\left(P_{t} \mid \Omega_{t-1}\right)
$$

which is still not a solution for $P$ for it still contains the expectational variable $E\left(P_{t} \mid \Omega_{t-1}\right)$. To eliminate this term, we set eq. [2.11] one period forward and then take expectations conditional on $\Omega_{t-1}$. Doing this yields

$$
E\left(P_{t} \mid \Omega_{t-1}\right)=\frac{E M_{t} \mid \Omega_{t-1}}{\alpha}+\frac{\beta}{\alpha} E\left(P_{t+1} \mid \Omega_{t-1}\right)
$$

\footnotetext{
${ }^{14}$ By specifying the information set as such I am avoiding the question of how much information individuals optimally choose to inquire. But the informational requirements are not such that "the entire population have degree in economics" (BEGG (1982)).

${ }^{15}$ A forecast of $P_{t}$ made two periods prior to $t$ will differ under the REH only if the information set changes between $t-2$ and $t-1$. Therefore
}

$$
E\left(P_{t} \mid \Omega_{t-1}\right)=E\left(P_{t} \mid \Omega_{t-2}\right) \quad \text { when } \quad \Omega_{t-1}=\Omega_{t-2}
$$


where $E\left(\left\{E\left(P_{t+1} \mid \Omega_{t}\right\} \mid \Omega_{t-1}\right)\right.$ has been replaced by $E\left(P_{t+1} \mid \Omega_{t-1}\right)$ by the law of iterated expectations ${ }^{16}$. If this process of iterated replacement is repeated for $t \rightarrow \infty$ then all expectations of future values of $P$ are eliminated ${ }^{17}$ such that

$$
P_{t}=\frac{M_{t}}{\alpha}+\frac{1}{\alpha} \sum_{i=0}^{\infty}\left(\frac{\beta}{\alpha}\right)^{i} \mathrm{E}\left(M_{t+i} \mid \Omega_{t+i-1}\right)
$$

It will be useful for the later analysis to use the growth rates of variables rather than in level form. The development of the price level can be transformed into an expression for the inflation rate taking the logarithm of $P_{t}$ and $M_{t}$. Utilizing some useful relationships, ${ }^{18}$ eq. [2.13] can be written as

$$
\pi_{t}^{R}=\frac{\hat{m}_{t}}{\alpha}+\frac{1}{\alpha} \sum_{i=0}^{\infty}\left(\frac{\beta}{\alpha}\right)^{i} \mathrm{E}\left(\hat{m}_{t+i} \mid \Omega_{t+i-1}\right)
$$

where $\pi_{t}=\ln P_{t}-\ln P_{t-1}$ is the inflation rate and $\hat{m}_{t}=\ln M_{t}-\ln M_{t-1}$ is the growth rate of the money stock in period $t$. Formulated in this fashion, the process of inflation, $\pi_{t}$, is determined by the growth rate of the current and expected money stock from $t$ onwards. In a similar way, the inflation process with adaptive expectations from eq. [2.8] can be written in these terms,

$$
\pi_{t}^{A}=\frac{\hat{m}_{t}}{\alpha}+\frac{\beta}{\alpha} \lambda \sum_{i=0}^{\infty}(1-\lambda)^{i} \pi_{t-i}
$$

With expectations being driven by rational agents, according to [2.15] the development of inflation $\pi_{t}^{R}$ is determined solely by the expectations of future monetary policy. Comparing this with the solution for adaptive expectations in [2.16] shows that expectations are completely forward-looking under the $\mathrm{REH}$ - the past plays no role in the process of expectation formation. Under

\footnotetext{
${ }^{16}$ In simple words, the best guess at time $t-1$ about what individuals at time $t$ will expect for the price level in the following period is merely the best guess at time $t-1$ for $P_{t+1}$. A more formal proof of this "law" can be found in MCCALlum (1996), p. 184.

17 The residual expectational term $\sum_{i=1}^{\infty}\left(\frac{\beta}{\alpha}\right)^{i} E\left(P_{t+i-1} \mid \Omega_{t-1}\right)$ converges toward zero.

${ }^{18}$ Inflation is defined as the growth rate of $P_{t}$ between periods $P_{t+1}$ and $P_{t}$,

$$
\pi_{t}=\frac{P_{t}-P_{t-1}}{P_{t-1}}
$$

from which can be seen that $P_{t} / P_{t-1}=1+\pi_{t}$. Taking the natural logarithm of both sides of this equation and using the approximation $\ln \left(1+\pi_{t}\right) \approx \pi_{t}$, eq. [2.13] can be written in rate-of-change terms as in [2.15].
} 
adaptive expectations, the inflation process $\pi_{t}^{A}$ is governed solely by observable variables - any change in the government's future expected path of policy has no influence on the result. Eq. [2.15] is also therefore instructive because it emphasizes that the process governing inflation depends on policy decisions (in this case, the money stock) that are expected for each period in the entire infinite future. To solve for $\pi_{t}^{R}$ therefore requires the analysis of future behavior of the monetary authority. This implies, however, that we know something about the incentives of the policymaker when making decisions of $\hat{m}$. When the decision rules of the monetary authority change in the future, perhaps because his or her preferences have changed, then the relationships underlying money demand will also shift thus conditioning the expectation of future inflation. ${ }^{19}$

Many economic processes are stochastic in nature so the process underlying the outcome variable is very often assumed to be influenced by exogenous disturbances. This is usually formulated by assuming a random variable $u_{t}$ with a probability distribution centered at zero and having a constant and finite variance, $\sigma_{u}^{2}$, that becomes known only at the end of period $t$. It is therefore not part of the information set at period $t-1$, when expectations are made. To be consistent with the REH the "best" forecast a rational agent can make in $t-1$ of $u_{t}$ is its mean value, i.e. $E\left(u_{t} \mid \Omega_{t-1}\right)=0$. Therefore the result in [2.15] does not change qualitatively (but of course the expectational error for period $t$ is $\left.\pi_{t}-E\left(\pi_{t} \mid \Omega_{t-1}\right)=u_{t}\right)$. With the exception of the model in section [6.1], all the models discussed will be deterministic in the sense that any unexpected events originate in the behavior of the government.

\subsection{The time inconsistency of optimal plans}

The assimilation of rational expectations into mainstream macroeconomics led economists to examine in more detail the implications of expectations in the design of economic policy. When expectations are no longer fixed by past realizations of policy, then the behaviorial patterns of private individuals become interdependent with the actions of a centralized policymaker. The pre-

\footnotetext{
19 The rational expectations hypothesis has some very powerful implications which also deserve a short mention. It is, e.g. the only expectation formation mechanism that does not exhibit any systematic errors. Also, given all available information, the errors of rational expectations are on average zero. Furthermore, expectational errors are uncorrelated with past expectational errors, i.e. $E\left[\left(\pi_{t}-E \pi_{t}\right)\left(\pi_{s}-\mathrm{E} \pi_{s}\right)\right]=0, \forall s \neq t$.
} 
ceding section established that under rational expectations, the predictions of economic policy depend crucially on the specification of the objectives and and incentives of the policymakers, and upon the constraints on their actions. It is no longer possible to assume that the government is passive agent that can be programmed like a computer. Instead, it is necessary to view the policymaker as a rational and maximizing agent reacting to incentives as private agents do. By specifying a government objective function policy is made endogenous: The government maximizes its objective under the constraints imposed by private equilibrium behavior.

Given such an interaction, the economic choices of the private sector and government take on a strategic quality. Economic policy can be elevated to the level of a strategy. The introduction of strategic elements into mainstream economics was burgeoned by KYDLAND AND PRESCOTT in their seminal paper Rules Rather then Discretion: The Inconsistency of Optimal Plans (1977). The authors argued that the study of dynamic macroeconomic systems must take into account the incentive structure of economic agents: "... only if ... expectations were invariant to the future policy plan would optimal control theory be appropriate" for planning the outcome of future policy measures. But they pointed out that under the premises of rational expectations, "changes in policy induce changes in structure, which in turn necessitate reestimation of future changes in policy". ${ }^{20}$ Since optimal control theory disregards the strategic interaction between economic agents they conclude that it is not the appropriate tool for economic planning.

The general problem of time inconsistent policies can be examined in a two-period horizon. The government's optimal policy describes a sequence of policy actions, $M_{1}$ and $M_{2}$, specifying how the government should act both now (period 1) and in the future (period 2) to maximize a well-defined social welfare function. A macro welfare function ${ }^{21}$ can be defined over policy choices and the economic choices of the private sector, $X_{1}$ and $X_{2}$, which pose constraints on the government's maximization problem,

$$
V=V\left\{X_{1}, X_{2}, M_{1}, M_{2}\right\}
$$

Private agents' decisions in period 1 are a function of current government policy and (uncertain) future policy. In the following period 2 agents' decisions

\footnotetext{
${ }^{20}$ See Kydland And Prescott (1977), p. 474.

${ }^{21}$ See Blanchard and Fischer (1989), p. 568 for a rationalization of this type of function in a model framework.
} 
are also made on the basis of the past history of previous decisions,

$$
\begin{aligned}
& X_{1}=X_{1}\left(M_{1}, M_{2}\right) \\
& X_{2}=X_{2}\left(X_{1}, M_{1}, M_{2}\right)
\end{aligned}
$$

so that welfare can be written as

$$
V\left\{X_{1}, X_{2}, M_{1}, M_{2}\right\}=V\{\underbrace{X_{1}\left(M_{1}, M_{2}\right)}_{X_{1}}, \underbrace{X_{2}\left(X_{1}\left(M_{1}, M_{2}\right), M_{1}, M_{2}\right)}_{X_{2}}, M_{1}, M_{2}\}
$$

An optimal sequence of policies for $t=1,2$ maximizes social welfare $V$ with the constraints given by private sector behavior in [2.18]. The first derivative of $V$ according to $M_{1}$ and $M_{2}$ provides the conditions for a maximum:

$$
\begin{aligned}
\frac{\partial V}{\partial M_{1}} & =\frac{\partial V}{\partial X_{1}} \frac{\partial X_{1}}{\partial M_{1}}+\frac{\partial V}{\partial M_{1}} \stackrel{!}{=} 0 \\
\frac{\partial V}{\partial M_{2}} & =\frac{\partial V}{\partial X_{1}} \frac{\partial X_{1}}{\partial M_{2}}+\frac{\partial V}{\partial X_{2}}\left[\frac{\partial X_{2}}{\partial X_{1}} \frac{\partial X_{1}}{\partial M_{2}}+\frac{\partial X_{2}}{\partial M_{2}}\right]+\frac{\partial V}{\partial M_{2}} \\
& =\frac{\partial V}{\partial X_{2}} \frac{\partial X_{2}}{\partial M_{2}}+\frac{\partial V}{\partial M_{2}}+\frac{\partial X_{1}}{\partial M_{2}}\left[\frac{\partial V}{\partial X_{1}}+\frac{\partial V}{\partial X_{2}} \frac{\partial X_{2}}{\partial X_{1}}\right] \stackrel{!}{=} 0
\end{aligned}
$$

Optimal policy $M^{*}$ is a sequence of current and future policy actions, $M^{*}=$ $\left\{M_{1}^{*}, M_{2}^{*}\right\}$. Kydland And Prescott define a policy $M^{*}$ to be time consistent if for each time period $t=1,2, M_{t}$ maximizes [2.20], taking as given the sequence of previous policy actions. For a policy to be consistent, the government disregards the effect that future policy may have on current decisions. It can easily be seen that by applying this consistency condition on the the maximization condition in $t=2$ given $X_{1}$ is reduced to

$$
\begin{array}{ll}
\left.\frac{\partial V}{\partial M_{1}}\right|_{X_{1}=\bar{X}_{1}} & \stackrel{!}{=} 0 \\
\left.\frac{\partial V}{\partial M_{2}}\right|_{X_{1}=\bar{X}_{1}} & =\frac{\partial V}{\partial X_{2}} \frac{\partial X_{2}}{\partial M_{2}}+\frac{\partial V}{\partial M_{2}} \stackrel{!}{=} 0
\end{array}
$$

If the condition in [2.22] holds then the policy sequence $\left\{M_{1}, M_{2}\right\}$ is time consistent. The crux of the matter is that an optimal policy that satisfies the condition in [2.21] must not necessarily be time consistent. Under certain conditions then, a policy may not actually remain optimal with the passage of time. These conditions may be derived by simply comparing the first-order 
conditions [2.21] with [2.22]. A consistent policy is simultaneously optimal if and only if

$$
\frac{\partial X_{1}}{\partial M_{2}}\left[\frac{\partial V}{\partial X_{1}}+\frac{\partial V}{\partial X_{2}} \frac{\partial X_{2}}{\partial X_{1}}\right]=0
$$

and it therefore follows that an optimal policy is time consistent when one of the following conditions hold:

$$
\text { (1) } \frac{\partial X_{1}}{\partial M_{2}}=0 \quad \text { or } \quad(2) \quad \frac{\partial V}{\partial X_{1}}+\frac{\partial V}{\partial X_{2}} \frac{\partial X_{2}}{\partial X_{1}}=0
$$

The first condition in [2.24] states that future policy decisions must have no influence on current private decisions for the optimal policy sequence $\left\{M_{1}^{*}, M_{2}^{*}\right\}$ to be time consistent. The expectations process underlying (1) implies that current decisions rely on a backward-looking procedure (such as adaptive expectations in [2.8]), so that current decisions are indeed invariant to future policy. The moment we allow for a forward-looking expectation formation of rational expectations, then, by definition,

$$
\frac{X_{t}}{M_{s}} \neq 0 \quad \forall s>t
$$

and condition (1) is no longer valid under a discretionary regime. Lack of a "commitment technology" would therefore lead to time inconsistency. If the government were to make a binding precommitments to the ex ante optimal policy $M_{1}$, the incentive to deviate ex post would be immaterial. Accordingly, private decisions in period 1 would be made taking as given the policy decision such that

$$
\left.\frac{X_{1}}{M_{2}}\right|_{M_{2}=\bar{M}_{2}}=0
$$

and the time consistency problem is solved. One way to solve the time inconsistency dilemma is therefore to alter the existing rules or the institutional structure within an economy in order to limit the scope for discretionary opportunism on the part of policy makers. One would assume that the constraint put on the government's period 2 action would render the solution as suboptimal. The rather ironic and often misunderstood implication of the theoretical concept of dynamic consistency is that the government should be placed in an institutional environment that keeps it from maximizing social welfare in order to succeed in maximizing it. ${ }^{22}$ No public-choice interpreta-

22 See Chari, V. V. (1988), p. 21. This also leads to the paradox result that if the government can fool people into believing that it will credibly commit itself to follow the policy rules, then it can "cheat" them, i.e., deviate from $\bar{M}_{2}$, for their own good. 
tions of government behavior are necessary to rationalize this behavior.

The second condition in [2.24] relates to the government's incentive structure embedded in the social welfare function $V$. If the effect of changes in $X_{1}$ upon $V$ both directly and indirectly through $X_{2}$ is not zero, then the maximization of welfare is not entirely under the control of a benevolent government. One way to view this situation is by postulating a conflict of interest between the policy maker and private individuals due to the existence of economic externalities. Whereas it is individually rational for an a private agent to ignore the externalities, a rational policy maker will try to internalize them. Without these externalities the government could achieve a first-best solution relative to his preferences and subsequently would have no incentive to reoptimize and improve social welfare contingent on private sector decisions. The existence of externalities puts the government in a second-best situation. As will be illustrated in the following sections policy surprises can be viewed as providing additional policy instruments in second-best situations, and hence there may be an incentive to use them.

In summary then, if one or both conditions in [2.24] do not hold, then there will be a discrepancy between ex ante and ex post optimal policy. ${ }^{23}$ The issue of credibility emerges here from the incentive structure of a government that is not committed to a full sequence of actions in both periods. Ex ante, before some choices have been made by the private sector, an optimal policy induces some response of private behavior. Usually this policy sequence is announced, so that private decisions are made contingent on the announcement. Depending on the context these decisions can take the form of, e.g. sector-specific capital, investments in human capital or wage contracts. But ex post, after the choices of private individuals have been made, the response to policy may be very different from the ex ante response. This renders the government's ex post constraints different from the ex ante constraints. It will therefore renege on the announcement in order to achieve a first-best outcome.

\footnotetext{
${ }^{23}$ CAlvo (1987), p. 229 adds that a policymaker must also be able to predict with a small degree of error, the impact of his announcements on the private sector's behavior, i.e., its choices of $X_{t}$. Otherwise, the government has no basis with which to formulate its welfare maximization. CALvo goes on to note that time consistency may therefore only be a problem facing governments that are not only fine-tuning policy, but undertaking major reforms.
} 


\section{ELEMENTS OF A GAME-THEORETICAL ANALYSIS}

Although Kyldand and Prescott did not frame their arguments in a very formal manner, they were well aware of the fact that the strategic situation they were attempting to describe would lend itself naturally to a game theoretic interpretation. In this respect they themselves spoke of economic policy as "a game against rational economic agents". The strategic situation of a government maximizing welfare under the constraints imposed by the behavior of the other "players" is not unlike the situation that game theory has successfully analyzed in many microeconomic situations, namely the study of individual rational choice in strategic situations.

The individualistic approach of game theory does not, at first glance, make it a suitable device for discussing macroeconomic problems in which a large number of private agents interact with one another only indirectly. The domain of macroeconomics, especially the neoclassical school, is one in which individual agency often appears to be particularly significant, i.e., behavior appears to be minimally socialized. Yet in retrospect it is perhaps important to remember that the game-theoretic program rendered by NeUMANN AND MoRgenstern (1944) is an attempt to resocialize the analysis of rationality in economic environments. "Proper understanding of any social situation would require game-theoretic analysis...game theory has now definitely become an important analytical tool in understanding the operation of our economic system." ${ }^{1}$. In other words, game theory as applied to the formation of economic policy can be seen as an attempt to establish the micro-foundations of macroeconomic policy.

This section will cover the most important building blocks for a gamebased analysis of macroeconomic policy, as they will be discussed in the following chapters. Three major social structures define the strategic situation

\footnotetext{
${ }^{1}$ See Harsanyi (1995), p. 293.
} 
of a macroeconomic policy game: the payoff structure, the game structure, and the information structure.

\subsection{Game and payoff structure}

The game structure includes three essential elements: the players, the set of actions available to the players and the rules regulating the use of the actions. In order to place the structure in a context amenable to a gametheoretical analysis, the following discussion will rely on the concept of the representative agent. The formalization of the macroeconomy in terms of a representative agent was advanced by the New Classical and New Keynesian school of thought and involves the aggregation of economic entities. ${ }^{2}$

At a very basic level then, the players are individuals who make decisions. Accordingly, the macroeconomic games that will be discussed will involve two representative agents, a political entity, referred to as the government $G$ and grouping of individuals, the private sector $P S$. It is assumed that these players make rational decisions in the microeconomic sense that they are able to compare relevant alternatives and rank them in terms of preference. Under REH rationality also encompasses a strategic rationality where the government and private sector take into account the behavior of the other player by assuming that they are also behaving strategically rational. Furthermore under situations characterized by uncertain events, it is assumed that the players either know the probability associated with each state of the world or do not know them and updates them using Bayes' rule. ${ }^{3}$

An action or move by player $i$ is the choice he can make and will be denoted by $a_{i}$. The player's action set, $A_{i}$, is the entire set of actions available to him. The action of player could involve anything that the he can delegate, such as the growth of the money stock, the appointment of a new central

\footnotetext{
${ }^{2}$ Other reasons for using the representative agent concept can be cited as providing a means of avoiding the Lucas' critique and their aid in the construction of Walrasian models. The validity of the concept for use in macroeconomics has been questioned of late, the main thrust of dissent centered on the methodological aggregation problem inherent in macro that undermines the entire attempt of looking at complex systems through the lens of microfoundations. We will not delve further into this debate, but refer the reader to HARTLEy, J. (1997) for an extensive discussion of this debate.

3 To model this subjective expected utility maximization a pseudo-player called Nature is introduced who takes random actions at specified points in the game with specified probabilities.
} 
banker, the level of wages or the dissolution of the player's action set itself. The actions of the policymaker will often be referred to as policy actions, or just plain policy. In a macroeconomic game the terms actions and decisions will be used interchangeably taking the bold assumption is made throughout that there is no lag between the time the decision is made and the time action is taken. An action set can be either discrete or continuous.

If actions are executed during the passage of time (as compared with simultaneous moves), then the specification of the timing of actions becomes an essential element of the game structure. It becomes necessary to specify in which way time is taken to pass (i.e., the chronological duration between the moves, where 0 gives the continuous case). Therefore, the rules of the game specify the order of moves. This allows us to analyze the consequences of different policy regimes upon the outcome of the game. A regime of discretion, for example, is modelled by setting the order of moves such that the government can take his action after the decisions of the private sector have been made. By reversing the order of timing, the regime is said to be one of commitment, since the government cannot reoptimize his policy decision contingent on the actions of private individuals (refer to Chapter 4 for details).

With the action sets and rules are specified, each of the players adopts a strategy that maximizes its utility (payoff). A strategy $s_{i}$ is a rule that instructs the player which action to select at each instant of the game. A strategy is a function of observed history of actions and is independent of current decisions or of another player's strategy. The distinction between strategies and actions is not important for many economic situations, but it does become relevant for certain equilibrium concepts such as subgame perfection.

The payoff structure of the game is essential since it determines the motives underlying the actions of the game participants. The payoff $U_{t}^{i}$ of a player $i$ can be described as the utility the player receives after all the other players (as well as Nature) have picked their strategies and the decisions have been made in period $t$. The government's preferences are summarized by a macro welfare function, $U^{G}\left(m_{t}, x_{t}\right)$ which depends on its choice of policy $m_{t}$ as well as the choice of the private sector $x_{t}$. Private sector PS utility is $U^{P S}\left(x_{t}, m_{t}\right)$ is a function of its choice and government policy selected at time $t$. In many applications both these utility functions are continuous and have well defined first and second derivatives. It is assumed that are both 
are concave in $m_{t}$ and $x_{t}{ }^{4}$

\subsection{Information structure}

Economic policy is an ongoing process that involves discrete moves (policy choices) over a finite time period. It is therefore insightful to analyze macroeconomic games in a multiperiod context. In sequential-move games information becomes a central element in determining the outcome of a game. At a most fundamental level information must suffice in a game so that the individual player knows what he is doing, i.e. knowing what their preferences are, what the structure of the game is, and what the payoffs from playing the game are. An important characteristic of sequential games lies in the conditioning of players' perceptions about the environment and the strategies to be played by the opponent.

Depending upon the setup of the game, the informational characteristics can be divided into categories. The strongest informational requirement are met by a game of perfect information, because the player has not only knowledge of the past moves, but also knows exactly where he is in a game tree. ${ }^{5}$ Conversely, if the information structure is not perfect, then economic agents can use their private information for the pursuit of strategic ends. Under imperfect information a policy maker may find it favorable to pursue a course of action that he would not follow under conditions of perfect information. In this case time itself is a constraining element in the range of policy alternatives the government has at its disposal. Furthermore in an intertemporal context, the utility of policy actions becomes sensitive to the fashion in which future realizations of policy are discounted.

A much more contentious point is the assumption of common knowledge. In a strategic setting in which decision-makers are assumed to condition their

4 The concavity of the utility functions requires that the second derivatives in the control variables are negative, i.e.

$$
\frac{\partial^{2} U^{G}}{\partial m_{t}^{2}}<0 \quad \text { and } \quad \frac{\partial^{2} U^{P S}}{\partial x_{t}^{2}}<0
$$

which means that the first derivative of $U^{i}$ is a decreasing (monotonic) function of the respective control variable.

${ }^{5}$ A sequential move game can be presented in so-called extensive form, which takes the form of a tree. Players undertake actions at their decision nodes, contingent on an information set. See RASMUSSEN (1994), for a detailed explanation. 
choices on what they expect other decision-makers to do the players must possess some information on rationality, payoffs and beliefs and on the game's structure. The common knowledge assumption implies that each player must have knowledge about the other players. Specifically, "information is common knowledge if it is known to all other players, if each player knows that all the other players know it, if each player knows that all the players know that all the players know it, and so forth ad infinitum." 6

\subsection{Solution concepts}

The concept of an equilibrium is central to modeling the interdependency of decision-making between government and private sector. An equilibrium strategy profile is a pair $s^{*}=\left\{m_{t}^{*}, x_{t}^{*}\right\}$ such that no player has an incentive to deviate from these actions for every time period. In other words, the equilibrium strategies $s^{*}$ adopted by the other players are the strategies that maximize their individual payoffs.

\subsubsection{One stage games}

One shot (ore one stage) games are played only once so that neither past nor future confrontations between $G$ and $P S$ play any role in determining the outcome. Both players have full information about both the state of the environment and the objectives of the other. The dominant solution concept used in this setup is a Nash equilibrium which can be defined by the property that the strategy of $G$ and $P S$ (taken from the action sets $A^{G}$ and $A^{P S}$ ), which is taken as given by the other players, is actually optimal for the respective player and vice versa. For a strategy pair $\left\{m^{*}, x^{*}\right\}$ to be a Nash equilibrium the payoffs must fulfill

$$
\begin{aligned}
U^{G}\left(m^{*}, x^{*}\right) & \geq U^{G}\left(m^{\prime}, x^{*}\right) \forall m^{\prime} \in A^{G} \\
U^{P S}\left(m^{*}, x^{*}\right) & \geq U^{P S}\left(m^{*}, x^{\prime}\right) \forall x^{\prime} \in A^{P S}
\end{aligned}
$$

Very often the policy-decision space as defined by $A^{G}$ and $A^{P S}$ is in $R$ so that $U^{G}$ and $U^{P}$ are continuous and differentiable functions. The Nash conditions can then be derived from the first-order conditions,

\footnotetext{
${ }^{6}$ See Rasmussen (1994), p. 44.
}

$$
\left.\frac{\partial U^{G}(m, x)}{\partial m}\right|_{x=x^{*}} \stackrel{!}{=} 0 \quad \text { and }\left.\quad \frac{\partial U^{P}(x, m)}{\partial m}\right|_{m=m^{*}} \stackrel{!}{=} 0
$$


The conditions in [3.4] are necessary conditions for the government policy $m$ to be time consistent. It is possible to derive reaction functions from these first-order conditions which give the optimal response of one player to a specific action of the other, $m^{r}(x)$ and $x^{r}(m)$. Using the properties of implicit functions on the Nash conditions in [3.4] we can illustrate how the policy variable $m$ changes through changes in the private sector's strategy $x$,

$$
\frac{\partial m}{\partial x}=-\frac{\frac{\partial^{2} U^{G}}{\partial x \partial m}}{\frac{\partial^{2} U^{G}}{\partial m^{2}}}
$$

Since by definition the function $U^{G}$ is concave in $m$ it is possible to establish that $\partial^{2} U^{G} / \partial m^{2}<0$ always holds. ${ }^{7}$ Accordingly, the reaction function $m^{r}(x)$ can be characterized by two cases. For $\partial^{2} U^{G} / \partial x \partial m>0$, the government's policy $m$ is increasing in $x$, i.e., government utility can be increased by choosing a complementary strategy. Otherwise for $\partial^{2} U^{G} / \partial x \partial m>0, m$ is said to be a strategic substitute for a private sector choice of $x$.

One special case of equilibrium obtains when the choice of $x$ is governed by rational expectations. Then the private sector is completely informed about the objectives and constraints the government is facing. This means that it has perfect information about the reaction function of the government $m^{r}(x)$ and uses it when computing its optimal decision. A rational expectations equilibrium is symmetric with $m^{r}(x)=x^{r}(m) \Rightarrow m=x$ and expectations are said to be self-fulfilling in equilibrium. Drawing the reaction function for the government in a $(m, x)$ space, the intersection with the $45^{\circ}$ line gives the rational expectations equilibrium. Figure [3.1] shows that for the case of strategic substitutes (b), the slope of the reaction function $m^{r}(x)$ is negative and subsequently there can be only one unique equilibrium. Complementary strategies (a) may result in multiple equilibria, the implication being that there may be a large degree of indeterminacy regarding the outcome of the game. For example, in Figure [3.1] (a), the equilibrium outcome may involve either high $\left(m_{2}\right)$ or low $\left(m_{1}\right)$ values of the policy variable.

The exact nature of the equilibrium depends on the institutional structure in which policy is carried out. The institutional environment limits the number of ex post options the policymaker can choose from. If the policy maker has full discretion then under certain conditions it has an incentive to

\footnotetext{
7 See footnote no. [4].
} 
Fig. 3.1: RATiOnAL EXPECTATIONS EQUILIBRIUM

(a)

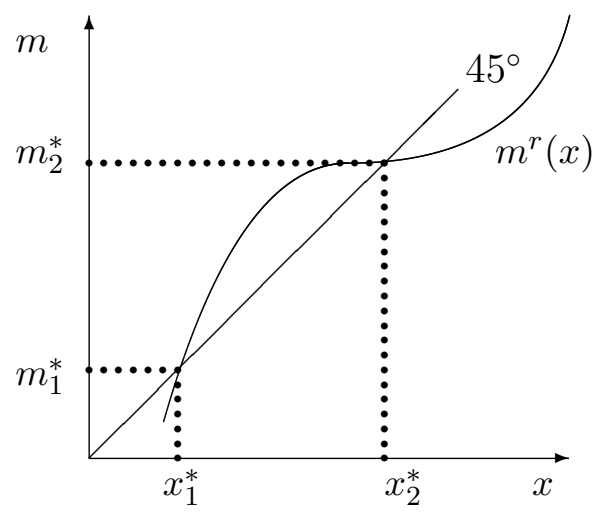

(b)

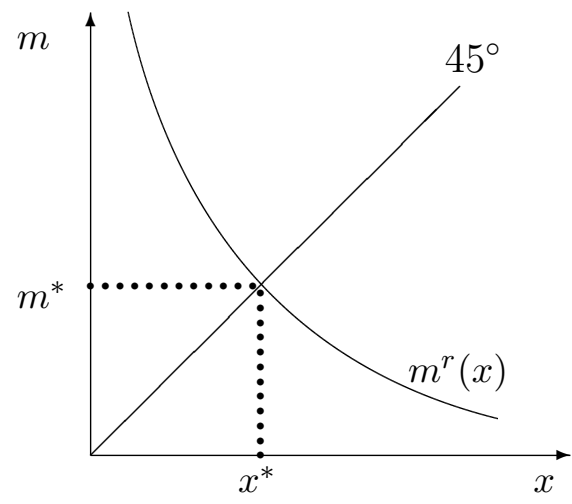

use these discretionary powers to revise policy so to maximize the social welfare. The other extreme of institutional constraint is a binding commitment, in which the policymaker cannot change policy once it is announced. As we will see below this institutional setup is superior in terms of welfare to that of discretion. Discretionary powers in the hands of a government are selfdefeating, because the government acts as if optimization is unconstrained when it fact it is (through $x(m)$ ). This leads to the paradox result that welfare can in fact improved by increasing the number of explicit constraints the policy maker faces. ${ }^{8}$

\subsubsection{Dynamic games}

Once the time-dimension is included explicitly in a macroeconomic game context, the Nash equilibrium loses some of its appeal as the predominant solution concept. For one thing, the Nash concept does not ensure that equilibrium conditions are satisfied at every stage of the game. When players are in no position to bind themselves to a certain strategy, the refinement of subgame perfection or perfect equilibrium rules out those equilibria that depend

\footnotetext{
8 This seems paradox since under normal circumstances, unconstrained optimization is always superior to constrained optimization. But because institutional constraints act as $e x$ post limitations on the policy maker's behavior they condition private sector expectations and thus have a direct impact on the results of the policy measure. This will be a recurring theme in the sections that follow.
} 
on non-credible announcements or threats. ${ }^{9}$ This has special relevance for the time-consistency argument and will be given due credit in the following section [4.1].

For our purposes the Nash equilibrium is additionally too weak to account for reputational effects that will be the topic of Chapters 5 and 7 and will be extensively discussed there. Briefly, these effects come into play when a player in a multi-period setting is able to exploit some uncertainty that other players have concerning his/her preferences and rely on the presence of asymmetric information between the players and the information that is conveyed by the aggregate history of the game. Events that are off-the-equilibrium path are not exogenous to the game, but are derived endogenously from the strategies of the other players. To tackle a multi-period setting requires a criterion that goes beyond the requirement of Nash equilibrium that the strategy of each player be an optimal response to the equilibrium strategy of the other player. The concept of sequential rationality is an example of a refinement of Nash equilibrium. A sequentially rational equilibrium is characterized by a situation in which each player maximizes his payoffs at each point in time, reoptimizing his decisions and taking into account that they will reoptimize in the future.

\footnotetext{
${ }^{9}$ This important refinement of the Nash concept originates from the seminal work of Selten, R. (1975)
} 


\section{CREDIBILITY}

The difficulties that many developing economies have encountered when pursuing policy reform are alleged to originate from a lack of credibility. For example, the disappointing private investment response to reforms is often attributed to the uncertainty regarding the future course of policy. This credibility deficit acts in a way like an economic constraint and supresses economic growth, translating into a situation in which investors prefer to stay in a more liquid situation by optimally delaying domestic investment ${ }^{1}$. In a similar vein, the reason so many trade liberalization attempts have ended so unsuccessfully is the failure of the domestic government to create a credible trade liberalization policy. Here the argument is again based on the diversion investment flows: if the private sector perceives trade reform as being only temporary, investment will not shift from the protected import-competing sectors to the ex post efficient export sectors ${ }^{2}$.

These examples illustrate quite convincingly that the problem of establishing the credibility of policy measures can be at least as important as the primacy of choosing efficient policy measures. The issue of credibility emerges for reforming governments from the incentive structure of the government. Desirable policies (i.e. those that remedy an allocational inefficiency) may suffer from a lack of credibility if policy decisions are taken sequentially over time (under discretion). If there are no institutional safeguards to limit dis-

\footnotetext{
${ }^{1}$ Rudiger Dornbusch coined the metaphor of investors "sitting in the parking lot, with the engine running" to illustrate this situation. A recent empirical treatment of this phenomenon can be found in Aizenman and Marion (1993). A large amount of literature thrives on the notion of the "waiting option" of investment. See PINDYCK, R. (1991) for a detailed account and further literature. RoDRIK (1991) shows that the intrinsic uncertainty of private investors acts as a tax on investment.

${ }^{2}$ For example, Peru's attempt at trade liberalization in the early 80 's was abandoned because investors, believing that tariffs would soon rise again, imported massive quantities of foreign goods and decreased domestic investment. See Ibarra (1995), Staiger And Tabellini (1989), Rodrik (1989), Aizenman (1992) and SRivastava (1994) for related models.
} 
cretionary authority and the government lacks a non-distorting policy instrument, the socially optimal policy will yield a second-best outcome. The fact that private sector decisions are often irreversible in nature puts a constraint on their ability to respond timely to shifts in government policy.

The following section departs from the more verbal descriptions of the preceding discussion and places the concept of credibility in a generalized game-theoretical framework. The standard setting of a macroeconomic policy game is delineated in which a benevolent government announces a policy measure that is designed to alleviate a suboptimal situation in the domestic economy. The policy measure will be referred to in general terms as a reform, as it wants to break with past policies and increase economic welfare. A reform is only then effective if it is able to elicit a response from the private sector. In Section 4.2 thereafter, we return to the special case of a disinflation policy, emphasizing how credibility problems linked with the government's (or more specifically central bank's) incentive to temporarily boost the economy results in excessively high equilibrium inflation - the celebrated inflationary bias of monetary policy.

\subsection{Subgame perfect equilibrium and credibility}

Consider an economy in which the rate of return to capital has been artificially depressed to $r-k_{0}$, where $r$ stands for the marginal product of capital and $k_{0}$ for a policy-induced distortion. To keep the analysis as general as possible, we assume that the distortion can result from many sources, e.g., an explicit tax on investment, an import-substitution policy that results in inefficient allocation between tradable and non-tradable sectors, or the presence of unemployment compensation or income tax so that the privately chosen quantities of marketable output will tend to be too low $^{3}$.

The objective of reform is to persuade investors to move their capital in the desired direction: repatriation of flight capital in the first case or reallocation of capital from import-competing to export-oriented ones in the second. To meet these ends, the government announces a reform, $r$, by which the government would reduce the tax on investment. When enacted then, such a reform would reduce $k_{0}$ to $k$ (with $k<k_{0}$ ). Private agents have

\footnotetext{
${ }^{3}$ The last type of distortion is the predominant assumption used in monetary games to generate an activist policy. See the BARRo AND Gordon-type model of section [4.2] for more details.
} 
the choice of investing in the domestic economy, which promises a return of $r-k$ if the government enacts the tax reform and $r-k_{0}$ if it does not. An alternative employment of capital (such as foreign investment) yields a return of $r^{*}$. Pre-reform policies are assumed to have kept $r-k_{0}$ no higher than $r^{*}$ (i.e. $r-k_{0} \leq r^{*}$ ), so if reform is not forthcoming, the private sector will (weakly) prefer the investment with a return of $r^{*}$.

The government is assumed to maximize a well-defined social welfare function $U$ which summarizes the incentives of the government for enacting a policy reform. Reducing domestic distortions by lowering the domestic tax on investment (i.e reducing $k_{0}$ to $k$ ) would increase welfare through its positive effect on the allocation investment by reducing the distortionary effects of taxation. But at the same time this policy, when enacted, would reduce tax revenues, thereby lowering government utility. Given these incentives it follows that the government's preferred course of action would ultimately be to announce a tax reform, but not to execute these reforms once the choice is pending. This allows the government to secure the fruits of reform (increased investment activity) without the concomitant loss in tax revenues, given that the investment decision of the private sector is irreversible. This is the first-best outcome to the government's decision problem (labeled as $U_{1}$ ). If reform is enacted it is only able to achieve a second-best outcome, $U_{2} \cdot{ }^{4}$ Finally, the government's third-best outcome $U_{3}$ would be for the private sector to withhold domestic investment entirely, choosing instead the "safe" return of $r^{*}$. The preference structure of the government is such that its payoffs can be (ordinally) ranked according to first-, second- and third-best outcomes, where $U_{1}>U_{2}>U_{3}$.

From what has been said thus far we can see that the actions of both parties are strategically interdependent. The decision of the private sector regarding the allocation of its investment depends on the government's preannounced intentions and subsequent actions and the same holds true vice versa. To see this interdependence more clearly, Figure 4.1 shows extensive form representation of the the macroeconomic policy game between a government and private sector. The action set of the government is $A^{G}=\{$ " $r$ ", $r, n r\}$, with $r$ and $n r$ standing for the actions reform and no reform, respectively.

\footnotetext{
${ }^{4}$ Government utility is measured in the short-term. Thus reform $r$ will have positive long-term effects, but in the short-run, due to the adjustment process, reform will pose a negative burden such that $U_{2}<U_{1}$.
} 
Fig. 4.1: Discretionary Regime

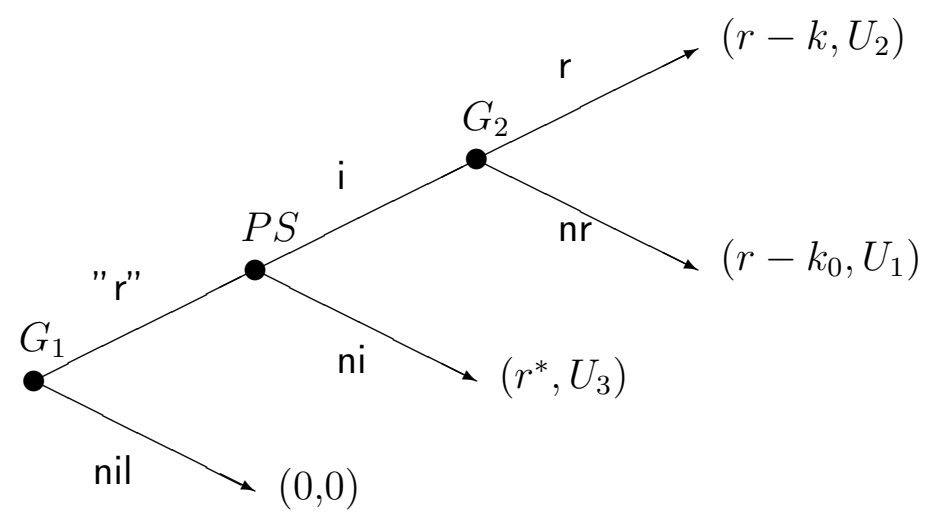

"r" stands for the announcement of the government. ${ }^{5}$ The private sector can choose either to invest in the domestic economy, i, or an alternative investment project, ni, so its action set is limited to $A^{P}=\{\mathrm{i}, \mathrm{ni}\}$. In the first case it receives a gross return on its capital of $r$, and $r^{*}$ in the second case. Its net return, which is equivalent to its payoff, depends on the realization of reform (which involves in this case a reduction of the tax burden on investment). As we mentioned above, the government's payoff is positively related to the amount of investment, but also depends on whether taxes are actually imposed on capital and the reaction of private agents to the reform announcement.

\subsubsection{Discretionary regime}

Timing is one of the crucial elements of any macroeconomic policy game. Altering the sequence of moves that form the interaction between the private sector and government allows us to model alternative institutional settings within the same framework. The sequence of moves corresponding to discretionary regime is modeled in Figure 4.1: having the government chooses his action after observing the action of the private sector puts it into a position to use discretion when choosing policy. In other words, government is not precommitted to a policy choice, so that his contingent actions that does

\footnotetext{
5 This announcement can be considered "cheap", since it does not cost the government anything to make it. As we will see later in Section (5.2.2), this cheap talk can have a value in itself by coordinating actions. See FARRELL (1995) for more detail.
} 
not necessarily have to coincide with his announcement " $r$ ". Therefore, the sequence of moves in a discretionary regime is as follows. First, the government at node $G_{1}$ has the choice of making an announcement that he will reform capital taxation ( $r$ ) or make no announcement at all (nil). We assume that the latter choice is tantamount to taking no further action on reform, so the game ends here (status quo position). If " $r$ " is uttered then the game continue with the private sector deciding at node $P S$. Observing the private sector's decision, the government finally chooses its reform stance at node $G_{2}$.

We now turn to the equilibrium actions that correspond to the "solution" of the game. Assuming that the government makes an announcement (which it does as long as $U_{3}>0$ ), the strategy pair (i, nr) associated with the first-best outcome is clearly optimal for the government and dominates all other possible strategy pairings. Since reneging on the announcement " $r$ " by choosing $\mathrm{nr}$ is costless to the government it can improve welfare compared to sticking to its announcement $\left(U_{1}>U_{2}\right)$. The reason is that once private sector investment decisions have been made at node $P S$, capital is sunk and can be taxed without creating any distortion. The tax on capital is then equivalent to a lump-sum tax. This "surprise" tax on capital provides the government with an additional policy instrument that allows it to achieve its first-best outcome. ${ }^{6}$

The question that arises is whether the equilibrium (i, nr) is plausible. For once the government reaches its decision node at $G_{2}$ it is unlikely that it will carry out its announced policy of $r$ since it could just as well improve its welfare costlessly by selecting nr. Knowing this, it is better for rational private sector to terminate the game by choosingni at its decision node $P S$. The dilemma for the government is that the optimal solution is not dynamically consistent. The concept of time consistency finds its parallel here in the game-theoretic notion of subgame perfection, a refinement of the Nash equilibrium. A strategy profile is said to be a subgame perfect Nash equilib-

\footnotetext{
${ }^{6}$ In an alternative interpretation of trade reform, the distortion $k_{0}$ can be interpreted as inefficient protection of the import-substitution industries via import tariffs. If tariffs constitute an important revenue source for the government (taxes on trade and transactions constitute a significant portion of government revenue in some selected economies, SRIVASTAVA (1994), p. 450) then an announcement to reduce tariffs would shift resources out of the import-substitution industries into export oriented ones. The government's decision to proceed with reform (reduction of $t_{0}$ to $k$ ) would be only second-best: once resources have moved then it can maximize tariff revenues by reneging on the announcement.
} 
rium if (a) it is a Nash equilibrium for the entire game and (b) its relevant action rules are a Nash equilibrium for every subgame. ${ }^{7}$ The notion of subgame perfection is based on the distinction between moves that are taken in equilibrium and those that are said to be off-the-equilibrium path.

In the discretionary setting of Figure 4.1 the only subgame Nash equilibrium is ( $\mathrm{ni}, \mathrm{nr}$ ) which is equivalent to the consistent solution of macroeconomic policy. ${ }^{8}$ At node $G_{2}$ the government prefers $n r$ to $r$, but the private sector would prefer that reforms be carried out. Note that the information set of the government at $G_{2}$ is out-of-equilibrium, since it will never reach this node in the proposed equilibrium. Therefore, the action set of the government at this node is inconsequential to the private sector's expected payoff, since there is no chance that the government's choice will matter (since it will not be believed). But the strategy chosen at $G_{2}$ does effect what the private sector chooses at its in-equilibrium information set $P S$. The forward looking character underlying rational expectations decision-making makes the private sector evaluate the value to them of other strategies the government may employ and estimate what would happen if they cause a previously outof-equilibrium information set to be reached. ${ }^{9}$. An equilibrium (i,r) does not suffice the criterion of subgame perfection because it would involve a player (the government) in an irrational choice among available options at a later stage of the game. Thus, although the private sector would be better off with the strategy pair $(\mathrm{i}, \mathrm{r})$, the incentive of the government to renege on his announcement at $G_{2}$ renders the government's announcement of reform as non-credible and the private sector withholds investment by choosing ni.

\subsubsection{Commitment regime}

A different situation exists if the government had some means to commit to $r$. This would be tantamount to imposing institutional constraints that render the government's incentive to generate a policy "surprise" as nonexistent. This is achieved in the game-theoretical context by reversing the timing of

\footnotetext{
7 A more extensive discussion than presented here on this crucial game-theoretic concept can be found in KREPS(1990), pp. 421-425 or RASMUSEN (1996), pp. 93-98.

8 To be exact, it is also the only Nash equilibrium possible in the discretionary regime so that the there are no other Nash equilibria to disqualify with the subgame perfect concept.

9 The equilibrium concept of subgame perfectness is not compatible with expectation formation process that is backward-looking (such as adaptive expectations) in the sense that out-of-equilibrium strategies will not, by definition, influence the outcome of play.
} 
government actions (policy) relative to private actions. In a commitment regime decisions are made before the private sector makes its investment decision.

Fig. 4.2: Commitment Regime

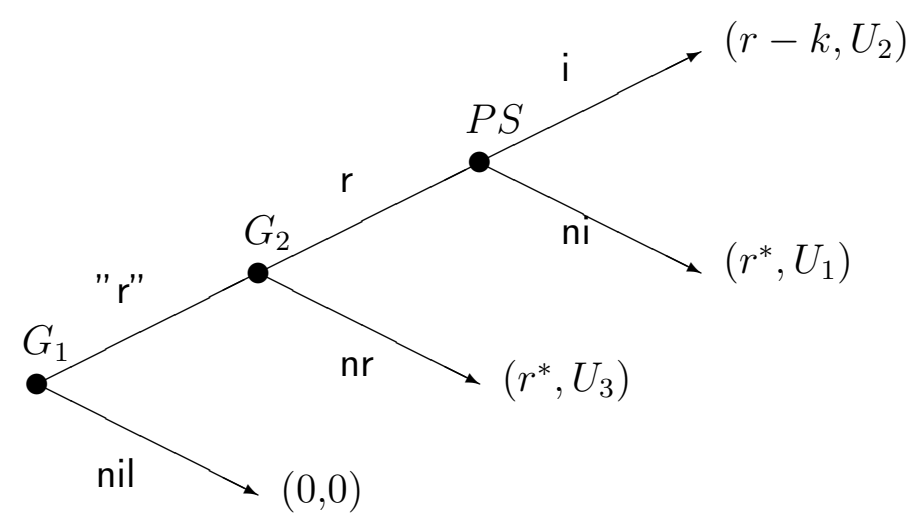

In Figure 4.2 a commitment regime is presented in extensive form. The dynamically consistent solution is the Nash equilibrium (i, r) which suffices the refinement of subgame perfection because the incentive to reoptimize ex post and subsequently deviate from the second best policy (with payoff $U_{2}$ ) is immaterial. The strategy $r$ is in fact the dominant strategy for the government. The government's announcement prior to its actions, " $r$ ", is is now perceived as credible by the private sector. By "burning the bridges" to the discretionary use of taxation the government achieves an outcome superior to that under discretion.

The presence of a commitment technology can be motivated by assuming that a policy surprise poses a cost to the government. Commitment can be enforced by a mechanism that introduces costs for the state when he abuses his discretionary power. ${ }^{10}$ An appropriate commitment mechanism for a sovereign decision-maker means finding a supra-national framework. For example, one could imagine that the government is in some form of contractual agreement with the international community. By the imposition of a third-party, reneging on policy would be answered by some form of sanc-

\footnotetext{
${ }^{10}$ A favorite analogy of a commitment technology is the commitment the Homerian Ulysses wisely followed so as not to succumb to the deadly call of the Sirens by voluntarily tying himself on the mast of his ship.
} 
tions that are costly to the government. ${ }^{11}$ In a game-theoretic formulation a commitment regime is created by changing the rules of the game such that the observation of the government's move (and not only its announcement) is therefore part of the information set of the private sector at node $P S$.

\subsubsection{Comments}

The importance of this section was to illustrate that the concept of credibility can be traced to the game-theoretic notion of subgame perfectness. By posing macreconomic policy as a game between a government and a private sector allows us to examine the role of institutions for the formulation of policy. In the institutional arrangment of a discretionary regime, we can therefore posit that the announcment " $r$ " (in Figure 4.1) is not credible ex ante because private agents are forward looking they take into account the incentives of the government to reoptimize ex post if it ever reached the subgame starting at $G_{2}$.

The common element of time consistency and subgame perfection is the assumption of rational expectations and the failure of a discretionary government to internalize the mapping from actual policy to expected policy. Given discretion, the government would like to generate policy surprises (i.e. strategies that do not coincide with " $r$ ") outside of equilibrium to a more favorable outcome, i.e. first-best outcome, $U_{1}$. In the game theoretic formulation the source of credibility deficit for the government stems from the fact that when private agents have rational expectations, actual policy maps into expected policy in equilibrium, taking the government to the third-best outcome, $U_{3}$. A credibility problem does not arise under precommitment. By setting private sector actions after the government decision, the precommitment regime denies the government the means and therefore the incentive to generate a surprise. The incentives to deviate from the announcement are irrelevant in this regime, and the government is able to successfully internalize the mapping from actual policy to expected policy.

Seen in the light of this section we can also conclude that the disappointing response of investment to efficiency-augmenting reforms in developing economies can be traced back to the propensity of governments to overuse their discretionary powers. The lack of effective control over discretionary powers is rampant in developing economies, where nascent democratic so-

${ }^{11}$ RODRIK (1989), p. 13-15 provides some further examples. 
cieties often lack institutional or consititutional safeguards that limit the executive grip on the economy. For example, Latin America

is dominated by a very powerful executive that can change and interpret law at will. No judiciary will monitor and no legislature, neither parliament nor private individuals, can efficiently protest against its discretionary power. ${ }^{12}$

Indeed, it is a rather sobering reality that even though many of the developing economies have turned to democratic systems, "the introduction of free elections does not imply that there are sufficient controlling devices to check the discretionary powers of the executive" and that many of the so-called democracies in LDCs are no less than "electoral dictatorships." ${ }^{13}$ Unfortunately, it is too early to say that many countries have turned to the better in this respect. The fact that the recently elected president of Venezuela, Hugo Chavez, seeks to enact "a law giving him special powers to push through economic measures without congressional approval" ${ }^{14}$, does not bode well for the credibility of this new regime.

\subsection{The Barro and Gordon model of monetary policy}

By focusing on the general structure of the time consistency argument in game theoretic terms, the discussion has not been very specific about the macroeconomic context. Considerable scientific attention has been concentrated on monetary policy in the context of stabilization policy, both in theoretical and empirical terms. The model framework most commonly found in the literature relies on the groundbreaking articles of BARRO AND GORDON [BG] (1983a and 1983b). ${ }^{15}$ The simple elegance of the model allows not only an understanding of the inflationary process, but also provides insight into how macroeconomic context can be transferred into a formal analysis. This

\footnotetext{
${ }^{12}$ See Brunetti And Weder (1994), p. 24.

${ }^{13}$ Ibid., p. 7. According to the authors, two of the main instruments that allow governments in LDCs to change rules and policies in arbitrary fashion are (1) the existence executive decrees and (2) the collusion between the executive and legislative branches of government.

${ }^{14}$ The Economist, February 6th 1999, p. 55.

15 Other contributions that take a similar approach can be found in BACKUS AND DRIFFIL (1985) and CANZONIERI (1985). A thorough survey of monetary policy games is provided by Cukierman (1992) and for the (German) reader with less time, Bofinger, P. (1991) can be recommended.
} 
section will provide a "raw-bones" description of the model and focuses on the underlying game-theoretical description.

\subsubsection{Game structure}

The model economy comprises of two players, a government $G$ and a private sector $P S$. The government controls monetary policy and can be thought of as the monetary authority. The government (or dependent monetary authority) is assumed to be able to control the growth of money supply directly (which assumes that the Quantity equation holds). Furthermore, the growth of money supply is directly linked to the inflation rate. The model is deterministic since this disregards any uncertainty regarding the transmission of money supply impulses. The government's action set $A^{G}=\left\{\pi_{t}\right\}$ with $\pi_{t} \in[0, \infty)$ is continuous and contains his choice of inflation. The private sector's action set is comprised of the wage increase it chooses contingent on inflation expectations, $\pi_{t}^{e}$. The existence of nominal contracts means that the private sector cannot revise its wage decision for the duration of the period.

\subsubsection{Payoff structure}

The defining characteristic of the government's incentives are two policy objectives, reduction of inflation, $\pi_{t}$ and the stimulation of production $Y_{t}\left(Y_{t}\right.$ can be interpreted as a proxy for the overall state of real activity so that in an alternative formulation, a policy objective is also the reduction of unemployment). The weights the government assigns to the objectives reflect its willingness to trade-off disinflation for economic stimulation. The macroeconomic trade-off is stylistically derived from aggregate supply relation such as a LUCAS-supply curve function describing the constraint imposed by the structure of the economy,

$$
Y_{t}=Y^{N}+\alpha\left(\pi_{t}-\pi_{t}^{e}\right)
$$

where $Y$ is output, $Y^{N}$ is the natural rate of output, and $\pi_{t}$ and $\pi_{t}^{e}$ are actual and forecasted or expected inflation. Output is therefore a increasing (linear) function of the discrepancy between actual and expected inflation. Unanticipated inflation is assumed to be socially undesirable for a number of more or less plausible reasons that have been put forth in the literature: inefficient redistribution of income and wealth, costs of economizing on money balances 
(so-called "shoe-leather" effects) and costs associated with the modification of the tax system. ${ }^{16}$ It thus takes the New Classical standpoint that monetary policy can only affect the real side of the economy if it is unexpected.

The objectives of the government are made explicit by assuming that it maximizes a one-period utility function. The general form of this additive function is

$$
U_{t}^{G}\left(\pi_{t}, Y-Y^{*}\right)=f\left(\pi_{t}-\pi^{*}\right)+g\left(Y-Y^{*}\right)
$$

with $\pi^{*}$ and $Y^{*}$ as the government's preferred rate of inflation and economic output, respectively. The BG-Type models share the common assumption that $f^{\prime}\left(\pi-\pi^{*}\right)<0$, meaning that the government dislikes a positive amount of inflation in excess of the preferred rate. In what follows, the preferred rate of inflation is to normalized to zero so that $f$ can be formulated as $f\left(\pi-\pi^{*}\right)=-a \pi_{t}^{2}$ with $a>0$ as the weight given to the government's (nonnegative) inflation rate. ${ }^{17}$

An important element in the BG-type model is the assumption that for a various number of reasons, the preferred output goal of the government, $Y^{*}$, exceeds the natural rate of output such that $Y^{*}=Y^{N}+\Delta$ with $\Delta>0$. Assuming that $Y_{t} \leq Y^{*} \forall t$ then the government prefers an output rate exceeding the natural rate by $\Delta .{ }^{18}$ This incentive structure imparts a temptation to increase inflation in order to raise output above the natural rate, with the "bliss" point of government utility being reached when $Y=Y^{*}$. Accordingly, the $g$ function in the government's utility is contstructed to insure that $g^{\prime}\left(Y-Y^{*}\right)<0$. Therefore, with 4.1 we can write the function $g$ as

$$
g\left(Y-Y^{*}\right)=-b\left(Y-Y^{*}\right)^{2}
$$

${ }^{16}$ Fischer And Modigliani (1978) provide a discussion of the costs of inflation. Still, there does not seem to be general agreement in what manner inflation can be socially costly. BLANCHARD AND FISCHER (1989) even note that "despite an impressive array of models in which inflation is socially costly, there appears to be professional consensus...that economics cannot justify the weight put on low inflation as a goal of policy" (p. 569, my italics).

${ }^{17}$ In the original formulation of the BG-model, the government's preferences are set so that it minimizes a given loss-function. The dual problem, maximization of utility, is used here which, however, does not alter the final results.

18 The presence of government imposed distortions, such as distortionary taxes on labor or income, are usually employed as a justification for this crucial assumption. In alternative presentations of the BG-model, these distortions may be captured by introducing a constant $k$ such that $Y^{*}=k Y^{N}$. The crucial assumption is that $k>1$. 


$$
=-b\left[\alpha\left(\pi_{t}-\pi_{t}\right)-\Delta\right]^{2}
$$

whereby the quadratic term can be interpreted as a quadratic approximation to the welfare loss (hence the negative sign in the utility term) of being away from $Y^{*}$. Collecting what has been said so far $U_{t}^{G}$ can be written as

$$
U_{t}^{G}=-a \pi_{t}^{2}-b\left(Y-Y^{*}\right)^{2}
$$

Combined with (4.1) and the fact that $\Delta=Y^{*}-Y^{N}$ the preferences of the government may be summarized by

$$
U_{t}^{G}\left(\pi_{t}, \pi_{t}^{e}\right)=-a \pi_{t}^{2}-b\left[\alpha\left(\pi_{t}-\pi_{t}^{e}\right)-\Delta\right]^{2}
$$

The private sector can be thought of as a monopoly trade union which dictates the wage bargaining process. The public's preferences are governed by their unwillingness to be caught by administrative (i.e. inflationary) surprises. Theses preferences may be represented by

$$
U_{t}^{P S}\left(\pi_{t}, \pi_{t}^{e}\right)=-\left(\pi_{t}-\pi_{t}^{e}\right)^{2}
$$

\subsubsection{One-shot game}

Many contributions to the analysis of a monetary policy game can be traced back to the canonical structure of the game outlined in the preceding section. In its simplest manifestation, the game takes the form of a one-stage game of complete information. Under this scenario neither past nor future confrontations between players influence their current strategy selection so that their objective functions correspond to their one-period utility functions $U_{t}^{G}$ and $U_{t}^{P S}$. Moreover, both the government and the private sector are fully informed about the preferences (i.e. utility functions) of the other player. The outcome of the game can be characterized by the strategies that are chosen in equilibrium, the consequences that these strategies entail for the players (measured in terms of payoff) as well as the utility for the players associated with the payoff. In a one-stage game this outcome depends in large part on the institutional structure within which the government conducts its policy. In the monetary policy game this structure can be described by the ability of the government to precommit to a preannounced policy of low inflation. In section 4.1 it was shown that the this institutional constraint can be set into game-theoretic language by altering the timing of the game. 
First, consider the case in which precommitment is feasible. The timing then is such that the government first makes an announcement at the outset of period $t$ that it will follow a monetary policy rule compatible with a low inflation rate. Then as a second step the government enacts a restrictive monetary policy (such as an open market transaction) that objectively conforms with low inflation. Finally, after having observed the government's announcement and action, $\{$ " $\pi=0 " ; \pi=0\}$, the private sector agrees upon the level of wages that will be kept constant in period $t .{ }^{19}$ Under this timing scheme, the government has no way to back away from his announcement and is therefore playing the role of a von Stackelberg leader, with the private sector as the follower. Since the actions of the government are observed and irreversible, announced actual and expected inflation are equal in equilibrium. The government's utility in the precommitment solution is

$$
U^{G}\left(\pi=0, \pi^{e}=0\right)=-b \Delta^{2} \equiv U_{2}
$$

which can be derived from the maximization of its objective functions in 4.6 (See Appendix A.1 for details). The subscript denotes that this is a second-best outcome for the government, as will we see briefly. ${ }^{20}$

In the absence of a commitment technology the government is said to possess unrestricted discretion in the choice of policy. Now, the government plays the role of the follower, enacting policy after private sector decisions have been made and, importantly, in a position to observe private sector behavior. The inflation rate chosen in aftermath of private sector action balances the benefits of increased economic activity in excess of the natural rate of output (along the Phillips curve in eq. 4.1) with the costs associated with higher inflation. The discretionary power of the government creates an incentive for the government to create a positive rate of inflation: if the private sector can in fact be convinced that the government will stick to its announcement it will set expectations to $\pi^{e}=0$. But then the government will be tempted to shift policy from $\pi=0$ to $\pi=\pi^{S}$ by a monetary stimulus

\footnotetext{
19 The notation $\{$ " $\pi=0 " ; \pi=0\}$ adopted here means that the government's first move is the announcement of a policy, low inflation " $\pi=0$ " and the second move is its action, which in this case abides by the announcement, $\pi=0$. Note that for convenience the term "low inflation" is to be taken synonymously with an inflation rate of zero.

${ }^{20}$ Since $b$ and $\Delta$ are always positive by definition, it may seem odd that utility $U_{2}$ is negative. But this follows directly from the definition of government utility in eq. 4.6. It can be verified that the range of function $U_{t}^{G}$ is $(-\infty, 0]$ and it follows that the "best" the government can do is zero utility.
} 
that increases output but invalidates the low expectation of inflation held by the private sector. This first-best outcome can be calculated ${ }^{21}$ as

$$
U^{G}\left(\pi=\pi^{S}, \pi^{e}=0\right)=-b \Delta^{2}\left(\frac{a}{a+\alpha^{2} b}\right) \equiv U_{1}
$$

Essentially, one can say that the government's incentive to deviate from the announced policy is driven by the prospect of achieving this superior outcome.

When the private sector has rational expectations though, it is not possible to trick it systematically into adjusting their expectations to create an output response - this "iron-law" of rational expectations was established in Section 2.4. The "surprise", first-best outcome is therefore unsustainable in a (subgame perfect) Nash equilibrium defined by the property that the strategy of each player (taken as given by the other players) is actually optimal for that player with the information $\Omega$ available. Therefore, the assumption of rational expectations and perfect information rule out any equilibrium in which expectations do not coincide with actual policy, i.e. $\pi^{e} \neq \pi$ cannot be part of a rational expectations equilibrium. The only time-consistent (Nash-) equilibrium requires that $\pi^{e}=E[\pi \mid \Omega]=\pi^{D}>0$, so that

$$
\begin{aligned}
U^{G}\left(\pi=\pi^{D}, \pi^{e}=\pi^{D}\right) & =-b \Delta^{2}\left(\frac{a+\alpha^{2} b}{a}\right) \\
& =-b \Delta^{2}\left(1+\frac{\alpha^{2} b}{a}\right) \equiv U_{3}
\end{aligned}
$$

The result is a third-best outcome $U_{3}$ involving excessive inflation but no gains in output. ${ }^{22}$ The term $\frac{\alpha^{2} b}{a}$ is a measure of the disutility of unexpected inflation, often referred to as the "inflationary bias" of monetary policy. A policy surprise is therefore self-defeating: facing increased inflationary expectations, the only utility-maximizing way for the government to react is to match private sector expectations since the higher $\pi^{e}$ is, the higher $\pi$ must be to minimize the negative effect on output.

Finally, to complete the list of outcomes consider the situation in which the government can commit to a policy rule of low inflation, but the private

\footnotetext{
${ }^{21}$ See Appendix A.2 for derivation of this result. The coefficients $b, \Delta, a$ and $\alpha$ are all positive. Therefore, $0<\frac{a}{a+\alpha^{2} b}<1$ and subsequently, $U_{1}>U_{2}$ (recalling that utility is always negative).

${ }^{22}$ Output $Y$ remains at the natural level $Y^{N}$. This can be verified by inserting the values $\pi=\pi^{e}=\pi^{D}$ in eq. 4.1 .
} 
sector does not hold the commitment to be credible so that it expects the discretionary outcome of inflation,

$$
\{" \pi=0 " ; \pi=0\} \quad \text { and } \quad \pi^{e}=\pi^{D}
$$

In this "punishment" outcome, the government's utility is at its lowest because private sector expectations drive up the price level to $\pi=\pi^{D}$ and the government cannot accommodate these expectations by stimulating real activity through the inflation rate,

$$
U^{G}\left(\pi=0, \pi^{e}=\pi^{D}\right)=-b \Delta^{2}\left(\frac{a+\alpha^{2} b}{a}\right)^{2} \equiv U_{4}
$$

Table 4.1 summarizes the results we have gathered thus far. The one-stage game has four possible equilibria where the result depends on a) the institutional structure and b) the way in which expectations are formed by the private sector. Under rational expectations, $U_{2}$ and $U_{3}$ were the two respective outcomes under discretion and precommitment that satisfy the Nash conditions. To establish an outcome such as $U_{1}$ requires an expectation formation process that precludes the use of all available information at the time the decision of the private sector is made (such as adaptive expectations). Outcome $U_{4}$ will be unlikely, unless we concede an entirely unpredictable expectation formation process.

Tab. 4.1: Outcomes of The One-STAGE GAME

\begin{tabular}{|c|c|c|c|}
\hline & \multicolumn{2}{|c|}{ Moves } & \\
\hline Utility & $G$ & $P S$ & Sequence \\
\hline$U_{1}$ & " $\pi=0 " ; \pi=\pi^{S}$ & $\pi^{e}=0$ & $G \rightarrow P S \rightarrow G$ \\
\hline$U_{2}(*)$ & " $\pi=0 " ; \pi=0$ & $\pi^{e}=0$ & $G \rightarrow G \rightarrow P S$ \\
\hline$U_{3}(*)$ & " $\pi=0 " ; \pi=\pi^{D}$ & $\pi^{e}=\pi^{D}$ & $G \rightarrow P S \rightarrow G$ \\
\hline$U_{4}$ & $" \pi=0 " ; \pi=0$ & $\pi^{e}=\pi^{D}$ & $G \rightarrow G \rightarrow P S$ \\
\hline
\end{tabular}

where $0>U_{1}>U_{2}>U_{3}>U_{4}$. The $(*)$ labels the two rational expectations equilibria that are the result of precommitment $\left(U_{2}\right)$ and discretion $\left(U_{3}\right)$, respectively.

A numerical example of the one-stage game is given in Table 4.2. For each ordered pair in the matrix the government's payoffs are labeled first, 


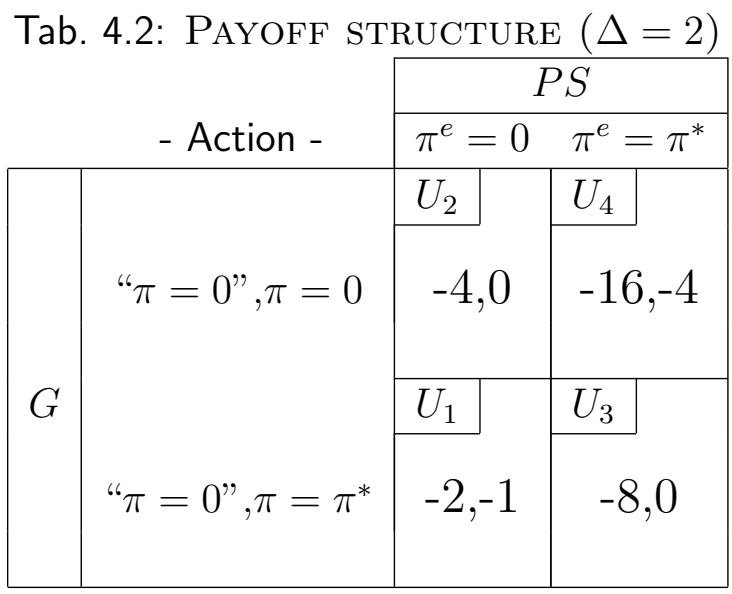

where the government has two actions, the announcement " $\pi_{t}=0$ " and the level of inflation, $\pi^{*}=\pi^{D}$ or $\pi^{S}$ depending on the type of regime. ${ }^{23}$ The payoff to the government can be ranked according from first- to fourth best, $U_{1}$ to $U_{4}$ (labeled in the left-hand corner of each box in the matrix). The game structure in Table 4.2 is isomorphic to the discretionary game that was presented in the previous section (Figure 4.1). Like strategy $\mathrm{nr}$ in that game, $\pi=\pi^{*}$ is a dominant strategy for the government since its payoffs are larger regardless of what the public does. Since this incentive structure is common knowledge the public will react to this inflation bias by setting expected inflation to $\pi^{e}=\pi^{*}$ also.

The outcome of the game depends in a crucial way on the government's incentive to inflate to a level exceeding the natural rate of the economy. These incentives are captured in $\Delta=Y^{*}-Y^{N}$. By comparing the outcomes for different values of $\Delta$ of one can establish that government utility (in all four cases) is increased as the distortion $\Delta$ is reduced. Also, it can be shown that as the weight given to inflation $a$ increases, the outcome under discretion $U_{3}$

\footnotetext{
${ }^{23}$ The parameters are normalized by setting $a=b=\alpha=1$ and $\Delta=2$. The government's discretionary and the surprise rate of inflation are then computed from their derivations in Appendix A.6 and A.8 as $\pi^{D}=2$ and $\pi^{S}=1$. The matrix in Table 4.2 should not be confused with the payoff matrix of game theoretic lore. First, as indicated in the text, the strategy space of the government is actually continuous (in $R^{+}$) rather than discrete. Secondly, the two columns in Table $4.2, \pi^{e}=0$ and $\pi^{e}=\pi^{*}$ denote alternative expectational settings (i.e. rational expectations or other). Therefore, the cells of the matrix must be understood as outcomes of different game structures, depending on the monetary regime and expectational setup.
} 
approaches the precommitment outcome $U_{2}$, i.e.

$$
\lim _{a \rightarrow \infty} U_{3}=U_{2}
$$

The more costly inflation is in terms of utility, the less likely the government will yield inflation as an expansionary instrument. In effect, very high values of a change the government's ex post constraints. This, though, is in its own interest, since the commitment solution is superior to the discretionary outcome. $^{24}$ Changing intertemporal contraints has a similar effect and will be discussed below.

\subsubsection{Trigger mechanisms and reputation}

The basic insight of the one-shot model is that if a government is able to exercise complete and costless discretion in its monetary regime, the economy will be thrown into an inferior Nash-equilibrium characterized by an inflationary bias with output still at its natural rate. It is important to note that monetary policy is time-inconsistent because discretion is costless to the government. Since the interaction between the government and public is reduced to a single confrontation, strategies are rendered "memory-less", i.e., the actor's choice of strategy does not take future consequences of this action into consideration (since there is no future!). The government's decision to "surprise" the public under a discretionary regime does not pose a constraint to its current actions. Therefore, we saw that one way to avoid the inflation in this one-shot game result is to impose formal restrictions on the government's discretionary powers. Another is to ensure that the government places a sufficient weight on the downside effects of inflation (i.e. a high value of $a$ ).

This section expands the analysis be viewing macroeconomic policy as an ongoing process with repeated actions between the government and the private sector. We intuitively expect that over time the powers of government will be closely monitored by the private sector. Deviations from the government's preannounced plans have consequences that extend to strategies chosen in the following periods. Translated in game theoretic terms, rational agents are engaged in a repeated game (otherwise known as a supergame) with a finite time horizon. In this dynamic setting both the government and

\footnotetext{
${ }^{24}$ See footnote 22 .
} 
private sector maximize the discounted sum of their respective one-period (expected) utilities, $U_{t}^{G}$ and $U_{t}^{P S}$ :

$$
\begin{aligned}
V^{G} & =\mathrm{E}\left[\sum_{t=0}^{T}(1+r)^{-t} U_{t}^{G}\left(\pi_{t}, \pi_{t}^{e}\right)\right] \\
V^{P S} & =\mathrm{E}\left[\sum_{t=0}^{T}(1+r)^{-t} U_{t}^{P S}\left(\pi_{t}, \pi_{t}^{e}\right)\right]
\end{aligned}
$$

where $r$ is the government's discount rate and $\mathrm{E}(\cdot)$ is the conditional expectations operator.

Once we assume that the government is optimizing its utility over time according to 4.14, a number of interesting questions arise. Are there, e.g., informal mechanisms in such a dynamic context that avoid the inefficient Nash-equilibrium above? In a repeated version of the $B G$-game the government's incentive to renege upon the announced policy " $\pi=0$ " may be removed by the threat of being "punished" for such "bad" behavior in a future period: unexpectedly high inflation in the current period with e.g. $\pi=\pi^{S}$, brings about higher inflation tomorrow, raising the cost of current policy surprises. This intertemporal trade-off forces the government to weigh the current gains from trying to achieve the first-best solution $U_{1}$ with the negative effects of subsequent higher expected inflation in the following periods. By forgoing short-term gains over time the government can, in short, build up a reputation that will cause the private sector to keep inflation expectations low. The efficacy of reputation, however, depends on the discount rate $r$ in (4.14) for since the costs of reneging are incurred in the future they matter less if the future is heavily discounted.

The important point here is the assumption that the time horizon of the government is infinite, i.e. $T=\infty$. Then the intertemporal constraint imposed by the private sector's appropriate trigger would then ensure that a low inflation commitment equilibrium of $\pi=0$ is maintained. Private agents could, for example, revise their beliefs according to the following tit-for-tat rule $^{25}$ : The private sector starts each period by setting wages on the expectation of low inflation. If actual inflation has been held down in the past, then expected inflation is held down currently; otherwise, inflationary expectations

\footnotetext{
25 See Barro And Gordon (1983b), p. 31-33. Rogoff (1987) offers an exhaustive discussion on a number of alternative "trigger"-mechanisms in the that can act as informal restraints.
} 
increase if actual inflation has increased, contrary to the announcement. The rationale behind this trigger strategy is to make any future deviation from the announcement costly by having a negative effect on $V^{G}$. The expectations mechanism of the private sector is rendered as a function of government behavior, $\pi_{t}^{e}=h_{t}^{e}\left(\pi_{t}\right)$ replacing the utility maximizing behavior of eq. (4.7),

$$
h_{t}^{e}\left(\pi_{t}\right)= \begin{cases}0, & \text { if } \pi_{t-s}=0 \quad \forall s<t ; \\ \pi^{D}, & \text { if } \pi_{t} \neq 0 .\end{cases}
$$

Given this expectations mechanism embodied in [4.16], the government optimizes an intertemporal tradeoff between the current gains and future costs of reneging. Consider a government that has in the past produced low inflation, i.e. whose aggregate policy history is $\pi=0, \forall t \in[-\infty, 0)$. At the beginning of period 1 (current period) the government has two options, (a) and (b). First, it can choose to generate a surprise inflation in the current period $t=0$ (after private sector decisions), boosting the economy above the natural rate of output. Current period utility is the first best outcome $U_{1}$ (see [reffirst-best]). Unfortunately, option (a) sets the private sectors' tit-for-tat rule [4.16] in motion, the government being punished with the sub-optimal discretionary solution $U_{3}\left(<U_{1}\right)$ in all further periods. Having expectations geared towards this outcome, the best thing the government can do is to accommodate these expectations with high inflation $\pi^{D}$. Alternatively, the second option (b) of the government has is simply to continue playing low inflation in all further periods from $t=1$ onwards, thus forgoing any short-run stimulation of the economy. The options and respective consequences can be summarized in Table 4.3, where the discounted stream of payoffs (present

Tab. 4.3: INTERTEMPORAL POLICY OPTIONS

\begin{tabular}{|c|c|c|c|}
\cline { 2 - 4 } \multicolumn{1}{c|}{} & $t=0$ & $t=1 \ldots \infty$ & Present value \\
\hline (a) & $\pi=\pi^{S}, \pi^{e}=0$ & $\pi=\pi^{D}, \pi^{e}=\pi^{D}$ & \\
& $U_{1}$ & $U_{3}$ & $V^{G, a}$ \\
\hline (b) & $\pi=0, \pi^{e}=0$ & $\pi=0, \pi^{e}=0$ & \\
& $U_{2}$ & $U_{2}$ & $V^{G, b}$ \\
\hline
\end{tabular}

value) in the table (from [4.14]) are

$$
V^{G, a}=U_{1}+\sum_{t=1}^{\infty}\left(\frac{1}{1+r}\right)^{t} U_{3} \quad \text { or } \quad V^{G, b}=\sum_{t=1}^{\infty}\left(\frac{1}{1+r}\right)^{t} U_{2}
$$


depending on what intertemporal policy the government adopts.

To determine whether $\pi_{t}=0$ (under option (a)) is the equilibrium level of inflation under the trigger-strategy in (4.16) it is necessary to consider whether the government has any incentive to defect from $\pi_{t}=0$. This question turns on the magnitude of the present value $V^{G}$, but it is not entirely straightforward to see which of these options delivers the highest present value (since $U_{1}>U_{2}$, but then $U_{2}>U_{3}$ ). What can be said is that the government will prefer the "opportunistic" option (a) to option (b) if $V^{G, a}>$ $V^{G, b}$. In Appendix A.3 we can show that from this inequality we can derive the following condition:

$$
r>\frac{a+\alpha^{2} b}{a}=\left(1+\frac{\alpha^{2} b}{a}\right)
$$

The government will accordingly behave "myopically" by raising inflation in period $t=0$ (option (a)) if the future is discounted heavily enough (large values of $r$ ) or if the utility loss from unexpected inflation (measured as $\alpha^{2} b / a$ in [4.18]) is low. Otherwise, option (b) is chosen and the precommitment equilibrium of the one-stage game is maintained as a Nash equilibrium of this repeated game. ${ }^{26}$. Accordingly, the time-inconsistency dilemma of the government raised in the preceding section may not present a serious issue provided the government places significant weight on the future (low values of $r$ ).

Without going into too much detail, it can be remarked that reliance on trigger strategies to overcome the inflationary bias suffer from many conceptual drawbacks. First of all, the trigger strategy [4.16] that was used above is but one of an infinite number of possible rules and a unique equilibrium would depend on the punishment strategy assumed. Secondly, there is the problem of how the private sector will coordinate upon one equilibrium without a systematic criterion for discriminating between them. The trigger strategy approach can be dismissed on these grounds, exactly because "there is no institution that coordinates the strategies of different individuals on a single unified strategy" and a free-rider problem prevails because "the private costs of monitoring policymakers' actions are higher than the marginal

\footnotetext{
${ }^{26}$ This result is analogous to the so-called Folk-Theorem that the precommitment equilibrium $U_{2}$ can be sustained as a (subgame perfect) Nash equilibrium in this repeated game provided that the discount rate is not "too high". See KrePs(1990), p.505-6, and RASMUSEN (1994), p.124 for a more complete elaboration on the Folk-Theorem.
} 
private benefit." 27 Thirdly, The assumption of full information further limits the applicability of trigger strategies since this necessitates an infinite horizon. Otherwise, the analogous problem of the "chain-store-paradox" arises: since the government cannot gain reputation in the last period it will produce the discretionary outcome, whatever the private sector's expectations. By method of backwards induction the discretionary solution then obtains for all periods up to the first. The assumption of perfect information will be dispensed with in the following section, where reputation effects are derived from a certain distribution of information between government and private sector.

\subsection{Alternative concepts of credibility}

The discussion of the preceding section serves the puropose of shedding light upon the concept of credibility. It has relied exclusively upon the the time consistency, resp. the concept of subgame perfection to describe situations in which a lack of credibility has effects similar to macroeconomic distortions. The source of this credibility deficit could be isolated to the discretionary powers of government: if the government possesses the power to carry out its policies in a disrectionary manner, then the ensuing discrepancy between ex ante and ex post policies combined with rational expectations will be selfdefeating. This method of coming to terms with the concept of credibility has been used quite extensively. But despite its almost canonical nature for the problem of credibility it must be stressed that this type of analysis, however elegant, cannot encompass the entire spectrum of macroeconomic reasoning. Indeed, the problem of credibility is wedged in an area where economics, political science and psychology intersect. This section would therefore not be complete if we were not to briefly touch upon some alternative concepts.

\subsubsection{Political constraints}

One of the intriguing results of the time-consistency argument is that the suboptimal outcome under a discretionary regime does not depend on whether the government is self-serving or benevolent - the government actually maximizes social welfare, but the private sector's expectations prove self-defeating

27 See Cukierman (1992), p. 209-210. 
in the end. Political constraints to credibility arise when there exists a conflict of interest between the policymaker and society as a whole because of a disagreement over the final goals of policy. Nevertheless, the previous models are not to be denied a strong political flavor by accounting for the objectives and constraints facing centralized policymakers. It is therefore only a natural step to model government behavior and the electoral behavior of rational voters.

Indeed, considerable effort has been conducted into examining the role played by political factors in determining credibility. A large part of this research acknowledges the fact that economic policy is influenced by the political process in democratic societies. In a representative democracy, for example, the aggregation of atomistic preferences into a collective government action takes place via the electoral system. Elections have two main effects. First, they impose new incentive constraints on the government: instead of maximizing social welfare they are assumed to maximize some index of popularity or prestige, specifically maximizing their chances of election by maximizing the number of votes cast for them. The relevance of elections for the issue of credibility stems basically from a difference between the preand post-election decision problems that a government confronts. Depending on the timing of elections, a government may have an incentive to deviate from (social welfare maximizing) optimal behavior in order to secure electoral gains. $^{28}$

Secondly, elections may create changes in government and thus lead to uncertainty about future policies and/or the motives of a newly installed government. Newly elected governments have an advantage in that they are not tarnished with the failures of the previous government and may be therefore more likely to be able to enforce credibility. The advantage of

\footnotetext{
${ }^{28}$ This is the famous 'political business cycle' line of reasoning, originating in NordHAus (1975) which can be succinctly summarized as follows. Prior to an election, a government expands the economy by exploiting the inflation-employment trade-off in the Philips-curve relation (in the same way the benevolent government exploits this trade-off to 'surprise' the private sector in the BARRO-GORDON-type model. This expansionary impulse increases his popularity (and thus his probability of winning the election). This deviation from optimal policy is reversed following the election as the government responds to the inflation. This story only works if we adhere to the objectionable assumption that a myopic electorate fails to realize the inflationary consequences of a pre-election boom - this clearly violates any rational expectations framework. See also GaBisch And LoREnz (1987), p. 66-73 for further discussion.
} 
this informational imperfection on theory has been to allow the political cycle models to be reconciled with the rational expectations point of view. Voters are modeled as being rational but imperfectly informed about some aspects of the economic environment and/or about the characteristics of the government.

\subsubsection{Inconsistent policies}

Typically, economic reforms are undertaken in times of dire economic crises. This makes it highly probable that a conflict will arise between different sets of policies pursued simultaneously. A pre-announced reform is most likely then to violate $e x$ ante budget constraints and accounting identities. Because a rational private sector will eventually realize that the government's reform policy is incompatible with its other macroeconomic policies and that this combination will lead to a crisis. Thus a fundamental aspect of establishing credibility is related to the perception that the public has of the internal consistency of the policies being pursued.

The inability to establish consistency between fiscal, exchange rate and financial policies has been at the root of the credibility dilemma in Latin America and other developing economies. An example of this problem is related to the experience of the Southern Cone countries with trade reform during the 70's. These countries attempted to keep their exchange rate fixed to the US dollar while at the same time expanding the fiscal deficit and adhering to backward-looking wage indexation schemes. By maintaining a pegged exchange rate while pursuing these expansionary policies the governments were artificially maintaining a high value of their currency and distorting the price of foreign goods relative to domestic goods, which would eventually to an unsustainable balance of payments crisis. As the private sector perceived that trade liberalization was incompatible with its other macroeconomic policies and thus lacking credibility, expectations of overevaluation, exchange controls and future devaluations developed. The designs of the government were aggravated by the optimising behavior of the private sector which optimally diversified its portfolio internationally (e.g. by capital flight). As with time-inconsistent policies, this type of policy inconsistency coupled with the expectational moment of the private sector moved the economy in the opposite direction from that intended by reform. ${ }^{29}$

${ }^{29}$ See Schweickert, R. (1994). 


\section{REPUTATION}

Thus far the rather restrictive has been maintained that the private sector is completely informed about the government's preferences and its capacity for making credible commitments. Once we depart from this assumption and assume instead that the government's intentions cannot be precisely discerned by the private sector (e.g. after a new government has taken office), the process by which the private sector learns about the government's "type" takes on a pivotal role in the analysis. This section introduces a manifestation of uncertainty into the analysis that will be labeled as intrinsic, defined in terms of a situation in which private economic agents have only imperfect information about some particular attribute of the government they are facing. ${ }^{1}$ When this kind of uncertainty prevails there is room for manipulation of expectations and a policymaker can potentially lead private sector beliefs astray and maneuver them into a position that can eventually be exploited. Thus, the presence of intrinsic uncertainty not only underscores the role of information in the monetary game, but also fundamentally alters the behavior of the government.

Central to the following is the concept of reputation. Under the approach introduced in the previous section, reputation evolves under perfect information when the private sector utilizes its inflationary expectations strategically (via a trigger) as a device for disciplining the government into maintaining low inflation. By executing policy consistently (i.e. absent any policy "surprises") over consecutive periods the government can build up a its reputation, with the future benefits of "good" behavior and current benefit of discretionary policy holding the scale. It was shown that this temporal link

\footnotetext{
${ }^{1}$ The categorization chosen here follows BlackBuRn and Christensen (1989), p. 19. The other type of uncertainty that can prevail in a macroeconomic environment is extrinsic to the domestic economy and describes the imperfect information about exogenous, stochastic shocks that influence the clout of policy. Examples are demand shocks or termsof-trade shocks. Extrinsic uncertainty will be introduced in the exchange-rate model of Section [6].
} 
from current observed policy to future expected policy can discipline the government and uphold its credibility, as long as the government places significant weight on the future. The link is effective only under the premises that the time horizon is infinite and there exists an institution that is able to coordinate the expectations amongst the private sector. In contrast, the term reputation used in this chapter must be interpreted in a precise way, namely as a time-dependent variable measuring the private sector's probabilistic assessment of a governmental trait (such as its payoff structure). Over a finite string of periods this assessment is revised according to a learning process involving Bayes' rule which persuades the government to treat its reputation much like an "asset" that can be built up, maintained or run down, depending on its preferences.

Chapter 5 is organized as follows. Before turning to the issue of reputation, Section 5.1 attempts to generalize the strategic interaction between the government and the private sector undergoing reform. In this so-called signaling game, one party has information that the other lacks. Differences in information available to players make their strategies critically dependent on their beliefs and expectations. ${ }^{2}$ The presence of asymmetric information requires a somewhat different refinement of the equilibrium concept which will be introduced in Section 5.2. Unfortunately, the standard refinement of perfect Bayesian equilibrium is not enough to guarantee uniqueness and these signaling games therefore result in a plethora of equilibria. With the help of some equilibrium refinements based on out-of-equilibrium beliefs it is possible to rule out outcomes that go against the grain of intuition.

In Section 5.3 we will also resort again to monetary policy as a generic example of macroeconomic policy to examine how reputation evolves under intrinsic uncertainty in the dynamic setting of a two-period game. Instead of relying on the conscious attempt of the private sector to discipline the government, the notion of reputation used here is based on a learning process on the part of the private sector that involves observation of policy to elicit the private information being held back strategically by the government. To be exact, the uninformed private sector is confronted with the

${ }^{2}$ The notion that an informed player may act strategically in a setting of intrinsic uncertainty was first examined in the classic job market signaling model of Spence, A. (1973), as well as RothSCHILD AND STigLitz's (1976) model of an insurance market. See also KREPS, D. (1990) for a rigorous treatment of both these models, both in traditional (pp. 629-645) and game-theoretical terms (pp. 645-650). 
problem of extracting information about the identity of a policymaker from past observations of monetary policy. This information that trickles in over time is deemed relevant by a rational private sector for predicting inflation for the subsequent period. The government, in turn, is also well aware of this learning-process so when deciding whether to invest in any reputational assets, the government again faces an intertemporal trade-off. In contrast to the trigger strategy approach, "the learning approach that will be used in the following parameterizes credibility in terms of the degree of cohesion between the actions or announcements of policymakers and the beliefs of the government." 3 This not only reduces the severity of the time-consistency problem that we discussed previously, but this framework also avoids the conceptual problems involved with an infinite time horizon and coordination.

\subsection{Signaling and Government Behavior}

The economic situation that will be be the focus of this section is that of a government enacting (or thought to be enacting) some kind of macroeconomic reform. This macroeconomic setting is cast in game-theoretic terms by presenting an example of a class of signaling games called sender-receiver games. At the start of the game, the situation is characterized as one of economic disequilibrium resulting from an external shock or domestic policy weakness (such as a number of failed attempts at structural reform). A reform policy is announced that would, if enacted, alleviate the distortion but would produce short-term costs on the economy.

In close analogy to the game-settings discussed in Section 4.1, the setup will resort to a representative agent model which involves the private sector (PS, the Receiver) and government $(G$, the Sender). The structure of the game can be presented in extensive form fashion in Figure 5.1. In terms of this figure, Nature has chosen to start the game at one of the two nodes (drawn as open dots) labeled $T_{w}$ for a weak government and $T_{s}$ for the strong type of government. The prior probability that Nature chooses the strong government (the so-called common prior) is $\theta$ and, accordingly, Nature selects a weak government with probability $1-\theta .{ }^{4}$ Intrinsic uncertainty enters the

\footnotetext{
3 See Cukierman (1992), p. 142 .

4 Having the "type" of government being chosen as a lottery may seem an oversimplification. But as HARSANYi (1995) notes "it is our common experience as human beings that the results of social forces seem to admit only of probabilistic predictions. This ap-
} 
Fig. 5.1: Government Signalling

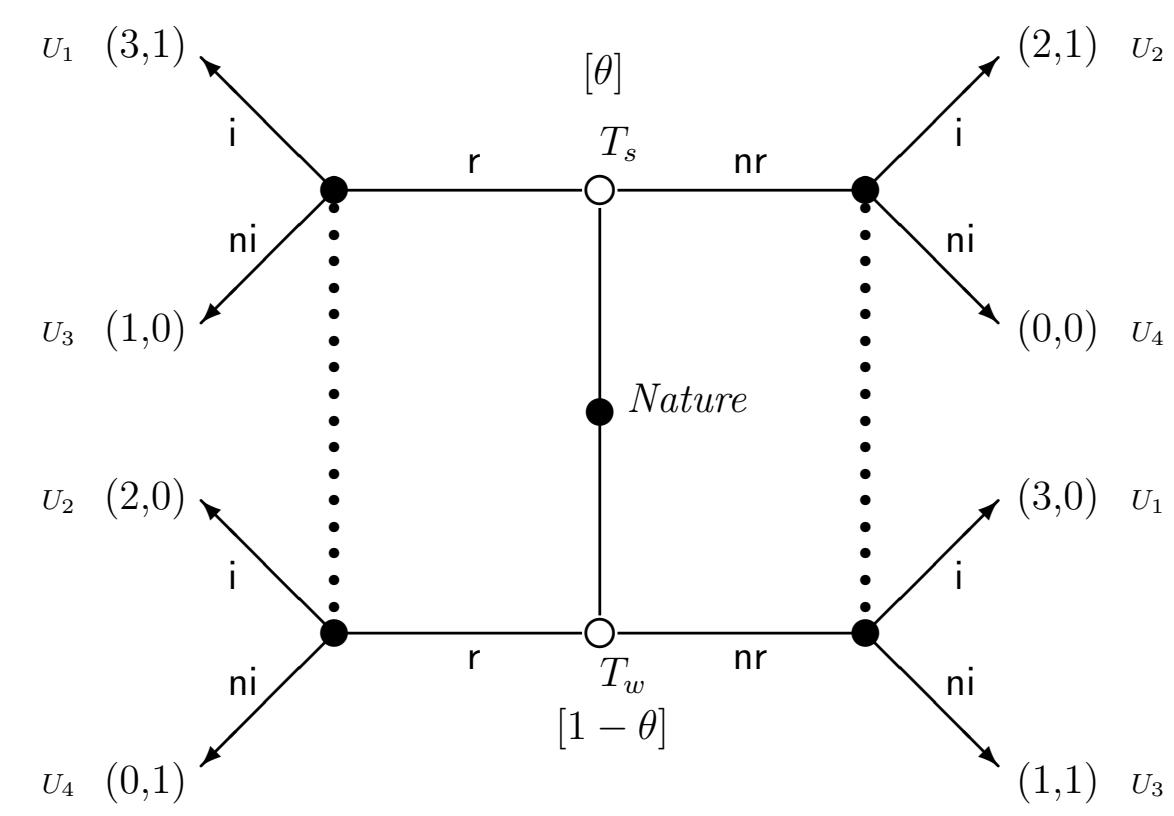

model by assuming that the government possesses private information about its type, i.e., it is able to observe the move of Nature but the private sector, on the other hand, is not aware of the type they are facing when the game commences.

The two dispositions of government, weak $T_{w}$ and strong $T_{s}$, reflect the policymaker's attitude towards reform. The government knows (i.e. has private information about) his own disposition or type, and its respective utility is aligned according to its inclination to reform and the investment response of the private sector. Preferences are aligned in the sense that both types of government would prefer a a minimum of reform effort, but we assume that a weak government dislikes the costs of adjustment (that are essential for the long-term success of reform) even more than a strong government does. ${ }^{5}$ Since both types of government share a common interest in a positive

pears to be the case even in situations in which we are exceptionally well informed about relevant social forces. Even in such situations, the best we can do is to make probabilistic predictions about the results that these social forces may produce." (p. 297)

${ }^{5}$ One could rationalize these differing attitudes by positing that the weak government discounts the future more heavily than a strong government does. It follows that to 
investment response of the private sector both derive a positive utility of 2 when the private sector chooses [i]. The fact that a strong government is more inclined to carry out reform enters the structure of the game by calibrating the payoff such that the government gets additional utility of 1 if his "preferred" policy is chosen: a strong government derives an incremental payoff for the strategy reform $[r]$. The weak manifestation of government, on the other hand, receives an additional payoff if the reform is not carried out [nr]. It follows that for both types of government the policy outcomes can be ranked from first- to fourth best, $U_{1}$ to $U_{4}$ in Table 5.1. It is interesting to note that the first or second-best outcome can only be achieved if the investment response [i] is forthcoming, regardless of the type of government the private sector is facing.

\section{Tab. 5.1: PAyoff STRUCTURE of The GOVERnMent}

\begin{tabular}{|c|c|c||c|c|}
\cline { 2 - 5 } \multicolumn{1}{c|}{} & \multicolumn{4}{c|}{ Government disposition } \\
\cline { 2 - 5 } \multicolumn{1}{c|}{} & \multicolumn{2}{|c||}{$T_{s}$} & \multicolumn{2}{c|}{$T_{w}$} \\
\hline $\mathrm{i}$ & $U_{1}$ & $U_{2}$ & $U_{2}$ & $U_{1}$ \\
\hline $\mathrm{ni}$ & $U_{3}$ & $U_{4}$ & $U_{4}$ & $U_{3}$ \\
\hline
\end{tabular}

where $1>U_{1}>U_{2}>U_{3}>U_{4}>0$ and $\left({ }^{*}\right)$ denotes the policymaker's preferred choice of policy given his type $T_{i}$.

We now turn to the decision-making process of the private sector. There are two options that the private sector may choose from: either domestic investment [i] or the "waiting option" [ni] by which we mean the deferment of any irreversible investment until the uncertainty regarding the sustainability of reform subsides. When private sector makes its move (corresponding to the closed dots in Figure 5.1), it does so by observing the government's choice was (and the respective payoffs), but not knowing with complete certainty

compensate a weak government for the short-term costs of adjustment would require a greater positive investment response from the private sector than for a strong government. 
whether the government is committed to reform. This is illustrated by the dotted lines in Figure 5.1, signifying that the investor does not know which node she is on when she makes her decision so her information set is $\Omega=$ $\left\{T_{s}, T_{w}\right\}$ when she makes the decision. The second player's utility, $U^{P S}$, has been calibrated such that it prefers the option of domestic investment to waiting option when the government is regarded as "strong" (type $T_{s}$ ), i.e. when the sustainability of reform is ensured. Therefore we calibrate the private sector's utility such that

$$
U^{P S}\left(\mathrm{i} \mid T_{s}\right)=1 \quad>\quad 0=U^{P S}\left(\mathrm{ni} \mid T_{s}\right) .
$$

On the other hand, the private sector must anticipate that the government could be of the weak sort. In this case it would be better to remain in a waiting position and observe if the reforms are sustainable or not (one could also rationalize this response by assuming that the private sector does not like the choice of irreversible investment under a government not committed to structural adjustment). Therefore, to reflect these facts it suffices that the utility of the private sector be chosen such that

$$
U^{P S}\left(\mathrm{ni} \mid T_{w}\right)=1 \quad>\quad 0=U^{P S}\left(\mathrm{i} \mid T_{w}\right)
$$

The sequence of moves in the game is the essentially same as in the commitment regime of our model in Section 4.1.2, with the government taking the role of a von Stackelberg leader. The timing of the game can thus be summarized as follows:

1. Nature determines the government's type $T_{i}(i=s, w)$ with prior probability $\operatorname{prob}\left(T=T_{s}\right)=\theta$ (solid dot in the middle of Figure 5.1).

2. The government learns about its type and chooses the action that initiates a reform policy or not (decision at open dots, $[\mathrm{r}]$ or $[\mathrm{nr}]$ ).

3. Private investors observe the government's choice (his "signal"), and based on this may either choose the "waiting option" [ ni ] or irreversible investment [i ] (solid dots).

Before investigating the situation game-theoretically it is perhaps useful to follow our intuition. It might seem that the investor should observe the government's signal (reform or waiting-option) and from this signal elicit the government's true disposition to reform. It is common knowledge that the 
payoffs an $s$-type government derives a positive payoff for choosing reform while a $w$-type government prefers the option of avoiding reform. Complicating this matter, though, is the fact that preferences are aligned when it comes to investment: regardless of the government's type, it is more important (in terms of payoff) that the "supply-response" is achieved, i.e., to induce domestic investment. Given this incentive structure, a strong government may encounter difficulties to convincingly separate itself from the intentions of a weak government due to the overriding incentive of both types to obtain a first- or second-best solution (refer to Table 5.1). Accordingly a weak government can profit from the prevailing intrinsic uncertainty by playing a "wolf in sheep's clothing" by signaling its commitment to carry out reform, even though this is not his first-best choice.

If the subjective probability (belief) that the government is strong is sufficiently high at the beginning of the game, one can suspect that the investor should choose the waiting option before investing (ni) if the government does not signal its commitment to reform (strategy $r$ ). Consequently, both types of government, $T_{s}$ and $T_{w}$, will choose the path of reform. Whereas this is the "natural" choice of the s-type government, the weak government masquerades its commitment in order to elicit a supply-response which he also profits from.

\subsection{Perfect Bayesian equilibrium}

An important property of the economic environment of intrinsic uncertainty is that the rational yet unknowing private sector is unable to ascertain at which node it is after the government has chosen its strategy. Their information $\Omega=\left\{T_{w}, T_{s}\right\}$ set can apparently not be classified as a singleton, because the private sector does not observe Nature's move. It is impossible to apply the formal criterion of subgame perfection to this case because, in game-theoretic speak, it is not possible to identify a proper subgame. This requires the private sector to make a probability assessment of the type of government they are facing from the observation of the action of the (informed) government. Since the strategies chosen by the private sector are in effect a function of their beliefs, an equilibrium can no longer be defined on solely on strategies alone, but must also include the specification of beliefs such that the strategies are best responses.

But this is not the end of the story. As long as the players play their equi- 
librium strategies, then any equilibrium concept specifying the strategies and how the private sector rationally revises the beliefs held in equilibrium would suffice. Such an equilibrium concept would, however be incomplete since it leaves room for arbirtrary beliefs off the equilibrium path. Although these off-equilibrium events have a zero probability of occurring in equilibrium, they must be specified for they have the potential to set in motion the other player's out-of-equilibrium strategies and beliefs which may in turn have an effect on the equilibrium strategies. Thus any solution concept for (dynamic) games under intrinsic uncertainty also requires "that actions taken off the path of play must be rationalized by some beliefs about what has happened up to the point where the actions must be taken." 6

These general considerations lead us to the following definition ${ }^{7}$,

Definition 5.1: A perfect Bayesian equilibrium in a macroeconomic game is a strategy profile $s$ and a set of beliefs $\mu$ held by the private sector such that in every period of the game:

1. The strategies for the remainder of the game are optimal for the private sector given the belief system $\mu$ and given the strategies of the government.

2. The strategies for the remainder of the game are optimal for the government, given its type and given the strategies of the private sector.

3. Given the equilibrium strategies of the government, the beliefs of the private sector at each information set are rational given the evidence, meaning that the posterior beliefs of the private sector are derived from the observation of the government's strategy. The beliefs are updated according to Baye's rule under the hypothesis that they are in equilibrium.

Equipped with this equilibrium refinement it is now possible to tackle the imminent problem of predicting the outcome of the macroeconomic situation between the informed government and uninformed private sector that was described above. Essentially, this involves selecting a plausible strategy profile and then testing whether the strategies are best responses to each other (in accordance with (1) and (2) of Definition 5.1). Then, depending on the set

\footnotetext{
${ }^{6}$ See Kreps, D. (1990), p. 432.

${ }^{7}$ Aadapted from the general definition provided by RASmusen (1994), p. 146.
} 
of beliefs and the probability that Nature will choose a specific government, the economy can be characterized by two types of equilibrium. In a separating both types of government choose their first-best strategy, $[r]$ for the strong government and [nr] for the weak government. A pooling equilibrium is characterized with both governments selecting identical actions.

\subsubsection{Pooling equilibrium}

In a pooling equilibrium both types of government, strong and weak alike, select identical strategies. Following the definition given above, finding a Nash equilibrium involves exogenously specifying a common prior $\theta$ and beliefs that are not on the equilibrium path. Then, together with the beliefs held in equilibrium, a plausible strategy profile is tested as to whether the strategies are best responses to each other. Consider first an equilibrium strategy profile in which both types of government select the same strategy [r]. Assume furthermore that Nature selects a strong government with probability of $\theta=0.9$ and this being common knowledge to both players. After observing the government's signal $[r]$, the private sector's probability assessment as to the type of government it is facing at his information set $\Omega=\left\{T_{s}, T_{w}\right\}$ (corresponding to the open nodes in Figure 5.1) should be consistent with Bayes' rule.

We now ask what equilibrium beliefs are reasonable for the private sector to hold after observing the signal $[r]$ in the forefront of its investment decision. The private sector knows (and the government knows that its knows) that for a strong government the no-reform strategy [nr] is strictly dominated by [r], so the private sector can entirely dismiss as implausible beliefs associated with a strong government choosing to opt out of a reform. Therefore, it is rational for the private sector to attach to signal $[r]$ the belief $\mu\left(r \mid T_{s}\right)=1$. For a weak government, no dominant strategy is available, rendering the signal [r] ambiguous: there is the possibility that a weak government may mimic a strong government. This means that $\mu\left(r \mid T_{w}\right)>0$. Given the dissembling nature of the weak government, the signal $[r]$ does not provide any further information on which to revise prior belief $\theta$.

The private sector's beliefs $\mu\left(T_{s} \mid \mathbf{r}\right)$ and $\mu\left(T_{w} \mid \mathbf{r}\right)$ at information set $\Omega=$ $\left\{T_{s}, T_{w}\right\}$ (closed nodes) as to the type of government he is facing after receiving the signal is determined by Bayes' rule and the government's strategy $\left[\mathbf{r}\right.$. The posterior probability $\mu\left(T_{s} \mid \mathbf{r}\right)$ is computed the following way. The 
probability that signal $[\mathrm{r}]$ will be sent by any of the two governments is

$$
\begin{aligned}
\operatorname{prob}(\mathbf{r}) & =\operatorname{prob}\left(T_{s}\right) \operatorname{prob}\left(\mathbf{r} \mid T_{s}\right)+\operatorname{prob}\left(T_{w}\right) \operatorname{prob}\left(\mathbf{r} \mid T_{w}\right) \\
& =\theta+(1-\theta) \operatorname{prob}\left(\mathbf{r} \mid T_{w}\right)
\end{aligned}
$$

Then, using Bayes' rule in light of the government's signal of [r] means that the former likelihood $(\theta)$ that the private sector is facing a strong government is updated in the following fashion,

$$
\begin{aligned}
\mu\left(T_{s} \mid \mathbf{r}\right) & =\frac{\theta \cdot \operatorname{prob}\left(\mathbf{r} \mid T_{s}\right)}{\operatorname{prob}(\mathbf{r})} \\
& =\frac{\theta}{\theta+(1-\theta) \cdot \operatorname{prob}\left(\mathbf{r} \mid T_{w}\right)}
\end{aligned}
$$

The concept of a Perfect Bayesian equilibrium leaves us with a degree of freedom how the private sector interprets signal $[r]$, as long as these beliefs do not violate [5.4]. If the government's type is independent of its decision to proceed with reform, then the government's action of $r$ provides no further information to the investor on which to revise his information and his beliefs are equal to the prior distribution such that

$$
p \equiv \mu\left(T_{s} \mid \mathbf{r}\right)=0.9 \quad \text { and } \quad 1-p \equiv \mu\left(T_{w} \mid \mathbf{r}\right)=0.1
$$

In game-theoretic literature this is referred to as a passive conjecture. ${ }^{8}$ The investors best response given these posterior beliefs following $[r]$ is to play [i], since the expected payoff for playing [i] exceeds that of playing [ni],

$$
\begin{aligned}
p \cdot U^{P S}\left(\mathrm{i} \mid T_{s}\right)+(1-p) \cdot U^{P S}\left(\mathrm{i} \mid T_{s}\right) & >p \cdot U^{P S}\left(\mathrm{ni} \mid T_{s}\right)+(1-p) \cdot U^{P S}\left(\mathrm{ni} \mid T_{s}\right) \\
\Rightarrow 0.9 \cdot 1+0.1 \cdot 0 & >0.9 \cdot 0+0.1 \cdot 1
\end{aligned}
$$

Given this response from the private sector the $s$-type government can achieve its first-best outcome $U_{1}$ whereas the $w$-type must take a second-best outcome $U_{2}$, since he does not act true to his beliefs by reforming.

This perfect Bayesian equilibrium must be additionally sustained by the out-of-equilibrium beliefs of the uninformed player,

$$
q \equiv \mu\left(T_{s} \mid \mathrm{nr}\right) \quad \text { and } \quad 1-q \equiv \mu\left(T_{w} \mid \mathrm{nr}\right)
$$

\footnotetext{
${ }^{8}$ Looking at [5.4] it is easy to see that assuming passive conjectures is tantamount to setting $\operatorname{prob}\left(\mathbf{r} \mid T_{w}\right)=\operatorname{prob}\left(\mathbf{r} \mid T_{s}\right)=1$. If the weak government never sends the signal $[\mathrm{r}]$, then $\operatorname{prob}\left(T_{s} \mid \mathbf{r}\right)=1$.
} 
To determine whether both government types are willing to send the same signal $[r]$, we need to specify how the investor would react if the government unexpectedly chose not to reform (signal nr). Notice that a weak government's posterior beliefs in [5.6] are not computable using Bayes's rule (as was possible for the $(r, r)$ equilibrium), since there is zero prior probability that the private sector will observe the event [nr] that he is meant to condition his decision upon.

First, both players know that for a committed government $T_{s}$, strategy [nr] is strictly dominated by strategy $[\mathrm{r}]$ so that any belief $\mu\left(T_{s} \mid \mathrm{nr}\right)$ would be consistent with the equilibrium. For the weak government, however, if the investor's response to [nr] is [i], then type $T_{w}$ can achieve a first-best outcome which is superior to the outcome it can achieve by choosing $[r]$. For $(r, r)$ to be an equilibrium the out-of-equilibrium belief $1-q \equiv \mu\left(T_{w} \mid \mathrm{nr}\right)$ must possess a value that ensures that the private sector's best response is [ni ] after observing signal [nr]. This is the case when the expected payoff for the private sector for not investing, [ni] exceeds that for strategy [i],

$$
\begin{aligned}
q \cdot U^{P S}\left(\mathrm{ni} \mid T_{s}\right)+ & (1-q) \cdot U^{P S}\left(\mathrm{ni} \mid T_{w}\right)>q \cdot U^{P S}\left(\mathrm{i} \mid T_{s}\right)+(1-q) \cdot U^{P S}\left(\mathrm{i} \mid T_{w}\right) \\
& \Rightarrow q \cdot 0+(1-q) \cdot 1>q \cdot 1+(1-q) \cdot 0 \\
& \Rightarrow q<0.5
\end{aligned}
$$

Establishing the equilibrium accordingly involves restricting the weak government's set of out-of-equilibrium beliefs in a way does not contradict the proposed equilibrium. It follows that in our case the posterior probability that a weak government will not reform, $1-q \equiv \mu\left(T_{w} \mid \mathrm{nr}\right)$ must be greater than 0.5 for equilibrium $(r, r)$ to be sustained. We can rationalize such a reaction by the private sector to [nr] as follows: the investor interprets signal [nr] (which is never realized in equilibrium), as a sign that the government is not committed to reform. The investor revises his probability assessment that the government is weak to $1-q>0.5$, which exceeds the prior probability that Nature has chosen a weak government of $1-\theta=0.1$. The outcome of this pooling equilibrium, together with the respective beliefs that underpin the equilibrium is summarized in Table 5.2.

There are an infinite number of equilibria in which the weak government is able masquerade as a strong government by choosing its preferred choice of policy. The outcome is sustained by a belief system that puts a sufficiently high probability $(1-q>0.5)$ that a weak government would choose not to reform. The incentive to masquerade depends on the set of beliefs held 
Tab. 5.2: PoOling EquiLibrium I

\begin{tabular}{|r|c|c|}
\hline \multicolumn{3}{|c|}{$\theta=0.9$} \\
\hline Government: & $\mathrm{r}$ if weak & $\mathrm{r}$ if strong \\
\hline Private sector: & $\mathrm{i}$ & $\mathrm{i}$ \\
\hline Beliefs: & $p=0.9 ; \quad$ any $q<0.5$ \\
\hline
\end{tabular}

by private agents. The equilibrium is sustained when the private sector believes that only a weak government would not choose reform. Given these beliefs it is in the interest of a weak government to choose reform, deny itself its preferred action in order to elicit the the reaction [i] in equilibrium. The strong government finds itself in a dilemma situation since it cannot successfully separate itself from the weak government, its reputation has been "tarnished" by the presence of intrinsic uncertainty. For $q>0.5$, the weak government prefers not to masquerade as a strong government and the proposed equilibrium breaks down.

\subsubsection{The Intuitive Criterion}

We will now examine an equilibrium characterized by the outcome of both governments choosing [nr], associated with common prior of $\theta=0.9$ and an out-of-equilibrium signal of $[r]$ (see Table 5.3). Since both governments again

Tab. 5.3: Pooling EQuilibrium II (A)

\begin{tabular}{|r|c|c|}
\hline \multicolumn{3}{|c|}{$\theta=0.9$} \\
\hline Government: & $\mathrm{nr}$ if weak & $\mathrm{nr}$ if strong \\
\hline Private sector: & $\mathrm{i}$ & $\mathrm{i}$ \\
\hline Beliefs: & any $p<0.5 \quad q=0.9$ \\
\hline
\end{tabular}

"pool" their actions, the private sector learns nothing on which to revise their beliefs and their posterior assessment $q \equiv \mu\left(T_{s} \mid \mathrm{r}\right)$ is equivalent to the prior $\theta$. Their best response then is to choose [nr]. To underpin a Nash equilibrium it is necessary to "adjust" the posterior beliefs held off the path of play so that $1-p \equiv \mu\left(T_{s} w \mid \mathrm{r}\right)>0.5$. Such beliefs would induce the private sector 
to select [ni], thus deterring the strong government from choosing $[r]$ instead of [nr], the equilibrium action, thereby sustaining the equilibrium.

The outcome in equilibrium is counterintuitive. On closer inspection we can eliminate this outcome by arguing that the private sector's out-ofequilibrium beliefs are not rational: if $(n r, n r)$ is the equilibrium, then a weak government will net first-best $U_{3}$ in the equilibrium; choosing $[r]$ would only net the player second-best $U_{2}$. The weak government would therefore never willingly defect to an action of $[r]$, because the best he can do with this outof-equilibrium action provides him with lower utility than what is possible in the equilibrium. By contrast it is in the interest of the strong government to separate itself from the intentions of a weak government by signaling its commitment (i.e. by sending $[r]$ ), since he only gets $U_{2}$ in the equilibrium outcome but could conceivably get $U_{1}$.

We can rule out this unappealing equilibrium by applying an equilibrium refinement called the Intuitive Criterion ${ }^{9}$ which restricts beliefs such that a pooling result of (nr, nr) cannot be rationalized as a Nash equilibrium. This refinement makes it entirely rational for the private investor to restrict himself to a belief in which the weak government never chooses reform, by simply removing the possibility from the game that a weak government ever could choose $[\mathrm{r}]$. That means setting $1-p=0$. It follows that the posterior belief is $p=1$ (the government is strong with probability of one if it sends the signal $r$ ) and the strong government, realizing this, applies forward induction in the knowledge that he can go ahead with reform without fearing that investment will not follow. But these incentives, of course unravels the presupposed equilibrium $(\mathrm{nr}, \mathrm{nr}){ }^{10}$

9 This verbal presentation of the Intuitive Criterion does not do justice to the niceties of formal reasoning that supports it. See CHO AND KREPS (1987), p. 202 for a more elaborate treatment. We will return to this concept and examine its implications in more detail in Section 7.3.2.

10 Applying the same sequence of reasoning to the previous equilibrium in Table 5.3 does not break the equilibrium, au contraire. Signaling $[\mathbf{r}]$, the strong government has no rational reason to defect from this equilibrium choice, whereas a weak government could conceivably gain by defecting to [nr]. Subsequently, we should entirely eliminate the possibility that s strong government will send [nr] under the given payoffs. Hence, we set $q=0$ and $1-q=1$, i.e. the private sector faces a weak government with certainty upon receiving [nr]. The best response to this out-of-equilibrium signal is [ni], but this response instead supports the equilibrium rather than destroying it. 


\subsubsection{Separating equilibrium}

We will turn now to separating equilibria. One separating equilibrium exists in which the government reforms only if it is strong and does not reform if it is weak. It derives its equilibrium status by having Nature choose the weak type with a high probability. The low probability of a strong government exerts a negative influence on investment behavior since investors do not want to be caught with the "wrong" government and their optimal choice is therefore ni. These results are summarized in Table 5.4

\section{Tab. 5.4: SEPARATING EQUILIBRIUM I}

\begin{tabular}{|r|c|c|}
\hline \multicolumn{3}{|c|}{$\theta=0.1$} \\
\hline Government: & nr if weak & $\mathrm{r}$ if strong \\
\hline Private sector: & ni & ni \\
\hline Beliefs: & $p=0.1$ & $q=0.9$ \\
\hline
\end{tabular}

It is possible to rationalize other equilibria in which both governments separate out in equilibrium by altering the structure of the game. One important ground rule for modelling is that the description of the game should include all relevant opportunities for the players. Therefore, if there is a possibility that the players can communicate with each other then this should be reflected in the extensive form and in the list of possible strategies. The standard theory of signaling suggests that communication taking the form of non-binding messages should be uninformative, when such talk is not accompanied by any immediate policy action. However, casual observation suggests that governments can sometimes move bond and exchange rates with mere words.

\subsubsection{Cheap Talk}

Recent literature shows that cheap talk "can sometimes convey information and affect real (payoff-relevant) actions", even when announcements can be made at no cost. ${ }^{11}$ It seems therefore natural to assume that in the macroeconomic signalling game outlined above, a strong government would have an incentive to emphasize verbally its commitment to reform.

${ }^{11}$ See FARRELL (1995) p. 186. 
To see this consider again the Pooling equilibrium II (a) above, which was labelled as "unreasonable". This outcome fails because if the government is weak then he will deviate from the prescribed path of play and choose $[r]$. A strong government, on the other hand, could get $U_{1}$ instead of $U_{2}$ for deviating, if the private sector recognizes the out-of-equilibrium signal $[r]$ as a signal that he is, indeed, strong. In other words, the equilibrium in $(\mathrm{nr}, \mathrm{nr})$ falls apart if there was a way for a strong government to make the uninformed player revise his beliefs to $\mu\left(T_{w} \mid r\right)=0$ (or equivalently, to $\left.\mu\left(T_{s} \mid \mathbf{r}\right)=1\right)$. If we were in this equilibrium and if we imagined that the government could accompany his signal of cooperation with a little speech (such as an announcement by government officials prior to carrying out the reform), one could imagine the government saying something like:

\begin{abstract}
"You, the public, expected me not to carry out reforms. But now you can see for yourself that by embracing a reform course I am indeed a strong government committed to reform. The only conceivable benefit to me for reforming comes if I am a strong government. So you see that this declaration I make (and subsequent deviation from your expectations) is only conceivably in my interests if I am strong. That should convince you that I am and justify my deviation."
\end{abstract}

This announcement, together with the supposed actions taken in equilibrium, should be interpreted as a conscious attempt on the part of the government to signal that he is strong when he deviates and chooses $[r]$. Note well that this speech works only when, compared with supposed equilibrium payoffs, a strong government would benefit from deviating and choosing signal r. A weak government would also choose this signal if he thinks that the no reform option will scare investors into a waiting position [ni]. Signal $[r]$ can be ruled out for the weak government only by fixing the equilibrium and assuming that the players believe that they can indeed obtain what the equilibrium promises. Thus the government's words, in addition to its actions, can be a valuable source of information regarding future policies. If mere speech has the power to influence expectations in such a manner then it is conceivable that an equilibrium in Table 5.5 could be sustained.

When it comes to the credibility of the speech above, some caveats apply. If the speech is believed, and if the investor works out that the speech should be believed, then the absence of the speech should cause him to deduce that the government is not committed to reform. But we cannot conclude that 
Tab. 5.5: Separating Equilibrium II - "Cheap-TAlK"

\begin{tabular}{|r|c|c|}
\hline \multicolumn{3}{|c|}{$\theta=0.9$} \\
\hline Government: & nr if weak & r if strong \\
\hline Private sector: & ni & ni \\
\hline Beliefs: & $p=1$ & $q=0$ \\
\hline
\end{tabular}

a weak government would not make the speech: failure to do so would not convince investors of the government's commitment, consigning the government to a third-best outcome compared with second-best he would get by making the speech. Thus the credibility of this speech turns on the fact that a weak government would never make it.

\subsubsection{Correlated strategies}

The refinement described above shows how the opportunity of players to tell each other how to interpret certain actions can affect the outcome of play. But even if we discount the possibility of such explicit communication between government and investor, we can imagine that the private sector may observe exogenous signals on which it can condition its reaction. Very often decisions related to major reform steps are initiated by foreign creditors or organizations (World Bank or IMF). A third party could act as a mediator, offering loans to supplement reform on concessional terms. Since the relevant institution is probably more informed (after negotiations and mandatory policy appraisals) than the public as to the government's type, we can imagine that it possesses private information that the public does not have. If it were able to revise the probability that the government is strong to $q<0.5$ and send a signal to the public, then the strong government could successfully separate itself from a weak government. The players strategies are said to be correlated with the mediator's signal. ${ }^{12}$ We have thus the paradox result that if the foreign creditor is all to optimistic about the government's commitment to reform (by assessing the probability of $q>0.5$ that the government is strong), it may in fact disable the ability of a willing reformer to

\footnotetext{
12 This idea is due to AUMANN (1974), which applies more generally to cases in which the players observe the outcome of a random event, such as a coin flip, before choosing their strategies. For more details see Holler AND Illing (1993), pp. 90-93.
} 
signal its true commitment.

Of course the presence of supranational mediators could also backfire if these organizations also offer "carrot-and-stick" policies to coerce governments into accepting reform. With many economic reform projects tied to such conditionality, a weak government may well choose to mimic the strong government over an extended period of time, because this allows it to have prolonged access to the financial aid resources. Ironically, by perturbing the private sector's ability to accrue information as to the type of government it is facing, "conditionality makes the well-meaning strong government's job harder by causing it to be confused with its less committed weak counterparts", making us reject the separating equilibrium. ${ }^{13}$

\subsubsection{Some remarks on the equilibrium concept}

The equilibrium notion that was presented in this section has some major implications for the remaining sections. First, it involves the assumption of learning behavior with investors revising their beliefs in the presence of new information. This notion is captured by Bayes' Theorem, which allows the investor to update his prior beliefs (given by $\theta$ ) after observing the government's choice of signal. The investor thus consciously updates his assessment of the sustainability of reform and chooses her best response given these posterior beliefs. In a multi-period setting of monetary policy this Bayesian updating of beliefs gives a meaningful notion of learning and will be examined in detail in the following Section 5.3.1.

Second, we saw that the formation of posterior beliefs alone does not suffice to establish an equilibrium. What constitutes a best choice in an equilibrium is affected by what one supposes will be another's actions out-ofequilibrium, i.e. the hypothetical question of how the private sector receives a signal which should not have been sent by any type according to the prescribed equilibrium play. Since beliefs that are off-the-path of play (in our case for signal nr) are not computable using Bayes' rule (zero probability that $P S$ will observe the event) we are left with a degree of freedom in choosing

\footnotetext{
${ }^{13}$ See RodrIK, D. (1992), p. 91. In the context of trade policy reform, the same author examines a game between a liberalizing government and a less commited redistributive type government (RODRIK, D. (1989)). He finds that the existence of foreign aid "makes a pooling equilibrium more likely, and increases the probability that a genuinely reformminded government will be confused with one whose motives are different." (p. 767)
} 
beliefs that rationalize the private sector's choice of ni (with sufficiently high probability). Beliefs that are not bound by any prior beliefs thus affect the shape of the equilibrium itself, i.e. they are endogenously generated by the equilibrium concept. What this essentially means is that a government, in choosing a signal, cannot think through equilibrium if he had no idea about the investor's beliefs (and hence actions) if he deviated.

Third, there are a multitude of conceivable beliefs: almost any behavior can be rationalized by simply imposing suitable out-of-equilibrium beliefs. This makes the tasks of the modeller more difficult. Much of the effort in recent game-theoretic literature that has been expended in trying to "fine-tune" equilibrium concepts to eliminate counterintuitive outcomes (like (nr,nr) above). As above, this involves restricting "suitably" what players might be expected to do in response to deviations from a given equilibrium.

Fourth, the generalized setting of the game outlined in this section yields some insights into reputational mechanisms that will be the bread and butter of sections to come. In terms of the signaling example above, the government's reputation at a certain point in time can be summarized by the investors' current beliefs about his type at his decision nodes $[p],[1-p],[q]$ and $[1-q]$. A government can "accumulate" or "build up" his reputation by consistently implementing the reforms it announces. With this incoming information, investors are able to revise their beliefs for every repetition of the game. If a government follows through on reform in $T-1$, then their Bayesian learning makes investors revise their beliefs in $T$ accordingly. The main concern here is when and whether a weak government can take advantage of a small prior probability $q$ (a priori belief that the government is strong) to effectively commit himself to playing as if he were an s-type government. Since reputations can be viewed as assets, even a weak government with a strong aversion towards reform may be willing to incur short-run adjustment costs to build up his reputation. In another sense, a government that is at the end of its term (short horizon) will be less willing to make investments in reputation, so we should expect that such investments will be more likely for governments just voted into office. 


\subsection{Monetary stabilization policy under intrinsic uncertainty}

This section formalizes the notion of reputation in a monetary policy game. The necessary element that drives this model is the presence of private information on the part of the government. The discussion of the preceding section established that it is possible to model a situation by postulating that the private agents do not know the characteristics of the government they are facing. The monetary policy game to be considered here will take this idea to a higher degree of sophistication in a multi-period setting. This model has been accredited to the status of a "benchmark" model of stabilization policy. Although it takes its cue from the one-shot model examined in Section 4.2 , there are some stark differences. Instead of a "memory-less" confrontation between a private sector and a government, the monetary authority (which will simply be referred to as government) and private sector interact over a finite time horizon. This allows us to analyze the effects of changes in the policy regime, the consequences of such regime shifts on private behavior, and the feedback of private expectations on government incentives. The analysis will build upon the model presented in BACKUS AND DRIFFIL (1985a, 1985b), Barro (1986), and Horn And Persson (1988). The game theoretic notion of reputation used in the following was first introduced formally by KREPS AND WILSON (1982) to analyze the market situation of an incumbent monopolist facing a potential rival.

The analysis builds upon the intrinsic uncertainty we examined above. When the government announces its intention to fight inflation regardless of output cost, the public is uncertain whether this is in fact the case, or whether it is simply an attempt to manipulate expectations. Incomplete information thus manifests itself in uncertainty about the inflation-employment tradeoff. ${ }^{14}$ We assume that the government has private information about the weight given to its output goal, $b$. It is convenient for the dynamic analysis to simplify the the government's preference function in [4.5], making it linear rather than quadratic in its output goal. ${ }^{15}$ Therefore the government's

\footnotetext{
${ }^{14}$ One could also have uncertainty enter the model by assuming imperfect information about the government's attitudes and its bargaining position vis-a-vis interest groups, its fiscal constraints, etc.

15 The benefit of this reformulation will be seen to be that the inflation rate under discretion is independent of the expected inflation rate, which substantially simplifies the
} 
utility in period $t$ can be written as

$$
U_{i, t}^{G}=-\frac{a}{2} \pi_{t}^{2}+b_{i}\left[\alpha\left(\pi_{t}-\pi_{t}^{e}\right)-\Delta\right]
$$

where the public's scepticism is formally expressed by assuming two types of government, $i=s, w$, which differ according to their relative inflationary preferences. The first type is a "strong" government $T_{s}$ puts a relative low weight $b_{s}$ on economic stimulation via surprise inflation (brought forth by a monetary expansion). The second manifestation of government $\left(T_{w}\right)$ is weak and its preferences relative to the strong government is reflected in the fact that $b_{w}>b_{s}$, i.e. it has a greater concern for output relative to inflation. Given this form of the utility function we can compute the discretionary level of inflation by repeating the procedure as in Appendix A.2. ${ }^{16}$ To focus on the details of the expectations formation process, we will assume that $b_{s}=0$, i.e. there is no trade-off for the $s$-government between higher inflation for economic stimulation. Then government type $i$ 's level of discretionary inflation is

$$
\begin{aligned}
\pi_{s}^{D} & =\frac{\alpha b_{s}}{a}=0 \\
\pi_{w}^{D} & =\frac{\alpha b_{w}}{a}
\end{aligned}
$$

where it is easy to see that $\pi_{s}^{D}<\pi_{w}^{D}$ as long as $b_{w}>0$.

\subsubsection{Bayesian learning process of the private sector}

The public is unsure which type and therefore payoff structure they are facing. They will therefore view the government's motives with scepticism, and attach a positive probability that the government will renege on its policy announcement. In the language of Bayesian theory, people assign a positive prior $\theta_{t}$ to the event that the government is strong $\left(T_{s}\right)$ given their information set $\Omega_{t-1}$. As time passes (i.e. through repeated realizations of the game), people combine actual realizations of the policy with their prior in calculations.

16 Taking the derivative of $U^{G}$ with respect to $\pi_{t}$, first-order conditions are

$$
\left.\frac{\partial U_{t}^{G}}{\partial \pi}\right|_{\pi^{e}=\text { const. }}=-a \pi-b \alpha \stackrel{!}{=} 0
$$

. Isolating $\pi_{t}$ for alternative values of $b$ result in 5.9 and 5.10 . 
order to form a posterior distribution on the policy parameters, which is used to make forecasts of future policy. Therefore, their beliefs are malleable and time dependent on previous realizations of policy. Taken together these beliefs characterize the learning process of the public over a finite time interval $\tau$. At the beginning of period $t$, the private prior probability to the event that the government is strong is

$$
\theta_{t}=\operatorname{prob}\left(T_{s} \mid \pi_{t-j}=0, \forall j=1, \ldots, t\right)
$$

The private sector assigns a probability

$$
1-\theta_{t}=\operatorname{prob}\left(T_{w} \mid \pi_{t-j}=0, \forall j=1, \ldots, t\right)
$$

to the complementary event that the government is weak. Before the game starts, Nature chooses a strong government with a probability of $\theta_{0}$. This prior is common knowledge, but only the government is aware of its type. Notice that this is a conditional probability: after the government reveals its actions to the public, it revises $\theta$ in light of observed behavior. The $a$ posteriori probability $\theta_{t+1}$ may be classified as an improvement in the public's assessment of the type it is facing through the government's choice of strategy in $t$.

As the game is played in consecutive periods, the government's reputation evolves. If the private sector observes the policy $\pi_{t}=0$ or $\pi_{t}=\pi_{w}^{D}$, then Bayes' rule suggests how the public rationally update their beliefs at the beginning of $t+1$ with information $\Omega_{t}=\left\{\pi_{t-j}\right\}, \forall j=1, \ldots, t$ :

$$
\begin{aligned}
\theta_{t+1} & =\operatorname{prob}\left(T_{s} \mid \pi_{t}=0\right) \\
& =\frac{\operatorname{prob}\left(T_{s} \text { and } \pi_{t}=0\right)}{\operatorname{prob}\left(\pi_{t}=0\right)} \\
& =\frac{\operatorname{prob}\left(T_{s}\right) \cdot \operatorname{prob}\left(\pi_{t}=0 \mid T_{s}\right)}{\operatorname{prob}\left(\pi_{t}=0 \mid T_{s}\right) \cdot \operatorname{prob}\left(T_{s}\right)+\operatorname{prob}\left(\pi_{t}=0 \mid T_{w}\right) \cdot \operatorname{prob}\left(T_{w}\right)}
\end{aligned}
$$

Let $\rho_{t} \equiv \operatorname{prob}\left(\pi_{t}=0 \mid T_{w}\right)$ be the period- $t$ probability assigned by the private sector that $T_{w}$ masquerades a non-inflationary government by choosing $\pi_{t}=$ 0 . A strong government always chooses zero inflation with certainty (from [5.9] we know that $\left.\pi_{s}^{D}=0\right)$, so that $\operatorname{prob}\left(\pi_{t}=0 \mid T_{s}\right)=1$. With $\theta_{t} \equiv \operatorname{prob}\left(T_{s}\right)$, the posterior probability in $t+1$ therefore simplifies to

$$
\theta_{t+1}=\frac{\theta_{t}}{\theta_{t}+\left(1-\theta_{t}\right) \rho_{t}}
$$


Since a weak government has an incentive to inflate (given $\Delta>0$ ), $\rho_{t}$ is greater than zero, reflecting the temptation of surprise inflation $\pi_{w}^{D}$. If the public observes $\pi_{t}=0$ then this signal of past performance will increase the probability assessment that it is dealing with a strong government. Thus, $\theta_{t+1}>\theta_{t}$ always holds true even if there is only a slight probability that a weak government will select a restrictive course of $\pi_{t}=0$. If the weak government never chooses zero inflation $\left(\rho_{t}=0\right)$ then the private sector is informed with certainty that it is facing a strong government. The government then enters period $t+1$ with a maximum of reputation endowed $\left(\theta_{t}=1\right){ }^{17}$

If, on the other hand, the private sector observes the discretionary solution, $\pi_{t}=\pi_{w}^{D}$, then the government exposes itself as weak and it loses its ability to influence expectations in future periods. Since an $s$-type government would never choose an inflation rate other than $\pi_{t}=0$, we know that $\operatorname{prob}\left(\pi_{t}=\pi^{D} \mid T_{s}\right)=0$ and it follows from [5.13] that

$$
\theta_{t+1}=\frac{\theta_{t} \cdot 0}{0 \cdot \theta_{t}+\left(1-\rho_{t}\right) \cdot\left(1-\theta_{t}\right)}=0
$$

For an inflation rate $\pi_{t} \neq 0$ or $\pi_{t} \neq \pi^{D}$ is observed by private agents we assume that reputation is destroyed, i.e. $\theta_{t+1}=0 .{ }^{18}$ This description of the dynamic learning process provides us with a definition of reputation to be used in the following chapters,

Definition 5.2: Reputation is a time-dependent state variable, $\theta_{t} \forall t \in[1, \ldots, \tau]$ that measures the private sector's probabilistic assessment of a certain trait in the government's character. $\theta_{t}$ evolves over time and finite time horizon $\tau$ according to

$$
\theta_{t+1}\left(\theta_{t}\right)= \begin{cases}0, & \text { if } \pi_{t} \neq 0 \\ \frac{\theta_{t}}{\theta_{t}+\left(1-\theta_{t}\right) \rho_{t}} & \text { if } \pi_{t}=0 .\end{cases}
$$

As shall be made clearer below, $\theta_{t+1}$ as a function of $\theta_{t}$ is a sufficient statistic for the history of play up to date $t$. This simplifies the analysis considerably,

\footnotetext{
17 One could argue that if the belief structure of the private sector is such that it believes that a weak government will always masquerade the strong government by choosing $\pi_{t}=0$ and thus $\rho_{t}=1$ then reputation will be ruined even if the private sector is facing a strong government. But then, of course, a "weak" government that never chooses its discretionary inflation rate would be, by definition, strong.

18 As we have already discussed, for actions $\pi_{t} \notin\left\{0, \pi^{D}\right\}$ that are off-the-path of play Bayes' Law does not apply. These actions have an a priori probability of zero; therefore a posteriori beliefs cannot be formed in $t+1$ and the choice of them is arbitrary.
} 
as all relevant information needed by the players to compute their optimal decisions in equilibrium is contained in $\theta_{t}$.

\subsubsection{Incentives of the government}

Since the private sector is unsure of the true identity of government, the weak government has an incentive to conceal its identity for some time by imitating a strong government (i.e. by playing low inflation). From [5.9] it can be seen that $\pi_{s}^{D}=0$ the $s$-type government therefore always chooses zero inflation in every period, irrespective of private beliefs (discretionary and commitment levels of inflation are equivalent). In this setting only the $w$-type government carries a strategic role since for him the output-inflation tradeoff holds (because $b_{w}>0$ ) meaning that he may be tempted to create inflationary surprises over time. We consider his incentive structure in the following. ${ }^{19}$

\subsubsection{Expected inflation}

If the weak type of government is to optimize single-period utility in [5.7] it has two options: it will either choose its short run inflation rate of $\pi_{t}=\pi^{D}$ with probability $\rho_{t} \equiv \operatorname{prob}\left(\pi_{t}=0 \mid T_{w}\right)$ or else play the preferred strategy of the strong government (the so-called wolf in lamb's clothes option) by choosing $\pi_{t}=0$ with probability $1-\rho_{t}{ }^{20}$ The reason the $T_{w}$-government may be inclined to choose an action that is suboptimal in $t$, namely $\pi_{t}=0$ is because it can derive a positive utility in the following period for behaving like a strong government. It is therefore assumed that the weak policymaker possesses a certain amount of current (i.e. period-t) reputation, as summarized by $\theta_{t}$. Accordingly, the expected inflation $\pi_{t}^{e}$ is the joint expected value of zero inflation, $\operatorname{prob}\left(\pi_{t}=0\right)=\theta_{t}+\left(1-\theta_{t}\right) \rho_{t}$, and discretionary inflation, $\operatorname{prob}\left(\pi_{t}=\pi^{D}\right)=\left(1-\theta_{t}\right)\left(1-\rho_{t}\right)$, so that

$$
\begin{aligned}
\pi_{t}^{e} & =\operatorname{prob}\left(\pi_{t}=0\right) \cdot 0+\operatorname{prob}\left(\pi_{t}=\pi^{D}\right) \cdot \pi^{D} \\
& =\left(1-\theta_{t}\right)\left(1-\rho_{t}\right) \pi^{D}
\end{aligned}
$$

\footnotetext{
${ }^{19}$ The assumption that $b_{s}=0$ will be relaxed in Section (7). It can be shown then that the strong government can undertake a strategic role by choosing a level of inflation lower than initially expected by the private sector (i.e. lower than 5.9). VICKERS (1986) elaborates on the monetary policy situation in detail.

${ }^{20}$ For the sake of clarity, the index for the weak government will be removed so that $\pi_{w}^{D} \equiv \pi^{D}$.
} 
is the best forecast of period-t's inflation rate, given $\rho_{t}$ and $\theta_{t}$. Combined with [5.17], the government's single period utility in [5.7] can be rewritten as

$$
U_{t}^{G}=-\frac{1}{2} a \pi_{t}^{2}+b_{w}\left[\alpha\{\pi_{t}-\underbrace{\left(1-\theta_{t}\right)\left(1-\rho_{t}\right) \pi^{D}}_{\pi_{t}^{e}}\}-\Delta\right]
$$

with $\frac{d U_{t}^{G}}{d \theta_{t}}>0$. Equation [5.18] illustrates that government utility is an increasing function of $\theta_{t}$. This is the source of government reputational incentives: its motivation for playing low inflation is to hold down subsequent inflationary expectations $\pi_{t}^{e}$, which in turn helps improve future utility.

Consider the situation the weak government faces in the last period $\tau$. Since it can no longer profit from its reputation, the weak government has no incentive to keep inflation low, so it will select its discretionary level of inflation, $\pi_{\tau}=\pi^{D}$. The private sector knows about these incentives for the last period and sets $\rho_{t}=0$. Expected inflation in period $\tau$ from [5.17] is thus

$$
\pi_{\tau}^{e}=\left(1-\theta_{\tau}\right) \pi^{D}
$$

Economic stimulation in excess of the natural rate (from [4.1]) due to unexpected inflation in the last period $\tau$ can be computed as

$$
\begin{aligned}
\alpha\left(\pi_{\tau}-\pi_{\tau}^{e}\right) & =\alpha\left(\pi^{D}-\left(1-\theta_{\tau}\right) \pi^{D}\right) \\
& =\frac{\alpha^{2} b_{w}}{a} \theta_{\tau}>0
\end{aligned}
$$

The weak government's period- $\tau$ utility is

$$
\begin{aligned}
U_{\tau}^{G} & =-\frac{1}{2} a\left(\pi^{D}\right)^{2}+b_{w}\left[\alpha \pi^{D} \theta_{\tau}-\Delta\right] \\
& =\frac{\alpha^{2} b_{w}^{2}}{a}\left[\theta_{\tau}-\frac{1}{2}\right]-b_{w} \Delta
\end{aligned}
$$

\subsubsection{Current disutility of reputation}

In the current period $(\tau-1)$ the weak government faces an intertemporal trade-off. It must weigh the short-term output awards of unexpected inflation in [5.20] against the long-run impact of losing its reputation in the final period $\tau$. Since the weak government does not choose $\pi_{\tau-1}=0$ with certainty, expected inflation in period $\tau-1$ is

$$
\pi_{\tau-1}^{e}=\left(1-\theta_{\tau-1}\right)\left(1-\rho_{\tau-1}\right) \pi^{D}
$$


from equation [5.17]. If the government mimicks the strong government with $\pi_{\tau-1}=0$ and $0<\rho_{\tau-1}<1$, its one-period expected utility $U_{\tau-1}^{G}$ is

$$
\begin{aligned}
U_{\tau-1}^{G}\left(\pi_{\tau-1}=0\right) & =-\frac{1}{2} a(0)^{2}+b_{w}\left[\alpha\left\{0-\left(1-\theta_{\tau-1}\right)\left(1-\rho_{\tau-1}\right) \pi^{D}-\Delta\right]\right. \\
& =-\frac{\alpha^{2} b_{w}^{2}}{a}\left(1-\theta_{\tau-1}\right)\left(1-\rho_{\tau-1}\right)-\Delta b_{w}<0
\end{aligned}
$$

The above equation represents the current disutility the weak (mimicking) government must incur to gain reputation in the following period (hence the negative sign in [5.23]). On the other hand, a weak government's current utility for revealing itself $\left(\pi_{\tau-1}=\pi^{D}\right)$, and securing the short-term benefits of surprise inflation can be computed as

$$
\begin{aligned}
U_{\tau-1}^{G}\left(\pi_{\tau-1}=\pi^{D}\right) & =-\frac{1}{2} a\left(\pi^{D}\right)^{2}+b_{w}\left[\alpha\left\{\pi^{D}-\left(1-\theta_{\tau-1}\right)\left(1-\rho_{\tau-1}\right) \pi^{D}-\Delta\right]\right. \\
& =\frac{\alpha^{2} b_{w}^{2}}{a}\left[\frac{1}{2}-\left(1-\theta_{\tau-1}\right)\left(1-\rho_{\tau-1}\right)\right]-\Delta b_{w}
\end{aligned}
$$

The net current loss of the weak government for choosing to mimic the strong government (and thus uphold reputation in $\tau$ ) is the difference between [5.23] and [5.24]:

$$
U_{\tau-1}^{G}\left(\pi_{\tau-1}=0\right)-U_{\tau-1}^{G}\left(\pi_{\tau-1}=\pi^{D}\right)=-\frac{\alpha^{2} b_{w}^{2}}{2 a}<0
$$

\subsubsection{Future benefit of reputation}

The costs of low inflation in the current period are only accepted in order to enhance one's reputation for low inflation in the following period. The weak government must balance the current loss in [5.25] for a policy of zero inflation in $\tau-1$ with the future benefit of entering period $\tau$ with reputation intact. The weak policymaker sets $\pi_{\tau-1}=0$ with a probability of $\rho_{\tau-1}$, which generates an increase in reputation $\theta_{\tau}$ in the following period $\tau$ according to Bayes' rule (see [5.16]),

$$
\theta_{\tau}=\frac{\theta_{\tau-1}}{\theta_{\tau-1}+\left(1-\theta_{\tau-1}\right) \rho_{\tau-1}}>\theta_{\tau-1}
$$

The expected present utility of the weak government with positive reputation in $\tau-1$ is computed by discounting future utility $U_{\tau}^{G}$ from [5.21] with $\delta \equiv(1+r)^{-\tau}$,

$$
U_{\tau}^{G}\left(\theta_{\tau}>0\right)=\delta\left[-\frac{1}{2} a\left(\pi^{D}\right)^{2}+b_{w} \alpha\left(\pi^{D}\right)^{2}-b_{w} \alpha \pi_{\tau}^{e}-b_{w} \Delta\right]
$$


Since $\rho_{\tau}=0$, expectations for $\tau$ are $\pi_{\tau}^{e}=\left(1-\theta_{\tau}\right) \pi^{D}$, so that the above equation can be rewritten as

$$
\delta U_{\tau}^{G}\left(\theta_{\tau}>0\right)=\delta \frac{\alpha^{2} b_{w}^{2}}{a}\left[\theta_{\tau}-\frac{1}{2}\right]-\delta b_{w} \Delta
$$

When, alternatively, the private agents observe the government choosing short-run optimal inflation, $\pi^{D}$ in $\tau-1$, they revise their beliefs accordingly and reputation is completely destroyed for the final period $\tau$ so that $\theta_{\tau}=0$. Therefore, future disutility of having no reputation in the final period is computed with [5.21] as

$$
\delta U_{\tau}^{G}\left(\theta_{\tau}=0\right)=-\delta \frac{\alpha^{2} b_{w}^{2}}{2 a}-\delta b_{w} \Delta
$$

Thus the discounted net future benefit of entering period $\tau$ with a positive reputation $\theta_{\tau}$ is the difference between [5.28] and [5.30],

$$
\delta U_{\tau}^{G}\left(\theta_{\tau}>0\right)-\delta U_{\tau}^{G}\left(\theta_{\tau}=0\right)=\delta \theta_{\tau} \frac{\alpha^{2} b_{w}^{2}}{a}>0
$$

From the equation above we can see that

$$
\frac{\partial\left(\delta \theta_{\tau} \frac{\alpha^{2} b_{w}^{2}}{a}\right)}{\partial \theta_{\tau}}>0
$$

i.e., net future benefit of reputation increases in $\theta_{\tau}$ : the greater the accumulated reputation up to $\theta_{\tau-1}$, the greater the discounted benefit in $\tau$ that the weak government can reap for playing low inflation.

\subsubsection{Indifference curve}

The tradeoff between the current loss of investing in reputation and the future benefits can be visualized by computing an indifference curve for various values of $\theta_{\tau}$ and $\pi_{\tau-1}$. The indifference curve can be written in functional form as

$$
\theta_{\tau}\left(\pi_{\tau-1}\right)=\frac{\left(\pi_{\tau-1}-\pi^{D}\right)^{2}}{2 \delta\left(\pi^{D}\right)^{2}}
$$

(see Appendix (A.4) for derivation) where the slope of the indifference curve can be calculated as

$$
\left.\frac{\partial \theta_{\tau}}{\partial \pi_{\tau-1}}\right|_{\pi_{\tau-1}^{e}}=\frac{1}{\delta}\left(\frac{\pi_{\tau-1}-\pi^{D}}{\left(\pi^{D}\right)^{2}}\right)
$$


Fig. 5.2: INDIFFERENCE CURVE

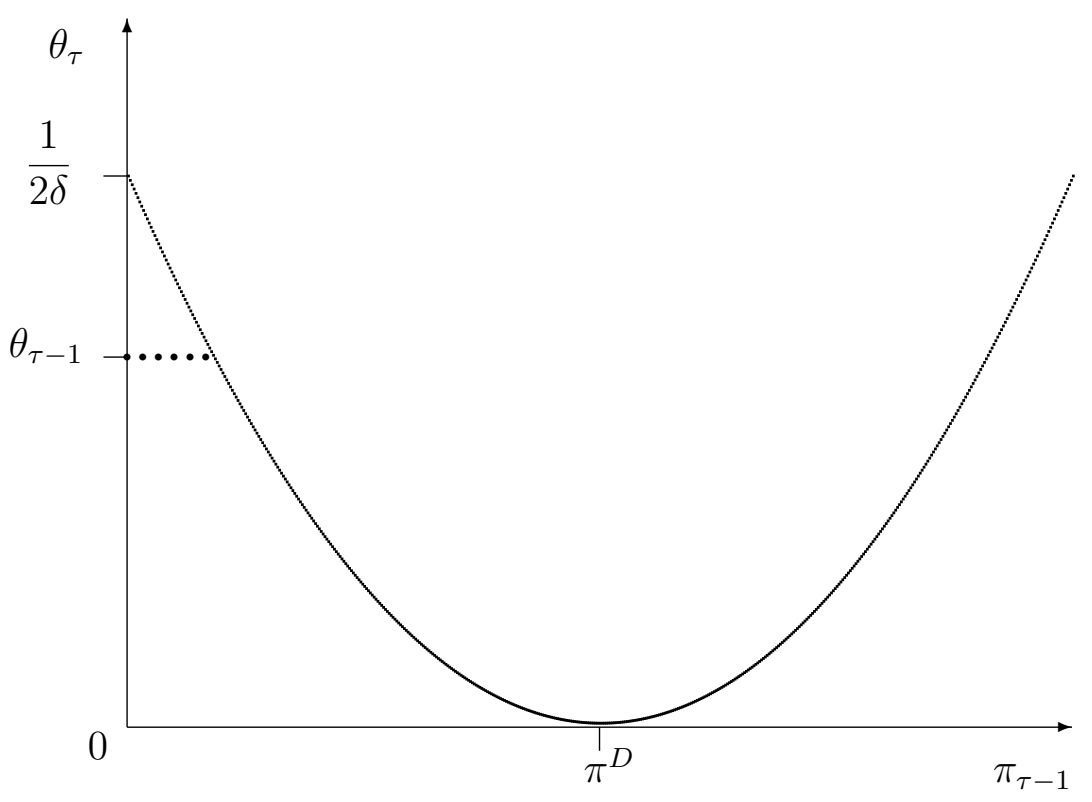

The curve depicted in Figure 5.2 shows combinations of inflation and reputation that deliver the same amount of (expected) intertemporal utility to the weak government. Notice that reputation reaches its minimum when the government chooses its discretionary policy $\pi^{D}$ : since playing the discretionary policy destroys reputation completely, any combination of $\left(\theta_{\tau}, \pi_{\tau-1}\right)$ with $\pi_{\tau-1} \neq \pi^{D}$ is accompanied by a higher utility for the government. The marginal benefit of an additional increment of surprise inflation is increasing in $\pi_{\tau-1}$ to the left of $\pi^{D}$ (due to the negative slope of the indifference curve) and decreasing to the left. The indifference curve is flat for $\pi_{\tau-1}=\pi^{D}$ since the marginal gain of higher unexpected is then zero. The prior probability that the government is strong $\theta_{\tau-1}$ lies somewhere between 0 and the maximum amount of reputation to be achieved between period $\tau-1$ and $\tau$. This maximum value is $1 / 2 \delta$ and corresponds to an inflation rate of $\pi_{\tau-1}=0$ (where the indifference curve intersects the vertical axis).

\subsubsection{Equilibrium policy}

By combining the terms for the current loss and future gains of reputation it is possible to calculate the net present expected utility $V_{\tau-1}$ of a weak 
government for choosing a policy of low inflation. This overall measure of utility equals current (dis)utility in period $\tau-1$ (from 5.25) plus the present discoutned value of utility in $\tau$ computed at $\tau-1$ (from 5.30),

$$
\begin{aligned}
V_{\tau-1}=U_{\tau-1}^{G}\left(\pi_{\tau-1}=\pi^{D}\right)-U_{\tau-1}^{G}\left(\pi_{\tau-1}=0\right) & +\delta U_{\tau}^{G}\left(\theta_{\tau}>0\right)-\delta U_{\tau}^{G}\left(\theta_{\tau}=0\right) \\
& =\frac{\alpha^{2} b_{w}^{2}}{a}\left[\delta \theta_{\tau}-\frac{1}{2}\right]
\end{aligned}
$$

The government has a certain amount of current reputation, as summarized by the value of $\theta_{\tau-1}$, if it has not inflated up to $\tau-1 .^{21}$ Note that the sign of $V_{\tau-1}$ depends solely on the term inside the brackets, $\delta \theta_{\tau}-\frac{1}{2}$. Thus the government's discount rate, $\delta$, and reputation $\theta_{\tau}$ determine the sign of $V_{\tau-1}$ in the following way:

$$
V_{\tau-1}\left\{\begin{array}{llll}
>0 & \text { if } & \theta_{\tau}>\frac{1}{2 \delta} \\
=0 & \text { if } & \theta_{\tau}=\frac{1}{2 \delta} \\
<0 & \text { if } & \theta_{\tau}<\frac{1}{2 \delta}
\end{array}\right.
$$

The sign of $V_{\tau-1}$ is linked with the weak government's incentives to mimick or not. Positive values of $V_{\tau-1}$ would induce the weak government to abstain from surprise inflation since then the future (discounted) benefit of reputation outweighs the short-term costs of low inflation. For negative values of $V_{\tau-1}$, on the other hand, the weak government lacks the long-term incentive to "invest" in reputation and plays high inflation in both periods. When $V_{\tau-1}=$ 0 , the government is indifferent between investing in reputation and choosing the short-term strategy of high inflation. Thus depending on the parameter values of $\theta_{\tau}$ and the discount factor $\delta$ in [5.36] which are common knowledge to the public, the game will possess alternative outcomes, which we can interpret as intertemporal equilibria of the game.

${ }^{21}$ Rearranging the terms in [5.34] yields

$$
U_{\tau-1}^{G}\left(\pi_{\tau-1}=0\right)-U_{\tau-1}^{G}\left(\pi_{\tau-1}=\pi^{D}\right)=\delta U_{\tau}^{G}\left(\theta_{\tau}=0\right)-\delta U_{\tau}^{G}\left(\theta_{\tau}>0\right)
$$

Given this formulation, BARro AND Gordon (1983a, p. 107) interpret the LHS as the 'temptation to cheat', i.e., the gain from an unexpected deviation from $\pi_{t}=0$. The RHS of the equation is the 'enforcement power', which motivates the weak government to maintain a low-inflation reputation in the current period by choosing $\pi_{\tau-1}=0$. 


\subsubsection{Unique separating equilibrium}

The net discounted utility for reputation is negative for parameter values of $\delta<\frac{1}{2 \theta_{\tau}}$. Since the reputational variable $\theta_{\tau}$ is defined in the region $0 \leq$ $\theta_{\tau} \leq 1$, the inequality condition above holds only for values of $\delta<0.5$. Thus for a discount factor less the 0.5 (or alternatively speaking, a discount rate $r>2 / 3$ ) the short-run benefits of surprise inflation will prevail over any reputation-building incentives.

The $T_{w}$-government chooses $\pi_{\tau-1}=\pi^{D}$ with certainty so that $\rho_{\tau-1}=0$. The weak government therefore chooses $\pi^{D}$ from the start of the game and inflation comes unexpected (since $\pi^{e}=\left(1-\rho_{\tau-1}\right) \pi^{D}<\pi^{D}$ ) from 5.17. But the public knows with certainty that it is facing a weak government, so in the second and all following periods adjusts expectations accordingly. The strong government can successfully reveal its type in this equilibrium by selecting $\pi_{\tau-1}=0$. The equilibrium is unique in the sense that there can be only one set of strategies chosen at every point of time in the two-period interval $t=\{\tau-1, \tau\}$, as long as the discount factor remains constant,

$$
\begin{array}{llll}
T_{s}: & \pi_{\tau-1}^{s}=0 & \text { and } & \pi_{\tau}^{s}=0 \\
T_{w}: & \pi_{\tau-1}^{w}=\frac{\alpha b}{a} & \text { and } & \pi_{\tau}^{w}=\frac{\alpha b}{a}
\end{array}
$$

A exceptional feature of this equilibrium is that its existence does not depend on any subjective beliefs of the private sector. The future is discounted so heavily that any long-term considerations are dominated by the ultimate short-term goal of deriving an output boost in the first period.

\subsubsection{Pooling equilibrium}

For values of $\delta>0.5$ the future does matter to the weak government. The decision whether to play $\pi_{\tau}=0$ for the benefit of reputation in $\tau-1$ depends on the initial prior reputation in $\tau-1$. From [5.36] prior reputation must suffice the condition $\theta_{\tau}>\frac{1}{2 \delta}$ in the final period $\tau$. If the weak government chooses $\pi_{\tau-1}=0$ then observed policy does not convey any information about the identity of the government, so reputation remains unchanged, $\theta_{\tau-1}=\theta_{\tau}$. Therefore, the reputational incentives are large enough for the government to resist the temptation to inflate in period $\tau-1$ when $\theta_{\tau-1}=\theta_{\tau}>\frac{1}{2 \delta}$. In period $\tau$, of course, the weak government has no strategic incentive to invest 
in reputation, so that he chooses his preferred strategy $\pi^{D}$. For initial values of $\theta_{\tau-1}>\frac{1}{2 \delta}$, an equilibrium exists in $t=\{\tau-1, \tau\}$ such that

$$
\begin{array}{llll}
T_{s}: & \pi_{\tau-1}^{s}=0 & \text { and } & \pi_{\tau}^{s}=0 \\
T_{w}: & \pi_{\tau-1}^{w}=0 & \text { and } & \pi_{\tau}^{w}=\frac{\alpha b}{a}
\end{array}
$$

This solution illustrates the fact that a sufficient amount of reputation can sustain a policy of low inflation in the long-run. This is more likely to happen the higher a government's reputation is when it enters office at the start of the game (the larger is $\theta_{\tau-1}$ ) and the lower is its discount rate (the higher is $\delta)$.

\subsubsection{Reputation over a finite time horizon}

The analysis is now generalized for more than two periods. This involves deriving a time path for $\theta_{t}$ over a discrete time interval $\{t=0 \ldots \tau\}$. Recall that inflationary expectations of the private sector in $t$ are from Eq. [5.17],

$$
\pi_{t}^{e}=\left(1-\theta_{t}\right)\left(1-\rho_{t}\right) \pi^{D}
$$

The condition for choosing a low inflation policy in $t-1$ for increased reputation in $t$ can be computed from [5.36] as

$$
\delta\left(\frac{b_{w}^{2} \alpha^{2}}{a}-b_{w} \alpha \pi^{e}\right)-\frac{b_{w} \alpha^{2}}{2 a} \geq 0
$$

where $\tau$ has been replaced by $t \in\{0 \ldots \tau\}$ and the general form of Eq. [5.27] has been used. When the equality sign holds in the condition above the weak type of government is indifferent between a policy of zero-inflation and inflation. It therefore randomizes its choice of $\pi_{t-1}$ setting $\pi_{t-1}=0$ with probability $\rho_{t-1}$ and $\pi_{t-1}=\pi^{D}$ with probability $\left(1-\rho_{t-1}\right)$. Therefore, the $w$-government is indifferent when private sector expectations are

$$
\pi_{t}^{e}=\frac{b_{w} \alpha}{a}\left(1-\frac{1}{2 \delta}\right)
$$

Together with Eq. [5.41] the weak government in $t$ evaluates the following condition

$$
\left(1-\theta_{t}\left(\theta_{t-1}\right)\right)\left(1-\rho_{t}\left(\theta_{t-1}\right)\right)=\left(1-\frac{1}{2 \delta}\right)
$$


where both the probability that the government is strong, $\theta_{t}$, and the probability that a weak government masquerades as a strong government, $\rho_{t}$, are defined as functions of $\theta_{t-1} \cdot \theta_{t}\left(\theta_{t-1}\right)$ is updated according to the Bayesian formula in [5.16]. Since the RHS of Eq. [5.44] is a constant, the equilibrium probability $\rho_{t}\left(\theta_{t-1}\right)$ must fall as the weak government builds reputation by following a low inflation policy,

$$
\frac{\mathrm{d} \rho_{t}\left(\theta_{t-1}\right)}{\mathrm{d} \theta_{t}\left(\theta_{t-1}\right)}<0
$$

The relationship in [5.44] defines a first-order difference equation for $\tau^{R} \leq$ $t \leq \tau-1$, where $\tau^{R}$ is the starting point for the randomization period. The solution for [5.44] yields a time path for $\theta_{t}$ and $\rho_{t}$ in which the weak government randomizes such that expectations remain constant in this phase. ${ }^{22}$ Together with the terminal condition $\rho_{\tau}=0$, the time paths for $\theta_{t}$ and $\rho_{t}$ are

$$
\begin{aligned}
\theta_{t} & =\left(\frac{1}{2 \delta}\right)^{\tau+1-t} \\
\rho_{t} & =\frac{\frac{1}{2 \delta}-\theta_{t}}{1-\theta_{t}}=\frac{\frac{1}{2 \delta}-\left(\frac{1}{2 \delta}\right)^{\tau+1-t}}{1-\left(\frac{1}{2 \delta}\right)^{\tau+1-t}}
\end{aligned}
$$

With [5.41], private sector expectations are constant during the randomization period,

$$
\pi_{t}^{e}\left(\theta_{t}, \rho_{t}\right)=1-\frac{1}{2 \delta}
$$

To compute $\tau^{R}$ note that in the interval $0 \leq t \leq \tau^{R}$ the weak government sets $\pi_{t}=0$ with certainty $\left(\rho_{t}=1\right)$ and there is no update of beliefs, $\theta_{0}=\theta_{t}$ since the private sector cannot differentiate between governments. Randomization thus occurs in period $t+1$ with $\rho_{t}=1$ when

$$
\theta_{0}<\theta_{t}<\left(\frac{1}{2 \delta}\right)^{\tau+1-t}
$$

The solution for $\tau^{R}$ is the largest integer for which this inequality holds,

$$
\tau^{R}=\inf \left[t \quad \mid \quad \theta_{0}<\left(\frac{1}{2 \delta}\right)^{t+1}\right]
$$

\footnotetext{
${ }^{22}$ The weak government never randomizes in the final period $\tau$, but plays $\pi^{D}$ with certainty $\left(\rho_{\tau}=0\right)$.
} 
At date $\tau^{R}, \theta_{\tau^{R}}=\theta_{0}$ and $\rho_{\tau}$ satisfies Eq. [5.47].

Summarizing, the equilibrium time path can be characterized as follows. Reputation develops according to

$$
\begin{gathered}
\theta_{t}= \begin{cases}\theta_{0} & \text { for } t \leq \tau-\tau^{R} \quad \text { if } \quad \pi_{s}=\pi_{s-1} \quad \forall s \leq t-1 \\
\left(\frac{1}{2 \delta}\right)^{\tau+1-t} & \text { for } t>\tau-\tau^{R} \quad \text { if } \quad \pi_{s}=\pi_{s-1} \quad \forall s \leq t-1 \quad \\
0 & \text { otherwise }\end{cases} \\
\rho_{t}= \begin{cases}\theta_{0} & \text { for } t<\tau-\tau^{R} \quad \text { if } \quad \pi_{s}=\pi_{s-1} \quad \forall s \leq t-1 \\
\frac{1}{2 \delta}-\theta_{t} & \text { for } \tau-\tau^{R} \leq t<\tau^{R} \quad \text { if } \quad \pi_{s}=\pi_{s-1} \quad \forall s \leq t-1 \\
0 & \text { otherwise }\end{cases}
\end{gathered}
$$

The private sector follows the same strategy independently of what type of government it faces. Under rational expectations private agents expect a discretionary rate of inflation $\pi^{D}$ with probability $\left(1-\theta_{t}\right)\left(1-\rho_{t}\right)$, the product of the probability that the government is $T_{s}$ and the probability that the weak government devalues at $t$.

According to Eqs. [5.51] and [5.52], a weak government's monetary stabilization program may go through three distinct phases. If $\tau^{R}>0$, then for a duration of $\tau-\tau^{R}$ (computed from [5.50]), a weak government is sure to imitate a $T_{s}$ government. During this phase, the incentive to invest in reputation is strong enough that the weak government abstains from inflating with certainty. Expected inflation is therefore $\pi_{t}^{e}=0$. Following this, there is a period in which the weak government is indifferent between revealing its type and mimicking a strong government. It therefore randomizes its strategy during this period so that expected inflation is the probability weighted average

$$
\pi_{t}^{e}=\left(1-\rho_{t}\right) \pi^{D}+\rho_{t} \cdot 0=\left(1-\rho_{t}\right) \pi^{D}>0
$$

The incentive to mimic a strong government decreases over time as the game approaches $\tau^{R}$. Eventually there is a point where the short-run gains from inflating more than compensate the subsequent costs of losing reputation so the government may reveal itself in some period prior to $\tau$. 


\section{Part II}

\section{EXCHANGE-RATE-BASED STABILIZATION POLICY}




\section{INTRODUCTION}

The use of the exchange rate to achieve economic goals has, historically speaking, not always been met with success. An infamous precedent was the final collapse of the Bretton Woods agreement, in which industrial nations finally abandoned their efforts to sustain a fixed exchange rate system. In the aftermath of Bretton Woods and in congruence with the prevailing economic ideology of the times, many developing countries that adopted more flexible exchange rate regimes during the 1980's found their efforts to attain macroeconomic stability thwarted by the debt crisis of 1982. For many, exchange rate flexibility became another name for chronic inflation. Even for members of the IMF Executive board, enthusiasm for an active exchange rate policy "went too far"; according to their view exchange rates should move towards more rigidity as a way to introduce financial discipline and provide a nominal anchor. ${ }^{23}$ It is no wonder then that the tides again have turned in favor of using the exchange rate as an instrument to attain macroeconomic stability. ${ }^{24}$. Responding in part to the failure of monetary (orthodox) stabilization, disinflation policies that include an exchange-rate-based stabilization have been widely used in the developing economies (especially in Latin America) to combat chronic inflation.

The main component of an ERBS is the announcement of a reduction or freeze in the rate of devaluation aimed at curbing inflationary pressures, whether these originate in excessive budget deficits or in the wage and pricesetting behavior of the private sector. Specifically, an ERBS tackles the

\footnotetext{
23 See Sebastian EdWARds, 1995, p. 2.

24 The rather nostalgic appeal for using a fixed exchange rate as a way to maintain price stability originates in the pre-World War II period from its undeniably decisive role in bringing hyperinflation under control (by restoring convertibility of the domestic currency to the dollar or equivalently to gold). Historical examples in Austria (1924), Germany (1924), Poland (1924), Greece (1946) and others make a case for fixing the exchange rate to a nominal anchor. THOMAS SARGENT (1986), third chapter, offers an extensive and insightful discussion of the role of the gold standard in hyperinflation of the 20's.
} 
problem of inflation by using the exchange rate as the main nominal anchor, where an inflation-prone country (unilaterally) pegs the exchange rate of its currency to the currency of another country that has a tradition of low inflation. ${ }^{25}$ The basic argument is that by importing the anti-inflationary regime of stable countries through an exchange rate peg, price-setters in the goods, labor and foreign exchange market adjust their inflationary expectations to the rate of inflation prevailing in that of the anchor country.

Governments that use the exchange rate in discretionary fashion to ease their external position tend to abuse this instrument, thus introducing an inflationary bias into the economy. One major rationale for resorting to a fixed exchange rate regime is the belief that the mere announcement of an ERBS program will help to reduce inflationary expectations, thus raising the probability of the program's success. The adoption of a predetermined exchange rate anchor thus serves as a commitment technology and, given a disreputable history of failed stabilization attempts, represents a fundamental change in the exchange rate regime of the government. Given a suitable institutional framework the introduction of a fixed exchange rate acts as a constraint in the government's ability to surprise the private sector through an unanticipated devaluation. The caveat is that a fixed exchange rate rule is basically a commitment to carry out a given monetary policy and subsequently domestic policymakers completely forgo the use of monetary policy for stabilization purposes. ${ }^{26}$

An historical example of an ERBS are the orthodox stabilization ${ }^{27}$ efforts of Argentina and Chile in the late 70s. The cornerstone of stabilization was a preannounced exchange rate against the US-dollar, the so-called tablita, with a decreasing rate of devaluation that was below the ongoing rate of inflation. If everything had gone according to plan, the inflation rate should

\footnotetext{
${ }^{25}$ Some ERBS programs have alternatively relied on less stringent exchange rate schemes than a fixed parity. For example some countries implemented a rule-based crawling peg system with a low rate of depreciation (e.g. Mexico 1987), or a preannounced gradual reduction in the rate of devaluation.

${ }^{26}$ This assumes, of course, the existence of an open capital market. Then it holds that "a country cannot simultaneously maintain fixed exchange rates and an open capital market while pursuing a monetary policy oriented toward domestic goals." (OBSTFELD, M. (1998), p. 14-15.).

${ }^{27}$ Labeled as "orthodox" to distinguish stabilization programs from "heterodox" programs that additionally rely on price or wage controls to cushion the effects on the economy.
} 
have converged quite rapidly to the world inflation rate plus the preset rate of devaluation. In fact, Argentina's program succeeded in dampening inflation, but contrary to what the architects had expected, the speed of convergence of the inflation rate to the preannounced rate of devaluation proved to be very slow. The ensuing real appreciation of the currency had the less desirable effect of deteriorating the current account balance, "reaching a deficit of around 3\% of GDP in 1979 and 1980." 28 The severe imbalance in the external account fueled expectations of a devaluation and the program was eventually abandoned in 1981. The same pattern of asynchronous inflation and devaluation rate, deteriorating current account and subsequent default were to be observed in the Chile. The real appreciation of the Chilean peso (over $30 \%$ with respect to $1975^{29}$ ) led to a dramatic deterioration in the external position, with the current account deficit increasing to $14.5 \%$ of GDP in $1981 .^{30}$ The record on inflation front shows that during the initial phase the Chilean experience was no better than Argentina was in reducing inflation to tolerable levels. ${ }^{31}$ As the external environment became hostile (due to the debt crisis, the fall in copper prices, capital flight and a gaping balance of payments deficit) the government was forced to renege on its exchange rate commitment and devalued the currency in 1982.

A similar pattern emerges when observing the more recent historical record on the use of managed exchange rate policies in Table 5.6. In most cases the trade balance deteriorated to a considerable degree in the year following the announcement of the exchange rate regime, the sole exception being Israel's program of 1985, which also had the unique property among the selected programs of being quite effective in bringing down inflation. Neither the Argentine Austral Plan of 1985, nor the Brazilian Cruzado Plan of 1986 succeeded in achieving a lasting stabilization. In Brazil, a deteriorating external position and large fiscal deficits led to unsustainable imbalances that finally undermined the stabilization attempt. ${ }^{32}$.

\footnotetext{
28 Kiguel And Liviatan (1994), p. 10.

29 Ibid., p. 12.

30 Carlos A. VÉGH (1992), p. 649. According to this source, the huge current account deficits were largely financed by large capital inflows.

31 To be fair, the Chilean program did eventually bring inflation down to international levels, but "this took five years, with the decisive period (of pegging the exchange rate) lasting two years" (KIGUEL AND LiviATAN (1994), p. 12).

32 As AGÉNOR AND TAYLOR (1992) note, "The balance of payments deteriorated sharply as a result of the trade deficit and also because of widespread speculation that corrective
} 
Argentina's more recent ERBS program, initiated in 1990 is still up and running, even despite the aftershocks of the so-called 'tequila effect' and the Asian crisis that followed. It qualifies as a prime example of successful disinflation using a fixed parity (fixed to the US-dollar in a currency board), bringing an end to almost four decades of high inflation. The achievement was markedly more successful than previous attempts with an ERBS. Mexico used a crawling target zone, where the (preannounced) rate of devaluation was deliberately set below the rate of ongoing inflation. Until the collapse of the peg in 1994, the program did quite well in reducing inflation to tolerable levels, albeit with the familiar side-effect of external imbalance.

Tab. 5.6: ERBS PROGRAMS IN PRACTICE

\begin{tabular}{|c|c|c|c|c|c|c|c|}
\hline \multicolumn{6}{|c|}{ Selected Exchange-rate-based stabilization programs 1985-1990 } \\
\hline Country & Date & \multicolumn{3}{|c|}{ Inflation } & \multicolumn{3}{|c|}{ Trade Balance } \\
& & $(-1)$ & $(0)$ & $(+1)$ & $(-1)$ & $(0)$ & $(+1)$ \\
\hline Argentina & $6 / 85$ & 1,189 & 50 & 110 & 1,462 & 1712 & 888 \\
\hline Argentina & $3 / 90$ & 20,274 & 287 & 18 & 1038 & 1935 & 1151 \\
\hline Brazil & $2 / 86$ & 289 & 52 & 481 & 2,021 & 2460 & 585 \\
\hline Israel & $1 / 85$ & 446 & 24 & 20 & -603 & -639 & -355 \\
\hline Mexico & $12 / 87$ & 159 & 52 & 20 & 1879 & 1770 & -456 \\
\hline
\end{tabular}

Source: Kamien, S. (1991) and International Financial Statistics, various issues. Inflation rates measure consumer inflation, month over year-earlier month. Trade balance is given in millions of US\$ for the quarter in which the program was initiated. (-1) refers to the 12 months prior to the program announcement, (0) refers to the year in which the announcement was made, and $(+1)$ refers to the following 12 months.

To summarize then, the empirical evidence suggests that the ERBS were generally more effective than previous "experiments" with money-based programs in combatting chronic inflation. But on closer inspection the stylized facts emerge that reductions in inflation were usually only gradual, with the inflation rate converging only sluggishly to the new parity, resp. rate of devaluation, resulting in a deterioration of the trade balance and current account. Also, once macroeconomic imbalances went out of control the authorities action would include a major devaluation of the domestic currency." (p. 560). 
were more than willing to renege on their previous commitment to the fixed exchange rate.

What went wrong? With modern macroeconomic views emphasizing expectations and institutional constraints, the ERBS approach has become closely linked with the issue of credibility. In this line of reasoning, one compelling explanation representative of many is that "the persistence of inflation was driven by lack of credibility about the ability or willingness of the authorities to adhere to the exchange rate rule in the event of adverse shocks" 33 A central feature of general idea that motivated these ERBS was that the mere proclamation of a realignment (such as with the tablitas) of exchange rates could suffice to deaccelerate inflation. As commentator observed, the program would be able to

... break inflationary expectations by announcing in advance an exchange rate path ... It was hoped that confidence in the reform would be built up month by month as the announced exchange rates we[re] (sic) successfully maintained, and that the increased confidence in the reform would provide an 'expectation bonus' in terms of reduced inflationary expectations and a consequent reduction in current inflation. ${ }^{34}$

The "announcement effect" (i.e. the immediate effects occurring when a change in policy is announced) can be as powerful as the implementation of policy itself. At the time that an ERBS is announced, however, the public has only the previous track record of the government on which to formulate its expectations of future policy. If the public is not persuaded by the proclamation to believe in the sustainability of an ERBS then the economy will not move quickly to a new equilibrium with lower price expectations. Consequently, the reduction in inflation will be lower than the reduction in the rate of devaluation so that there will be a real appreciation of the currency which undermines the competitiveness of the economy. If the parity is to be retained in such a situation there is no automatic mechanism to generate the real depreciation necessary to reduce the increasing current account deficit. The consequence will be to default on the ERBS. As the evidence quite strikingly illustrates, "The major flaw with fixed exchange rates is that credibility usually comes before - not after — policy making has been carried out." 35

\footnotetext{
33 See Kiguel and Liviatan (1994), p. 16.

${ }^{34}$ See BAXter, M. (1985), p. 344.

35 See Colombatto and Macey (1996), p. 197.
} 


\section{COMMITMENT VS. DISCRETION IN A STOCHASTIC MODEL}

Ultimately, the mere announcement of an ERBS program should suffice to exert a downward pressure on inflationary expectations, but this depends on whether the intentions of the government are aligned with the announcement. Very often we can observe that there is no institutional impediment to alter the exchange rate once it has been imposed, thus putting into question the credibility of the government's initial announcement. By implementing legislation that makes an ex post alteration of the parity costly for the government, the degree of commitment to an ERBS program can be significantly increased. Argentina's program of 1990, for example, strictly limited the authorities' discretion to alter the exchange rate regime once it was established. The executive's power was checked by a convertibility law that required congressional approval for any change in the parity. Furthermore, the currency board installed prohibited fiscal deficits to be financed by the central bank and even "legalized the use of the dollar as a unit of account and a means of exchange", further emphasizing the government's commitment to the nominal anchor. ${ }^{1}$

Another question involves the usage of the exchange rate in achieving real targets, such as when the current account has to be improved (so-called expenditure-switching). By sacrificing the discretionary use of the exchange rate in an ERBS regime the policy objective is reduced to the single target of maintaining a low inflation rate, in effect "tying the hands" of the government and stifling the real development of the economy. The exchange rate loses its favorable characteristic as an instrument for regaining macroeconomic equilibrium especially when random shocks are constantly a threat to the external balance. "[F]orgoing the use of the exchange rate instrument for the sake of the anti-inflation target is thus a cost... the cost of not being able

\footnotetext{
${ }^{1}$ See Rainer Schweickert (1993), p. 1 and Kiguel and Liviatan (1994), p. 24.
} 
to use the exchange rate to achieve a real target." 2 Although establishing effective institutional constraints may be viewed as the sine qua non for a successful ERBS program, an ERBS program is difficult to manage in small economies coping with external imbalances. For these countries maintaining a nominal anchor in the face of a mounting trade deficit is not a viable option. Thus although establishing credibility may be view as the major rationale behind an ERBS, maintaining a nominal anchor is often not a viable option for countries coping with large and persistent external imbalances.

The following formal analysis will address the role that a nominal exchange rate plays in a program of disinflation, both under the aspect of discretion and flexibility. The approach followed bears a striking resemblance to the the model of monetary policy in Section (4.2). The analysis is based on a theoretical framework which again employs the representative agent model of a government that is concerned about the distortionary effects of inflation, but also would like to avoid a deterioration in the trade balance. The model additionally includes a stochastic element to the game-theoretic discussion, to account for a worsening of the external environment which impinges negatively on the current account.

\subsection{Model structure}

The analytical framework is a simple macroeconomic model of a small open economy producing traded and non-traded goods. The economy's (log) nominal exchange rate (the price of foreign money in terms of domestic money) is determined by the government at the beginning of each period $t$. The government is concerned about the distortionary costs of inflation, $\pi_{t} \equiv p_{t}-p_{t-1}$ (where $p_{t}$ is the log of the domestic price level in period $t$ ). In addition, the government is concerned about actual deviations from its external balance target, $b^{*}-b_{t}$, where $b^{*}$ is the target current account balance and $b_{t}$ is the current account balance at time $t$. Stabilization of domestic prices can be achieved by establishing a nominal anchor, i.e. by fixing the domestic currency to the currency of another country that has a tradition of low inflation. But whereas a policy of price stabilization calls for a pegging of the nominal exchange rate, the ability of the government to reduce a current account imbalance lies in reducing the nominal exchange rate - this is where a potential

\footnotetext{
${ }^{2}$ See Corden, M. (1994), p. 80-81.
} 
conflict of interests may arise. Consequently, the policymaker's preferences entail a tradeoff between internal and external goals. ${ }^{3}$ This potential conflict of policy objectives (low inflation versus a balanced current account) is captured in a simple loss function $L_{t}$. Specifically, on any date $t$ a governmental loss function can be formulated as

$$
L_{t}\left(b_{t}, \pi_{t}\right)= \begin{cases}\left(b_{t}-b^{*}\right)^{2}+a \pi_{t}^{2}, & \text { if } b^{*}>b_{t} ; \\ a \pi_{t}^{2}, & \text { if } b^{*} \leq b_{t} .\end{cases}
$$

where the coefficient $a>0$ indicates the relative concern of the government for price stability versus the balance of payments. The loss function in [6.1] is assumed to correspond to a societal loss function. Once the desired current account target $b^{*}$ is reached $\left(b^{*} \leq b_{t}\right)$, the government becomes indifferent between alternative values of a balance of payments surplus. The aggregate loss $L_{t}$ depends exclusively upon the variability of inflation around the socially optimal level $\pi^{*}$, which is set to zero for convenience.

The level balance of payments around the exogenously given target $b^{*}$ (equivalent to the current account since there are no capital transfers) is determined according to the following function:

$$
b_{t}=b^{*}+\sqrt{\alpha}\left[\left(e_{t}-w_{t}+\pi_{t}^{*}\right)-u_{t}-k\right] \quad \text { with } \alpha \geq 0
$$

where $w_{t}$ and is the level of wages in the non-traded sector, $e_{t}$ is the nominal exchange rate and $\pi_{t}^{*}$ is the inflation rate for tradable goods (foreign inflation). $\pi_{t}^{*}$ is determined on the world market and thus exogenous to the model. The variable $k$ captures distortions to the economy that cause the balance of payments to systematically fall short of the target level. The model assumes that $k<1$. This assumption provides the rationale for the government to seek an improvement of the current account above the socially optimal level. $\alpha$ is a sensitivity term that relates the size of change of the real exchange rate to the change in the balance of payments. This could similarly be a measure of the speed of adjustment of the trade balance to the change in the real exchange rate. ${ }^{4}$

\footnotetext{
${ }^{3}$ Models that similarly examine the trade-off between external balance and stabilization can be found in AgÉnor (1994), Cukierman, A. M. (1992), p. 83-95, and Devarajan AND RODRIK (1991).

4 After a devaluation it is likely that the trade balance may deteriorate at first only to improve over the passage of time ( $J$-curve effect). However, empirical evidence suggests that the effects will be generally more rapid in smaller, more open economies such as the ones we are considering here, so that a "devaluation could be considered a successful policy for improving the trade balance of LDCs." See BAHmAni-OskooeE AND MALIXI (1992).
} 
Given the formulation in [6.2], deviations of the current account around its target level can be attributed to variations in the (log of the) real exchange rate $e_{t}-w_{t}+\pi_{t}^{*}$ and distortion $k$ as well as $u_{t}{ }^{5}$ The random shock $u_{t}$, is a random variable symmetrically distributed with mean 0 and variance $\sigma^{2}$ ( $u_{t}$ can be thought of as a shock to the distortion $k$ ). The presence of this random element in the maximization of societal welfare gives the government an incentive to counteract its negative influence by adjusting the exchange rate so as to offset the shock. But the use of the exchange rate in such compensatory manner is entirely consistent with private sector expectations.

Nominal wages in the non-traded goods sector, $w_{t}$, are assumed to be set by a representative (monopoly) trade union encompassing all workers in that sector. According to standard trade union models of wage formation, a union aims at a given real wage rate. For simplicity we assume that labor market equilibrium requires a constant $(\log )$ real wage of 0 . This means that, to attain this real wage target, nominal wages $w_{t}$ must grow at the same rate as the $(\log )$ domestic price of foreign goods $\left(e_{t}+\pi_{t}^{*}\right)$. Under rational expectations the trade union uses all available information at date $t-1$ to negotiate a wage

$$
w_{t}=E\left\{e_{t} \mid \Omega_{t-1}\right\}
$$

where information set $\Omega_{t-1}$ includes full and accurate data on the government's incentives, constraints and information as of $t-1 .^{6}$ Hence the trade

${ }^{5}$ Among alternative definitions of the real exchange rate $E$, the definition chosen here follows Dornbusch AND Helmers (1988), where a measure of the wage index (domestic cost) is used to deflate the domestic currency,

$$
E=\frac{\text { Price of tradables }}{\text { Domestic cost }}=\frac{E_{n} \cdot P^{*}}{W_{d}}
$$

$E_{n}$ is the nominal exchange rate and $P^{*}$ is the price level of foreign goods in foreign currency. The term $e_{t}-w_{t}+\pi_{t}^{*}$ used in Eq. [6.2] is the logarithm form. Note that if $\pi_{t}^{*}$ is set to zero, then the $(\log )$ real wage and $(\log )$ real exchange are identical within this model.

${ }^{6}$ See, e.g., Oswald (1985) on trade union models of wage formation. The wage bargaining behavior of the trade union can be rationalized by formulating a payoff function for the union,

$$
V_{t}=-\left[w_{t}-\left(e_{t}+\pi_{t}^{*}\right)\right]^{2}
$$

The expected utility maximizing strategy (first-order conditions) of the union results in [6.4], since certainty equivalence holds when the loss function is quadratic. Furthermore, the result rules out any indexing in wage settlements by assumption. 
union's decision is, basically, their unbiased prediction of the nominal exchange rate $e_{t}$.

Domestic inflation, $\pi_{t}$, is a geometric weighted average of the increases in the price level of traded goods (measured in domestic currency) and wage inflation in the non-traded goods sector,

$$
\pi_{t}=\mu\left(e_{t}-e_{t-1}+\pi_{t}^{*}-\pi_{t-1}^{*}\right)+(1-\mu)\left(w_{t}-w_{t-1}\right)
$$

where $\mu$ measures the degree of openness of the economy and $0<\mu<$ $1 .^{7}$ An increase in the nominal exchange rate is assumed to translate into greater domestic inflation, the greater the small country's involvement in international trade. For a country isolated from international transactions (perhaps through thus use of exchange controls) the nominal exchange rate will have less impact on inflation.

In selecting its optimal policy, the government chooses a devaluation rule, taking into account its preferences, the wage level chosen by the union as well as the random shock at the beginning of the period. Since the government's preferences are quadratic (see 6.1), the rule must be linear in the observed realization of $u_{t}$ and its functional form

$$
\epsilon\left(u_{t}, k\right)=\kappa_{s}+\kappa u_{t}
$$

minimizes the unconditional expectation $\mathrm{E} L_{t}$ subject to $e_{t}-e_{t-1}=\epsilon\left(u_{t}, k\right)$. The rule reflects the fact that the government observes $u_{t}$ before making the final decision on the exchange rate in period $t$. This information lead allows it to adjust the rate of devaluation by a proportion $\kappa$ of the random shock.

Fig. 6.1: Timing of The Stochastic Game

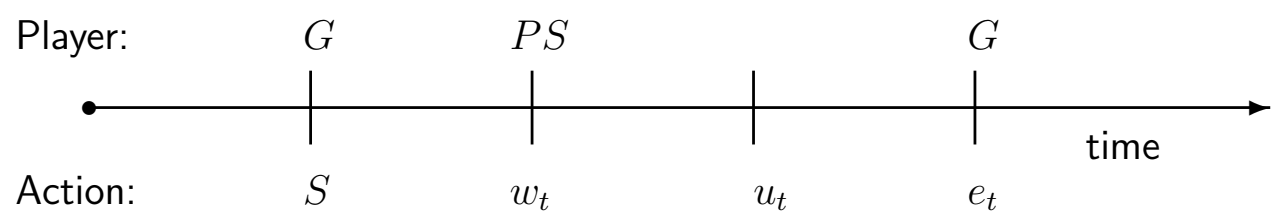

The policy game has the following timing. First, the policymaker makes an announcement, $S=(1,2)$ on its policy intentions. Subsequently, the

\footnotetext{
7 The expression in [6.5] is in log form and can be derived from the geometric weighted average of the domestic price level, $P=\left(E * P^{*}\right)^{\mu} W^{(1-\mu)}$.
} 
economy-wide nominal wage $w_{t}$, at which workers agree to supply labor for all the non-traded firms' demand, is determined in the labor market. This negotiated wage is made contingent on the announcement $S$ made by the government on its exchange rate course without actually observing the choice or the random shock. Finally, the policymaker observes the shock $u_{t}$ before making the final decision on the exchange rate $e_{t}$ at the beginning of period $t$. This informational lead allows it to adjust the exchange rate contingent on the actual realization of the shock. ${ }^{8}$ The timing is illustrated in graphical form in Figure (6.1), where $G$ and $P S$ are the government and private sector, respectively.

\subsection{Equilibrium policy under alternative regimes}

This section proceeds to derive the optimal choice of the coefficients $\kappa_{s}$ and $\kappa$ under four different settings of the policy environment. The distinguishing feature of the static equilibrium lies in the varying degree of institutional constraint that is placed upon the government's use of the nominal exchange rate as a policy instrument. For simplicity it has been assumed that real exchange rate (and thus the current account) is not influenced by world inflation, i.e. $\pi_{t}^{*}=0$.

\subsubsection{Semi-discretionary regime (C)}

First, consider the case in which there exists a commitment technology that somehow forces the government to reveal its private information truthfully, i.e., its announcement $S$ corresponds exactly with its exchange rate policy. This regime could be enforced, e.g., by having the policymaker commit to a choice of $\kappa_{S}$ ex ante, i.e., before nominal wages are set, and this choice is known to the union before signing wage contracts. In this way the government's policy choice simultaneously determines wage setter's expectations.

\footnotetext{
${ }^{8}$ Matthew CAnzonieri (1985), p. 1060 makes an important distinction in the information structure of stochastic games. Under symmetric information both the wage setters and the government are assumed to observe $u_{t}$ at the same time, though it is no longer possible for the wage setters to incorporate this information into the contract wage $w_{t}$. Under private information only the government can observe the value or has a correct forecast of $u_{t}$ at the beginning of the period. It is therefore not possible for the wage setters to decompose the values for $\kappa_{S}$ and $\bar{\kappa}$ in the exchange rate rule. The model presented here will assume that the former information structure exists.
} 
After realization of the shock $u_{t}$ the government optimizes by choosing a suitable $\kappa$ to offset the shock around the external target $b^{*}$. We will characterize this regime as semi-discretionary (C) because the government's discretion is limited to compensating the negative impact of $u_{t}$ in the aftermath of its realization - other than for this purpose, the government is tied to its commitment not to use the exchange rate in order to improve the current account above the socially optimal level. Any inflation that does arise is therefore not unexpected. Optimal devaluation $e_{t}-e_{t-1}$ can be derived as

$$
\epsilon_{t}\left(u_{t}\right)=\kappa_{s}+\kappa u_{t}=\lambda u_{t}-(1-\mu)\left(e_{t-1}-w_{t-1}\right)
$$

where $\lambda \equiv \alpha /\left(\alpha+a \mu^{2}\right)$. It follows that under this regime, the current account balance and the inflation rate are, respectively,

$$
\begin{aligned}
b_{t} & =b^{*}-\sqrt{\alpha}\left(u_{t}+k\right)+\sqrt{\alpha} \lambda u_{t} \\
\pi_{t} & =\mu \lambda u_{t}
\end{aligned}
$$

(see Appendix B.1 for details). We can characterize this equilibrium in the following way. Under the exchange rate policy rule given in [6.7], the authority reacts to the random shock $u_{t}>0$ in the balance of payments by devaluating the currency at a rate of $\kappa u_{t}=\lambda u_{t}$. The flexibility of the exchange rate at the outset of period $t$ allows a smoothing of the balance of payments in the face of an unanticipated shock by the positive amount $\sqrt{\alpha} \lambda u_{t}$. The rate of devaluation $e_{t}-e_{t-1}$ is inversely related to the level of the real exchange rate in the penultimate period $\left(e_{t-1}-w_{t-1}\right)$. Furthermore, an economy that is more susceptible from shocks to the balance of payments due to its openness (large $\mu$ ), has a higher rate of devaluation (on average).

Under regime $C$ there is an increase inflation, but mean inflation is zero $\left(\mathrm{E} \pi_{t}=0\right)$ since the government is bound in this regime to make no attempt to offset the predictable component $k$. The benefit of a semi-flexible government exchange rate policy is bought at the cost of causing some inflation, $\pi_{t}>0$. As the magnitude of inflation increases with the openness coefficient $\mu$, the government's zeal towards stabilizing the external balance is dampened. In a similar vein, a government that places considerable weight in its policy objectives on the reduction of inflation will be less prone to devalue the currency in this compensatory manner. Note that any inflation that arises in this equilibrium is fully unexpected by the public - the optimal rule is chosen so as to have zero expected devaluation in equilibrium, i.e. $\kappa_{s}=0$. 
The unconditional expected policy loss can be computed as

$$
\begin{aligned}
\mathrm{E} L_{t}^{C} & =\alpha \mathrm{E}\left\{(1-\lambda) u_{t}+k\right\}^{2} \\
& =\alpha(1-\lambda) \sigma_{u}^{2}+\alpha k^{2}
\end{aligned}
$$

where $\sigma_{u}^{2}$ is the variance of $u_{t}$.

\subsubsection{Fixed exchange rate regime $(F)$}

Under a fixed exchange rate regime $(F)$ the optimal rule would dictate an adherence to a fixed parity $e_{t}=e_{t-1}$, for all $t$. In this regime the government irrevocably fixes the exchange rate, so that it cannot react to the random shock $u_{t}$ (i.e. rule cannot be made contingent on $u_{t}$ ). The trade balance in this regime can be computed as

$$
\begin{aligned}
& b_{t}=b^{*}-\sqrt{\alpha}\left(u_{t}+k\right) \\
& \pi_{t}=0
\end{aligned}
$$

(see Appendix B.2). Comparing the current account under fixed exchange rates with the result in regime $C$, we can see that the trade deficit has been reduced by the term $\sqrt{\alpha} \lambda u_{t}>0$. This means that exchange rate semiflexibility of the exchange rate allows the current account to be less sensitive to fluctuations in the external environment. Adherence to the strict rule (F) results in an expected loss of

$$
\begin{aligned}
\mathrm{E} L_{t}^{F} & =\alpha E\left(u_{t}+k\right)^{2} \\
& =\alpha k^{2}+\alpha \sigma_{u}^{2}
\end{aligned}
$$

We can therefore also posit that by "tying its hands" to a rule of fixed exchange rates the government's stabilization policy becomes unambiguously suboptimal in welfare terms: by adhering to a fixed exchange rate it is unable to compensate a shock via expenditure switching and the current account must take the full brunt of the shock. If the current account is highly sensitive to random shocks then it is advisable to use a more flexible exchange rate regime.

\subsubsection{Discretionary regime (D)}

In this section the management of the exchange rate is left to the discretion of the government, i.e., the government does not (or is unable to) commit in advance to an exchange rate policy rule. The government's 'reaction function' 
shows the actual devaluation as a function of the union's wage-setting behavior and can be derived from the first-order conditions of the government's maximization problem,

$$
\epsilon(\hat{w})=\left[1-\frac{a \mu}{\alpha+a \mu^{2}}\right] \hat{w}+\lambda\left(u_{t}+k\right)-\lambda\left(e_{t-1}-w_{t-1}\right)
$$

where $\hat{w} \equiv w_{t}-w_{t-1}=E\left\{e_{t} \mid \Omega_{t-1}\right\}-w_{t-1}$, the (expected) increase in wages the union selects. In terms of inflation, the reaction function ${ }^{9}$ is

$$
\pi_{t}^{r}=\frac{\alpha}{a \mu}\left(u_{t}+k\right)-\frac{\alpha}{a \mu}\left(e_{t}-w_{t}\right)
$$

Without knowledge of the government's choice at the beginning of period $t$, the trade union must make a forecast of the policymaker's choice of exchange rate $e_{t}$ - the forecast cannot therefore be made conditional on the actual policy that will be actually be carried out. The forecast $E\left\{e_{t} \mid \Omega_{t-1}\right\}$ is made by the union assuming rational expectations. In Appendix B.3 it can be shown that this non-cooperative equilibrium is characterized by the following values for devaluation, inflation and the trade balance,

$$
\begin{aligned}
\epsilon\left(u_{t}, k\right) & =\lambda u_{t}-(1-\mu)\left(e_{t-1}-w_{t-1}\right)+\frac{\alpha}{a \mu} k \\
\pi_{t} & =\mu \lambda u_{t}+\frac{\alpha}{a \mu} k \\
b_{t}= & =b^{*}-\sqrt{\alpha}\left(u_{t}+k\right)+\sqrt{\alpha} \lambda u_{t}
\end{aligned}
$$

A first result is that without a binding commitment to a policy rule, the government has an incentive to devalue the currency in excess of the amount necessary to cushion the shock - the optimal discretionary rule prescribes a devaluation that is greater than when the government can commit to policy. This is because the union of the non-traded sector correctly interprets the incentives of the government and accordingly increases wages at the rate

$$
w_{t}-w_{t-1}=\mu\left(e_{t-1}-w_{t-1}\right)+\frac{\alpha}{a \mu} k
$$

to compensate for the devaluation bias of $(\alpha / a \mu) k>0$. Wage setters orientate their wage increases on the previous level of 'surprise' in the real

\footnotetext{
${ }^{9}$ Appendix B.3 shows how the reaction function can be derived from the first-order conditions of the minimization problem
} 
exchange rate, $e_{t-1}-w_{t-1}$. At the rate of wage inflation in [6.19], the government is no longer tempted to improve its external balance goal and in fact accommodates the wage increase in the non-traded sector. At the level of devaluation given in [6.16] the government is unwilling to trade off a higher inflation rate for a reduction in the balance of payments and thus incurs a loss of

$$
\begin{aligned}
\mathrm{E} L_{t}^{D} & =\alpha(1-\lambda) E\left[u+\frac{k}{(1-\lambda)}\right]^{2} \\
& =\alpha(1-\lambda) \sigma_{u}^{2}+\alpha k^{2}+\underbrace{\left(\frac{\alpha^{2}}{a \mu^{2}}\right) k^{2}}_{\text {excess loss }}
\end{aligned}
$$

where $\frac{\alpha^{2}}{a \mu^{2}} k^{2}$ is the excess loss due to the inflationary bias of a discretionary regime compared with the loss incurred in regime $C$ (see eq. [6.10]).

\subsubsection{Surprise regime $(M)$}

Finally, in order to complete the possible cases in the static equilibrium, consider the discretionary scenario above in which the private sector does not espouse rational expectations and instead falsely believes the policymaker to commit to an exchange rate rule. Since the trade union believes the zerodevaluation announcement, it disregards the inflationary bias and chooses $w_{t}-w_{t-1}=\mu\left(e_{t-1}-w_{t-1}\right)$. To maximize its utility the government sets the rate of devaluation as in regime $\mathrm{D}$ (see eq. [6.16]), but inflation remains at its precommitment level $\left(\pi_{t}=\mu \lambda u_{t}\right)$. The government avoids the inflation bias of the previous regime, but improves its external balance goal compared with the discretionary regime. Government loss in this regime is

$$
\mathrm{E} L_{t}=\alpha(\lambda-1) \sigma_{u}^{2}+\alpha k^{2}
$$

which is equivalent to the loss in the commitment regime: under these circumstances, private agents can be 'fooled' for their own good. The defining characteristics of the four regimes that have been treated above are summarized in Table (6.1). 


\section{Tab. 6.1: Alternative exchange Rate Regimes}

\begin{tabular}{|c|}
\hline Regime F \\
\hline $\begin{array}{l}\text { The government irrevocably pegs the exchange rate for all } t \text { to } \epsilon=e_{t}-e_{t-1} \text {. In } \\
\text { this regime their is no room for any variations in the exchange rate necessary to } \\
\text { offset the random disturbance which the government observes at the beginning } \\
\text { of } t \text {. }\end{array}$ \\
\hline Regime C \\
\hline $\begin{array}{l}\text { The government binds itself to a conditional exchange rate rule, } \epsilon_{t}=\lambda u_{t}-(1- \\
\mu)\left(e_{t-1}-w_{t-1}\right) \text {. This allows the government to select an appropriate (i.e. loss } \\
\text { minimizing) devaluation in the face of the random shock } u_{t} \text { at the beginning } \\
\text { of period } t \text { which would otherwise increase the deficit in the current account } \\
\text { by } \sqrt{\alpha} u_{t} \text {. The government does not seek to offset the systematic distortion } k \text {. }\end{array}$ \\
\hline Regime D \\
\hline $\begin{array}{l}\text { Government cannot commit to an any exchange rate rule. In an attempt to } \\
\text { reduce the current account deficit beyond its target level (due to distortion } \\
k \text { ) the government in fact accommodates wage increases that are the result of } \\
\text { higher devaluation expectations and devaluation is augmented by this devalu- } \\
\text { ation bias. The equilibrium level of inflation is augmented by an inflationary } \\
\text { bias compared with the commitment regime's counterpart. }\end{array}$ \\
\hline Regime $\mathrm{M}$ \\
\hline $\begin{array}{l}\text { Institutional arrangement analogous to Regime } \mathrm{D} \text {, but here the trade union } \\
\text { is myopic and does not take into account that the government will have an } \\
\text { incentive ex post to devalue once wages have been set. The government can thus } \\
\text { pursue to offset the distortion } k \text { without increasing inflationary expectations. }\end{array}$ \\
\hline
\end{tabular}

\subsection{Welfare comparison}

A comparative static analysis reveals that the excess amount of inflation in [6.17], $(\alpha / a \mu) k$, is an increasing function of $\alpha$, the sensitivity parameter that relates real exchange rate to changes in the current account. Similarly, the distortion $k$ systematically drives the balance of payments into a larger deficit. On the other hand, a large preference for stabilizing inflation via the nominal anchor (large $a$ ) reduces ceteris paribus the inflationary bias of the discretionary regime. When the coefficient of openness $\mu$ is below unity but high, changes in the nominal exchange rate generated by the government will be effective in terms of the real targets approach, but have the negative effect of passing through the nominal side of the economy resulting in inflation 
(from [6.18]). The overall effect depends on the parameters. We can see that in the semi-discretionary regime, the sign of

$$
\frac{\partial \pi_{t}}{\partial \mu}=\frac{u_{t} \alpha\left(\alpha-a \mu^{2}\right)}{\left(\alpha+a \mu^{2}\right)^{2}}
$$

is negative for $\alpha<a \mu^{2}$. Therefore, if the inflation goal of the government $a$ is set high enough and the sensitivity coefficient $\alpha$ is low then the government can end up reducing inflation even after accounting for the compensatory devaluation.

The results of the static analysis of equilibria under alternative regimes are listed in Table (6.2). A welfare comparison between the unconditional fixed exchange rate regime $\mathrm{F}$ and the institutionally less restricting regime $\mathrm{C}$ reveals that

$$
E\left(L_{t}^{C}-L_{t}^{F}\right)=-\alpha \lambda \sigma_{u}^{2}<0
$$

This is the unambiguous gain that derives from an optimal stabilization ${ }^{10}$. Note also that this gain increases when $a$ is large, i.e., when the potential gain from stabilization is substantial. Likewise, a comparison between regime C and D shows that

$$
E\left(L_{t}^{C}-L_{t}^{D}\right)=-\frac{\alpha^{2}}{a \mu^{2}} k^{2}<0
$$

which is also negative for all parameter values in their range. The extra benefit of regime $\mathrm{C}$ may be regarded is due to the devaluation bias of pure discretion.

A comparison between a regime of pure discretion and the simple rule of a fixed exchange rate does not deliver such clear cut results. Taking the difference between expected losses shows that

$$
\mathrm{E}\left(L_{t}^{F}-L_{t}^{D}\right)=\alpha \lambda \sigma_{u}^{2}-\frac{\alpha^{2}}{a \mu^{2}} k^{2}
$$

where the sign of the equation depends in an obvious way on the values of $\alpha, a, k$ and $\sigma_{u}^{2}$ — the resulting welfare difference remains ambiguous, depending on the parameter values. If the RHS of (6.25) is positive then regime $\mathrm{D}$ is preferred to regime $\mathrm{F}$ in welfare terms, i.e. $\mathrm{D} \succ \mathrm{F}$, and for

\footnotetext{
${ }^{10}$ We refer to this as a "gain" even though the sign is negative because we are comparing two losses with each other. In this case a negative value reduces the magnitude of the loss, and is therefore welfare-enhancing.
} 
Tab. 6.2: Policy outcomes under Alternative ReGimes

\begin{tabular}{|c|c|c|c|}
\hline Regime & $b_{t}$ & $\pi_{t}$ & $\mathrm{E} L_{t}$ \\
\hline \hline $\mathrm{F}$ & $b^{*}-\sqrt{\alpha}\left(u_{t}+k\right)$ & 0 & $\alpha \sigma_{u}^{2}+\alpha k^{2}$ \\
\hline $\mathrm{C}$ & $b^{*}-\sqrt{\alpha}\left(u_{t}+k\right)+\sqrt{\alpha} \lambda u_{t}$ & $\mu \lambda u_{t}$ & $\mathrm{E} L_{t}^{F}-\alpha \lambda \sigma_{u}^{2}$ \\
\hline $\mathrm{D}$ & $b^{*}-\sqrt{\alpha}\left(u_{t}+k\right)+\sqrt{\alpha} \lambda u_{t}$ & $\mu \lambda u_{t}+\frac{\alpha}{a \mu} k$ & $\mathrm{E} L_{t}^{F}-\alpha \lambda \sigma_{u}^{2}+\frac{\alpha^{2}}{a \mu^{2}} k^{2}$ \\
\hline $\mathrm{M}$ & $b^{*}-\sqrt{\alpha}\left(u_{t}+k\right)+\sqrt{\alpha} \lambda u_{t}$ & $\mu \lambda u_{t}$ & $\mathrm{E} L_{t}^{F}-\alpha \lambda \sigma_{u}^{2}$ \\
\hline
\end{tabular}

negative values, $\mathrm{F} \succ \mathrm{D}$. It follows that if the volatility of the random shock is high enough (measured in $\sigma_{u}^{2}$ ), then a regime of discretion is the better choice for improving welfare.

A fixed exchange rate avoids the loss due to the inflation bias of regime $\mathrm{D}$, measured in terms of $k$ (second term in RHS of [6.25]). On the other hand, a discretionary regime can offset the negative effects of disturbance $u$, as shown in positive term involving $\sigma_{u}^{2}$ in the equation above. If random shocks are large and their random occurrence large, then there exist circumstances in which the use of discretion would be preferable to the strict rule of a fixed exchange rate regime. If policymakers are thus granted discretion in the face of unusually severe shocks (large $\sigma_{u}^{2}$ ) then social welfare may in fact be improved. But this comparative welfare gain can only be achieved if the policymaker is confined to using discretion within the statutory limits of a semi-flexible exchange rate regime.

\subsection{Discussion}

Three points can be clarified from the preceding discussion. First of all, the comparison between eqs. [6.23] and [6.24] show that a the semi-discretionary regime $\mathrm{C}$ always fares better in welfare terms when compared with the fixed exchange regime $\mathrm{F}$ or the discretionary $\mathrm{D}$. This means that flexibility in the arrangement of an exchange rate regime is a desirable feature in an environment in which the current account is influenced by unforeseen external events, such as large swings in the terms of trade. The efficacy of regime $\mathbf{C}$ though, presupposes rigidity in wages and price-setting behavior ex post as 
well as a perceived commitment of this regime. If the use of the exchange rate can be checked so that any inflation that arises is related to the stabilization of the current account, then this is the regime of choice. Any excessive antiinflation bias (such as in regime F) may be suboptimal in welfare terms.

Secondly, if commitment in regime $\mathrm{F}$ or $\mathrm{C}$ is not feasible, or not perceived as credible, then the outcome will be biased towards an inflationary outcome resulting from the depreciation of the exchange rate. The combination of limited credibility and a rational private sector inevitably translates into a devaluation bias when the government discretion cannot be checked appropriately. Any perceived inflationary bias could conceivably be avoided through institutional discipline, but the rules underpinning this discipline must be fashioned armor-proof, so that the commitment to a fixed exchange rate cannot be revoked. The track record of ERBS programs in practice tells us that there usually are no institutional impediment to alter the exchange rate when the need arises (the exception being, thus far, Argentina's program of 1990). Under these circumstances, the adoption of any regime that requires an amount of restraint regarding the discretionary use of the exchange rate rates amounts to nothing more than a declaration of good intentions. The incentive structure under a pegged arrangement may thus lead to periodic devaluations.

Thirdly, not all regime options may be available to the policymaker. Due to a combination of specific economic, social and political characteristics of the country it is conceivable that the exchange rate authority may not have at its disposal the choice for a semi-discretionary regime. It is then questionable whether the government can limit the use its exchange rate authority so as to avoid an imminent devaluation bias. Within the framework of the static model we observed that the choice between the fixed exchange rate regime $F$ and one with discretion $\mathrm{D}$ is not straightforward since the sign in

$$
\mathrm{E}\left(L_{t}^{F}-L_{t}^{D}\right)=\alpha \lambda \sigma_{u}^{2}-\frac{\alpha^{2}}{a \mu^{2}} k^{2}
$$

can be positive or negative, depending on the parameter values. Therefore the decision which regime to favor is not that clear cut. The greater the distortion $k$ the government must cope with, the greater will be its temptation to abuse devaluation, and the less desirable a fixed arrangement will be. However, under abnormally large swings in the random shock (large $\sigma_{u}^{2}$ ) a welfare improvement could be achieved choosing regime $\mathrm{D}$ over $\mathrm{F}$ if exchange 
rates could temporarily be adjusted to offset the destabilizing effect on the current account balance. In this scenario then, the goal of disinflation is secondary to the goal of reducing the external balance. By setting down an institutional "escape clause" determining exactly when such abnormal conditions prevail, private agents can adjust expectations accordingly and a bias can be avoided. ${ }^{11}$

\footnotetext{
11 This idea originates from OBSTFELD (1997). A regime incorporating escape clauses may be formulated by assuming that the exchange rate authority follows a simple rule when the shock $u_{t}$ is small in absolute value and acts with discretion when the absolute value of the shock is large in order to shield the economy from current account deterioration.
} 


\section{REPUTATION}

In examining the theoretical implications of ERBS programs, we have thus far been concerned with a one-time encounter of the private sector and government. Uncertainty entered the model through a random external shock that influenced the balance of payments in the initial period. This section adds a different kind of uncertainty by assuming that the government possesses private information in a game that is enacted over a finite number of periods. In this model, a weak government uses its information advantage for strategic purposes by mimicking the optimal policy of a inflation averse government. The longer the weak government adheres to the fixed exchange rate, the lower will be the expected rate of devaluation. Under a well-defined set of expectations, a government committed to low inflation also plays a strategic role in this model by signaling its commitment through an appropriate policy choice. In successive periods, a strong government provides a valuable signal to the private sector if it sends a signal which its weak nemesis would not find worthwhile to send.

The incentive to engage in mimicking or signaling activity has implications on inflation and the external balance and the "reputation effect" that influence the decisions of both the strong and weak government may alleviate the devaluation bias associated with the time consistency problem faced by the government in the preceding section. Credibility in an ERBS can ultimately be achieved if the policymaker worries enough about his reputation and balances future losses of credibility against immediate prospective balance-of-payment gains.

\subsection{Model structure}

The uncertainty that drives the expectation formation process of the private sector is of the intrinsic sort, i.e., the public is incompletely informed about 
the government's objectives ${ }^{1}$. This type of uncertainty is formalized by postulating that, at the outset of the game, Nature chooses a type of policymaker with a certain probability. For simplicity there are again only two types of government which may be categorized by their relative policy objectives, $a_{i}$ for $i=\{s, w\}$. A strong government, labeled $T_{s}$, is more concerned with the distortionary costs of high inflation than a weak government, $T_{w}$, whose objectives are more properly satisfied by a reduction in the current account deficit. The $i$-type government's one-period loss functions in period- $t$ can be written as

$$
L_{t}^{i}=\left(b-b^{*}\right)^{2}+a_{i} \pi_{t}^{2} \quad \text { with } \quad i=\{s, w\}
$$

By simplifying notation such that $\epsilon_{t}=e_{t}-e_{t-1}$ and $\hat{w}_{t}=w_{t}-w_{t-1}$, these two policy objectives can be written from [6.2] and [6.5] as

$$
\begin{array}{r}
b_{t}=b^{*}+\sqrt{\alpha}\left(\epsilon_{t}-\hat{w}_{t}-k\right) \\
\pi_{t}=\mu \epsilon_{t}+(1-\mu) \hat{w}_{t}
\end{array}
$$

The nonuniform inflationary preferences of the two governments are modeled by assuming that $0<a_{W}<a_{S}<\infty$. The respective government is aware of its type throughout the game. It is important to note that in contrast with the monetary reputation model, the $s$-type government values both a low level of inflation and a balanced external account (i.e., $a_{s}$ is non-zero). Thus by this construction, a strong government can administer a policy response inducing a real appreciation of the currency, rather then just fixing the exchange rate at a preordained level. In this manner it can, under certain circumstances, successfully separate itself from a weak government.

Wage setters in the non-traded goods sector (organized once again in a monopolistic trade union) do not know the government's true identity when wages are negotiated and the nominal exchange rate is set at the beginning of period- $t$. However, the union does possess a prior distribution of the government's type gleaned from the past record of exchange rate policy captured in the information set $\Omega_{t-1}$, where $\Omega_{t-1}$ is defined by the past history of the exchange rate, $\Omega_{t-1}=\left\{e_{t-1}, e_{t-2}, \ldots\right\}$. The union assesses the probability that the government is a $s$-type at $t$ to be $\theta_{t}=\operatorname{prob}\left(T_{s} \mid \Omega_{t-1}\right)$. It is assumed common knowledge at the start of the game that the private sector attaches an exogenously determined probability $\theta_{0}$ and $1-\theta_{0}$ to the two possible

\footnotetext{
${ }^{1}$ This could be rationalized by assuming that the government has just come to office.
} 
manifestations of government, $T_{s}$ and $T_{w}\left(0<\theta_{0}<1\right)^{2}$.

As time proceeds and policy is enacted, $\theta_{t}$ is revised in light of the observed policy, i.e., if the government sticks to a fixed exchange rate, this will convey the idea that the government may indeed be strong, which holds down private sector expectations on inflation. In this way, the government's reputation can be identified with the probability $\theta_{t}$, with which the union believes that it is the type which is committed to holding a fixed exchange rate $^{3}$.

\subsection{Incentives to mimic and signal}

This section derives the incentive structure of both the $s$ - and $w$-type governments in a two-period setting. The duration of the game may be thought of as the period of office of the government. The government's incentives are characterized by a policy choice in period one which may deviate from the optimal, non-strategic level that would otherwise be chosen. This divergence from per period optimal choice involves costs but also benefits in the form of an increase in reputation. The strong government may try to signal its preferences in $t=1$ to reduce future expected inflation. By choosing a rate of devaluation, $\epsilon_{t}=e_{t}-e_{t-1}$, lower than its non-strategic value, a $T_{s}$ government can attempt to signal its true preferences. These incentives make it more difficult (i.e. more costly in terms of welfare loss) for a weak government to succeed in mimicking the strong government in order to boost reputation $\theta_{2}$.

In the following, the rate of devaluation for both types of government, $\epsilon_{t}^{w}$ and $\epsilon_{t}^{s}$ for $t=\{1,2\}$ is computed when the respective government completely disregards the influence that its policy might have on the private sector's beliefs about its type. To derive this non-strategic choice of devaluation the government's objective function is maximized myopically with respect to the nominal exchange rate for both periods. From the general form of the twoperiod objective function in [4.14] the intertemporal governmental loss $V_{w}^{G}$ and $V_{s}^{G}$ can be derived from the per-period loss functions $L_{1}$ and $L_{2}$ in [7.1]

\footnotetext{
2 To focus on the intrinsic uncertainty aspect of the model, random disturbances do not occur in the model, so that we set $u_{t}=0, \forall t$.

${ }^{3}$ Return to Section 5.3.1 for the derivation of $\theta_{t}$ using Bayes' rule in the monetary context.
} 
as

$$
\begin{aligned}
V_{i}^{G}= & L_{1}^{i}+\delta L_{2}^{i} \\
= & \alpha\left(\epsilon_{1}-\hat{w}_{1}-k\right)^{2}+a_{i}\left(\mu \epsilon_{1}+(1-\mu) \hat{w}_{1}\right)^{2} \\
& +\delta\left[\alpha\left(\epsilon_{2}-\hat{w}_{2}-k\right)^{2}+a_{i}\left(\mu \epsilon_{2}+(1-\mu) \hat{w}_{2}\right)^{2}\right]
\end{aligned}
$$

where $\delta \equiv(1+r)^{-1}$ is the discount factor. ${ }^{4}$ Since the non-traded sector fixes wages at the beginning of period $t=1$, it is incapable of responding to the devaluation made after the wage decision. Therefore, setting $\hat{w}_{1}=0$ for simplification of algebra does not have any bearing on the following analysis. Taking first-order conditions of [7.4] and subsequently solving for $\epsilon_{1}$ and $\epsilon_{2}$ for both types of government $i=s, w$ delivers the non-strategic policy

$$
\epsilon_{1}^{s}=\lambda_{s} k \quad \text { and } \quad \epsilon_{2}^{s}=\lambda_{s}^{\prime} \hat{w}_{2}+\lambda_{s} k
$$

for the strong government and

$$
\epsilon_{1}^{w}=\lambda_{w} k \quad \text { and } \quad \epsilon_{2}^{w}=\lambda_{w}^{\prime} \hat{w}_{2}+\lambda_{w} k
$$

for the weak government. The coefficients are

$$
\lambda_{i}=\frac{\alpha}{\alpha+a_{i} \mu^{2}}>0 \quad \text { and } \quad \lambda_{i}^{\prime}=1-\frac{a_{i} \mu}{\alpha+a_{i} \mu^{2}}
$$

for $i=s, w$. Both governments' non-strategic choice involve a positive devaluation in the first period that tries to offset the distortion $k$ in the current account, but the strong government devalues the currency to a lesser degree (since $\lambda_{s}<\lambda_{w}$ ), given its relative aversion towards inflation.

In the final period 2, both types of government have nothing to gain from any strategic activity, since they have then nothing to fear from a lost reputation. Thus lacking any incentive to mimic or signal, the governments have a well-defined strategy given by their non-strategic optimal period-2 decision in [7.5] and [7.6] and the wage decision $\hat{w}_{2}=\mathrm{E}\left(\epsilon_{2}^{i} \mid \Omega_{t-1}\right)$. In period1 , on the other hand, the government's devaluation policy depends on the information structure it is facing.

\footnotetext{
4 The simplifying assumption is made here that both types of governments possess the same discount rate $r$, resp. discount factor $\delta$. More realistically, one could assume that the strong, inflation averse government cares more about long-run policy than a weak government. This would translate into a higher discount factor (i.e. $\delta_{s}>\delta_{w}$ ).
} 


\subsubsection{Perfect information}

Under perfect information the government's type is known to all players at the beginning of the game encounter so that the nontradeable sector can identify unambiguously the type of policymaker it is facing. Rational wage setting coincides with forming price, or inflationary expectations rationally. The private sector thus computes wage increases following [7.5] and [7.6] such that

$$
\begin{aligned}
& \hat{w}_{2}=\mathrm{E} \epsilon_{2}^{s}=\frac{\lambda_{s} k}{1-\lambda_{s}^{\prime}}=\frac{\alpha k}{\mu a_{s}} \text { for } T_{s} \\
& \hat{w}_{2}=\mathrm{E} \epsilon_{2}^{w}=\frac{\lambda_{w} k}{1-\lambda_{w}^{\prime}}=\frac{\alpha k}{\mu a_{w}} \text { for } T_{w}
\end{aligned}
$$

and the full information strategy set can be computed as

$$
\epsilon_{1}^{i}=\lambda_{i} k \quad \text { and } \quad \epsilon_{2}^{i}=\frac{\alpha}{\mu a_{i}} k \text { for } i=s, w
$$

This result basically replicates the time inconsistent solution of the discretionary regime in the preceding section. In this case, a fixed exchange rate $\left(\epsilon_{1}=\epsilon_{2}=0\right)$ is optimal only if the government gives the inflationary goal an infinite weight,

$$
\lim _{a_{i} \rightarrow \infty} \epsilon_{1}^{i}=\lim _{a_{i} \rightarrow \infty} \epsilon_{2}^{i}=0 \quad \text { for } \quad i=s, w
$$

\subsubsection{Imperfect information}

If intrinsic uncertainty is prevalent, then wage setters are not informed about the government's type at the outset of period 2. But both governments enter period 2 with a posterior distribution $\theta_{2}$ to the event that the government is strong and this is common knowledge to both players. Since the true type of government is not known to the public with certainty, the policy chosen in the first period has potential information value for the wage decision made in the following period. A weak government, i.e. one that is more concerned with a balanced current account $\left(a_{w}<a_{s}\right)$ may use this to its advantage and tend, at the start of its term in office in $t=1$, to act as if it were not a weak government by nominally devaluing the currency to a less than full information expectations in [7.9] would warrant. This allows this type of government to reap the awards of higher reputation in period 1. In order to distinguish itself from its weak nemesis, a strong government can establish its reputation by opting for a policy that a weak policymaker 
would find too costly to mimic. Thus, both governments' actions under this information structure are driven by the desire to obtain a high reputation $\theta_{2}$ and a concomitant reduction in inflation expectations in period 2. The outcomes depend on the effects of period-1 actions on the wage decisions of the private sector. We make the following proposition:

Proposition 7.1: The higher the probability of having a $T_{s}$ policymaker in office (i.e., the higher reputation $\theta_{2}$ ), the lower the rate of increase in wages in the non-tradable sector. By lowering expectations of a devaluation in period 2 both types of governments reduce their expected loss from an increase in the privately held belief $\theta_{2}$ that the government is indeed inflation averse type $T_{s}$.

Proof The wage decision for period 2 is made on the basis of

$$
\hat{w}_{2}=\mathrm{E} \epsilon_{2}=\theta_{2} \epsilon_{2}^{s}+\left(1-\theta_{2}\right) \epsilon_{2}^{w}
$$

Using [7.12] and substituting the second period devaluation levels from Eqs. [7.5] and [7.6] the wage increase in the non-tradable sector is

$$
\begin{aligned}
\hat{w}_{2} & =\frac{\lambda_{w}+\theta_{2}\left(\lambda_{s}-\lambda_{w}\right)}{1-\lambda_{w}+\theta_{2}\left(\lambda_{w}-\lambda_{s}\right)} k \mu \\
& =\frac{\alpha k}{\mu}\left[\frac{\alpha+a_{s} \mu^{2}+\left(a_{w}-a_{s}\right) \theta_{2} \mu^{2}}{a_{w}\left(\alpha+a_{s} \mu^{2}\right)+\left(a_{s}-a_{w}\right) \theta_{2} \alpha}\right]
\end{aligned}
$$

For positive values of $\theta_{2}$ the equation above turns negative (when $\alpha<$ $\left.\theta_{2} a_{w} \mu^{2}+\left(1-\theta_{2}\right) a_{s} \mu^{2}\right)$. The private sector may therefore reduce devaluation expectations and subsequently wage demands in period 2 if there is even a slight chance that it is facing a strong government. Without any reputation at all on entering period 2, expectations are skewed towards a weak government. Differentiating this equation with respect to $\theta_{2}$ yields

$$
\frac{\partial \hat{w}_{2}}{\partial \theta_{2}}=\frac{\alpha k}{\mu}\left[\frac{\left(a_{w}-a_{s}\right)\left(\alpha+a_{s} \mu^{2}\right)\left(\alpha+a_{w} \mu^{2}\right)}{\left(a_{w}\left(\alpha+a_{s} \mu^{2}\right)+\theta_{2} \alpha\left(a_{s}-a_{w}\right)\right)^{2}}\right]<0
$$

By definition we know that $a_{s}>a_{w}$, rendering the expression in [7.14] negative. Increasing second period reputation has the effect of reducing private sector inflationary expectations. [q.e.d.]

What are the policies chosen by the two governments when acting strategically? Mimicking a strong government lets a $T_{w}$ maintain the impression 
among wage setters in the nontraded sector that inflation is their primary target. This increases $\theta_{2}$ and therefore lowers second period expectations. As long as $\theta_{2}$ is above zero, the optimal policy in period 2 accordingly leads to a surprise real devaluation ${ }^{5}$,

$$
\epsilon_{2}^{w}-\hat{w}_{2}=\frac{\alpha k}{\mu}\left[\frac{\left(a_{s}-a_{w}\right) \theta_{2} \mu}{a_{w}\left(\alpha+a_{s} \mu^{2}\right)+\left(a_{s}-a_{w}\right) \theta_{2} \alpha}\right]>0
$$

where the magnitude of the 'surprise' is increasing in reputation $\theta_{2}$. The high inflation government therefore has an incentive to mimic the inflation averse government in the first period if this can induce the trade union to believe that it is indeed a low inflation type (and therefore increase $\theta_{2}$ ). Obviously, following a mimicking strategy in period 1 is suboptimal for the weak government and therefore poses a cost. The decision whether to mimic or not therefore involves trading off period 1 costs against period 2 (strategic) benefits.

The incentive structure of the strong government is also influenced by strategic considerations. As long as the public does not believe it is facing a strong government with certainty (i.e. as long as $\theta_{2}<1$ ), the optimally chosen policy leads to a surprise real appreciation of the currency,

$$
\epsilon_{2}^{s}-\hat{w}_{2}=\frac{\alpha k}{\mu}\left[\frac{\left(a_{w}-a_{s}\right)\left(1-\theta_{2}\right) \mu}{a_{w}\left(\alpha+a_{s} \mu^{2}\right)+\left(a_{s}-a_{w}\right) \theta_{2} \alpha}\right]<0
$$

for $\theta_{2}<0$. A higher value of $\theta_{2}$, leading to a lower wage increases, decreases the optimal appreciation thus dampening the costs associated with an enlarged current account deficit. Since the private sector is aware of the incentives of the weak government, an inflation averse government $T_{s}$, when in office, establishes credibility by revaluing the currency, a measure that would be too costly for a weak government to mimic. Signaling in such a manner, however, may not be a desirable option if its costs exceed the cost of being mistaken for a weak government. Note that if reputation has been firmly established with $\theta_{2}=1$ the strong government refrains from any surprise appreciation $\left(\epsilon_{2}^{s}-\hat{w}_{2}=0\right)$.

\footnotetext{
${ }^{5}$ Recall that $e_{t}-w_{t}$ is equivalent to the real exchange rate, since foreign inflation, $\pi_{t}^{*}$ is held at a constant level.
} 


\subsection{Separating equilibrium}

The equilibrium concept drawn upon in this policy game is Perfect Bayesian equilibrium $(\mathrm{PBE})^{6}$. A strategy profile $\tilde{s} \equiv\left\{\tilde{\epsilon}_{t}^{s}, \tilde{\epsilon}_{t}^{w}, \tilde{w}_{t}\right\}$ is a PBE if

1. the strategies chosen during the duration of the game are Nash given the beliefs and strategies of the other players. This means that in every period $\tilde{s}$ is chosen optimally for any $\theta_{t}$.

2. the posterior beliefs $\theta_{t}$ are derived from the common prior $\theta_{0}$ and the observation of government policy. The derivation is based on Bayes' rule, when it applies.

The first condition implies that wage setters hold rational expectations in each period:

$$
\tilde{w}_{t}=\theta_{t} \tilde{\epsilon}_{t}^{s}+\left(1-\theta_{t}\right) \rho_{t} \tilde{\epsilon}_{t}^{w}
$$

where $\tilde{\epsilon}_{t}^{s}$ and $\tilde{\epsilon}_{t}^{w}$ denote the equilibrium strategies of weak and strong government chosen in period $t$, respectively. Both governments take into account the effect of its current policy on wage setters' future beliefs when computing their optimal policy. This is the source of reputational effects, discussed in the previous section. The second condition establishes the learning process in equilibrium. Suppose that in equilibrium, the strong government never sets the exchange rate above a threshold value $\bar{\epsilon}$. Let $\rho_{1} \equiv \operatorname{prob}\left(\epsilon_{1} \leq \bar{\epsilon} \mid T_{w}\right)$ be the equilibrium probability that the weak type does not devalue below the threshold value $\bar{\epsilon}^{7}$. For the two-period case this process can be specified as

$$
\begin{aligned}
& \theta_{2}=0 \text { if } \epsilon_{1}>\bar{\epsilon} \\
& \theta_{2}=\frac{\theta_{1}}{\theta_{1}+\left(1-\theta_{1}\right) \rho_{1}} \text { if } \epsilon_{1} \leq \bar{\epsilon}
\end{aligned}
$$

There are two types of equilibrium that can be the result of the game. In a pooling equilibrium both types send the same first-period signal,

$$
\tilde{\epsilon}_{1}^{w}=\tilde{\epsilon}_{1}^{s} \quad \Rightarrow \quad \theta_{2}=\theta_{1} \quad \text { if } \quad \epsilon_{1}=\tilde{\epsilon}_{1}^{s}
$$

\footnotetext{
${ }^{6}$ See section 3.3.2 for a general discussion

7 The probability $\rho$ could also be characterized as a statistical index. Seen in this light, this probability would be determined by factors such as the success rate of governments which historically have maintained a fixed exchange rate.
} 
Therefore wage setters are not able to update the prior probability $\theta_{1}$, so that $\theta_{1}=\theta_{2}$. Given the incentive of the weak government to masquerade as a strong one, the private sector is not able to extract any information regarding the government's type by observing $\epsilon_{1}$. If, on the other hand, $\epsilon_{1}^{s} \neq \epsilon_{1}^{w}$, then the private learning process implicit in Condition (2) implies that when

$$
\tilde{\epsilon}_{1}^{w} \neq \tilde{\epsilon}_{1}^{s} \quad \Rightarrow \quad \begin{cases}\theta_{2}=1, & \text { if } \epsilon_{1}=\tilde{\epsilon}_{1}^{s} ; \\ \theta_{2}=0 & \text { if } \epsilon_{1}=\tilde{\epsilon}_{1}^{w} .\end{cases}
$$

From this definition a separating equilibrium emerges in which the private sector is able to distinguish between the types from the signal $\epsilon_{1}$ and revise beliefs accordingly.

The definition of an equilibrium arising from [7.19] and [7.20] specifies only how the private sector builds its beliefs from events that occur along the equilibrium path and is therefore incomplete. Since Bayes' rule does not apply for zero-probability, out-of-equilibrium events, any exogenously determined posterior belief can be admissible. To pin down posterior beliefs in a preliminary manner it will be assumed for simplicity that

$$
\theta_{2}=0, \quad \text { if any out }- \text { of }- \text { equilibrium policy is observed. }
$$

In order to find a suitable candidate $\tilde{s}$ for a separating equilibrium we derive conditions that an equilibrium must satisfy, given the constraints on the governments' incentive structures.

Consider first an inflation averse $T_{s}$ government. We know from [7.21] that all other policies other than $\tilde{\epsilon}_{1}^{s}$ (i.e. also those not on the equilibrium path) induce the private sector to set $\theta_{2}=0$. Therefore, with the prospect of having reputation completely destroyed in period 2 , the only viable alternative for $T_{s}$ must be to pursue the non-strategic optimal policy $\epsilon_{1}^{s}=\lambda_{s} k \equiv d_{s}$. So the policy $\tilde{\epsilon}_{1}^{s}$ is an equilibrium if

$$
V^{G}\left(\tilde{\epsilon}_{1}^{s}, \theta_{2}=1\right) \leq V^{G}\left(d_{s}, \theta_{2}=0\right)
$$

We also know that the nominal devaluation chosen in a separating equilibrium by the strong government, $\tilde{\epsilon}_{1}^{s}$, is less than the nonstrategic value $d_{s}$. Only by depreciating the currency by less than it would have found under perfect information unambiguously reveals its type and consequently lowers the incentive for the private sector to increase devaluation expectations in the future. 
Turning now to the $T_{w}$ government, we know that in a separating equilibrium it will always choose its short-run discretionary policy $\lambda_{w} \equiv d_{w}$, so that

$$
\tilde{e}_{1}^{w}=d_{w}
$$

Since the weak government reveals itself in this equilibrium, wage setters in the non-traded sector observe $\tilde{\epsilon}_{1}^{w}$ and attach a posterior probability of zero to the event that the government is a low inflation $T_{s}$ type, i.e. it sets $\theta_{2}=0$. For $\tilde{\epsilon}_{1}^{w}$ to be an equilibrium there must be no incentive for the weak government to mimic the perfect information strategy $d_{s}$ of the strong government. Therefore,

$$
V_{w}^{G}\left(d_{s}, \theta_{2}=1\right) \geq V_{w}^{G}\left(\tilde{\epsilon}_{1}^{w}, \theta_{2}=0\right)
$$

must hold in this case. The "truth-telling" constraints" of Eqs. [7.22] and [7.24] ensure that both governments reveal their true identity in equilibrium. The existence of a separating equilibrium means that the intertemporal loss $V_{s}^{G}$ incurred by a strong government for the sake of signaling its type (i.e. $\left.\tilde{\epsilon}_{1}^{s}<d_{s}\right)$ must be less than the loss associated with the non-strategic devaluation $d_{s}([7.22])$. This inequality sets an upper bound on values for $\epsilon_{1}$ for which a separating equilibrium is the result of the game. Appendix B.5.1 shows that the upper bound is a range such that

$$
S_{\min } \equiv \lambda_{s} k\left(1-\Psi_{s}\right) \leq \epsilon_{1} \leq \lambda_{s} k\left(1+\Psi_{s}\right) \equiv S_{\max }
$$

In a similar way, condition [7.24] states that for the weak government the loss associated with an initially lower rate of depreciation for reputationbuilding must exceed the short-term benefit of playing the preferred $T_{w^{-}}$ strategy, $d_{w}$. From this inequality Appendix B.5.2 derives a lower bound on plausible equilibrium strategies,

$$
W_{\min } \equiv \epsilon_{1} \leq \lambda_{s} k\left(1-\Psi_{w}\right) \quad \text { and } \quad \epsilon_{1} \geq \lambda_{s} k\left(1+\Psi_{w}\right) \equiv W_{\max }
$$

where

$$
\Psi_{i} \equiv \frac{\sqrt{a_{i} \delta\left(a_{s}-a_{w}\right)\left[\alpha\left(a_{s}+a_{w}\right)+2 a_{s} a_{w} \mu^{2}\right]}}{a_{w} a_{s} \mu}>0
$$

From the definition of $a_{s}$ and $a_{w}$ it is known that $\lambda_{w}>\lambda_{s}$ and, therefore, $\Psi_{w}<\Psi_{s}$. It follows that for the range of values

$$
S_{\min }<W_{\min }<d_{s}<W_{\max }<S_{\max }
$$


holds. For the strong government the range of values for $\epsilon_{1}$ defined in [7.25] the incentives are strong enough for the government to depreciate by less than would have been chosen under perfect information. Note that the optimal range for signaling behavior of the $T_{s}$-government is an increasing function of the difference between $a_{s}$ and $a_{w}$. Thus the larger the divergence in inflation preferences between the two manifestations of government, the less costs the strong government must incur to signal its type. For the weak government, [7.27] defines a range of values for which it is optimal for the weak government to reveal its type by choosing its non-strategic policy choice $\epsilon_{1}^{w}=\lambda_{w} k$ in the first period.

Possible candidates for a separating equilibrium $\tilde{s}$ are defined by the intersection of the three ranges

$$
\left[S_{\min }, S_{\max }\right] \cap\left(-\infty, W_{\min }\right] \cap\left[W_{\max },+\infty\right)
$$

Since $a_{s}>a_{w}$ and therefore $\lambda_{s}<\lambda_{w}$ the set in [7.29] is non-empty (see Appendix B.5.3). This taken together with [7.28] leads to the following proposition:

Proposition 7.2: Assume that $\tilde{s}$ is a separating equilibrium. Then in this equilibrium a strong government chooses an exchange rate in the range $\epsilon_{1}^{s} \in$ $\left[S_{\min }, W_{\min }\right]$ and a weak government chooses $\epsilon_{1}^{w}=\lambda_{w} k$.

Proof First, it is necessary to establish that a weak government's optimal choice in a separating equilibrium is $\tilde{\epsilon}_{1}^{w}=d_{w}$. To see why, note that in a separating equilibrium, wage setters expect an exchange rate of

$$
\hat{w}_{2}=\frac{\alpha k}{\mu a_{s}}
$$

and these expectations are correct in equilibrium. But this is the most unfavorable wage increase for the weak policymaker, because $\hat{w}_{2}$ is increasing in $\left[\frac{\alpha k}{\mu a_{s}}, \frac{\alpha k}{\mu a_{w}}\right]$ (from [7.13]). Since expectations and subsequently overall loss cannot be reduced any further with a value $\epsilon_{1}^{w} \neq d_{w}$, the only viable choice for a weak government is $\epsilon_{1}^{w}=d_{w}$.

Now turn to the strong government. It is necessary to show that values of $\epsilon_{1}$ in the range $\left[W_{\max }, S_{\max }\right]$ do not constitute a separating equilibrium. For the strong government, a devaluation in the lower range $\left[S_{\min }, W_{\min }\right]$ strictly dominates any value of $\epsilon_{1}$ in the upper range (because the costs of inflation are excessively high). A devaluation in the higher range of values is therefore 
not viable for a strong government ${ }^{8}$. Using the same argument from the preceding paragraph, any value of $\epsilon_{1} \in\left[S_{\max }, W_{\max }\right]$ is suboptimal also for a weak government, so we can rule out these values from the start.

Secondly, in a separating equilibrium the value of $\tilde{\epsilon}_{1}^{s}$ cannot be less than $S_{\text {min }}$. For otherwise it would be more favorable for a $T_{s}$-government to choose the non-strategic value $d_{s}$, even if he thereby forgoes any strategic advantage (since the private sector believes him to be weak with certainty, $\theta_{2}=0$ ). This follows from the way $S_{\min }$ was derived in [7.22]. Also, one can establish the fact that $\epsilon_{1}^{s}$ cannot exceed $W_{\min }$ in a separating equilibrium. For otherwise a weak government would find it profitable to mimick a strong government by choosing the same first period exchange rate as the strong government. The private sector would be confident that it faces a strong government with certainty $\left(\theta_{2}=1\right)$, thus improving its payoff, as can be seen from [7.24]. [q.e.d.]

\subsubsection{Indifference curves}

The selection process of a particular equilibrium that meets the requirements of Proposition 7.2 can be illustrated using Figure 7.1. Generally speaking, an indifference curve $V\left(\epsilon_{1}, \theta_{2}\right)=\bar{V}$ depicts all combinations of first-period exchange rate $\epsilon_{1}$ and reputation $\theta_{2}$ that deliver the same overall loss. These can be algebraically derived in Appendix B.7 using [7.4] such that

$$
V_{w}\left(\epsilon_{1}, \theta_{2}\right)=\bar{V}_{w} \quad \text { and } \quad V_{s}\left(\epsilon_{1}, \theta_{2}\right)=\bar{V}_{s}
$$

Two particular indifference curves, $\bar{V}_{s}^{0}$ and $\bar{V}_{s}^{0}$ drawn in Figure 7.1 have the special property that at the levels of loss associated with these indifference curves the strong (weak) government is indifferent between its short-run strategy $d_{s}\left(d_{w}\right)$ and the benefits associated with reputation $\theta_{2}$. Note that when the governments choose their non-strategic policy $d_{s}$, resp. $d_{w}$, the slope of the indifference curve is zero. At these levels of devaluation the marginal gain of an unexpected revaluation (resp. devaluation) is zero. At the left of these points the marginal gain of devaluation is positive, reflected

\footnotetext{
${ }^{8}$ In fact, we can see from 7.25 that $W_{\max }>d_{s}$, i.e. the lowest possible value of $\epsilon_{1}$ in this equilibrium "window" exceeds the optimal short-run strategy $d_{s}$ (by a factor of $\left.\left(1+\Psi_{w}\right)\right)$. This means that it makes no sense for a strong government to even consider reputational benefits for values of $\epsilon_{1}>W_{\max }$, since it can always to better by playing $d_{s}$.
} 
Fig. 7.1: SEPARATING EQUILIBRIUM

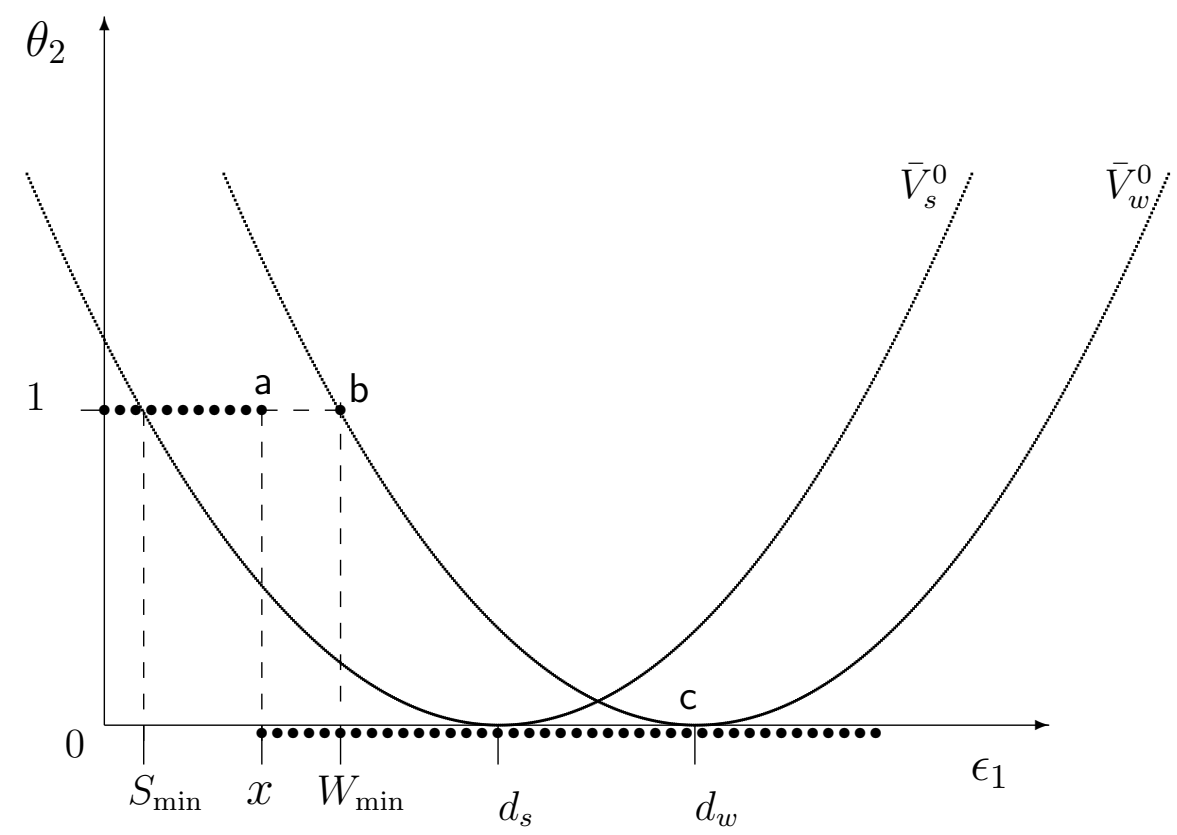

in a downward sloping indifference curve. This is the "trade-off" between the use of the exchange rate for expansionary purposes and reputation ${ }^{9}$

The two curves as they have been drawn in the figure, possess the important feature that they cut the $\theta_{2}$-axis above the point where $\theta_{1}=1$. If this were not the case, then both governments would never have any incentive to act strategically, since any level of $\epsilon_{1}$ would be associated with full reputation. Bereft of any strategic interaction, the outcome would be trivial. The intercept values of $\bar{V}_{s}^{0}$ and $\bar{V}_{s}^{0}$ must therefore be greater than 1 for a meaningful analysis and this depends on the magnitude of the parameters.

Now consider the following proposition:

\footnotetext{
${ }^{9}$ By extension of the argument, the slope of the indifference curve is negative to the right of $d_{s}$, resp. $d_{w}$, where the exchange rate exceeds the non-strategic choices for devaluation. Both governments therefore would never rationally choose such high rates of devaluation because then the marginal gain of reducing the rate of devaluation would be negative. We can therefore exclude this region from our considerations. This is similar to the argument we used to dismiss $\left[W_{\max }, S_{\max }\right]$ in Proposition 7.2 .
} 
Proposition 7.3: Let $x$ be some number such that $S_{\min } \leq x \leq W_{\min }$ and $\hat{w}_{1}=0$. Assuming that expectations are formed rationally there then exists a separating equilibrium in which

$$
\begin{aligned}
& {\tilde{\epsilon_{1}}}^{s}=x \quad \text { and } \quad \hat{w}_{2}=\frac{\alpha k}{\mu a_{s}} \quad\left(\theta_{2}=1\right) \\
& {\tilde{\epsilon_{1}}}^{w}=d_{w} \quad \text { and } \quad \hat{w}_{2}=d_{w} \quad\left(\theta_{2}=0\right)
\end{aligned}
$$

Proof The validity of Proposition 7.3 can be established by using the graphical representation of Figure 7.1. The learning process of the private sector in [7.18] that governs the evolution of reputation $\theta_{2}$ is represented by the dotted line. We know from Proposition 7.2 that for a separating equilibrium to exist a necessary condition is that the strong government's choice of exchange rate must be within the range $\epsilon_{1}^{s} \in\left[S_{\min }, W_{\min }\right]$. One possible candidate that suffices this condition is $\epsilon_{1}^{s}=x$, drawn in the figure above. Furthermore, in this equilibrium the weak government separates itself from the strong government by choosing $d_{w}>x$. The weak government has no economic reason for deviating from equilibrium since the loss at point $\mathrm{c}$ is strictly less than the loss associated with point a (i.e. the lower devaluation $\epsilon_{1}$ it would have to submit to in order to achieve a positive $\theta_{2}$ ). Therefore when wage setters observe $\epsilon_{1}=x$ they infer that they are facing a strong government with certainty, setting $\theta_{2}=1$ and $\rho_{1}=0$. Alternatively, on observing $\epsilon_{1}=d_{w}$ the public knows with certainty that the government is weak and sets $\theta_{2}=0 . \quad$ [q.e.d.]

\subsubsection{Refinements of the equilibrium}

The equilibrium discussed above is not unique. In fact, any $x$ between $S_{\min }$ and $W_{\min }$ are possible choices for the strong government in equilibrium. But it can be clearly seen that the strong government is better off the closer $x$ is towards $W_{\min }$, for the closer $\epsilon_{1}^{s}$ is to $W_{\min }$, the smaller the loss in terms of first-period targets that the strong government incurs to separate himself from the weak government. What prevents the $T_{s}$-government from deviating from this equilibrium and selecting a different policy in this direction (such as $x^{\prime}>x$ ) is that it would be degraded by the public as a weak government which follows from the 'pessimistic' assumption of out-of-equilibrium beliefs in [7.21]. A refinement of the equilibrium proposed in Proposition 7.3 leads to the following proposition: 
Proposition 7.4: Assuming that expectations are formed rationally there exists a unique separating equilibrium in which

$$
\begin{array}{r}
{\tilde{\epsilon_{1}}}^{s}=W_{\min } \quad \text { and } \quad \hat{w}_{2}=\frac{\alpha k}{\mu a_{s}} \quad\left(\theta_{2}=1\right) \\
{\tilde{\epsilon_{1}}}^{w}=d_{w} \quad \text { and } \quad \hat{w}_{2}=d_{w} \quad\left(\theta_{2}=0\right)
\end{array}
$$

Proof The beliefs supporting an equilibrium in which $x<W_{\min }$ are economically implausible, in the sense that they are inconsistent with rational behavior of a weak government. To see this note that the loss for the weak government is identical at points $b$ and $c^{10}$. Therefore, under no plausible circumstances would it make economic sense for the weak government to deviate from its non-strategic strategy $d_{w}$ to mimic the policy of strong government. The strong government's only rationale for not signaling its type at a lower cost with $x^{\prime}$ is the existence of out-of-equilibrium beliefs that are not reasonable on closer examination ${ }^{11}$.

To formally rule out strategies such as $x$ that are implausible in equilibrium, the test of equilibrium dominance (also referred to as the Intuitive Criterion) can be invoked. Consider the Perfect Bayesian equilibrium $\tilde{s}=\left\{x, d_{w}\right\}$ that was established in Proposition 7.3. In this particular equilibrium any deviation of the weak government is dominated by its equilibrium value $\tilde{\epsilon}_{1}{ }^{w}=d_{w}$. This means that any deviation from this value yields a higher overall loss than in equilibrium $\tilde{s}$ for the weak government, irrespective of how private beliefs are revised after the deviation. Equilibrium $\tilde{s}$ fails the test of equilibrium domination if there exists a policy $x^{\prime}$ such that

$$
\begin{aligned}
V_{s}^{G}(x) & >V_{s}^{G}\left(x^{\prime}\right) \\
V_{w}^{G}\left(d_{w}\right) & <V_{w}^{G}\left(x^{\prime}\right)
\end{aligned}
$$

Thus $x$ cannot be part of a separating equilibrium if there is another policy choice $x^{\prime}$ which gives a better outcome (i.e. lower loss) for $T_{s}$, but is unattractive for $T_{w}$ even if it could thereby convince the public that it

\footnotetext{
${ }^{10}$ The less-than-heroic assumption is made that when indifferent between separating and mimicking the $T_{w}$-government is always better off not to mimic.

${ }^{11}$ Remember that out-of-equilibrium choice of $x^{\prime}$ is actually impossible, so when it does occur there is no obvious way the private sector should set their expectations - any equilibrium could be justified with an arbitrary set of beliefs. The pessimistic conjecture of [7.21] therefore actually reduces the number of equilibria to avoid the non-trivial result of a policy equilibrium characterized by such beliefs.
} 
is a strong government with probability $\theta_{s}=1$. The leaves $\tilde{\epsilon}_{1}^{s}=W_{\min }$ as the unique equilibrium value that a strong government chooses in order to minimize its loss $V_{s}^{G}$. [q.e.d.]

The proposition above establishes a separating equilibrium in which the strong government is able to signal its policy at the lowest possible cost. We can therefore posit that the constraint in [7.24] should just be binding. ${ }^{12}$

\subsection{Pooling equilibrium}

Up to now the analysis has covered only the case of a separating equilibrium where the government's true identity $\left(T_{s}\right.$ or $\left.T_{w}\right)$ is revealed beyond doubt to the private sector by its period-1 choice of policy. In a pooling equilibrium, by contrast, both types choose the same level of devaluation $\epsilon_{1}^{w}=\epsilon_{1}^{s}$ so the public has no further information on which to discriminate between the possible types. Specifically, in a pooling equilibrium a weak policymaker prefers to mimic the strong government by selecting an devaluation rate less than its non-strategic level, $\epsilon_{1}^{w}<d_{w}$ (with the private sector in ignorance of its type). This strategy is preferred over choosing $\epsilon_{1}^{w}=d_{w}$ (and being believed to be weak with $\theta_{2}=0$ ). A strong government must be inclined to select its equilibrium devaluation close to its short-run strategy choice $d_{s}$ rather than pursuing a signaling strategy significantly below $d_{s}$ which would alternatively allow it to distinguish itself unambiguously from its weak counterpart. Therefore, we can posit the conditions that are necessary to support a pooling equilibrium as,

$$
\begin{aligned}
V_{w}^{G}\left(\tilde{\epsilon}_{1}^{w}, \theta_{2}\right) & \leq V_{w}^{G}\left(d_{w}, \theta_{2}=0\right) \\
V_{s}^{G}\left(\tilde{\epsilon}_{1}^{s}, \theta_{2}\right) & \leq V_{s}^{G}\left(d_{s}, \theta_{2}=0\right)
\end{aligned}
$$

for the $T_{w}$ and $T_{s}$ government respectively. Since both types select the same level of devaluation, the public is unable to elicit the type from observation of first-period devaluation: the government's type is independent of its action

\footnotetext{
12 The Appendix shows that when $W\left(\epsilon_{1}\right)=0$ (i.e. when in [B.25] the equality sign
} holds) then

$$
W_{\text {min }}=\lambda_{s} k\left[1-\frac{\sqrt{a_{w} \delta\left(a_{s}-a_{w}\right)\left[\alpha\left(a_{s}+a_{w}\right)+2 a_{s} a_{w} \mu^{2}\right]}}{a_{w} a_{s} \mu}\right]
$$


(compared with the separating equilibrium). The exchange rate decision in period 1 therefore provides no further information on which to revise beliefs. Assuming passive conjectures (see Section 5.2.1), the prior beliefs remain unrevised upon entering the second period with $\theta_{1}=\theta_{2}$. Second-period wage increases that are made on the basis of this measure of reputation are

$$
\hat{w}_{2}\left(\theta_{2}\right)=\frac{\alpha k}{\mu}\left[\frac{\alpha+a_{s} \mu^{2}+\left(a_{w}-a_{s}\right) \theta_{1} \mu^{2}}{a_{w}\left(\alpha+a_{s} \mu^{2}\right)+\left(a_{s}-a_{w}\right) \theta_{1} \alpha}\right]
$$

from [7.13].

The solution to this problem involves deriving regions of $\epsilon_{1}$ for which the above inequalities are true and subsequently, deriving a set of devaluation rates for which a pooling equilibrium is deemed plausible for both the strong and weak government. Appendix B.6.1 and B.6.2 derive algebraically a region $\bar{P}$ for which both inequalities in [7.38] and [7.39] hold,

$$
\bar{P}=\left[W_{\min }, W_{\max }\right] \cap\left[S_{\min }, S_{\max }\right]
$$

Furthermore, Appendix B.6.3 shows that the set $\bar{P}$ is non-empty when

$$
S_{\max }>W_{\min }
$$

This establishes the necessary condition for the existence of a pooling equilibrium for certain values of $\theta_{1}$. This inequality condition can be written alternatively as

$$
\left(\lambda_{s}-\lambda_{w}\right)+\Psi^{\prime}\left(\lambda_{s} \sqrt{a_{s}}+\lambda_{w} \sqrt{a_{w}}\right)>0
$$

where

$$
\Psi^{\prime} \equiv \frac{\left(\alpha+a_{w}^{2}\right) \sqrt{\theta_{1} \delta\left(a_{s}-a_{w}\right)\left[2 a_{w}\left(\alpha+a_{s} \mu^{2}\right)+\theta_{1} \alpha\left(a_{s}-a_{w}\right)\right]}}{a_{w} \mu\left[a_{w}\left(\alpha+a_{s} \mu^{2}\right)+\theta_{1} \alpha\left(a_{s}-a_{w}\right)\right]}>0
$$

The first term in [7.43] is always negative (because $a_{s}>a_{w}$ by definition) and the second always positive. Both depend on the difference between $a_{s}-a_{w}$. Looking at the first term, we can therefore posit that if inflation preferences of the two types of governments are close to each other (i.e. when $\lambda_{s}-\lambda_{w}$ is close to 0 ), then a separating outcome is more likely. In a similar vein, if the economy exhibits little distortion $k$, then the incentives for the weak government to masquerade are diminished and accordingly, it will rather not invest in reputation.

The following proposition can then be made, 
Proposition 7.5: Assume that $\tilde{s}\left(\tilde{\epsilon}_{1}^{\tilde{w}}, \tilde{\epsilon}_{1}^{s}\right)$ is a pooling equilibrium. Then for a given prior reputation $0<\theta_{1}<1$ it holds that $\tilde{\epsilon}_{1}^{w}=\tilde{\epsilon_{1}^{s}} \in \bar{P}$.

Proof With the governments sending the same signal, the private sector has no means to infer the government's type from $\epsilon_{1}$ and therefore wages are modified according to [7.40] (which is a function of the prior $\theta_{1}=\theta_{2}$ ). To demonstrate that pooling equilibria are uniquely associated with the set $\bar{P}$ suppose for a contradiction that $\epsilon_{1} \notin P$. In this case, at least one type of policymaker $(i=s, w)$ would opt to choose his non-strategic policy $\epsilon_{1}=d_{i}$, even if in so doing he would expose himself as weak with $\theta_{2}=0$ and subsequently completely forfeit any reputational advantage (this follows directly from the conditions in [7.38] and [7.39]). Since either $T_{s}$ or $T_{w}$ could reduce their overall loss by deviating from the equilibrium, a pooling equilibrium with $\epsilon_{1} \notin P$ must be rejected. [q.e.d.]

Fig. 7.2: Pooling Equilibrium I

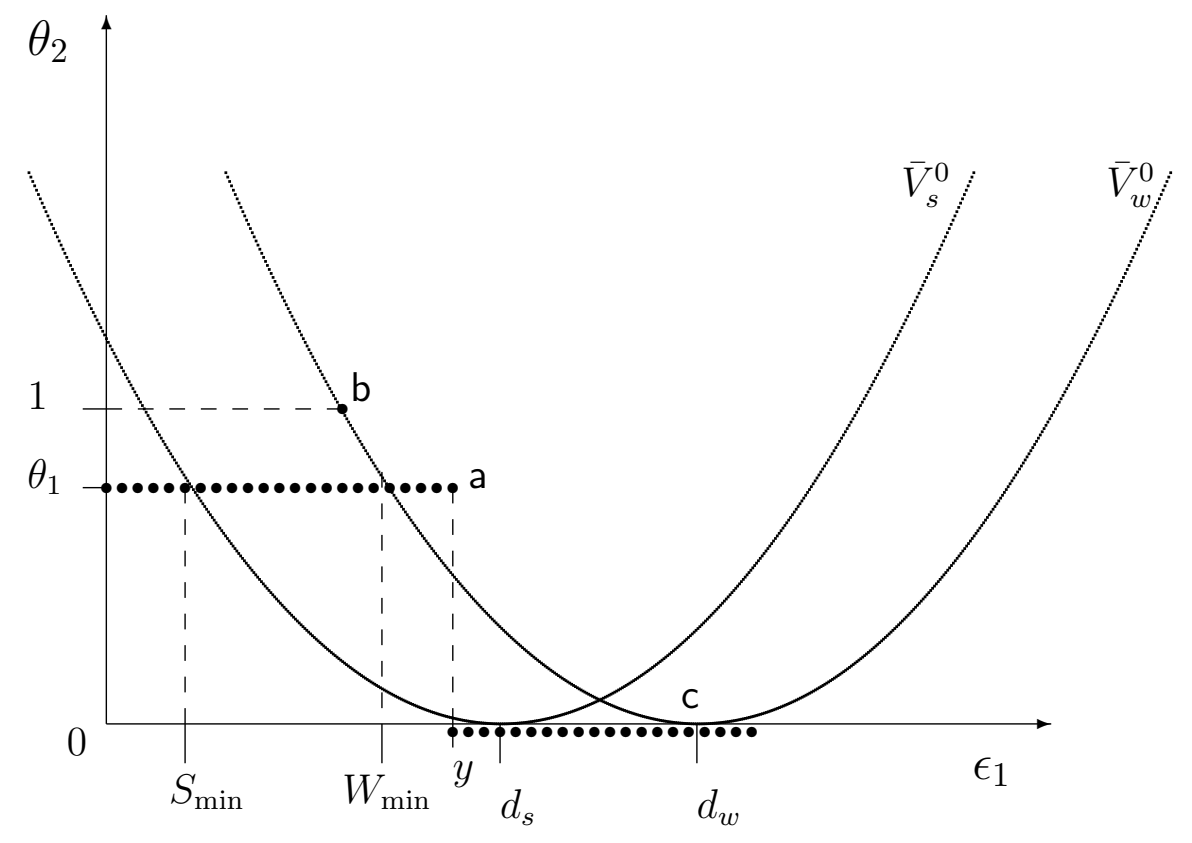

A pooling equilibrium can be illustrated in Figure [7.2], which relies on the same indifference curves, $\bar{V}_{s}^{0}$ and $\bar{V}_{w}^{0}$ that were derived in the preceding section. Again, the dotted lines depict the learning process of the trade union. 
By construction of the indifference curves in [7.2] it can be seen that for any value of the exchange rate below the threshold $W_{\text {min }}$, the weak government would be better off choosing its non-strategic value $d_{w}$, so that no pooling equilibrium is stable below $W_{\text {min }}$. Due to the mimicking incentives of the weak government, a strong government will refrain from choosing an exchange rate in excess of $d_{s}$. Therefore, a particular equilibrium corresponding to $\epsilon_{1}=y$ qualifies as a candidate for a pooling equilibrium.

Proposition 7.6: Assume that $\bar{P}$ is non-empty. Let $y$ be some number such that such that $W_{\min } \leq y \leq d_{s}$. Then there exists a pooling equilibrium with the following properties,

$$
{\tilde{\epsilon_{1}}}^{s}={\tilde{\epsilon_{1}}}^{w}=y \quad \text { and } \quad \theta_{2}= \begin{cases}\theta_{1}, & \text { if } W_{\min } \leq \epsilon_{1} \leq y \\ 0 & \text { otherwise }\end{cases}
$$

It follows from this proposition that the trade union sets its wages according to

$$
\hat{w}_{2}\left(\theta_{2}\right)= \begin{cases}\frac{\alpha k}{\mu}\left[\frac{\alpha+a_{s} \mu^{2}+\left(a_{w}-a_{s}\right) \theta_{1} \mu^{2}}{a_{w}\left(\alpha+a_{s} \mu^{2}\right)+\left(a_{s}-a_{w}\right) \theta_{1} \alpha}\right], & \text { if } W_{\min } \leq \epsilon_{1} \leq y ; \\ \frac{\alpha k}{a_{w} \mu} & \text { otherwise. }\end{cases}
$$

Proof To confirm that $y$ is indeed the exchange rate chosen in equilibrium, it is necessary to consider whether any type of government would prefer to deviate from this equilibrium, given the private learning process implied by $\hat{w}_{2}$. Note that the equilibrium exchange rate-reputation $\left(y, \theta_{1}\right)$ combination corresponds to point (a) in the figure above. The only viable deviation for the weak government would be $d_{w}$, taking the government to point (c) in the graphic which lies on a higher indifference curve. This would put the government at a disadvantage compared with the equilibrium combination. In similar terms, a strong government cannot gain by deviating to a higher level of devaluation since any $\epsilon_{1}>y$ would cause the private sector to believe it is weak with $\left(\theta_{1}=0\right)$. [q.e.d.]

The above proposition implicitly defines a set of pooling equilibria for $\epsilon_{1} \in\left[W_{\min }, d_{s}\right]$. The question remains whether the beliefs accompanying the strategies under Proposition [7.6] are intuitively sensible. First, note that $V_{G}^{s}$ is strictly decreasing ceteris paribus in $\epsilon_{1}$ for $\epsilon_{1} \leq d_{s}$. Therefore it is possible to reason persuasively that irrespective of private beliefs, the 
exchange rate $y$ is strictly dominated by any strategies such that $y<\epsilon_{1}<$ $d_{s}$. By similar reasoning the weak government would incur lower costs by selecting a $\epsilon_{1}<y<d_{w}$. The private beliefs in Proposition [7.6] are therefore unreasonable, since both governments will gain by pooling at an exchange rate above $y$. Following this line of reasoning we can single out $\epsilon_{1}=d_{s}$ as the only candidate for a pooling equilibrium. Since both governments choose the identical exchange rate $d_{s}$, the private sector cannot infer their type and private beliefs are

$$
\theta_{2}= \begin{cases}\theta_{1}, & \text { if } \epsilon_{1}=d_{s} \\ 0 & \text { otherwise }\end{cases}
$$

This unique pooling equilibrium is illustrated in Figure [7.3]. By removing dominated strategies from the list of possible candidates modifying beliefs in accordance, we have reduced the number of sensible equilibria quite considerably.

We can go further than this. To rule out formally this last equilibrium (corresponding to point (a) in Figure [7.3]), we invoke once again the Intuitive Criterion (see Section 5.2.1.1 for elaboration) to examine whether this particular equilibrium is supported by implausible beliefs. Consider the equilibrium corresponding to point (a) where $\epsilon_{1}^{s}=\epsilon_{1}^{w}=d_{s}$ and $0<\theta_{2}<1$. Assume now hypothetically that the strong government incurs a lower expected loss at point (b) than at point (a), i.e.,

$$
V^{s}\left(\epsilon_{1}^{s}=z, \theta_{2}=1\right)<V^{s}\left(\epsilon_{1}^{s}=d_{s}, \theta_{2}=\theta_{1}\right)
$$

Note that the exchange rate corresponding to point (b) occurs off the equilibrium path, in other words a signal that no government type would send in equilibrium, given the beliefs as dictated in [7.47]. Then it is possible to make the following statements:

1. From the definition of [7.48] we can see that a strong government would fare better by choosing $\epsilon_{1}^{s}=z$ and being believed to be strong with $\theta_{2}=1$ than choosing $d_{s}$ in the proposed equilibrium.

2. The weak government would do worse by choosing $z$ rather than $d_{s}$, since point (b) lies on $\bar{V}_{w}^{0}$, the indifference curve that also goes through point (c). Thus, regardless of the inferences drawn by the private sector (i.e. even if he were believed to be strong with $\theta_{2}=1$ ), the weak government would never choose $z$. 
Fig. 7.3: PoOling Equilibrium II

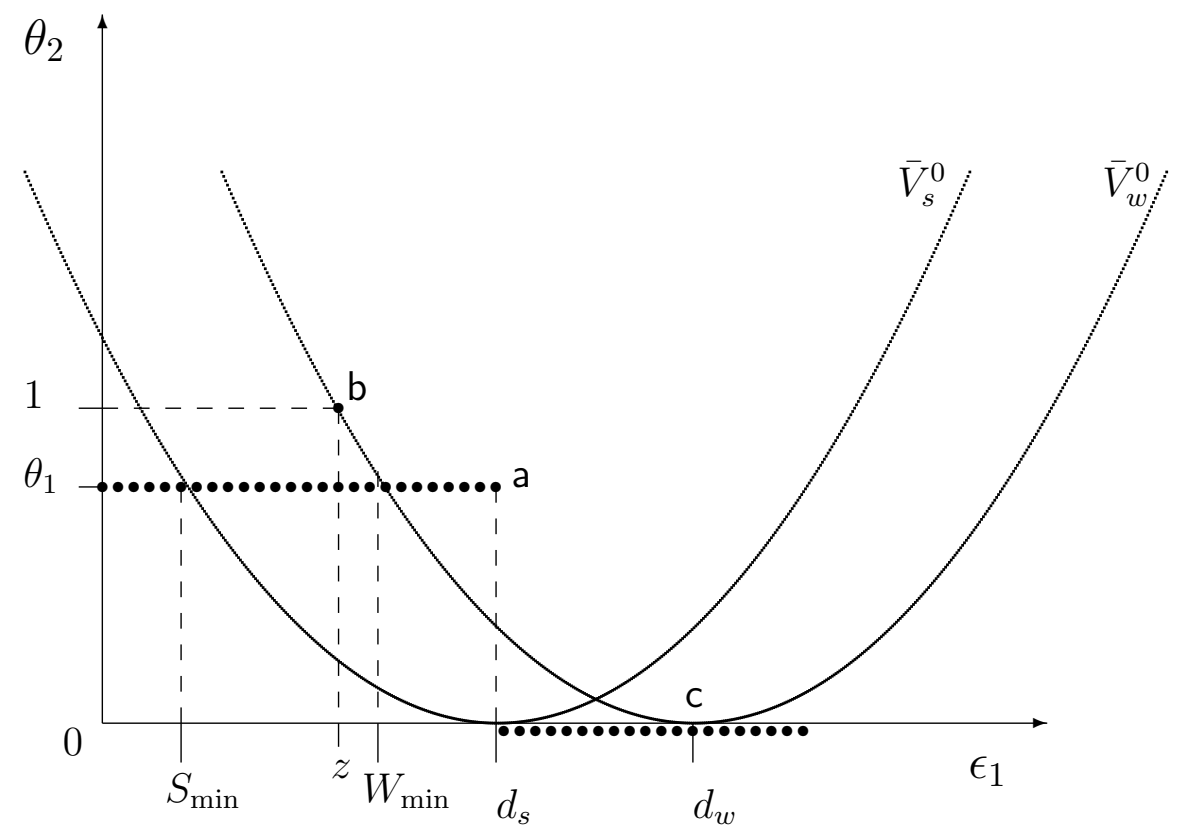

Assuming that [7.48] holds true, it follows that the equilibrium involving point (a) does not pass the Intuitive Criterion since

$$
\begin{aligned}
V^{s}\left(d_{s}, \theta_{2}=\theta_{1}\right) & >V^{s}(z, \theta=1) \\
V^{w}\left(d_{s}, \theta_{2}=\theta_{1}\right) & <V^{w}(z, \theta=1)
\end{aligned}
$$

allowing us to reject this remaining equilibrium ${ }^{13}$.

\subsection{Welfare comparison}

In the two-period model examined above we were able to establish that for a strong government to successfully separate itself from its weak counterpart it must choose actions that make it entirely unprofitable (i.e. measured in

\footnotetext{
${ }^{13}$ It is worthwhile noting that in the equilibrium associated with point (a), the out-ofequilibrium signal $\epsilon_{1}=z$ is strictly dominated for the strong government when we accept that the original beliefs set forth in [7.47] are valid.
} 
loss terms) for the weak government to copy. Therefore, even for the eventuality that the $T_{s}$ government is correctly identified by the private sector after observation of the period-1 exchange rate, the period- 2 action taken in equilibrium involves an exchange rate lower than would have been chosen in the complete information case. This means that the reputational incentives tend to reduce the devaluation bias of the strong government, a bias that made the discretionary regime of the preceding Chapter 6 entirely suboptimal. Perhaps more apparent, the incentives of the weak government to mimic a strong government in order to reap the awards of reputation also put a downward bias on the rate of devaluation. But the fact that reputation does matter can also work the other way around if it so costly that it makes it prohibitive for the weak government to invest in, thus breaking a possible separating equilibrium (with the weak government choosing $d_{w}$ in both periods). And irrespective of the government's type, we know that a lower rate of devaluation will deteriorate the current account balance, thus reducing welfare.

The observation that the information structure of the game-setting is decisive for the outcome has a direct bearing on the level of welfare, as measured in terms of loss. In particular, it can be informative to compare the government's losses in a game of incomplete information to the losses when when complete information is assumed. Returning to Section 7.2, it is possible to compute the respective intertemporal loss from [7.4] by inserting the full information strategies of $\epsilon_{1}^{s}, \epsilon_{1}^{w}, \epsilon_{2}^{s}, \epsilon_{2}^{w}$ and $\hat{w}_{2}$ from Eqns. [7.8] to [7.10]. This results in

$$
\begin{aligned}
V_{C}^{s} & =\alpha k^{2}\left[\frac{\left(\alpha+a_{s} \mu^{2}\right) \delta}{a_{s} \mu^{2}}+\frac{a_{s} \mu^{2}}{\alpha+a_{s} \mu^{2}}\right] \\
V_{C}^{w} & =\alpha k^{2}\left[\frac{\left(\alpha+a_{w} \mu^{2}\right) \delta}{a_{w} \mu^{2}}+\frac{a_{w} \mu^{2}}{\alpha+a_{w} \mu^{2}}\right]
\end{aligned}
$$

where the subscript $\mathbf{C}$ denotes complete information.

By the same method the two-period loss associated with the separating equilibrium (subscript $S E$ ) can also be calculated. According to Proposition [7.3], we know that a strong government will choose $\epsilon_{1}^{s}=x \in\left[S_{\min }, W_{\min }\right]$ so that

$$
V_{S E}^{s}=\alpha k^{2}\left[\frac{\left(\alpha+a_{s} \mu^{2}\right) \delta}{a_{s} \mu^{2}}\right]+\alpha(x-k)^{2}+x a_{s} \mu^{2}
$$




$$
=V_{C}^{s}+\frac{\left[\alpha(x-k)^{2}+x a_{s} \mu^{2}\right]^{2}}{\alpha+a_{s} \mu^{2}}
$$

A weak government's optimal first period policy is $\epsilon_{1}^{w}=d_{w}$ so we can write the intertemporal loss as

$$
\begin{aligned}
V_{S E}^{w} & =\alpha k^{2}\left[\frac{\left(\alpha+a_{w} \mu^{2}\right) \delta}{a_{w} \mu^{2}}+\frac{a_{w} \mu^{2}}{\alpha+a_{w} \mu^{2}}\right] \\
& =V_{C}^{w}
\end{aligned}
$$

Eqn. [7.51] illustrates that under the assumptions of the model, a strong government does not gain from the presence of incomplete information, if a separating equilibrium is the outcome of the game. The mimicking threat of the weak government makes it necessary for the strong government to expand the deficit in the current account by devaluing the currency to a lesser degree (since $x<d_{s}$ ) than it would have done if the private sector were fully informed about its type. Nevertheless, although this is the price the government has to pay to break the reputational incentives of the weak government, the signaling incentive does tend to have the effect of reducing the first-period inflationary bias of the strong government. This effect can be seen by noting that first-period inflation under incomplete information, $\pi_{1, C}$, is lower than under complete, $\pi_{1, S}$, so that

$$
\pi_{1, C}-\pi_{1, S E}=\mu\left(d_{s}-x\right)>0
$$

since $x<d_{s}$ under all parameter constellations. The weak government, on the other hand, does no better in the separating equilibrium, since by definition this type chooses the short-run first-period strategy $\epsilon_{1}=d_{w}$ in both complete and incomplete information settings.

The strong government's loss associated with the 'refined' pooling equilibrium (subscript $P$ ) in which both governments choose $\epsilon_{1}^{s}=\epsilon_{1}^{w}=d_{s}$ with $0<\theta_{1}<1$ can be derived as

$$
V_{P}^{s}=\frac{\alpha k^{2} a_{s} \mu^{2}}{\alpha+a_{s} \mu^{2}}+\frac{\delta k^{2} a_{s}\left(\alpha+a_{w} \mu^{2}\right)^{2}\left(\alpha+a_{s} \mu^{2}\right)}{\mu^{2}\left[a_{w}\left(\alpha+a_{s} a_{w} \mu^{2}+\theta_{1} \alpha\left(a_{s}-a_{w}\right)\right]^{2}\right.}
$$

To compare this result with the level of welfare achieved under full information, it is convenient to take the difference between [7.56] and [7.49]. The resulting term,

$$
\begin{aligned}
& V_{P}^{s}-V_{C}^{s}= \\
& \quad\left(1-\theta_{1}\right) \frac{\delta k^{2} \alpha^{2}\left(a_{s}-a_{w}\right)\left(\alpha+a_{s} \mu^{2}\right)\left(\alpha \theta_{1}\left(a_{s}-a_{w}\right)+\alpha\left(a_{s}+a_{w}\right)+2 a_{s} a_{w} \mu^{2}\right)}{a_{s} \mu^{2}\left[a_{w}\left(\alpha+a_{s} a_{w} \mu^{2}+\theta_{1} \alpha\left(a_{s}-a_{w}\right)\right]^{2}\right.}
\end{aligned}
$$


is positive, meaning that the strong government cannot improve upon the complete information case when the governments separate. But it can be substantiated that higher the initial reputation $\theta_{1}$ the strong government enters the game, the better the result for the strong government, since this lets it approach the full information loss. We can see this by noting that

$$
\frac{\partial\left(V_{P}^{s}-V_{C}^{s}\right)}{\partial \theta_{1}}=-\frac{2 \delta k^{2} \alpha^{2} a_{s}\left(a_{s}-a_{w}\right)\left(\alpha+a_{w} \mu^{2}\right)^{2}\left(\alpha+a_{s} \mu^{2}\right)}{\mu^{2}\left[a_{w}\left(\alpha+a_{s} a_{w} \mu^{2}+\theta_{1} \alpha\left(a_{s}-a_{w}\right)\right]^{2}\right.}<0
$$

Finally, the informational structure that renders a pooling equilibrium as the plausible outcome can be favorable for the weak government, again compared with loss it would suffer under complete information. A weak government's loss in the pooling equilibrium is

$$
V_{P}^{w}=\frac{\alpha k^{2} \mu^{2}\left(\alpha a_{w}+a_{s}^{2} \mu^{2}\right)}{\alpha+a_{s} \mu^{2}}+\frac{\delta k^{2} a_{w}\left(\alpha+a_{s} \mu^{2}\right)^{2}\left(\alpha+a_{w} \mu^{2}\right)}{\mu^{2}\left[a_{w}\left(\alpha+a_{s} a_{w} \mu^{2}+\theta_{1} \alpha\left(a_{s}-a_{w}\right)\right]^{2}\right.}
$$

Taking the difference between [7.58] and [7.50] we come to the expression

$$
\begin{aligned}
V_{P}^{w}- & V_{C}^{w}= \\
& \frac{\mu^{4}\left(a_{s}-a_{w}\right)^{2}}{\left(\alpha+a_{s} \mu^{2}\right)\left(\alpha+a_{w} \mu^{2}\right)} \\
- & \frac{\theta \delta k^{2} \alpha\left(a_{s}-a_{w}\right)\left(\alpha+a_{w} \mu^{2}\right)\left(\alpha \theta_{1}\left(a_{s}-a_{w}\right)+\alpha\left(a_{s}+a_{w}\right)+2 a_{s} a_{w} \mu^{2}\right)}{a_{w} \mu^{2}\left[a_{w}\left(\alpha+a_{s} a_{w} \mu^{2}+\theta_{1} \alpha\left(a_{s}-a_{w}\right)\right]^{2}\right.}
\end{aligned}
$$

which can be positive or negative, depending on the parameter values. It can be seen, though, that the difference $V_{P}^{w}-V_{C}^{w}$ is decreasing in $\theta_{1}$, which can be confirmed with

$$
\frac{\partial\left(V_{P}^{w}-V_{C}^{w}\right)}{\partial \theta_{1}}=-\frac{2 \delta k^{2} \alpha^{2} a_{w}\left(a_{s}-a_{w}\right)\left(\alpha+a_{s} \mu^{2}\right)^{2}\left(\alpha+a_{w} \mu^{2}\right)}{\mu^{2}\left[a_{w}\left(\alpha+a_{s} a_{w} \mu^{2}+\theta_{1} \alpha\left(a_{s}-a_{w}\right)\right]^{2}\right.}<0
$$

Although the overall effect on welfare is ambiguous, the weak government undeniably benefits from the lowering of devaluation expectations that results from the possible presence of a strong government.

\subsection{Discussion}

Let us briefly interpret the main points of this section and add some caveats. It was shown that the presence of private information entirely alters the incentive structure that the government is confronted with prior to carrying out 
its policy. If signaling incentives are strong enough, a government committed to low inflation will not only refrain from a devaluation, it will ultimately revalue the currency (see [7.16]). This movement of the exchange rate would be too costly for the weak government to emulate, but provides a valuable signal to the private sector that the government is committed to the stabilization of inflation. ${ }^{14}$ From Proposition 7.3 it follows that the optimal range and thus the likelihood of signaling behavior is an increasing function of the difference between $a_{s}$ and $a_{w}$. This means that the larger the divergence in inflation preferences between the two types of government, the less costs the strong government must incur to signal its type. Hence the more likely the separating equilibrium will be the result of the game.

From a theoretical perspective we can also establish that the reputation mechanism described in this section does create strong incentives for both types of government to follow a policy of low inflation. Until the true type of policymaker is revealed in the final period, intrinsic uncertainty ensures that inflationary expectations are dampened. This holds true as long as the main prerequisite of intrinsic uncertainty holds, namely that there is even the remote possibility that the government is the strong type (i.e. $\theta_{1}>0$ ). Accordingly, eq. [7.55] illustrates that the inflationary bias of a strong government is reduced compared with the full information case. Similarly, a policy of low inflation can be sustained in the initial period even if a weak government is in office since there exist reputational "assets" to withdraw from its optimal short-run devaluation until the final period is realized. These findings therefore suggest that reputational mechanisms that harness discretionary behavior may in fact act as a substitute for the legislative implementation of a commitment regime.

However, the incentive to mimic a strong government and thus sustain a low inflation outcome depends on the time preference and initial assessment about the government's type. If there is a high degree of confidence that the government is strong in the initial period (i.e. large $\theta_{1}$ ) then this increases the incentives of the weak type to follow a course of low inflation because the cost of losing reputation and increasing expected inflation is also higher

\footnotetext{
${ }^{14}$ Chile, for example, revalued its currency twice during its ERBS program beginning in 1976, in an attempt to demonstrate the government's resolve in fighting inflation. This unfortunately did not prevent a balance of payments crisis which ultimately led to its downfall.
} 
— this makes a pooling outcome more likely. ${ }^{15}$ On the other hand, a high discount rate $r$ may inhibit the inflation-dampening effects of signaling in the separating equilibrium. To see this note that $S_{\min }$ in [7.25] increases as we reduce $\delta$. In the limiting case where $\delta=0$, the exchange rate $\epsilon_{1}^{s}$ chosen in equilibrium by the strong government is equal to the perfect information value $\lambda_{s} k$. This happens to be the highest rate of devaluation that the strong government would rationally choose. Thus as we decrease $\delta$, the signal that the strong government must send to ensure separation need not be as "strong" as would be the case if the future did play a greater role in the decisions of the government.

The mention of some caveats to the above seems appropriate given the policy implications. First of all, the macroeconomic model used to chart the development of the balance of payments and inflation is a stark simplification of the underlying process which does not take into consideration other influencing variables. Thus it would be conceivable to postulate that the signaling activity of the strong government not be limited to the variation of the exchange rate, as implied by the model. The imposition of capital controls or fiscal measures could also be regarded as measures that signal (albeit at a cost) the determination of the government to abide by a policy of low inflation. These measures could also be used in combination with each other to generate a positive influence on private sector expectations. ${ }^{16}$

Another caveat pertains to the empirical gravity of the arguments subsumed in the macroeconomic relationship between exchange rate, inflation and external balance. In the equations [7.1] to [7.3] we have assumed implicitly a "trade-off" between the alleviation of an external imbalance and the stabilization of the inflation rate, where the magnitude of this influence can be measured by $\sqrt{\alpha}$. This means that the model assumes some influence of the real exchange rate on the evolution of trade flows - this is the standard argument found in most textbooks. However, newer studies suggest only a weak link between the movement of the exchange rate and trade

\footnotetext{
15 This can be rationalized be noting that in the weak government's loss function in 7.58, loss decreases as $\theta_{1}$ rises.

${ }^{16}$ A model that follows this line of reasoning is PERsson And van WiJnbergen (1993). The authors examine the imposition of wage and price controls in conjunction with a monetary stabilization program. Their results suggest that these incomes policies support the monetary side of stabilization by enabling a low-inflation government to signal its type at a lower cost than a stabilization program that relies solely on monetary instruments. Such dual approach was successful in Israel's stabilization of 1985.
} 
flows. For example, in an empirical study of the Argentinian ERBS of 1991, WoHLmann (1998) establishes that the influence of relative price changes on trade flows is not as strong as standard theory would suggest. In fact, the author argues that the real appreciation was not the main cause of the external imbalance that ensued after the exchange rate was fixed. Most likely the deterioration of trade accounts had a number of causes, such as the strong growth and restructuring of industry as the economy became more market oriented in the early 1990s. Thus the magnitude of $\sqrt{\alpha}$ may be only small, depending on economic environment in which the ERBS is enacted. 


\section{CONCLUDING REMARKS}

It has become a well-established ritual to explain what goes wrong when nothing is supposed to go wrong in developing economies by appealing to the notion of "credibility" or "political instability". In this thesis I have adopted the position that these musings may suffice the needs of journalists and wayfaring policy-brokers, but for the economist interested at getting to the bottom of things, the metaphor of credibility rings hollow and poses a kind of puzzlement. A prime motivation for this thesis has therefore been a dissatisfaction with the causal explanations for policy failures. But also the simple curiosity about the role of non-economic entities such as speech, promises and beliefs has been encouraging and I do not doubt that these pages will also bear witness to the considerable degree of pleasure I derived from employing the logical consistency of a theoretical apparatus to these problems (some find this very hard to believe). In fact, if I had never come to read the microeconomic textbook of KREPS (1990) or the insightful analysis of credibility in Sobel (1985), I might have chosen an entirely different route to analyze credibility. Probably for these reasons, a unifying theme that runs through the entire thesis is basically methodological in nature. My aspiration is that the reader will have gained a significantly greater insight into the problems surrounding credibility and reputation, an insight whose major content may only be of providing a language to discuss that problem.

The issue of credibility has been confronted by proposing a framework that links the relevant macroeconomic variables with behaviorial assumptions about the key actors in a specific policy setting. We set out the discussion by showing that the mechanisms underlying policy formation are best idealized as a strategic interaction between a government and private sector. The game theoretic approach derives its momentum from the rational expectations school and a growing body of thought (such as the public-choice school) that envisions the government as rational and self-interested like the rest of the economy and not a mere puppeteer of optimal policies. There is a fine line to be drawn from the simple model of stabilization and reform in 
Chapter 2 that relied on rational expectations to the highly technical and intricate reasoning that was employed in Chapter 7 to examine the reputational effects of an ERBS. The link to ever more sophisticated methods of evaluating macroeconomic policy was made possible by using refinements of the basic Nash equilibrium. This points strongly toward the crucial role of expectations, but it also uncovers the incompleteness of the rational expectations concept. In elaborating these fine points I have slightly departed from the convention of many similar contributions by being very explicit about the game-theoretical notions of equilibrium, information, and subjective beliefs that underlie the results.

Of course, by emphasizing theoretical reasoning and paying only lipservice to case-studies and empirical investigations this undertaking runs the risk of constituting itself as another high priesthood concerned primarily with tools instead of facts. I want to stress that an in-depth knowledge of the empirical relationships, the "hard facts" of political and administrative reality are profound and many of the case studies that I have banished to the reference section perhaps underemphasize the role they play in coming to grips with the fine points of analysis. As one observer succinctly puts it,

When it comes to action, economic theory is only one input among many. It has to be combined with a grasp of political and administrative feasibility and above all has to take advantage of experience and observation, not rely wholly on logic. As has often been remarked, logic can be a way of going wrong with confidence. ${ }^{1}$

Many of the game theoretic approaches that were discussed could not hide the fact that they derive their heritage from the study of industrial economics. But the caveat applies that abstractions which may seem plausible in the study of duopolies are not necessarily plausible in the study of macroeconomic policy. This means that some of the abstractions necessary to yield a meaningful game-theoretic analysis are a bit "strained" — the game-theoretic formulations have been stripped down to the point where it is virtually only expectations that yield interesting dynamics and insight into the workings of policy and this puts any generalizations in doubt. For example, I admit to feeling uncomfortable about the habitual tendency of much economic research in this field to rely on highly "stylized" macroeconomic models to underpin the sometimes very complex interdependencies of modern

\footnotetext{
${ }^{1}$ Cairncross (1992), quoted from McCloskey (1994), p. 50.
} 
(open) economies. The prime example of this is the Lucas-type output relationship and natural rate hypothesis used extensively in monetary models. In the ERBS model, I relied on a very simplified relationship between the real exchange rate and the balance of payments (Eq. [6.2]) - I mentioned that newer studies put this link into question. Of course these simplifications are vital if there are to be any results at all within the game-theoretic framework. Through my experiences in "fine-tuning" the ERBS model of Chapter 7, I can attest that juxtaposing a more rigorous macroeconomic framework under the constraints of a game-theoretic formulation adds a large amount of complexity for a little amount of novel insight.

One last related point. We observed that the results were extremely sensitive to apparently minor alterations in the information structure. Thus in a world of uncertainty, almost any outcome can be rationalized. Under intrinsic uncertainty, prior beliefs have a major influence on the evolution of the private sector's actions, but what their origin is open to debate. One clue to the origin of common priors and thus of the potential success of any economic policy relies very often on individual traits of the policymakers themselves. HARBERGER (1993) relates the success of policy in certain Latin American countries to key individuals that were responsible positions. The influence of these personalities was so strong that "the policy would in all likelihood have failed (or never got started) but for the efforts of a key group of individuals, and within that group, one or two outstanding leaders." 2 . The origins of common priors are outside the realm of economic analysis, however sophisticated its methods may be. Economic reasoning brings us no further here and there is perhaps still a lot to learn from such disparate fields as political science and psychology on the issue of credibility. This would speak for a more interdisciplinary approach than was offered here.

\footnotetext{
${ }^{2}$ See Harberger (1993), p. 343
} 
APPENDIX 


\section{A. MONETARY POLICY}

\section{A.1 Precommitment solution}

When commitment is feasible then the government moves first (von Stackelberg leader). Common knowledge of this will mean that

$$
\pi_{t}^{e}=\pi_{t}
$$

once the private sector comes to move. The government's optimization problem thus treats private sector expectations [A.1] as a constraint in the maximization of $U_{t}^{G}$. By replacing [A.1] in equation [4.6], the government's utility simplifies to

$$
U_{t}^{G}=-a \pi^{2}-b \Delta^{2}
$$

First-order conditions for a maximum require that

$$
\frac{\partial U_{t}^{G}}{\partial \pi}=2 a \pi \stackrel{!}{=} 0
$$

and it follows that the government's choice of inflation is $\pi^{C}=0$. Replacing for $\pi_{t}$ in equation [4.6] utility is $U_{t}^{G}\left(\pi^{C}\right)=-b \Delta^{2}$

\section{A.2 Discretionary solution}

Under discretion the policymaker is not bound by his announcement " $\pi_{t}=$ 0 ", so he is no longer bound by the credibility constraint in [A.1]. First-order conditions are derived from [4.6] by taking the first derivative with respect to $\pi$,

$$
\left.\frac{\partial U_{t}^{G}}{\partial \pi}\right|_{\pi^{e}=\text { const. }}=-2 a \pi-2 b \alpha^{2}\left(\pi-\pi^{e}\right)-2 b \alpha \Delta \stackrel{!}{=} 0
$$

We can see that if expectations can be held to $\pi^{e}=0$ then the marginal benefit of increased production through (surprise) inflations $b \alpha^{2}\left(\pi-\pi^{e}\right)$. 
The reaction function $\pi_{t}\left(\pi_{t}^{e}\right)$ can be derived from the first-order conditions in [A.4] which delivers the utility-maximizing choice of $\pi_{t}$ for any given $\pi_{t}^{e}$,

$$
\pi_{t}\left(\pi_{t}^{e}\right)=\frac{\alpha^{2} b \pi^{e}+\alpha b \Delta}{a+\alpha^{2} b}
$$

With rational expectations the private sector uses equation [A.5] in calculating its inflation forecast. This means that $\pi_{t}^{e}=E \pi_{t}=\pi\left(\pi_{t}^{e}\right)$. Given these public perceptions, the government's best response (maximization of utility) is given by an inflation level of

$$
\pi^{D}=\frac{\alpha b \Delta}{a}
$$

which corresponds to the time consistent outcome. Utility is computed by substituting $\pi^{D}$ for $\pi_{t}$ and $\pi_{t}^{e}$ in government utility [4.6],

$$
\begin{aligned}
U^{G}\left(\pi^{D}\right) & =-a\left[\frac{\alpha b \Delta}{a}\right]-b[0-\Delta]^{2} \\
& =\frac{-\alpha^{2} b^{2} \Delta^{2}}{a}-\frac{a b \Delta^{2}}{a} \\
& =-b \Delta^{2}\left(\frac{\alpha^{2} b+a}{a}\right)
\end{aligned}
$$

If public perceptions can instead be held at a level associated with the announcement, $\pi_{t}^{e}=0$, then with [A.5] the inflation level will be

$$
\pi^{S}=\frac{\alpha b \Delta}{a+\alpha^{2} b}
$$

which is the "surprise" solution to this policy game. Government utility at this level of inflation is

$$
\begin{aligned}
U_{t}^{G}\left(\pi^{S}\right) & =-a\left[\frac{\alpha b \Delta}{a+\alpha^{2}}\right]^{2}-b\left[\alpha\left\{\frac{\alpha b \Delta}{a+\alpha^{2}}\right\}-\Delta\right]^{2} \\
& =-a\left[\frac{\alpha b \Delta}{a+\alpha^{2}}\right]^{2}-b\left[\frac{\alpha^{2} b \Delta}{a+\alpha^{2} b}-\frac{\Delta a}{a+\alpha^{2} b}-\frac{\alpha^{2} b \Delta}{a+\alpha^{2} b}\right]^{2} \\
& =\frac{\Delta^{2} a b\left[-a-\alpha^{2} b\right]}{\left(a+\alpha^{2} b\right)^{2}} \\
& =-b \Delta^{2}\left(\frac{a}{a+\alpha^{2} b}\right)
\end{aligned}
$$


A "punishment" solution obtains when the government sticks to its announcement of low inflation, but the private sector expects discretionary inflation $\pi^{D}$. In this case, utility is

$$
\begin{aligned}
U_{t}^{G}\left(\pi^{P}\right) & =-a[0]-b\left[\alpha\left(0-\frac{\alpha b \Delta}{a}\right)-\Delta\right]^{2} \\
& =-b \Delta^{2}\left(\frac{a+\alpha^{2} b}{a}\right)^{2}
\end{aligned}
$$

\section{A.3 Trigger strategy}

In our example of a trigger strategy, the government has two options at the beginning of period $t=0$, after private sector inflationary expectations, $\pi_{0}^{e}=0$, have been set. The government prefers option (a) over option (b), if

$$
V^{G, a}=U_{1}+\sum_{t=1}^{\infty}\left(\frac{1}{1+r}\right)^{t} U_{3}>V^{G, b}=\sum_{t=1}^{\infty}\left(\frac{1}{1+r}\right)^{t} U_{2}=V^{G, b}
$$

Substite for $U_{1}, U_{2}$ and $U_{3}$ from eqs. (4.9), (4.8) and (4.11), respectively:

$$
\left(-\frac{b \Delta^{2}}{\xi}\right)+\sum_{t=1}^{\infty}\left(\frac{1}{1+r}\right)^{t}\left(-b \Delta^{2} \xi\right)>\sum_{t=1}^{\infty}\left(\frac{1}{1+r}\right)(-b \Delta)^{2}
$$

with $\frac{a+\alpha^{2} b}{a} \equiv \xi$. The LHS of the inequality above can also be written as

$$
\left(-\frac{b \Delta^{2}}{\xi}\right)+\left(-b \Delta^{2} \xi\right)-\left(-b \Delta^{2} \xi\right)+\sum_{t=1}^{\infty}\left(\frac{1}{1+r}\right)^{t}\left(-b \Delta^{2} \xi\right)
$$

which is equivalent to

$$
\begin{array}{r}
\left(-\frac{b \Delta^{2}}{\xi}\right)+\left(-b \Delta^{2} \xi\right)-\left(-b \Delta^{2} \xi\right)+\sum_{t=0}^{\infty}\left(\frac{1}{1+r}\right)^{t}\left(-b \Delta^{2} \xi\right) \\
=\frac{-b \Delta^{2}}{\xi}+b \Delta^{2} \xi+\sum_{t=0}^{\infty}\left(\frac{1}{1+r}\right)^{t}\left(-b \Delta^{2} \xi\right)
\end{array}
$$

Using the definition of a geometric series,

$$
\sum_{t=0}^{\infty}\left(\frac{1}{1+r}\right)^{t}=\frac{1+r}{r}
$$

and after dividing both sides by $-b \Delta^{2}$, it is possible to write the inequality in $[$ A.12] as

$$
-\frac{1}{\xi}+\xi+\frac{1+r}{r} \xi>\frac{1+r}{r}
$$


which reduces to the condition used in the text,

$$
r>\xi=\frac{a+\alpha^{2} b}{a}
$$

\section{A.4 Reputational indifference curves}

To compute indifference curves we first compute the current loss of utility for any level of of current inflation $\pi_{\tau-1}$ solving for $\pi_{\tau-1}$ in equation [5.18],

$$
U_{\tau-1}^{G}\left(\pi_{\tau-1}\right)=-\frac{a \pi_{\tau-1}^{2}}{2}+b_{w} \alpha \pi_{\tau-1}-b_{w} \alpha\left(1-\theta_{\tau-1}\right)\left(1-\rho_{\tau-1}\right) \pi^{D}-b_{w} \Delta
$$

The weak government is indifferent between (net) current and future utility when

$$
U_{\tau-1}^{G}\left(\pi^{D}\right)-U_{\tau-1}^{G}\left(\pi_{\tau-1}\right) \stackrel{!}{=} \delta U_{\tau}^{G}\left(\theta_{\tau}>0\right)-\delta U_{\tau}^{G}(\theta=0)
$$

where the left-hand side gives the short-term gain of a discretionary policy in $\tau-1$ and the right-hand side represents future benefits of reputation. Solving for $\theta$ in [A.20] allows us to draw the indifference curve in a $\left(\theta_{\tau}, \pi_{\tau-1}\right)$ grid,

$$
\begin{aligned}
\theta_{\tau}\left(\pi_{\tau-1}\right) & =\frac{1}{2 \delta}\left(\frac{\pi}{\pi^{D}}\right)^{2}-\frac{1}{\delta}\left(\frac{\pi}{\pi^{D}}\right)+\frac{1}{2 \delta} \\
& =\frac{\left(\pi_{\tau-1}-\pi^{D}\right)^{2}}{2 \delta\left(\pi^{D}\right)^{2}}
\end{aligned}
$$

recalling that $\pi^{D}=\frac{b_{w} \alpha}{a}$.

\section{A.5 Time paths for $\theta_{t}$ and $\rho_{t}$}

The time paths for $\theta_{t}$ and $\rho_{t}$ can be derived from the first-order conditions in [5.44] via backward induction. In the final period $\tau$, the government reveals its type with certainty, $\rho_{\tau}=0$ so that [5.44]

$$
\theta_{\tau}=\frac{1}{2 \delta}
$$

(this is essentially the result derived in [5.36]). The value for $\rho_{\tau-1}$ is derived by replacing $\theta_{\tau}$ in the above equation with the Bayesian update

$$
\theta_{\tau}=\frac{\theta_{\tau-1}}{\theta_{\tau-1}+\left(1-\theta_{\tau-1}\right) \rho_{\tau-1}}
$$


Replacing $\theta_{\tau}$ with [A.23] in [5.44],

$$
1-\frac{\theta_{\tau-1}}{\theta_{\tau-1}+\left(1-\theta_{\tau-1}\right) \rho_{\tau-1}}=1-\frac{1}{2 \delta}
$$

and solving for $\rho_{\tau-1}$ yields

$$
\rho_{\tau-1}=\frac{(2 \delta-1) \theta_{\tau-1}}{1-\theta_{\tau-1}}
$$

In $\tau-1$ the indifference condition is

$$
\left(1-\theta_{\tau-1}\right)\left(1-\rho_{\tau-1}\right)=1-\frac{1}{2 \delta}
$$

Substituting [A.25] for $\rho_{\tau-1}$ results in

$$
\begin{array}{r}
\left(1-\theta_{\tau-1}\right)\left(1-\frac{(2 \delta-1) \theta_{\tau-1}}{1-\theta_{\tau-1}}\right)=1-\frac{1}{2 \delta} \\
\Rightarrow \theta_{\tau-1}=\frac{1}{4 \delta^{2}}
\end{array}
$$

In a similar fashion, $\theta_{\tau-2}$ and $\rho_{\tau-2}$ can be derived as

$$
\begin{aligned}
\rho_{\tau-2} & =\frac{(4 \delta-1) \theta_{\tau-1}}{1-\theta_{\tau-1}} \\
\theta_{\tau-2} & =\frac{1}{8 \delta^{3}}
\end{aligned}
$$

Per induction the time paths for $\theta_{t}$ and $\rho_{t}$ for $t=\{0 \ldots \tau\}$ are

$$
\begin{aligned}
\theta_{t} & =\left(\frac{1}{2 \delta}\right)^{\tau+1-t} \\
\rho_{t} & =\frac{\frac{1}{2 \delta}-\theta_{t}}{1-\theta_{t}}=\frac{\frac{1}{2 \delta}-\left(\frac{1}{2 \delta}\right)^{\tau+1-t}}{1-\left(\frac{1}{2 \delta}\right)^{\tau+1-t}}
\end{aligned}
$$




\section{B. EXCHANGE RATE POLICY}

\section{B.1 Semi-discretionary solution}

The equilibrium can be computed by working backwards (in time) starting from the optimal wage decision of the private sector, which is equivalent to the rational expectations of devaluation of the representative trade union. Since policy is binding and $u_{t}$ is not part of the information set at time $t$, the union acts rationally by setting their devaluation expectations to $\mathrm{E}\left\{e_{t} \mid \Omega_{t-1}\right\}-e_{t-1}=w_{t}-e_{t-1}=\kappa_{S}$. Substituting these terms in [6.2] and [6.5] yields

$$
\begin{aligned}
\pi_{t} & =\mu\left(e_{t}-e_{t-1}+\pi_{t}^{*}-\pi_{t-1}^{*}\right)+(1-\mu)\left(e_{t-1}-w_{t-1}+\kappa_{S}\right) \\
b_{t} & =b^{*}+\sqrt{\alpha}\left[e_{t}-e_{t-1}-\kappa_{S}-u_{t}-k\right]
\end{aligned}
$$

These expressions for $\pi_{t}$ and $b_{t}$ are plugged into the government's preference function $U_{t}^{g}$, which defines the utility function over $\kappa_{S}$ and $\kappa$,

$$
L_{t}=\alpha\left(\kappa u_{t}-e_{t-1}-u_{t}-k\right)^{2}-a\left[\kappa_{S}+\mu \kappa u_{t}+(1-\mu)\left(e_{t-1}-w_{t-1}\right)\right]^{2}
$$

The optimal state-contingent policy rule of the government is computed by taking first-order conditions of $L_{t}$ with respect to $\kappa_{S}$ and $\kappa$,

$$
\begin{aligned}
\frac{\partial E L_{t}}{\partial \kappa_{S}} & =E\left\{-2 a\left[\mu \kappa u_{t}+\kappa_{S}+(1-\mu)\left(e_{t-1}-w_{t-1}\right)\right\} \stackrel{!}{=} 0\right. \\
& \Rightarrow \kappa_{S}=(\mu-1)\left(e_{t-1}-w_{t-1}\right) \\
\frac{\partial E L_{t}}{\partial \kappa_{S}} & =E\left\{2 \alpha u_{t}\left(\kappa u_{t}-u_{t}-k\right)+2 a \mu u_{t}\left[\mu \kappa u_{t}+\kappa_{S}+(\mu-1)\left(e_{t-1}-w_{t-1}\right]\right\} \stackrel{!}{=} 0\right. \\
& \Rightarrow \kappa=\frac{\alpha}{\alpha+a \mu^{2}}
\end{aligned}
$$

where the property $E\left\{u_{t} \mid I_{t-1}\right\}=0$ and $E u_{t}^{2}=\sigma^{2}$ has been used. Combining both terms results in the optimal exchange rate rule

$$
\epsilon_{t}\left(u_{t}, k\right)=\kappa_{S}+\kappa u_{t}=\underbrace{\frac{\alpha}{\alpha+a \mu^{2}}}_{\lambda} u_{t}-(1-\mu)\left(e_{t-1}-w_{t-1}\right)
$$


The current account can now be computed by inserting $\epsilon_{t}$ for $e_{t}-e_{t-1}$ in equation [6.2] and making use of the fact that $\kappa_{S}=(\mu-1)\left(e_{t-1}-w_{t-1}\right)$. Inflation is computed in a similar fashion by substituting respectively with equation [6.5]. The aggregate expected loss $\mathrm{E} L_{t}$ can be derived by collecting the terms for $b_{t}$ and $\pi_{t}$ and inserting them in [6.1].

\section{B.2 Fixed exchange rate}

In the alternative commitment regime the government's exchange rate is fixed (and this can be enforced), with $e_{t}=e_{t-1}$ for all $t$. It follows that $\kappa_{s}=$ $\kappa=0$ and the government's loss is $L_{t}=\alpha\left[-u_{t}-k\right]^{2}$. Taking unconditional expectations and taking note of the fact that $\mathrm{E} u_{t}=\sigma_{u}^{2}$ results in the expected loss formula in the text.

\section{B.3 Discretionary solution}

In this equilibrium the government cannot commit in advance to a devaluation rule. In this case an equilibrium is defined by the Nash conditions that both players select a best strategy response to the strategy of the opponent. In equilibrium the optimal devaluation rule in this regime is derived from the minimization of $L_{t}$ given $E\left\{e_{t} \mid \Omega_{t-1}\right\}\left(=w_{t}\right)$ and $u_{t}$. This rule $\epsilon_{t}$ is computed first by inserting [6.6] into [6.5] and [6.2]. The resulting expressions for inflation and the current account balance are substituted in the government's loss function [6.1]. Taking first-order conditions with respect to $e_{t}$ and $u_{t}$ reveal that equilibrium policy must satisfy

$\alpha\left(e_{t}-\mathrm{E}\left(e_{t} \mid \Omega_{t-1}\right)-u_{t}-k\right)+a \mu^{2}\left(e_{t}-e_{t-1}\right)+a \mu(1-\mu)\left(\mathrm{E}\left(e_{t} \mid \Omega_{t-1}\right)-w_{t-1}\right) \stackrel{!}{=} 0$

The representative union thus forms its expectation of the forthcoming policy $e_{t}-e_{t-1}$ on the basis of [B.7]. As above, private information does not include the realization of $u_{t}$. The reaction function is derived from these first-order conditions by solving [B.7] for $e_{t}-e_{t-1}$,

$$
\begin{aligned}
\left(\alpha+a \mu^{2}\right) e_{t}= & \left.a \mu^{2} \mathrm{E}\left(e_{t} \mid \Omega_{t-1}\right)+u_{t}+k\right)+a \mu^{2} e_{t-1}-a \mu(1-\mu)\left(\mathrm{E}\left(e_{t} \mid \Omega_{t-1}\right)-w_{t-1}\right. \\
\Rightarrow e_{t}= & \left.\frac{\alpha}{\alpha+a \mu^{2}}+\frac{a \mu^{2}}{\alpha+a \mu^{2}}-\frac{a \mu}{\alpha+a \mu^{2}}\right) \mathrm{E}\left(e_{t} \mid \Omega_{t-1}\right) \\
& \quad+\frac{a \mu^{2}}{\alpha+a \mu^{2}} e_{t-1}+\frac{a \mu}{\alpha+a \mu^{2}} w_{t-1}-\frac{a \mu^{2}}{\alpha+a \mu^{2}} w_{t-1}+\frac{\alpha}{\alpha+a \mu^{2}}\left(u_{t}+k\right)
\end{aligned}
$$




$$
\begin{gathered}
\Rightarrow \quad e_{t}-e_{t-1}=\left(\lambda-\frac{a \mu}{\alpha+a \mu^{2}}+1-\lambda\right) \mathrm{E}\left(e_{t} \mid \Omega_{t-1}\right) \\
-\lambda e_{t-1}+\left(\frac{a \mu}{\alpha+a \mu^{2}}-(1-\lambda)\right) w_{t-1}+\lambda\left(u_{t}+k\right) \\
\Rightarrow \quad e_{t}-e_{t-1}=\left[\begin{array}{c}
\left.1-\frac{a \mu}{\alpha+a \mu^{2}}\right]\left(\mathrm{E}\left(e_{t} \mid \Omega_{t-1}\right)-w_{t-1}\right) \\
+\lambda\left(u_{t}+k\right)-\lambda\left(e_{t-1}-w_{t-1}\right)
\end{array}\right.
\end{gathered}
$$

Taking unconditional expectation of [B.8], and isolating $\mathrm{E}\left(e_{t} \mid \Omega_{t-1}\right)=w_{t}$, the wage setter's decision is

$$
w_{t}-w_{t-1}=\frac{\alpha}{a \mu} k+\mu\left(e_{t-1}-w_{t-1}\right)
$$

which shows that wage inflation will be higher the greater the government's target of the current account balance. By the construction of the problem, a government which faces the expectation as given in [B.9] will be motivated to choose a rate of devaluation $e_{t}-e_{t-1}$ that coincides with $w_{t}-w_{t-1}$. Replacing [B.9] in [B.7], the equilibrium policy rule under discretion is computed as

$$
e_{t}-e_{t-1}=\frac{\alpha}{\alpha+a \mu^{2}} u_{t}+\frac{\alpha}{a \mu} k-(1-\mu)\left(e_{t-1}-w_{t-1}\right)
$$

The terms $b_{t}, \pi_{t}$ can be derived by replacing $e_{t}$ and $w_{t}$ in the respective expressions.

\section{B.4 Expected loss}

Expected loss for the various regimes examined in Chapter 6 can be computed by replacing the respective values for $b_{t}$ and $\pi_{t}$ in the loss function [6.1]. For example, the expected loss for the discretionary regime can be computed by taking the values for the current account ([6.18]) and inflation (6.17]),

$$
\begin{aligned}
E L_{t}^{D} & =\left(b_{t}-b^{*}\right)^{2}+a \pi_{t}^{2} \\
& =E\left\{\left(b^{*}-\sqrt{\alpha}\left(u_{t}+k\right)+\sqrt{\alpha} \lambda u_{t}-b^{*}\right)^{2}+a(\underbrace{\mu \lambda u_{t}+\frac{\alpha}{a \mu} k}_{\pi_{t}})^{2}\right\} \\
& =E\left\{\alpha\left(u_{t}(1-\lambda)+k(\lambda+(1-\lambda))^{2}+a\left(\frac{\alpha(1-\lambda)}{a \mu}\left[u_{t}+k+\frac{\lambda}{(1-\lambda)} k\right]\right)^{2}\right\}\right.
\end{aligned}
$$




$$
\begin{aligned}
& =E\{\alpha(1-\lambda)^{2}\left[u_{t}+k+\frac{\lambda}{1-\lambda} k\right]^{2}+\underbrace{\frac{a \alpha^{2}(1-\lambda)^{2}}{a^{2} \mu^{2}}}_{=\alpha(1-\lambda) \lambda}\left[u_{t}+k+\frac{\lambda}{1-\lambda} k\right]^{2}\} \\
& =E\left\{(1-\lambda)(\alpha(1-\lambda)+\alpha \lambda)\left[u_{t}+k+\frac{\lambda}{1-\lambda} k\right]^{2}\right\} \\
& =\alpha(1-\lambda) E\left[u+\frac{k}{(1-\lambda)}\right]^{2}
\end{aligned}
$$

which can be written alternatively as

$$
E L_{t}^{D}=\alpha(1-\lambda) \sigma_{u}^{2}+\frac{\alpha}{1-\lambda} k^{2}
$$

since $E u_{t}=\sigma_{u}^{2}$.

\section{B.5 Separating equilibrium}

\section{B.5.1 Separating conditions, strong government}

The conditions for a separating equilibrium in the exchange rate game are derived by formulating the inequalities [7.22] and [7.24] and solving for $\epsilon_{1}$. For the $T_{s}$ government, the LHS of [7.22] is

$$
\alpha\left(\epsilon_{1}-k\right)^{2}+a_{s}\left(\mu \epsilon_{1}\right)^{2}+\delta\left[\alpha\left(\epsilon_{2}-\hat{w}_{2}-k\right)^{2}+a_{s}\left(\mu \epsilon_{2}+(1-\mu) \hat{w}_{2}\right)^{2}\right]
$$

with

$$
\theta_{2}=1, \quad \hat{w}_{2}=\frac{\alpha k}{\mu a_{s}} \quad \text { and } \quad \epsilon_{2}=\lambda_{s}^{\prime} \hat{w}_{2}+\lambda_{s} k=\frac{\alpha k}{\mu a_{s}}
$$

(from [7.12] and [7.10]). In analogous fashion the RHS of the inequality can be computed as

$$
\left.\alpha\left(\lambda_{s} k-k\right)^{2}+a_{s}\left(\mu \lambda_{s} k\right)^{2}+\delta\left[\epsilon_{2}-\hat{w}_{2}-k\right)^{2}+a_{s}\left(\mu \epsilon_{2}+(1-\mu) \hat{w}_{2}\right)^{2}\right]
$$

with

$$
\begin{aligned}
\theta_{2}=0, \quad \epsilon_{1}=\lambda_{s} k, \quad \hat{w}_{2}=\frac{\alpha k}{\mu a_{w}} \text { and } \\
\epsilon_{2}=\lambda_{s}^{\prime} \hat{w}_{2}+\lambda_{s} k=\frac{\alpha k\left(\alpha+a_{s} \mu(\mu-1)-\mu\left(a_{s}-a_{w}\right)\right)}{\left(\alpha+a_{s} \mu^{2}\right) a_{w} \mu}
\end{aligned}
$$


Taking these terms together, the inequality [7.22] is then

$$
\begin{aligned}
& V^{G}\left(\epsilon_{1}^{s}<\lambda_{s} k, \theta_{2}=1\right)-V^{G}\left(\epsilon_{1}^{s}=\lambda_{s} k, \theta_{2}=0\right)= \\
& \quad\left(\alpha+a_{s} \mu^{2}\right) \epsilon_{1}^{2}-2 \alpha k \epsilon_{1}+\alpha k^{2}-\alpha\left(\frac{\alpha k}{\left(\alpha+a_{s} \mu^{2}\right.}-k\right)^{2}-\frac{a_{s} \mu^{2} \alpha^{2} k^{2}}{\left(\alpha+a_{s} \mu^{2}\right)^{2}}- \\
& \quad \delta \alpha\left(\frac{\alpha k\left(\alpha+a_{s} \mu^{2}-a_{s} \mu+\mu a_{w}\right)}{\left(\alpha+a_{s} \mu^{2}\right) \mu a_{w}}-\frac{\alpha k}{\mu a_{w}}-k\right)^{2}+ \\
& \quad \delta a_{s}\left(\frac{\alpha k\left(\alpha+a_{s} \mu^{2}-a_{s} \mu+\mu a_{w}\right)}{\left(\alpha+a_{s} \mu^{2}\right) \mu a_{w}}-\frac{(1-\mu) \alpha k}{\mu a_{w}}\right)^{2}+ \\
& \quad \delta\left(\alpha k^{2}+a_{s}\left(\frac{\alpha k}{a_{s}}+\frac{(1-\mu) \alpha k}{\mu a_{s}}\right)^{2}\right) \leq 0
\end{aligned}
$$

The polynomial above reduces by simplification to

$$
\begin{aligned}
& S\left(\epsilon_{1}\right)=\left(\alpha+a_{s} \mu^{2}\right) \epsilon_{1}^{2}-2 \alpha k \epsilon_{1}+ \\
& \quad k^{2}\left(\alpha+\frac{\delta \alpha^{2}}{a_{s} \mu^{2}}-\frac{a_{s} \mu^{2}}{\alpha+a_{s} \mu^{2}}-\frac{\delta \alpha a_{s}\left(\alpha+a_{w} \mu^{2}\right)^{2}}{\left(\alpha+a_{s} \mu^{2}\right) a_{w} \mu^{2}}\right) \leq 0
\end{aligned}
$$

Solving for the root of $S\left(\epsilon_{1}\right)$ yields $S_{\min }$ and $S_{\max }$,

$$
\begin{aligned}
& \epsilon_{1,1} \equiv S_{\min } \geq \lambda_{s} k\left(1-\frac{\sqrt{a_{s} \delta\left(a_{s}-a_{w}\right)\left[\alpha\left(a_{s}+a_{w}\right)+2 a_{s} a_{w} \mu^{2}\right]}}{a_{w} a_{s} \mu}\right) \\
& \epsilon_{1,2} \equiv S_{\max } \leq \lambda_{s} k\left(1+\frac{\sqrt{a_{s} \delta\left(a_{s}-a_{w}\right)\left[\alpha\left(a_{s}+a_{w}\right)+2 a_{s} a_{w} \mu^{2}\right]}}{a_{w} a_{s} \mu}\right)
\end{aligned}
$$

These are the range of values for $\epsilon_{1}$ for which the polynomial term $S\left(\epsilon_{1}\right)$ is negative and the separating condition [7.22]) accordingly holds. The strong government will therefore choose a first-period devaluation rate $\epsilon_{1}$ that is lower than its perfect information counterpart in the region

$$
\left[S_{\min }, S_{\max }\right]
$$

\section{B.5.2 Separating conditions, weak government}

For the $T_{w}$-government, the LHS of the separating condition [7.24] is

$$
\alpha\left(\epsilon_{1}-k\right)^{2}+a_{w}\left(\mu \epsilon_{1}\right)^{2}+\delta\left[\alpha\left(\epsilon_{2}-\hat{w}_{2}-k\right)^{2}+a_{w}\left(\mu \epsilon_{2}+(1-\mu) \hat{w}_{2}\right)^{2}\right]
$$


with

$$
\begin{aligned}
\theta_{2}=1, \quad \hat{w}_{2}=\frac{\alpha k}{\mu a_{s}} \text { and } \\
\epsilon_{2}=\lambda_{w}^{\prime} \hat{w}_{2}+\lambda_{w} k=\frac{\alpha k\left(\alpha+a_{w} \mu(\mu-1)-\mu\left(a_{w}-a_{s}\right)\right)}{\left(\alpha+a_{w} \mu^{2}\right) a_{s} \mu}
\end{aligned}
$$

and the RHS of [7.24] is derived from

$$
\left.\alpha\left(\lambda_{w} k-k\right)^{2}+a_{w}\left(\mu \lambda_{w} k\right)^{2}+\delta\left[\epsilon_{2}-\hat{w}_{2}-k\right)^{2}+a_{w}\left(\mu \epsilon_{2}+(1-\mu) \hat{w}_{2}\right)^{2}\right]
$$

with

$$
\theta_{2}=0, \quad \hat{w}_{2}=\frac{\alpha k}{\mu a_{w}} \quad \text { and } \quad \epsilon_{2}=\lambda_{w}^{\prime} \hat{w}_{2}+\lambda_{w} k=\frac{\alpha k}{\mu a_{w}}
$$

The separating condition for the weak government can then be written as

$$
\begin{aligned}
& V^{G}\left(\epsilon_{1}^{w}<\lambda_{w} k, \theta_{2}=1\right)-V^{G}\left(\epsilon_{1}^{w}=\lambda_{w} k, \theta_{2}=0\right)= \\
& \left(\alpha+a_{w} \mu^{2}\right) \epsilon_{1}^{2}-2 \alpha k \epsilon_{1}+\alpha k^{2}-\alpha\left[\frac{\alpha k}{\left(\alpha+a_{w} \mu^{2}\right)}-k\right]^{2}-\frac{a_{s} \mu^{2} \alpha^{2} k^{2}}{\left(\alpha+a_{s} \mu^{2}\right)^{2}}- \\
& \delta \alpha\left[\frac{\alpha k\left(\alpha+a_{w} \mu^{2}-a_{w} \mu+\mu a_{s}\right)}{\left(\alpha+a_{w} \mu^{2}\right) \mu a_{s}}-\frac{\alpha k}{\mu a_{s}}-k\right]^{2}+ \\
& \delta a_{w}\left[\frac{\alpha k\left(\alpha+a_{w} \mu^{2}-a_{w} \mu+\mu a_{s}\right)}{\left(\alpha+a_{w} \mu^{2}\right) \mu a_{s}}+\frac{(1-\mu) \alpha k}{\mu a_{s}}\right]^{2}+ \\
& \delta\left[\alpha k^{2}+a_{w}\left(\frac{\alpha k}{a_{w}}+\frac{(1-\mu) \alpha k}{\mu a_{w}}\right)^{2}\right] \geq 0
\end{aligned}
$$

Collecting the terms, this expression simplifies to

$$
\begin{aligned}
& W\left(\epsilon_{1}\right)=\left(\alpha+a_{w} \mu^{2}\right) \epsilon_{1}^{2}-2 \alpha k \epsilon_{1}+ \\
& \quad k^{2}\left[\alpha+\frac{\delta \alpha^{2}}{a_{w} \mu^{2}}-\frac{a_{w} \mu^{2}}{\alpha+a_{w} \mu^{2}}-\frac{\delta \alpha a_{w}\left(\alpha+a_{s} \mu^{2}\right)^{2}}{\left(\alpha+a_{w} \mu^{2}\right) a_{s} \mu^{2}}\right] \geq 0
\end{aligned}
$$

Solving for $\epsilon_{1}$ in $W\left(\epsilon_{1}\right)$ yields

$$
\begin{aligned}
& \epsilon_{1,1} \equiv W_{\min } \leq \lambda_{s} k\left[1-\frac{\sqrt{a_{w} \delta\left(a_{s}-a_{w}\right)\left[\alpha\left(a_{s}+a_{w}\right)+2 a_{s} a_{w} \mu^{2}\right]}}{a_{w} a_{s} \mu}\right] \\
& \epsilon_{1,2} \equiv W_{\max } \geq \lambda_{s} k\left[1+\frac{\sqrt{a_{w} \delta\left(a_{s}-a_{w}\right)\left[\alpha\left(a_{s}+a_{w}\right)+2 a_{s} a_{w} \mu^{2}\right]}}{a_{w} a_{s} \mu}\right]
\end{aligned}
$$

defining two regions of values $\epsilon_{1}$ for which it is optimal for the weak government to reveal its identity,

$$
\left[-\infty, W_{\min }\right] \quad \text { and } \quad\left[W_{\max },+\infty\right] .
$$




\section{B.5.3 Equilibrium strategies}

The intersection of the two regions in [B.20] and [B.28] establishes a class of separating equilibria. A sufficient condition for the existence of an equilibrium is that the intersection of the regions is non-empty. This holds true when either $W_{\min } \geq S_{\min }$ or $S_{\max } \geq W_{\max }$. Rearranging the terms in [B.26] and [B.18] shows that

$$
\begin{aligned}
W_{\min } & \geq S_{\min } \\
\Rightarrow \lambda_{w}\left(1-\frac{\sqrt{\nu a_{w}}}{a_{w} a_{s} \mu}\right) & \geq \lambda_{s}\left(1-\frac{\sqrt{\nu a_{s}}}{a_{w} a_{s} \mu}\right) \\
\Rightarrow a_{w} & \leq a_{s}
\end{aligned}
$$

where $\nu=\delta\left(a_{s}-a_{w}\right)\left[\alpha\left(a_{s}+a_{w}\right)+2 a_{s} a_{w} \mu^{2}\right] \geq 0$. Since $a_{s}>a_{w}$ per definition it follows that the condition is always satisfied. The existence of the upper region can also be established unambiguously since

$$
\begin{aligned}
S_{\max } & \geq W_{\max } \\
\Rightarrow \lambda_{s}\left(1+\frac{\sqrt{\nu a_{s}}}{a_{w} a_{s} \mu}\right) & \geq \lambda_{w}\left(1+\frac{\sqrt{\nu a_{w}}}{a_{w} a_{s} \mu}\right) \\
\Rightarrow a_{s} & \geq a_{w}
\end{aligned}
$$

also holds.

\section{B.6 Pooling equilibrium}

The conditions which are necessary to sustain a pooling equilibrium are derived in close analogy to the steps that were used to calculate the separating conditions.

\section{B.6.1 Pooling conditions, weak government}

The condition that is necessary to establish a pooling solution for the weak government is

$$
\underbrace{V_{w}^{G}\left(\tilde{\epsilon}_{1}^{w}, \theta_{2}\right)}_{\text {LHS }}-\underbrace{V_{w}^{G}\left(d_{w}, \theta_{2}=0\right)}_{\text {RHS }} \leq 0
$$

from [7.38]. The LHS can be solved using the expression for the loss from $[7.4]$

$$
\alpha\left(\epsilon_{1}-k\right)^{2}+a_{w}\left(\mu \epsilon_{1}\right)^{2}+\delta\left[\alpha\left(\epsilon_{2}-\hat{w}_{2}-k\right)^{2}+a_{w}\left(\mu \epsilon_{2}+(1-\mu) \hat{w}_{2}\right)^{2}\right]
$$


where it has been established in the text that

$$
\theta_{2}=\theta_{1} \Rightarrow \quad \hat{w}_{2}=\frac{\alpha k}{\mu}\left[\frac{\alpha+a_{s} \mu^{2}+\left(a_{w}-a_{s}\right) \theta_{1} \mu^{2}}{a_{w}\left(\alpha+a_{s} \mu^{2}\right)+\left(a_{s}-a_{w}\right) \theta_{1} \alpha}\right]
$$

and accordingly,

$$
\begin{aligned}
\epsilon_{2} & =\lambda_{w}^{\prime} \hat{w}_{2}+\lambda_{w} k \\
& =\frac{\alpha k}{\mu}\left[\frac{\theta_{1} \mu\left(a_{w}-a_{s}\right)(1-\mu)+\alpha+a_{s} \mu^{2}}{\theta_{1} \alpha\left(a_{s}-a_{w}\right)+a_{w}\left(\alpha+a_{s} \mu^{2}\right)}\right]
\end{aligned}
$$

After the rearrangement of terms, the LHS can be written as

$$
\begin{aligned}
& V_{w}^{G}\left(\tilde{\epsilon}_{1}^{w}, \theta_{2}\right)=\alpha\left(\epsilon_{1}-k\right)^{2}+a_{w} \mu^{2} \epsilon_{1}^{2} \\
& \quad+\frac{\delta \alpha a_{w}^{2}\left(\alpha+a_{s} \mu^{2}\right)}{\mu^{2}}\left[\frac{\alpha+a_{w} \mu^{2}}{a_{w}\left(\alpha+a_{s} \mu^{2}\right)+\left(a_{s}-a_{w}\right) \theta \alpha}\right]
\end{aligned}
$$

The RHS is derived by noting that when $\theta_{2}=\theta_{1}=0$ then

$$
\hat{w}_{2}=\frac{\alpha k}{\mu a_{w}} \quad \text { and } \quad \epsilon_{2}=\lambda_{w}^{\prime} \hat{w}_{2}+\lambda_{w} k=\frac{\alpha k}{\mu a_{w}}
$$

and the RHS can then be written as

$$
V_{w}^{G}\left(d_{w}, \theta_{2}=0\right)=\alpha k\left[\frac{\delta\left(\alpha+a_{w} \mu^{2}\right)}{a_{w} \mu^{2}}+\frac{a_{w} \mu^{2}}{\alpha+a_{w} \mu^{2}}\right]
$$

Taking the above terms for LHS and RHS together, the pooling condition for the weak government in [7.38] can be written as a polynomial in $\epsilon_{1}$,

$$
\begin{aligned}
W\left(\epsilon_{1}\right) & \equiv V_{w}^{G}\left(\epsilon_{1}, \theta_{2}\right)-V_{w}^{G}\left(d_{w}, \theta_{2}=0\right) \\
= & \alpha\left(\epsilon_{1}-k\right)^{2}+a_{w} \mu^{2} \epsilon_{1}^{2}-\frac{\alpha k^{2} a_{w} \mu^{2}}{\alpha+a_{w} \mu^{2}} \\
& +\delta k^{2}\left[\frac{\alpha a_{w}\left(\alpha+a_{s} \mu^{2}\right)^{2}\left(a_{w} \mu^{2}+\alpha\right)}{\mu^{2}\left(a_{w}\left(\alpha+a_{s}+\mu^{2}\right)+\theta \alpha\left(a_{s}-a_{w}\right)\right)}-\frac{\alpha\left(\alpha+a_{w} \mu^{2}\right)}{a_{w} \mu^{2}}\right] \leq 0
\end{aligned}
$$

Solving this polynomial in $\epsilon_{1}$ yields the following pooling region of devaluation for the weak government,

$$
\begin{aligned}
& \epsilon_{1,1} \geq d_{w}\left(1-\Psi_{w}^{P}\right) \equiv W_{\min } \\
& \epsilon_{1,2} \leq d_{w}\left(1+\Psi_{w}^{P}\right) \equiv W_{\max }
\end{aligned}
$$

where

$$
\Psi_{w}^{P} \equiv \frac{\left(\alpha+a_{w}^{2}\right) \sqrt{\mathbf{a}_{\mathbf{w}} \theta_{1} \delta\left(a_{s}-a_{w}\right)\left[2 a_{w}\left(\alpha+a_{s} \mu^{2}\right)+\theta_{1} \alpha\left(a_{s}-a_{w}\right)\right]}}{a_{w} \mu\left[a_{w}\left(\alpha+a_{s} \mu^{2}\right)+\theta_{1} \alpha\left(a_{s}-a_{w}\right)\right]}>0
$$




\section{B.6.2 Pooling conditions, strong government}

The expression for

$$
\underbrace{V_{s}^{G}\left(\tilde{\epsilon}_{1}^{s}, \theta_{2}\right)}_{\text {LHS }}-\underbrace{V_{s}^{G}\left(d_{s}, \theta_{2}=0\right)}_{\text {RHS }} \leq 0
$$

can be similarly derived from the general form of the two-period loss function in 7.4, with $\theta_{2}=\theta_{1}$. Therefore, after replacing $\hat{w}_{2}, \epsilon_{2}$, and $\epsilon_{1}$ with

$$
\hat{w}_{2}=\frac{\alpha k}{\mu a_{w}} ; \quad \epsilon_{2}=\lambda_{s}^{\prime} \frac{\alpha k}{\mu a_{w}}+\lambda_{s} k \text { and } \epsilon_{1}=d_{s}
$$

the RHS can be written as

$$
V_{s}^{G}\left(d_{s}, \theta_{2}=0\right)=\alpha k^{2} a_{s}\left[\frac{\delta\left(\alpha+a_{w} \mu^{2}\right)}{a_{w}^{2} \mu^{2}}+\frac{\mu^{2}}{\alpha+a_{s} \mu^{2}}\right]
$$

Since the public is entirely unaware of what type of government it is facing in the game (after both types have chosen the same signal $\epsilon_{1}$ ), the same term for the expectations incorporated in $\hat{w}_{2}$ (with $\theta_{2}=\theta_{1}$ ) from B.31 is used to derive the pooling condition for the strong government. Hence,

$$
\hat{w}_{2}=\frac{\alpha k}{\mu}\left[\frac{\alpha+a_{s} \mu^{2}+\left(a_{w}-a_{s}\right) \theta_{1} \mu^{2}}{a_{w}\left(\alpha+a_{s} \mu^{2}\right)+\left(a_{s}-a_{w}\right) \theta_{1} \alpha}\right] \quad \text { and } \quad \epsilon_{2}=\lambda_{s}^{\prime} \hat{w}_{2}+\lambda_{s} k
$$

Collecting all the terms together, the polynomial describing the pooling condition is

$$
\begin{aligned}
S\left(\epsilon_{1}\right)= & \alpha\left(\epsilon_{1}-k\right)^{2}+a_{s} \mu^{2} \epsilon_{1}^{2}+\delta \alpha\left[\frac{\alpha k\left(\lambda_{s}^{\prime}-1\right) \omega}{\mu \varsigma}+k\left(\lambda_{s}-1\right)\right]^{2} \\
& +\delta a_{s}\left[\mu\left(\frac{\alpha k \lambda_{s}^{\prime} \omega}{\mu \varsigma}+k \lambda_{s}\right)+(1-\mu) \frac{\alpha k \omega}{\mu \varsigma}\right]^{2} \leq 0
\end{aligned}
$$

with

$$
\begin{aligned}
\varsigma & \equiv a_{w}\left(\alpha+a_{s} \mu^{2}\right)+\left(a_{s}-a_{w}\right) \theta_{1} \alpha \\
\omega & \equiv \alpha+a_{s} \mu^{2}+\left(a_{w}-a_{s}\right) \theta_{1} \mu^{2}
\end{aligned}
$$

and $\lambda_{s}$ and $\lambda_{s}^{\prime}$ as defined in the text. As a final step, the roots of $S\left(\epsilon_{1}\right)$ are solved, resulting in

$$
\begin{gathered}
\epsilon_{1,1} \geq d_{s}\left(1-\Psi_{s}^{P}\right) \equiv S_{\min } \\
\epsilon_{1,2} \leq d_{s}\left(1+\Psi_{s}^{P}\right) \equiv S_{\max }
\end{gathered}
$$


where

$$
\Psi_{s}^{P} \equiv \frac{\left(\alpha+a_{w}^{2}\right) \sqrt{\mathbf{a}_{\mathbf{s}} \theta_{1} \delta\left(a_{s}-a_{w}\right)\left[2 a_{w}\left(\alpha+a_{s} \mu^{2}\right)+\theta_{1} \alpha\left(a_{s}-a_{w}\right)\right]}}{a_{w} \mu\left[a_{w}\left(\alpha+a_{s} \mu^{2}\right)+\theta_{1} \alpha\left(a_{s}-a_{w}\right)\right]}>0
$$

Note that $\Psi_{s}^{P}$ and $\Psi_{w}^{P}$ are identical, except for the isolated $a_{s}$, resp. $a_{w}$ term within the square root. For the special case $\theta_{1}=1$, it can be confirmed that $\Psi_{i}^{P}=\Psi_{i}^{S}$ for $i=s, w$.

\section{B.6.3 Equilibrium strategies}

The inequalites in [B.36] and [B.42] define two distinct exchange rate regions for $T_{w}$ and $T_{s}$. Depending on the parameter values a necessary condition for a pooling equilibrium to be the outcome of the game requires that the intersection of these two regions,

$$
\left[W_{\min }, W_{\max }\right] \cap\left[S_{\min }, S_{\max }\right]
$$

be non-empty. Since for all parameter values (including $\theta_{1}$ ) it holds that $S_{\min }<W_{\min }<W_{\max }$, all that needs to be established for the intersection above to be non-empty is that $S_{\max }>W_{\min }$. An intersection and pooling equilibrium therefore exist when

$$
\begin{aligned}
S_{\max } & -W_{\min }>0 \\
\Rightarrow \lambda_{s} k\left(1+\sqrt{a_{s}} \Psi^{\prime}\right) & -\lambda_{w} k\left(1-\sqrt{a_{w}} \Psi^{\prime}\right)>0 \\
\Rightarrow \lambda_{s}-\lambda_{w} & +\Psi^{\prime}\left(\lambda_{s} \sqrt{a_{s}}+\lambda_{w} \sqrt{a_{w}}\right)>0
\end{aligned}
$$

where

$$
\Psi^{\prime} \equiv \frac{\left(\alpha+a_{w}^{2}\right) \sqrt{\theta_{1} \delta\left(a_{s}-a_{w}\right)\left[2 a_{w}\left(\alpha+a_{s} \mu^{2}\right)+\theta_{1} \alpha\left(a_{s}-a_{w}\right)\right]}}{a_{w} \mu\left[a_{w}\left(\alpha+a_{s} \mu^{2}\right)+\theta_{1} \alpha\left(a_{s}-a_{w}\right)\right]}>0
$$

\section{B.7 Reputational indifference curves}

The general form of the indifference curves $\bar{V}_{s}$ and $\bar{V}_{s}$ introduced in Chapter 7 are derived from [7.4],

$$
\begin{aligned}
& V_{s}^{G}\left(\epsilon_{1}^{s}, \theta_{2}\right)-\bar{V}= \\
& \quad \alpha\left(\epsilon_{1}-\hat{w}_{1}-k\right)^{2}+a_{s}\left(\mu \epsilon_{1}+(1-\mu) \hat{w}_{1}\right)^{2} \\
& \quad+\delta\left[\alpha\left(\epsilon_{2}-\hat{w}_{2}-k\right)^{2}+a_{s}\left(\mu \epsilon_{2}+(1-\mu) \hat{w}_{2}\right)^{2}\right]-\bar{V}=0
\end{aligned}
$$


for the strong government's indifference curve and

$$
\begin{aligned}
& V_{w}^{G}\left(\epsilon_{1}^{w}, \theta_{2}\right)-\bar{V}= \\
& \quad \alpha\left(\epsilon_{1}-\hat{w}_{1}-k\right)^{2}+a_{w}\left(\mu \epsilon_{1}+(1-\mu) \hat{w}_{1}\right)^{2} \\
& \quad+\delta\left[\alpha\left(\epsilon_{2}-\hat{w}_{2}-k\right)^{2}+a_{w}\left(\mu \epsilon_{2}+(1-\mu) \hat{w}_{2}\right)^{2}\right]-\bar{V}=0
\end{aligned}
$$

for the weak government, where $\bar{V}$ is a constant term. These two expressions are the implicit functions for the indifference curve function that has the form $\theta_{2}\left(\epsilon_{1}^{s}, \bar{V}\right)$ and $\theta_{2}\left(\epsilon_{1}^{s}, \bar{V}\right)$ respectively. For the strong government private sector expectations expressed in $\hat{w}_{2}$ are equivalent to

$$
\hat{w}_{2}=\frac{\alpha k}{\mu}\left[\frac{\alpha+a_{s} \mu^{2}+\left(a_{w}-a_{s}\right) \theta_{2} \mu^{2}}{a_{w}\left(\alpha+a_{s} \mu^{2}\right)+\left(a_{s}-a_{w}\right) \theta_{2} \alpha}\right]
$$

from [7.13]. Second period exchange rate is accordingly

$$
\epsilon_{2}^{s}=\frac{\alpha k}{\mu}\left[\frac{\left(1-\frac{a_{s} \mu}{\alpha+a_{s} \mu^{2}}\right)\left(\alpha+a_{s} \mu^{2}+\left(a_{w}-a_{s}\right) \theta_{2} \mu^{2}\right)}{a_{w}\left(\alpha+a_{s} \mu^{2}\right)+\left(a_{s}-a_{w}\right) \theta_{2} \alpha}+\frac{\mu}{\alpha+a_{s} \mu^{2}}\right]
$$

These terms are substituted in [B.46] and setting $\hat{w}_{1}=0$, the resulting term is

$$
\begin{aligned}
& V_{w}^{G}\left(\epsilon_{1}^{s}, \theta_{2}\right)-\bar{V}= \\
& \alpha\left(\epsilon_{1}^{s}-k\right)^{2}+a_{s} \mu^{2}\left(\epsilon_{1}^{s}\right)^{2}+\delta \alpha\left[\frac{\left(1-\frac{a_{s} \mu}{\alpha+a_{s} \mu^{2}}\right) \Xi k}{\mu \Lambda}+\frac{\alpha k}{\alpha+a_{s} \mu^{2}}-\frac{\alpha k \Xi}{\mu \Lambda}-k\right]^{2} \\
& +\delta a_{s}\left[\mu\left(\frac{\left(1-\frac{a_{s} \mu}{\alpha+a_{s} \mu^{2}}\right) \Xi k}{\mu \Lambda}+\frac{\alpha k}{\alpha+a_{s} \mu^{2}}\right)+\frac{(1-\mu) \alpha k \Xi}{\mu \Lambda}\right]^{2}-\bar{V}=0
\end{aligned}
$$

where

$$
\begin{aligned}
\Lambda & \equiv a_{w}\left(\alpha+a_{s} \mu^{2}\right)+\left(a_{s}-a_{w}\right) \theta_{2} \alpha \text { and } \\
\Xi & \equiv \alpha+a_{s} \mu^{2}+\left(a_{w}-a_{s}\right) \theta_{2} \mu^{2}
\end{aligned}
$$

The terms in the expression above can be collected and after isolating $\theta_{2}$ (as well as a bit of rearranging of terms) the equation for the strong government's indifference curve for any utility level $\bar{V}$ can be written as

$$
\begin{aligned}
& \theta_{2}\left(\epsilon_{1}^{s}, \bar{V}, T_{s}\right)= \\
& \quad \frac{a_{w}}{a_{s}-a_{w}}\left[\frac{\left(\alpha+a_{w} \mu^{2}\right) k}{\alpha a_{w} \mu} \sqrt{\frac{\delta a_{s} \alpha\left(\alpha+a_{s} \mu^{2}\right)}{\bar{V}-\left(\alpha+a_{s} \mu^{2}\right)\left(\epsilon_{1}^{s}\right)^{2}+2 \alpha k \epsilon_{1}^{s}-\alpha k^{2}}}-\frac{a_{s} \mu^{2}}{\alpha}-1\right]
\end{aligned}
$$


The procedure is analogous for the weak government, where the second period exchange rate can be derived as

$$
\epsilon_{2}^{w}=\frac{\alpha k}{\mu}\left[\frac{\left(1-\frac{a_{w} \mu}{\alpha+a_{w} \mu^{2}}\right)\left(\alpha+a_{s} \mu^{2}+\left(a_{w}-a_{s}\right) \theta_{2} \mu^{2}\right)}{a_{w}\left(\alpha+a_{s} \mu^{2}\right)+\left(a_{s}-a_{w}\right) \theta_{2} \alpha}+\frac{\mu}{\alpha+a_{w} \mu^{2}}\right]
$$

Substituting [B.48] and $\epsilon_{2}^{w}$ in the loss function [B.47] for a given level of loss $\bar{V}$, the indifference curve is

$$
\begin{aligned}
& \theta_{2}\left(\epsilon_{1}^{w}, \bar{V}, T_{w}\right)= \\
& \quad \frac{a_{w}}{a_{s}-a_{w}}\left[\frac{\left(\alpha+a_{s} \mu^{2}\right) k}{\alpha a_{w} \mu} \sqrt{\frac{\delta a_{w} \alpha\left(\alpha+a_{s} \mu^{2}\right)}{\bar{V}-\left(\alpha+a_{w} \mu^{2}\right)\left(\epsilon_{1}^{w}\right)^{2}+2 \alpha k \epsilon_{1}^{w}-\alpha k^{2}}}-\frac{a_{s} \mu^{2}}{\alpha}-1\right]
\end{aligned}
$$

\section{B.7.1 Indifference curves $\bar{V}^{0}$}

The two special indifference curves of Figure 7.1 can be derived mathematically the following way. First note that for the $T_{s}$-government all other combinations of $\epsilon_{1}$ and $\theta_{2}$ on this curve yield the same loss $\bar{V}_{s}^{0}$ as the government's short-run strategy $d_{s}$. Second, at $d_{s}$ we know from the text that the government has a reputation $\theta_{2}=0$. Therefore, with $\epsilon_{1}^{w}=d_{s}$ and $\theta_{2}=0$ second period expectations are such that

$$
\hat{w}_{2}=\frac{\alpha k}{\mu a_{w}}
$$

and the exchange rate change is subsequently

$$
\epsilon_{1}^{s}=\frac{\alpha k}{\mu a_{w}}\left[\frac{\left.\alpha+a_{s} \mu^{2}+\left(a_{w}-a_{s}\right) \mu\right)}{\alpha+a_{s} \mu^{2}}\right]
$$

Substituting these terms in the loss, $\bar{V}_{s}^{0}$ is computed as

$$
\bar{V}_{s}^{0}=\frac{a_{s} \alpha k^{2}\left(a_{w}^{2} \mu^{4}+\left(\delta\left(\alpha^{2}+a_{w} \mu^{2}\right)^{2}\right)\right.}{a_{w}^{2} \mu^{2}\left(\alpha^{2}+a_{w} \mu^{2}\right)}
$$

As a final step replace the above expression for $\bar{V}$ in [B.50] and a preliminary, rough result is

$$
\theta_{2}\left(\epsilon_{1}^{s}, \bar{V}_{s}^{0}\right)=\frac{\alpha a_{w} \Gamma+a_{w} a_{s} \mu^{2} \Gamma-1}{\alpha\left(a_{w}-a_{s}\right) \Gamma}
$$

with

$$
\Gamma \equiv \frac{1}{a_{w}\left(\alpha+a_{s} \mu^{2}\right)} \sqrt{1-\frac{a_{w}^{2} \mu\left[\alpha\left(\epsilon_{1}^{s}-k\right)+a_{s} \mu^{2} \epsilon_{1}^{s}\right]^{2}}{\delta \alpha k^{2} a_{s}\left(\alpha+a_{w}^{2}\right)^{2}}}
$$


After some further simplification, the formula for the strong government's indifference curve for loss $\bar{V}_{s}^{0}$ is

$$
\begin{aligned}
& \theta_{2}\left(\epsilon_{1}^{s}, \bar{V}=\bar{V}_{s}^{0}\right)= \\
& \quad \frac{a_{w}}{\left(a_{w}-a_{s}\right) \lambda_{s}}\left(1-\sqrt{\frac{\delta \alpha k^{2} a_{s}\left(\alpha+a_{w} \mu^{2}\right)^{2}}{\delta \alpha k^{2} a_{s}\left(\alpha+a_{w} \mu^{2}\right)^{2}-a_{w}^{2} \mu^{2}\left[\alpha\left(\epsilon_{1}^{s}-k\right)+a_{s} \mu^{2} \epsilon_{1}^{s}\right]^{2}}}\right)
\end{aligned}
$$

Using the same technique it is possible to derive the indifference equation $\bar{V}_{w}^{0}$ for the weak government. With $\epsilon_{1}=d_{s}$ and $\theta_{2}=0$ second-period decisions for the weak government are

$$
\hat{w}_{2}=\epsilon_{2}=\frac{\alpha k}{\mu a_{w}}
$$

and the weak government's loss is

$$
\bar{V}_{w}^{0}=\frac{\alpha k^{2}\left(a_{w}^{2} \mu^{4}+\left(\delta\left(\alpha^{2}+a_{w} \mu^{2}\right)^{2}\right)\right.}{a_{w} \mu^{2}\left(\alpha^{2}+a_{w} \mu^{2}\right)}=\bar{V}_{s}^{0} \frac{a_{w}}{a_{s}}
$$

Similarly, the indifference curve for the weak government used in the figures is derived by using [B.59] in [B.52] as

$$
\begin{aligned}
& \theta_{2}\left(\epsilon_{1}^{w}, \bar{V}=\bar{V}_{w}^{0}\right)= \\
& \quad \frac{a_{w}}{\left(a_{w}-a_{s}\right) \lambda_{s}}\left(1-\sqrt{\frac{\delta \alpha k^{2}\left(\alpha+a_{w} \mu^{2}\right)^{2}}{\delta \alpha k^{2}\left(\alpha+a_{w} \mu^{2}\right)^{2}-a_{w}^{2} \mu^{2}\left[\alpha\left(\epsilon_{1}^{s}-k\right)+a_{w} \mu^{2} \epsilon_{1}^{s}\right]^{2}}}\right)
\end{aligned}
$$

\section{B.7.2 Testing the Intuitive Criterion}

The test whether the equilibrium where both types of government pool the exchange rate $\epsilon_{1}=d_{s}$ requires the equilibrium refinement of the Intuitive Criterion. This involves comparing the points in Figure [7.3], (a) and (b) from the viewpoint of the strong government. As discussed in the text, the pooling equilibrium must be rejected (by virtue of the Intuitive Criterion) if,

$$
\underbrace{V^{s}\left(\epsilon_{1}^{s}=z, \theta_{2}=1\right)}_{\text {LHS }}<\underbrace{V^{s}\left(\epsilon_{1}^{s}=d_{s}, \theta_{2}=\theta_{1}\right)}_{\text {RHS }}
$$

In order to derive the value of the LHS, it is necessary to first calculate the exchange rate $z$ (associated with reputation $\theta_{2}=1$ ). This is done by evaluating the weak government's indifference curve $V_{w}^{0}$ at $\theta_{2}=1$, i.e.,

$$
\theta_{2}\left(\epsilon_{1}^{w}, \bar{V}_{w}^{0}, T_{w}\right) \stackrel{!}{=} 1
$$


and solving for $z$. This leads to

$$
z=\frac{\alpha k}{\alpha+a_{w} \mu^{2}}\left(1-\frac{\sqrt{a_{w} \delta\left(a_{s}-a_{w}\right)\left(\alpha\left(a_{s}+a_{w}\right)+2 a_{w} a_{s} \mu^{2}\right)}}{a_{w} a_{s} \mu}\right)
$$

Now we plug $z$ into the LHS of the inequality [B.60] which yields

$$
\begin{aligned}
& V^{s}\left(\epsilon_{1}^{s}=z, \theta_{2}=1\right)= \\
& \delta \alpha k^{2}\left[\frac{\left(\alpha+a_{s} \mu^{2}\right)\left(\alpha^{2}\left(a_{s}^{2}-a_{w}^{2}\right)+a_{s} a_{w}\left(\alpha^{2}+2 a_{s} \mu^{2} \alpha+a_{w}^{2} \mu^{4}\right)\right.}{a_{s}^{2} a_{w} \mu^{2}\left(\alpha+a_{w} \mu^{2}\right)^{2}}\right] \\
& \quad+\alpha k^{2}\left[\frac{2 \alpha \mu^{2}\left(a_{s}-a_{w}\right) \sqrt{a_{w} \delta\left(a_{s}-a_{w}\right)\left[\alpha\left(a_{s}+a_{w}\right)+2 a_{s} a_{w} \mu^{2}\right]}}{a_{w} a_{s}\left(\alpha+a_{w} \mu^{2}\right)^{2}}\right] \\
& \quad+\frac{\alpha k^{2} \mu^{2}\left(\alpha a_{s}+a_{w}^{2} \mu^{2}\right)}{\left(\alpha+a_{w} \mu^{2}\right)^{2}}
\end{aligned}
$$

The RHS of the inequality is simply computed by inserting $\epsilon_{1}^{s}=d_{s}$ and $\theta_{2}=\theta_{1}$ in the strong government's loss function,

$$
V^{s}\left(\epsilon_{1}^{s}=d_{s}, \theta_{2}=\theta_{1}\right)=\alpha k^{2}\left[\frac{\delta a_{s}\left(\alpha+a_{w} \mu^{2}\right)^{2}\left(\alpha+a_{s} \mu^{2}\right)}{\left[\theta \alpha\left(a_{s}-a_{w}\right)+a_{w}\left(\alpha+a_{s} \mu^{2}\right)\right]^{2} \mu^{2}}+\frac{a_{s} \mu^{2}}{\left(\alpha+a_{s} \mu^{2}\right)}\right]
$$




\section{LIST OF SYMBOLS}

Note: Equations or other mathematical expressions that are referred to in the text body will always be set in brackets, e.g. [5.3]. Sections, figures and tables will be referred to in parentheses, e.g. Section (4.2). In the following list the time subscript $t$ does not appear with the symbols. For a more detailed explanation of the following symbols in their context, refer to the parts of text in which they first appear.

\section{Greek letters}

$\alpha \quad$ Sensitivity parameter for the demand of real money balances (Part 1) or real exchange rate (Part 2).

$\beta \quad$ Another sensitivity parameter for the demand of real money balances

$\delta \quad$ Discount factor (for the government); equals $1 /(1+r)$

$\Delta \quad$ The amount the government prefers an output rate exceeding the natural rate $\left(\Delta \equiv Y^{*}-Y^{N}\right)$

$\epsilon \quad$ Rate of change of the exchange rate $\left(=e_{t}-e_{t-1}\right)$

$\theta \quad$ Prior probability of Nature choosing a strong government

$\lambda \quad$ Fraction of forecast error (in Section (2.3));

$\mu \quad$ Probability assessment of the private sector (Part I). Degree of openness of the economy (Part II).

$\pi \quad$ Inflation rate (or equivalently, the growth rate of domestic price level)

$\pi^{e} \quad$ Expected inflation rate. With the exception of Chapter 2, $\pi_{t}^{e}$ is always identical with the mathematical expectation, $\mathrm{E} \pi$

$\pi^{*} \quad$ Foreign inflation

$\rho \quad$ Probability that a weak government will choose a low inflation rate (thus mimicking a strong government)

$\sigma^{2} \quad$ Statistical variance

$\tau, \tau-1$ Future and current time periods (in a two-stage game)

$\Omega \quad$ Information set 


\section{Latin letters, small}

a Weight given to inflation in the government's preference function

$b \quad$ Weight given to the output goal by government (Chapters 4 and 5); or balance of payments (equivalent to current account) (Chapters

6 and 7 )

$b^{*} \quad$ Balance of payments target

$e \quad$ Nominal exchange rate

$h \quad$ Expectation function dependent on government behavior (inflation)

$k \quad$ Policy induced distortion

$m \quad$ Growth rate of the money stock

$r \quad$ Marginal product of capital, aka marginal return to investment (Chapter 4). Otherwise, discount rate

$r^{*} \quad$ Alternative return to domestic investment (e.g. foreign investment)

$u \quad$ Disturbance term, random variable with probability distribution

$w \quad$ Nominal wage rate in the non-traded sector $\left(\hat{w}_{t}=w_{t}-w_{t-1}\right)$ centered at zero, constant and finite variance $\sigma_{u}^{2}$

\section{Latin letters, capital}

$A^{G}, A^{P S} \quad$ Action sets of the government and private sector, respectively

$\mathrm{E}$

$G$

$L$

$M$

$P$

$P_{t}^{e}$

$P S$

$T_{s}, T_{w}$

$U^{G}$

$U^{P S}$

$V^{G}$

$V^{P S}$

$X_{1}, X_{2}$

$Y$

$Y^{N}$
Expectations operator

Abbreviation for Government

Government loss

Money supply

Domestic price level

Expectation of the domestic price level

Abbreviation for Private Sector

Strong, resp. weal type of government

Single-period utility of the government

Single-period utility of the private sector

Intertemporal utility of the government

Intertemporal utility of the private sector

Policy alternatives

Output

Natural rate of output (not necessarily equivalent

to the mathematical expectation) 


\section{BIBLIOGRAPHY}

[1] AgÉnor, Pierre-Richard (1994). "Credibility and exchange rate management in developing countries" Journal of Development Economics; 45 , p. $1-16$.

[2] Agénor, Pierre-Richard and Taylor, Mark P. (1992). "Testing for Credibility Effects" IMF Staff Papers; 39(3), p. 545-571.

[3] Agénor, Pierre-Richard and Taylor, Mark P. (1993). "Analysing Credibility in High-Inflation Countries: A New Approach" The Economic Journal; 103(March), p. 329-336.

[4] Alesina, Alberto and Tabellini, Guido (1988). "Credibility and Politics" European Economic Review; 32, p. 542-550.

[5] Andersen, Torben (1989). "Credibility of Policy Announcements" European Economic Review; 33, p. 13-30.

[6] Andersen, Torben, And Risager, Ole (1991). "The Role of Credibility for the Effects of a Change in the Exchange-Rate Policy" Oxford Economic Papers; 43, p. 85-98.

[7] Backus, David And Driffil, John (1985). "Rational Expectations and Policy Credibility Following a Change in Regime" Review of Economic Studies; 52, p. 211-221.

[8] Backus, David and Driffill, John (1985). "Inflation and Reputation" American Economic Review, 75, p. 530-538.

[9] Bahmani-Oskooee, Mohsen and Malixi, Margeret (1992). "More Evidence on the J Curve from LDCs" Journal of Policy Modeling; 14(5), p. 641-653. 
[10] Barro, Robert and Gordon, David (1983a). "A Positive Theory of Monetary Policy in a Natural Rate Model" Journal of Political Economy; 91, p. 15-37.

[11] Barro, Robert and Gordon, David (1983b). "Rules Discretion and Reputation in a Model of Monetary Policy" Journal of Monetary Economics, Vol. 12, p. 101-122.

[12] Barro, Robert (1986). "Reputation in a Model of Monetary Policy with Incomplete Information" Journal of Monetary Economics; 17, p. 3-20.

[13] Baxter, Marianne (1985). "The role of expectations in stabilization policy" Journal of Monetary Economics; 15, p. 343-362.

[14] BegG, David (1982). The rational expectations revolution in macroeconomics: theories and evidence, Oxford: Allan.

[15] Blackburn, Keith and Christensen, Michael (1989). "Monetary Policy and Policy Credibility: Theories and Evidence" Journal of Economic Literature; 27, p. 1-45.

[16] Blanchard, Olivier and Fischer, Stanley (1989) Lectures on Macroeconomics, MIT Press.

[17] Brunetti, Aymo and Weder, Beatrice (1992). "Political credibility and economic growth." WWZ-Studie Nr. 39, September, Basel.

[18] Cagan, Phillip (1956). "The Monetary Dynamics of Hyperinflation," in Studies in the Quantity Theory of Money, ed. by Milton Friedman. Chicago: University of Chicago Press.

[19] Calvo, Guillermo A. (1987) "Incredible Reforms", p. 217-233, in Debt, stabilization and development: essays in memory of Carlos DiazAlejandro, Oxford: Blackwell.

[20] Cairncross, Alec (1992) "From Theory to Policymaking: Economics as a Prefession" Banco Nazionale del Lavoro Quarterly Review 180, p. 320. Cited from McCloskey, Donald (1994) Knowledge and persuasion in economics, Cambridge University Press. 
[21] Canzoneri, Matthew B. (1985). "Monetary Policy Games and the Role of Private Information" American Economic Review; 75(5), p. 10561070.

[22] Chari, V. (1988). "Time Consistency and Optimal Policy Design" Federal Reserve Bank of Minneapolis Quarterly Review; (Fall), p. 17-31.

[23] Cho, In-Koo And Kreps, David M. (1987) "Signaling Games and Stable Equilibria" Quarterly Journal of Economics, 102, p. 179-221.

[24] Coes, D. V. (1994). "Macroeconomic Stabilization and Trade Liberalisation: Brazilian Experience and Choices" The World Economy; 17(4), p. $433-450$.

[25] Colombatto, Enrico and Macey, Jonathan (1996). "ExchangeRate Management in Eastern Europe: A Public-Choice Perspective" International Review of Law and Economics; 16, p. 195-209.

[26] Conlon, John R. (1993). "Can the Government Talk Cheap? Communication, Announcements, and Cheap Talk" Southern Economic Journal; 60(2), p. 418-429.

[27] Corden, Max (1994). Economic Policy, Exchange Rates and the International System.

[28] Croushore, Dean and Koot, Ronald (1994). "A Measure of Federal Reserve Credibility" Journal of Policy Modeling; 16(2), p. 215-231.

[29] Cukierman, Alan (1992). Central Bank Strategy, Credibility, and Independence: Theory and Evidence, MIT Press.

[30] Devarajan, Shantayanan. And Rodrik, Dani (1991). "Do the benefits of fixed exchange rates outweigh their costs? The Franc Zone in Africa" National Bureau of Economic Research, Working Paper; No. 3727

[31] Dixit, Avinash And Nalebuff, Barry (1992), Making Strategies Credible. p. 162-184, in The Strategy of Choice Zeckhauser, R. (ed.), Oxford.

[32] Dornbusch, R. (1991). "Credibility and Stabilization" Quarterly Journal of Economics; 15, p. 837-850. 
[33] Dornbusch, R. And Helmers, L. (1988) The Open Economy Tools for policymakers in developing economies. EDI Series in Economic Development, Oxford University Press.

[34] Drazen, Alan, and Masson, Paul (1994). "Credibility of Policies vs. Credibility of Policymakers" Quarterly Journal of Economics; , p. 735754 .

[35] Driffill, John (1988). "Macroeconomic Policy Games with Incomplete Information" European Economic Review; 32, p. 533-541.

[36] Edwards, Sebastian (1990). "The Sequencing of Economic Reform: Analytical Issues and Lessons from Latin American Experiences" The World Economcy; 13, p. 1-14.

[37] Edwards, Sebastian (1995). "Exchange Rate Anchors, Credibility, and Inertia: A Tale of Two Crises, Chile and Mexico" American Economic Review, Papers and Proceedings; 86(2), p. 176-180.

[38] Edwards, Sebastian (1995). "Exchange Rates as Nominal Anchors" Weltwirtschaftliches Archiv, p. 1-31.

[39] Falvey, Rod and Kim, Cha Dong (1992). "Timing and Sequencing Issues in Trade Liberalisation" The Economic Journal; 102(July 1992), p. 908-924.

[40] Farrell, Joseph (1995) "Talk is Cheap" American Economic Review, Papers and Proceedings Vol. 85(2).

[41] Farrell, Joseph (1995). "Cheap Talk on Specific Investments" Journal of Law, Economics and Organization; 11(2), p. 313-334.

[42] Funke, Norbert (1993). "Timing and Sequencing of Reforms: Competing Views and the Role of Credibility" Kyklos; 46(3), p. 337-362.

[43] Funke, Norbert (1991). "Die Glaubwürdigkeit von Wirtschaftsreformen: Bedeutung, Ursachen und Ansatzpunkte zur Lösung von Glaubwürdigkeitsproblemen" Die Weltwirtschaft; 2, p. 175-186.

[44] Gabisch, Günter And Lorenz, Hans-Walter (1987). Business Cycle Theory, Springer-Verlag. Berlin. 
[45] Gärtner, Manfred (1997). "Time-consistent monetary policy under output persistence" Public Choice; 92, p. 429-437.

[46] Goodhart, C. A. E. (1996). "Game Theory for Central Bankers: A Report to the Governor of the Bank of England" Journal of Economic Literature; 32(1), p. 101-114.

[47] Greenaway, David and Morrissey, Oliver (1993). "Structural Adjustment and Liberalisation in Developing Countries: What Lessons Have We Learned?" Kyklos; 46(2), p. 241-261.

[48] Harberger, Arnold (1993). "Secrets of Success: A handful of Heroes" American Economic Review, Papers and Proceedings, p. 343-355.

[49] Harsanyi, John C. (1995) "Games with Incomplete Information". American Economic Review, Vol. 85(3), p. 291-303.

[50] Hartley, James E. (1997) The Representative Agent in Macroeconomics. Frontiers in Political Economy, vol. 10. London and New York: Routledge.

[51] Horn, Henrik and Persson, Tabellini (1988). "Exchange Rate Policy, Wage Formation, and Credibility" European Economic Review; 32 , p. 1621-1636.

[52] Kiguel, Miguel and Liviatan, Nissan (1994). "Exchange-RateBased Stabilization in Argentina and Chile-A Fresh Look" World Bank Policy Research Working Paper; July (1318)

[53] Kremers, Jeroen (1990). "Gaining Policy Credibility for a Disinflation" IMF Staff Papers; 37(1), p. 116-145.

[54] Kreps, David M. (1990). A Course in Microeconomic Theory, Harvester Wheatsheaf.

[55] Kreps, David M. and Wilson, Robert (1982). "Reputation and Imperfect Information" Journal of Economic Theory; 27, p. 253-279.

[56] Kydland, Finn E. and Prescott, Edward C. (1977). "Rules Rather than Discretion: The Inconsistency of Optimal Plans" Journal of Political Economy; 85(3), p. 473-491. 
[57] Lizano, Eduardo (1994) "Wine and Bottles, Old or New? Rethinking Economic Policy in Latin America once more", Symposium PostStabilization Problems and Ongoing Reforms in Latin America, IberoAmerican Institute for Economic Research, University of Göttingen, Nov. 3-4, 1995.

[58] Lohmann, Susanne (1992). "Optimal Commitment in Monetary Policy: Credibility vs. Flexibility" American Economic Review; 82(1), p. 273286.

[59] Lucas, Robert. E., JR. (1976). "Econometric Policy Evaluation: A Critique" Carnegie-Rochester Conference Series on Public Policy; (1), p. 19-46.

[60] Machlup, Fritz (1983). "The Rationality of 'Rational Expectations"” Journal of Economics; 23(3), p. 172-182.

[61] Morris, Stephen (1995). "The Common Prior Assumption in Economic Theory" Economics and Philosophy; 11, p. 227-253.

[62] Obstfeld, Maurice (1997). "Destabilizing effects of exchange-rate escape clauses" Journal of International Economics; 43, p. 61-77.

[63] Palley, Thomas. I. (1993). "Uncertainty, expectations, and the future: if we don't know the answers, what are the questions?" Journal of Post Keynesian Economics; 16(1), p. 3-18.

[64] Persson, Torsten and Tabellini, Guido (1990) Macroeconomic Policy, Credibility and Politics in: Fundamentals of pure and applied economics, No. 38

[65] Persson, Torsten and van Wijnbergen, Sweder (1993). "Signaling, Wage Controls and Monetary Disinflation Policy" Economic Journal; 103, p. 79-97.

[66] Peruga, Rodrigo (1996). "Learning and the exchange rate: exchange rate responses to money announcements in the early 1980s" Journal of International Money and Finance; 15(2), p. 167-190.

[67] Rasmusen, Eric (1994) Games and Information, 2nd Edition, Blackwell. 
[68] Rodrik, Dani (1989). "Credibility of Trade Reform - a Policy Maker's Guide" World Economy; 12, p. 1-16.

[69] Rodrik, Dani (1996). "Understanding Economic Policy Reform" Journal of Economic Literature; 34(1), p. 9-41.

[70] Rogoff, Kenneth (1985). "The Optimal Degree of Commitment to an Intermediate Monetary Target" Quarterly Journal of Economics; 100(4), p. 1169-1189.

[71] Rogoff, Kenneth (1987). "Reputational Constraints on Monetary Policy" Carnegie-Rochester Conference Series on Public Policy; 26, p. 141182.

[72] Rothschild, M. And Stiglitz, J. (1976) "Equilibrium in Competitive Insurance Markets: An Essay on the Economics of Imperfect Information" Quarterly Journal of Economics, 80, p. 629-649.

[73] Sachs, Jeffrey And Zini, Alvaro Jr. (1996). "Brazilian Inflation and the Plano Real" World Economy; 19, p. 13-37.

[74] Schelling, Thomas (1982). "Establishing Credibility: Strategic Considerations" American Economic Review: Papers and Proceedings; 72, p. 77-91.

[75] Schelling, Thomas (1960). The Strategy of Conflict, Harvard University Press.

[76] Schweickert, Rainer (1993). "Lessons from Exchange Rate Based Stabilization in Argentina" Kiel Working Paper No. 567, March.

[77] Schweickert, Rainer (1994). "Stabilization and Real Adjustment in Emerging Market Economies-Lessons from Macroeconomic Reforms in the Southern Cone" Intereconomics; 29(5), p. 245-253.

[78] SEll, Friedrich. L. (1989). "Die Rolle ökonomischer Verhaltensweisen für 'Timing' und 'Sequencing' handelspolitischer Liberalisierungsprogramme" Zeitschrift für Wirtschafts- u. Sozialwissenschaften; 109, p. 449-466. 
[79] Selten, Reinhard (1975) "Reexamination of the Perfectness Concept for Equilibrium Points in an Extensive Game" International Journal of Game Theory. Vol. 4, p. 25-55.

[80] Sobel, J. (1985). "A Theory of Credibility" Review of Economic Studies; 52 , p. 557-573.

[81] Spence, A. (1974) Market Signalling, Harvard University Press: Cambridge.

[82] Stein, J. (1989). "Cheap Talk and the Fed: A Theory of Imprecise Policy Announcements" American Economic Review; 79(1), p. 32-42.

[83] Svennson, Lars (1996). "The Nobel Memorial Prize in Economics 1995 - The Scientific Contributions of Robert E. Lucas, Jr." Scandinavian Journal of Economics; 98(1), p. 1-10.

[84] Svennson, Lars (1997). "Optimal Inflation Targets, "Conservative" Central Banks, and Linear Inflation Contracts" American Economic Review; 87(1), p. 98-114.

[85] Taylor, John B. (1982). "Establishing Credibility; A Rational Expectations Viewpoint" American Economic Review: Papers and Proceedings; 72 , p. $81-85$.

[86] URIBE, M. (1997). "Exchange-rate-based inflation stabilization: The initial real effects of credible plans" Journal of Monetary Economics; 39, p. 197-221.

[87] VÉGH, CARlos (1992). "Stopping High Inflation-An Analytical Overview" IMF Staff Papers; 39(3), p. 626-695.

[88] Vickers, John (1986). "Signalling in a Model of Monetary Policy with Incomplete Information" Oxford Economic Papers; 38, p. 443-455.

[89] Wohlmann, Monika (1998). Der nominale Wechselkurs als Stabilitätsanker - Die Erfahrungen Argentiniens 1991-1995, Göttinger Studien zur Entwicklungsökonomik 5, Verveurt Verlag.

[90] ZatTler, Jürgen (1993). "Adjusting Adjustment-Supply Responses and the Sequencing of Reform Policies" Intereconomics; (November/December), p. 293-301. 